Portland State University

PDXScholar

$11-2012$

\title{
Experimental Tests and Numerical Analyses of Steel Truss Bridge Gusset Connections
}

Christopher Higgins

Oregon State University

Peter Dusicka

Portland State University

Michael Scott

Oregon State University

Follow this and additional works at: https://pdxscholar.library.pdx.edu/trec_reports

Part of the Civil Engineering Commons, and the Transportation Engineering Commons Let us know how access to this document benefits you.

\section{Recommended Citation}

Higgins, Christopher, Peter Dusicka, and Michael Scott. Experimental Tests and Numerical Analyses of Steel Truss Bridge Gusset Connections. OTREC-RR-12-03. Portland, OR: Transportation Research and Education Center (TREC), 2012. https://doi.org/10.15760/trec.76

This Report is brought to you for free and open access. It has been accepted for inclusion in TREC Final Reports by an authorized administrator of PDXScholar. Please contact us if we can make this document more accessible: pdxscholar@pdx.edu. 


\section{GOTREC}

FINAL REPORT

\section{Experimental Tests and Numerical Analyses of Steel Truss Bridge Gusset Connections}

OTREC-RR-12-03

November 2012 



\title{
EXPERIMENTAL TESTS AND NUMERICAL ANALYSES OF STEEL TRUSS BRIDGE GUSSET CONNECTIONS
}

\author{
Final Report \\ OTREC-RR-12-03 \\ by \\ Christopher Higgins, Ph.D., P.E. \\ Anthony Hafner \\ Oregon State University \\ Peter Dusicka, Ph.D. \\ Thomas Kay \\ Portland State University \\ for \\ Oregon Department of Transportation \\ Research Unit \\ 200 Hawthorne Avenue SE, Suite B-240 \\ Salem OR 97301-5192 \\ and \\ Oregon Transportation Research \\ and Education Consortium (OTREC) \\ P.O. Box 751 \\ Portland, OR 97207

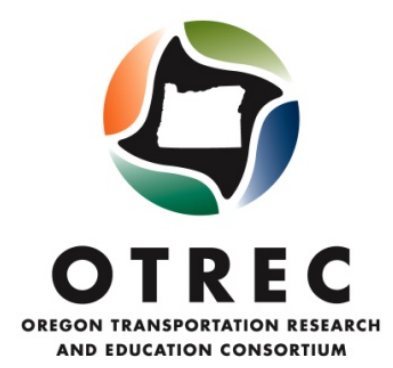

November 2012 



\section{Technical Report Documentation Page}

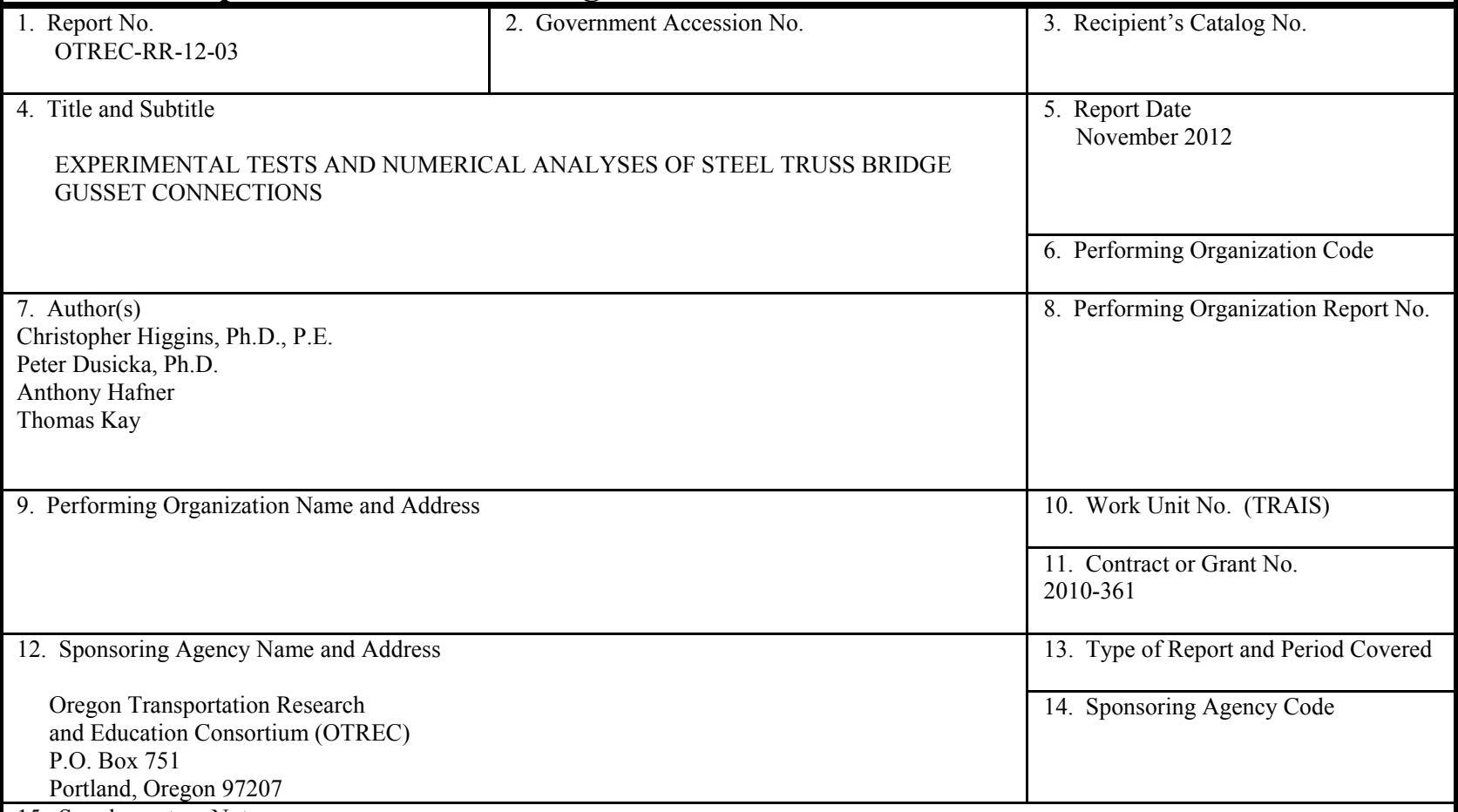

15. Supplementary Notes

16. Abstract

Gusset plates connect individual steel truss bridge members together at a node. In $10 \%$ of the 200,000 steel bridges in US in 2008 , failure of a single truss or connection could lead to collapse. Regular inspection and load rating are essential for the safe operation and maintenance of these bridges.

The Minneapolis I-35 Bridge collapse was the first gusset failure where a design flaw was implicated. Load rating gusset plates is a significant challenge given the number of connections and the complexity of accurately evaluating each one. The majority of research on gusset plate strength is from small-scale connections. More refined techniques are needed to conduct high-fidelity capacity evaluations.

Finite element analysis (FEA) is widely used in structural engineering. Using FEA in gusset plate evaluation presents challenges due to the connections' large-scale, high degree of geometric variability and complex load paths.
17. Key Words
gusset plates, steel truss, bridges
18. Distribution Statement
No restrictions. Copies available from OTREC:
www.otrec.us

19. Security Classification (of this report)

Unclassified

\section{Security Classification (of this page)}

Unclassified

\begin{tabular}{|l|l|}
\hline 21. No. of Pages & 22. \\
144 &
\end{tabular}




\section{ACKNOWLEDGEMENTS}

This project was funded by the Oregon Transportation Research and Education Consortium (OTREC). The authors would like to acknowledge the support staff of the Hinsdale Wave Research Laboratory and the Structural Engineering Research Laboratory for their assistance with the experimental work.

\section{DISCLAIMER}

The contents of this report reflect the views of the authors, who are solely responsible for the facts and the accuracy of the material and information presented herein. This document is disseminated under the sponsorship of the U.S. Department of Transportation University Transportation Centers Program and OTREC in the interest of information exchange. The U.S. Government and OTREC assume no liability for the contents or use thereof. The contents do not necessarily reflect the official views of the U.S. Government or OTREC. This report does not constitute a standard, specification, or regulation. 


\section{TABLE OF CONTENTS}

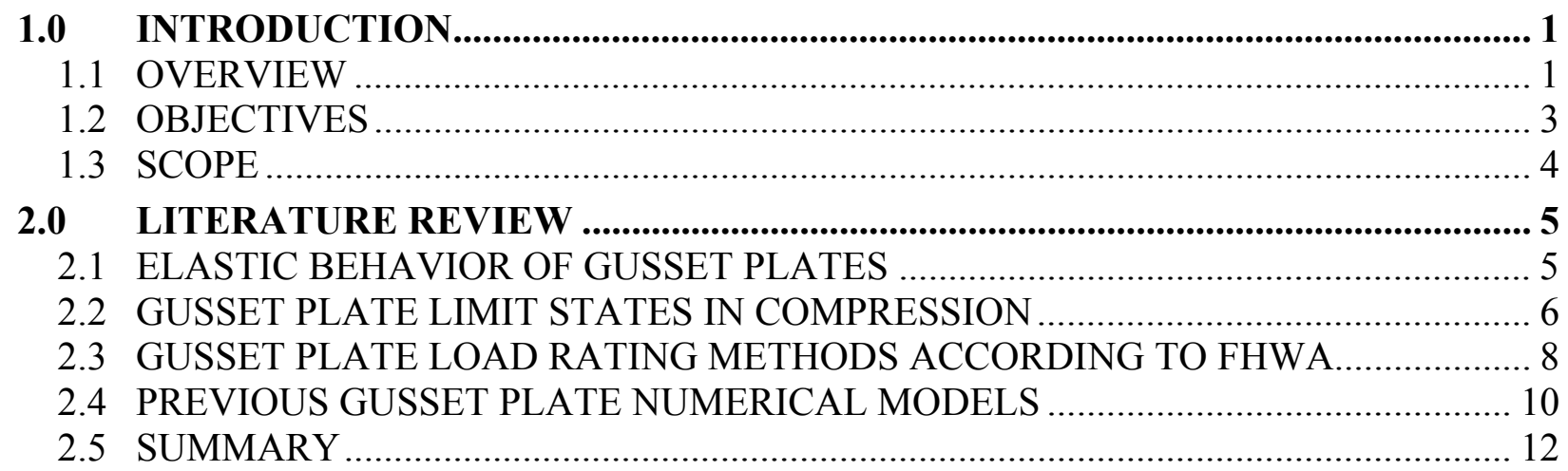

3.0 GUSSET CONNECTION EXPERIMENTAL PROGRAM (OREGON STATE

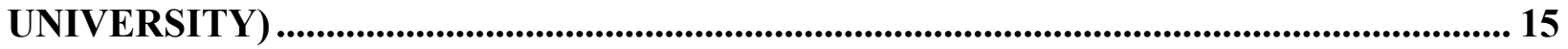

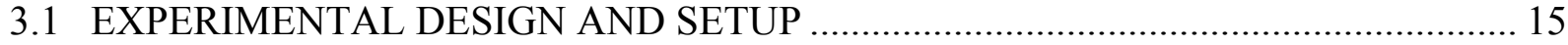

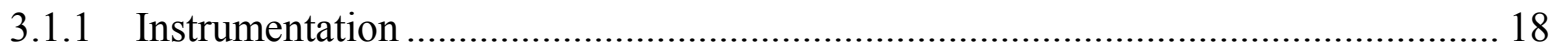

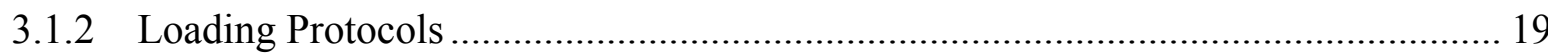

3.1.3 Development of M4 Brace Stiffness for Test Program ......................................... 20

3.1.4 Calibration of Strain Gages on Member M4 for Axial Force Calculation ............... 21

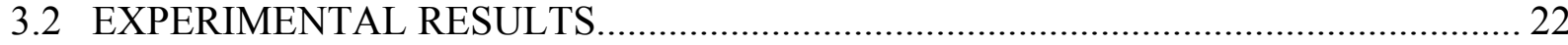

3.2.1 Compression Diagonal force-Plate Out-of-plane Displacement................................ 23

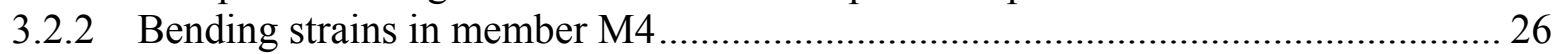

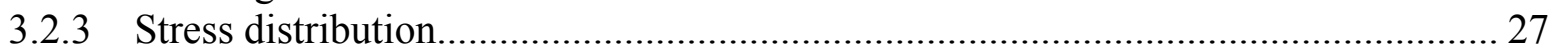

3.2.4 Comparison of stresses to Whitmore and Modified-Thornton methods................... 30

3.2.5 Comparison of Experimental Results to FHWA Guide........................................... 33

3.2.6 Modeling of member-connection interaction....................................................... 34

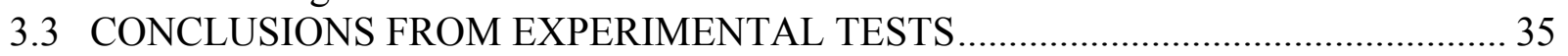

4.0 NUMERICAL MODELING (PORTLAND STATE UNIVERSITY) ....................... 37

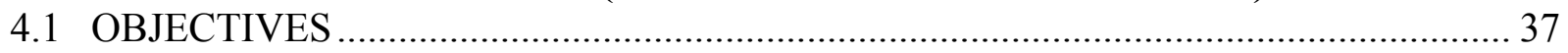

4.2 GUSSET CONNECTION MODEL DESCRIPTION ………………............................ 37

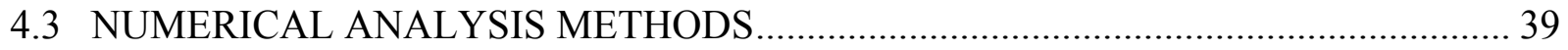

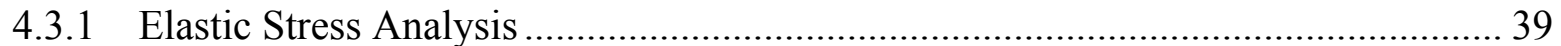

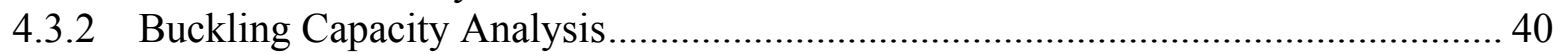

4.4 ANALYTICAL RESULTS AND EXPERIMENTAL VALIDATION ............................ 41

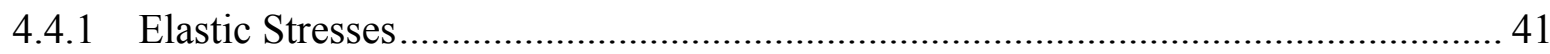

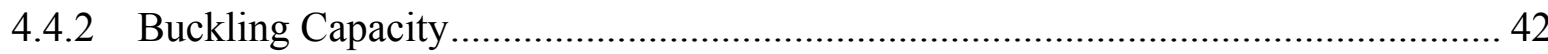

4.5 CONCLUSIONS AND MODELING RECOMMENDATIONS ……………................ 43

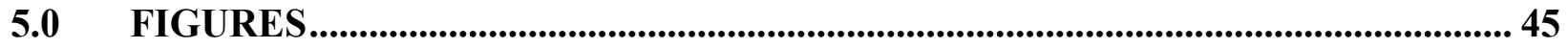

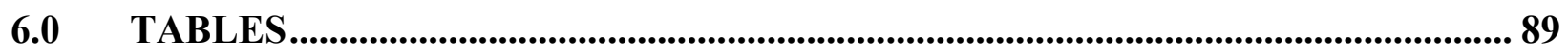

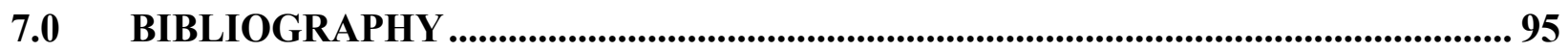

8.0 APPENDIX A - CONVERGENCE PLOTS ................................................................... 97

9.0 APPENDIX B - ADDITIONAL EXPERIMENT DATA........................................... 103

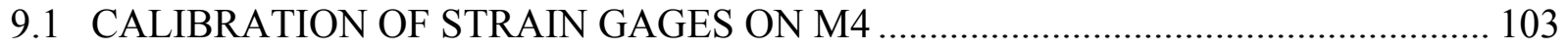

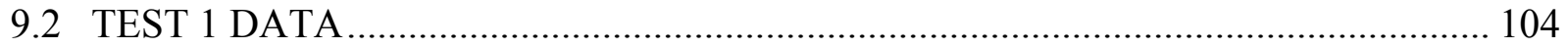


9.2.1 Relative Member-to-Gusset Displacement (bolt slip \& work point).................... 104

9.2.2 Gusset Free Edge Strain Versus Load and Displacement.................................. 106

9.2.3 Strain in M4 Connection Versus Load.................................................................. 107

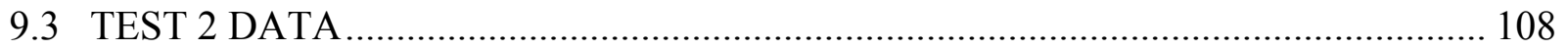

9.3.1 Relative Member-to-Gusset Displacement (bolt slip \& work point).................... 108

9.3.2 Gusset Free Edge Strain Versus Load and Displacement.................................. 110

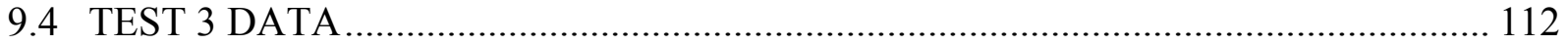

9.4.1 Relative Member-to-Gusset Displacement (bolt slip \& work point)..................... 112

9.4.2 Gusset Free Edge Strain Versus Load and Displacement..................................... 117

9.4.3 Strain in M4 Connection Versus Load.................................................................. 119

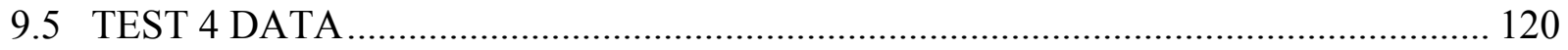

9.5.1 Relative Member-to-Gusset Displacement (bolt slip \& work point).................... 120

9.5.2 Gusset Free Edge Strain Versus Load and Displacement.................................... 122

9.5.3 Strain in M4 Connection Versus Load.............................................................. 123

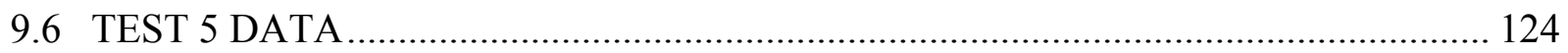

9.6.1 Relative Member-to-Gusset Displacement (bolt slip \& work point).................... 124

9.6.2 Gusset Free Edge Strain Versus Load and Displacement................................... 126

9.6.3 Strain in M4 Connection Versus Load................................................................. 127

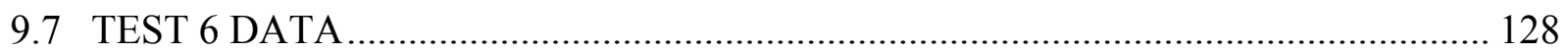

9.7.1 Relative Member-to-Gusset Displacement (bolt slip \& work point).................... 128

9.7.2 Gusset Free Edge Strain Versus Load and Displacement................................... 130

9.7.3 Strain in M4 Connection Versus Load................................................................. 131 


\section{LIST OF TABLES}

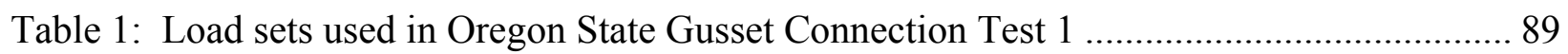

Table 2: Load sets used in Oregon State Gusset Connection Test 3 ...................................... 90

Table 3: Summary of coupon test results per ASTM A370 ............................................... 91

Table 4: Comparison of existing bridge member stiffness ................................................. 91

Table 5: Experimental test matrix with results ................................................................ 92

Table 6: Comparison of Experiment to FHWA Guide ..................................................... 93

Table 7: Loads used for elastic analysis of gusset connection FEA model ............................... 93

Table 8: Summary of experimental buckling loads and analytical predictions ......................... 94 


\section{LIST OF FIGURES}

Figure 1: Warren truss gusset plate connection tested by Whitmore (1957).......................... 45

Figure 2: Whitmore effective width and length definitions for member region of gusset plates

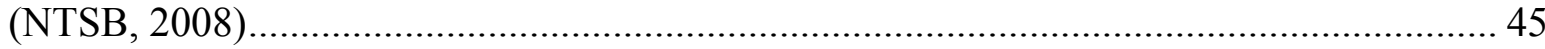

Figure 3: Test frame and gusset plate connection (Yamamoto, 1988) .................................... 46

Figure 4: Gusset plate test specimen assembly (Gross, 1990) ............................................. 46

Figure 5: OSU Gusset plate test specimen assembly ..................................................... 47

Figure 6: Plate dimensions and bolt patterns (all dimensions in inches or degrees) ................. 48

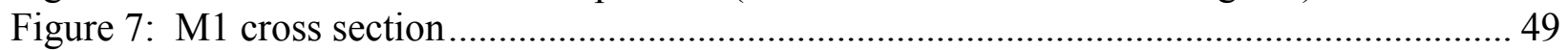

Figure 8: M4 cross sections for stiff and soft braces ...................................................... 49

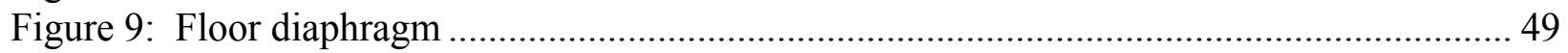

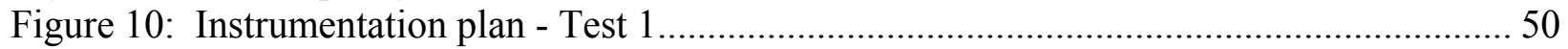

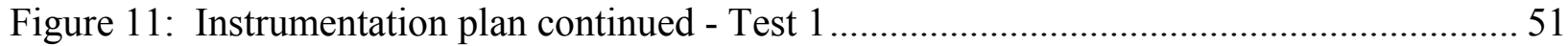

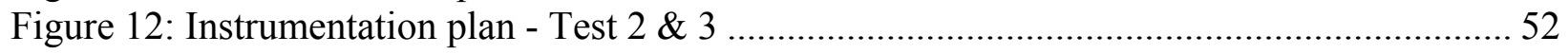

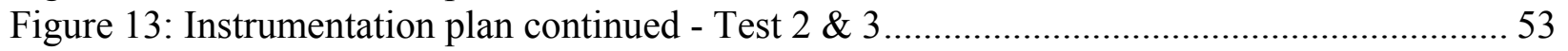

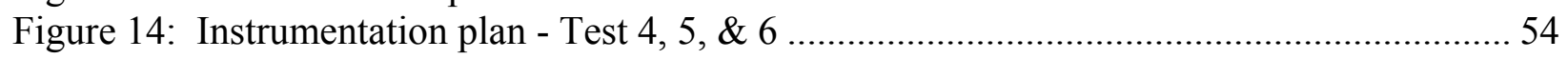

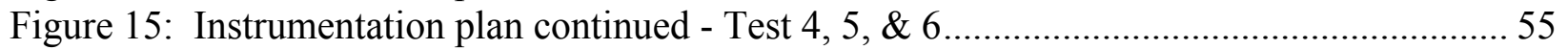

Figure 16: DIC measured initial out-of-plane imperfections (prior to imposed deformations on

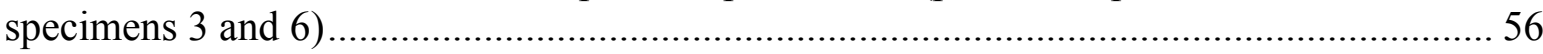

Figure 17: DIC measured out-of-plane displacement of specimen 2 at incremental load steps

throughout test (Failue image is not scaled and has limits of -18 to $122 \mathrm{~mm}$ ) ..................5 57

Figure 18: Hydraulic ram setup for imposing initial imperfections and DIC measured imposed

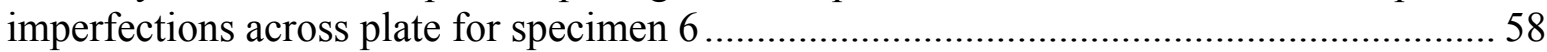

Figure 19: Load v out-of-plane displacement for all tests .................................................. 58

Figure 20: Test 1 Load v out-of-plane displacement for all cycles ........................................ 59

Figure 21: Test 1 Load v displacement for final cycle. (\#) shows step in load cycle................ 59

Figure 22: Test 3 Load v displacement with initial and final out-of-plane imperfections .......... 60

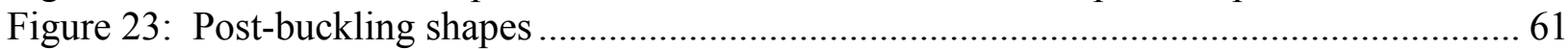

Figure 24: Strain profiles for M4 stiff brace showing out-of-plane bending of the member

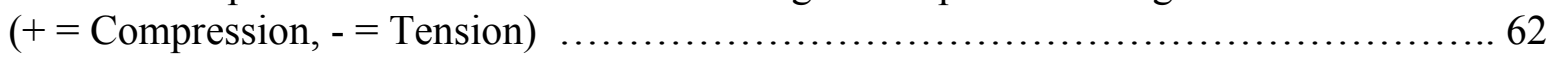

Figure 25: Strain profiles for M4 soft brace showing out-of-plane bending of the member $(+=$ Compression, $-=$ Tension $)$ 63

Figure 26: Plane A-A, Path B-B, \& Path C-C used to interpret plate stresses 64

Figure 27: Average stress across Whitmore width in M4 direction normalized to maximum

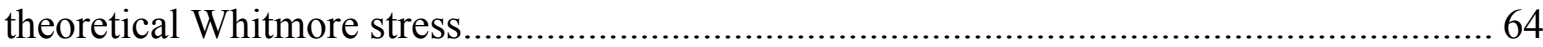

Figure 28: Average stress across Whitmore width in M4 direction normalized to theoretical

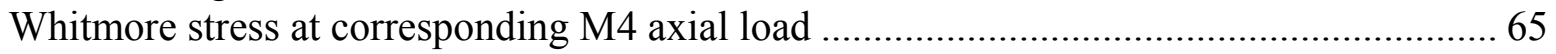

Figure 29: $1 / 4$-inch plates, stress in global x direction $(+=$ Tension, $-=$ Compression $)$.............. 65

Figure 30: $1 / 4-$ inch plates, stress in global y direction $(+=$ Tension, $-=$ Compression $)$.............. 66

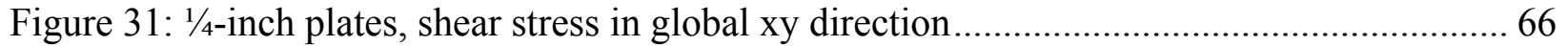

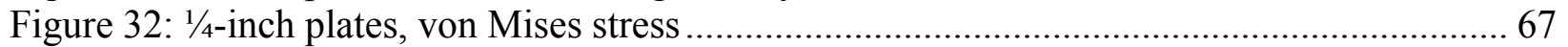

Figure 33: $1 / 4-$ inch plates, 1 st principle stress $(+=$ Tension, $-=$ Compression $) \ldots \ldots \ldots \ldots \ldots \ldots \ldots \ldots \ldots . . . . . . . . . . .67$

Figure 34: $1 / 4$-inch plates, 2nd principle stress $(+=$ Tension, $-=$ Compression $) \ldots \ldots \ldots \ldots \ldots \ldots \ldots \ldots \ldots . . . . . . . . . . . .68$ 
Figure 35: 1/4-inch plates, stress in M4 direction, path B-B and C-C only $(+=$ Tension, $-=$ Compression).

Figure 36: 3/8-inch plates, stress in global $\mathrm{x}$ direction $(+=$ Tension, $-=$ Compression $)$............. 69

Figure 37: 3/8-inch plates, stress in global y direction $(+=$ Tension, $-=$ Compression $)$............. 70

Figure $38:$ 3/8-inch plates, shear stress in global xy direction................................................ 70

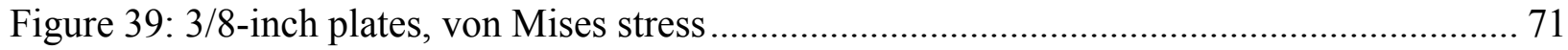

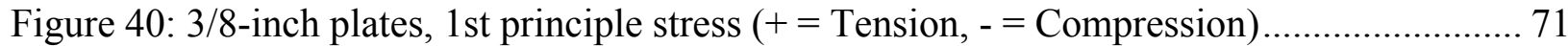

Figure 41: 3/8-inch plates, 2nd principle stress ( $+=$ Tension, $-=$ Compression $)$........................ 72

Figure 42: 3/8-inch plates, stress in M4 direction, paths B-B and C-C only $(+=$ Tension, $-=$

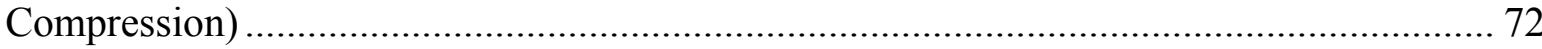

Figure 43: Combination loading, stress in global $\mathrm{x}$ direction $(+=$ Tension, $-=$ Compression $) \ldots 73$

Figure 44: Combination loading, stress in global y direction $(+=$ Tension, $-=$ Compression $) \ldots 73$

Figure 45: Combination loading, shear stress in global xy direction .................................. 74

Figure 46: Combination loading, von Mises stress............................................................ 74

Figure 47: Combination loading, 1st principle stress ( $+=$ Tension, $-=$ Compression $) \ldots \ldots \ldots \ldots \ldots . . . .75$

Figure 48: Combination loading, 2nd principle stress ( $+=$ Tension, $-=$ Compression $)$............. 75

Figure 49: Combination loading, stress in M4 direction, paths B-B and C-C only (+= Tension, -

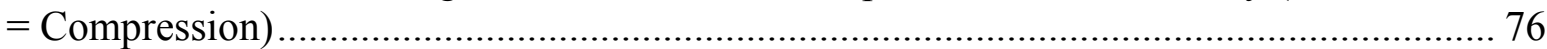

Figure 50: Stepped column analogy for member-plate interaction system ............................. 76

Figure 51: System interactions for buckling of a stepped column showing member interaction on

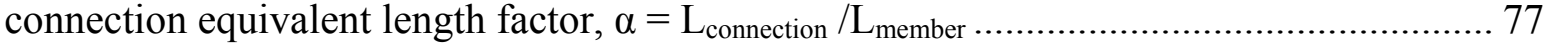

Figure 52: (a) experimental setup and (b) FEA model assembly ........................................ 78

Figure 53: Gusset plate connection member modeling...................................................... 79

Figure 54: Boundary conditions and locations of applied loads for gusset plate connection model

79

Figure 55: Measurements used to construct gusset connection model load-displacement plots. 80

Figure 56: Experimental and numerical buckled shape - Test 1............................................ 80

Figure 57: Stress contours from 100 kip axial load along M4, (a) von Mises stress, (b) $\mathrm{s}_{\mathrm{xx}}$ stress,

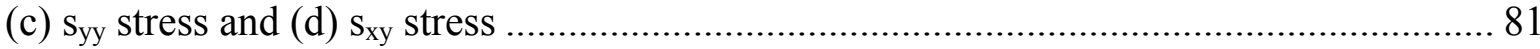

Figure 58: Stress planes and sample points used for elastic stress analysis ........................... 81

Figure 59: Specimen 1 vs FEA Model, von Mises stress ........................................... 82

Figure 60: Specimen 1 vs FEA Model, stress in global $x$ direction .................................... 82

Figure 61: Specimen 1 vs FEA Model, stress in global y direction ....................................... 83

Figure 62: Specimen 1 vs FEA Model, shear stress in global xy direction .............................. 83

Figure 63: Specimen 1 vs FEA Model, von Mises stress for M4 loaded to different magnitudes 84

Figure 64: Test 1 Experimental results vs. analytical results at different levels of initial imperfection 84

Figure 65: Test 2 Experimental results vs. analytical results at different levels of initial

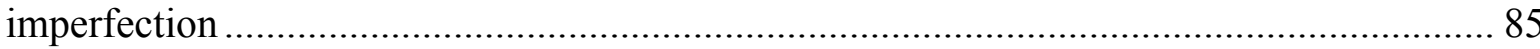

Figure 66: Test 3 Experimental results vs. analytical results with different initial imperfections .... 85

Figure 67: Test 4 Experimental results vs. analytical results with different initial imperfections.... 86

Figure 68: Test 5 Experimental results vs. analytical results with different initial imperfections.... 86

Figure 69: Test 6 Experimental results vs. analytical results with different initial imperfections .......87 


\subsection{INTRODUCTION}

\subsection{OVERVIEW}

Gusset plate connections are commonly used in steel truss bridges to connect individual members together at a node. The connection typically consists of a steel plate on each side of the connected members, which are then bolted or riveted together. A large number of steel deck truss bridges are currently in service. The Federal Highway Administration (FHWA) estimates that 465 steel deck truss bridges and approximately 11,000 deck truss bridges exist in the National Bridge Inventory (NTSB, 2008). According to Barr et al (2011) there were 200,000 steel bridges in United States in 2008 and $10 \%$ of these bridges are further classified as non-loadpath-redundant (fracture critical) bridges, meaning a failure of a single truss member or connection could lead to collapse. This makes periodic inspections and load rating practices essential for the safe operation and maintenance of these bridge types.

Historically, only the truss members were considered for load rating. The rationale for omitting load rating for connections comes from what is thought to be conservative assumptions employed during connection design, combined with a small number of connection failures in the historical record; namely the 1996 gusset plate failure on the Grand River Bridge in Lake County, OH (NTSB, 2008) and the 2007 collapse of the I-35W Bridge in Minneapolis, MN (Holt and Hartmann, 2008). The collapse of the I-35 Bridge in Minneapolis was catastrophic resulting in 13 deaths and 145 injuries - and was the first gusset failure where a design error was implicated as the cause of collapse, thus revealing a new vulnerability in steel truss bridges which had previously been thought to be both economical and reliable. After the I-35W Bridge 
collapse, the FHWA issued a set of guidelines for load rating gusset plate connection (FHWA, 2009), based on existing practice.

Inclusion of gusset plate connections in load ratings poses a significant challenge to bridge owners due to the large number of connections in the inventory and the complexity of analysis required to accurately evaluate each connection. Load transfer to bridge gusset plates in situ is delivered by multiple members - all potentially with axial, shear and moment - through the fasteners into bearing on the gusset plate. However, current gusset plate design philosophy is rooted in elementary beam theory analysis and applicable specification rules, combined with the experience and judgment of the designer (Bjorhovde and Chakrabarti 1985). The majority of experimental research on gusset plate strength capacity is from small-scale gusset connections consisting of a single braced member and relatively few fasteners subject to monotonic axial tension or compression, which is hardly representative of bridge gusset connections. The complexity of stress fields and failure states found in bridge gusset plates is addressed in design by applying approximate methods to arrive at a rapid, conservative solution, but one that may lack accuracy. Thus, development of more refined techniques for conducting high-fidelity capacity evaluations on existing bridge connections is desirable.

To produce new data on the effectiveness of available analysis techniques and validate new methodologies for designing new connections and load rating existing connections subject to sway buckling failure modes observed in the $\mathrm{I} 35 \mathrm{~W}$ bridge, experimental research is needed. The effects of multiple variables must be examined on large-scale gusset plates. These variables include: plate thickness, combination versus monotonic member loading, and initial out-of-plane imperfection of the gusset plates. An additional parameter unique to this research is the effect of out-of-plane stiffness of the diagonal compression member on the sway buckling strength of 
gusset plates. The key input parameters currently incorporated in design and load rating guidelines are plate material, geometry and thickness.

Another technique to assess the effectiveness of the current guidelines is finite element analysis (FEA). FEA is widely used in structural engineering applications, with modern commercial software packages capable of modeling systems with non-linear material behavior, complex geometry, contact interactions and complex loading conditions. FEA implementation in bridge connection evaluations does present some challenges due to the connection's largescale, high degree of geometric variability and complex load paths. Large-scale FEA gusset connection models have yet to be calibrated with experimental results. There is no consensus among practitioners regarding how complex a FEA model must be to accurately capture a bridge gusset connection's ultimate strength capacity. Complex FEA modeling involves significant development time, specialized training, and can often come at the cost of long computation time. This consequently translates into significant cost for bridge owners, and can delay the incorporation of revised connection load-rating procedures into bridge inspection programs.

\subsection{OBJECTIVES}

The impetus for this work arises from the need for accurate and rapid assessment of bridge gusset connections, a re-evaluation of existing design methods, and a desire to better understand the parameters affecting the sway buckling strength of truss bridge gusset plate connections.

The objectives of this research are as follows:

1. Investigate the contributions of initial out-of-plane imperfection, out-of-plane bending stiffness of the compression diagonal member, plate thickness, and combined loading-tosway-buckling capacity of gusset plates through large-scale experimental studies. 
2. Compare the experimental results to existing load-rating techniques including Whitmore, Modified-Thornton, and the FHWA Guide to determine their effectiveness at predicting capacity.

3. Develop FEA models capable of evaluating gusset plate stresses and ultimate strength limit states and compare with experimental test results.

4. Evaluate FEA modeling techniques for computational efficiency and ability to predict ultimate strength of bridge gusset plate connections subject to sway compression failures. In this research, the experimental work was conducted at Oregon State University under the direction of Professor Christopher Higgins, and the FEA studies were conducted at Portland State University under the direction of Professor Peter Dusika.

\subsection{SCOPE}

This work focuses on connection-level experimental tests and analysis of bridge gusset plates. Therefore, the numerical and experimental emphasis will be on the local gusset connection, and does not include global truss numerical models or global truss experimental testing. However, the local member stiffness interactions on the gusset plate performance are included in this study. The experiments focus on sway-buckling behavior of the gusset connections and were designed to ensure failure occurs at the connection of interest. Also, since the primary research focus is on stresses and limit states of the gusset plates themselves, analytical representations for attached members and fasteners were designed and modeled such that failure occurred in the gusset plate. 


\subsection{LITERATURE REVIEW}

\subsection{ELASTIC BEHAVIOR OF GUSSET PLATES}

Modern gusset plate design has been most influenced by Whitmore (1952), who studied the stress distributions in a $1 / 4$-scale model of a bottom-chord, Warren-truss gusset plate connection, similar to the one shown in Figure 1. Prior to Whitmore, gusset plate design consisted of sizing the plate to accommodate the required number of fasteners, then selecting a plate thickness based on classical beam formula analysis and engineering judgment. Whitmore recognized that the use of beam theory was questionable, since gusset plates act like deep members. He aimed to characterize the stress distribution in a gusset plate subject to load and the magnitude and location of maximum stress, and develop a simplified design method for determining maximum stresses in a gusset plate. The experimental loading regime was kept in the elastic range of the gusset plate and was applied such that one diagonal member was in tension, the other diagonal member was in compression and the bottom chord was in tension. Stresses were calculated from an array of strain gages positioned across the plate.

Whitmore's findings showed that maximum stresses normal to the diagonals occurred near the ends of the compression and tension diagonals. Maximum shear stress occurred along a plane just above the bottom chord and below the diagonal members. Based on his findings, he proposed a simplified method for calculating maximum normal stresses in a gusset plate by using what has become known as the Whitmore effective width (Figure 2), which is defined as the length of the line perpendicular to the member axis passing through the last bolt row of fasteners, intersected by two 30-degree lines drawn from the first outer row of fasteners to the last row. Maximum normal stress is calculated by multiplying the material's yield stress by the Whitmore 
effective width times the plate thickness. This technique for calculating maximum normal stress in a gusset plate continues to be a fundamental rule in gusset plate design.

Two studies by Irvan (1957) and Hardin (1958) expanded on Whitmore's work using a scale model of a bottom-chord Pratt truss gusset. Irvan's findings supported Whitmore's in regards to the location of maximum tensile, compressive and shear stresses in the gusset plate, which occurred at the ends of the compression, tension and plane above the horizontal chord, respectively. However, Irvan proposed an alteration to the Whitmore effective-width concept by drawing the two 30-degree lines from the bolt group's center of gravity to the last bolt row, as opposed to the outer gage lines, resulting in a narrower effective width. Research by Hardin corroborated Irvan's results and recommendations.

Yamamoto (1986) reported on elastic stress distributions in full-scale Warren truss and Pratt truss gusset connections, based on tests conducted for the Honshu-Shikoku Bridge Authority in Japan. Yamamoto found that Whitmore's methods were adequate for predicting maximum stress magnitudes, but the locations of the maximum stresses can shift depending on the global loading condition of the connection, specifically whether the bottom chord is loaded in tension or compression.

\subsection{GUSSET PLATE LIMIT STATES IN COMPRESSION}

Buckling is the primary failure mode for gusset plates subject to compression. According to Thornton (1984), compressive capacity can be calculated with standard column buckling equations by considering the gusset plate as an idealized equivalent column with a width of unity along the brace's line of action and length from the end of the Whitmore section to the plate edge, similar to that shown as $L_{2}$ in Figure 2. The slenderness ratio $k L / r$ is calculated assuming a fixed-fixed boundary condition with an effective length factor of $k=0.65$. Alternatively, one can 
use the average of $L_{1}, L_{2}$ and $L_{3}$ for the equivalent column length, provided it is not greater than $L_{2}$. Thornton asserted that this is a conservative design approach since both plate action and the gusset's post-buckling strength is ignored.

$\mathrm{Hu}$ and Cheng (1987) conducted experimental tests on gusset plate buckling capacity in a simple braced-frame connection; considering effects of gusset plate thickness, boundary conditions, eccentricity and edge stiffening reinforcement. Thin gusset plates were found to buckle at loads significantly lower than those predicted using Whitmore's effective width approach. Load at bifurcation was also shown to be highly dependent on boundary conditions (sway and non-sway conditions were tested), plate thickness and whether edge stiffeners were used. Yam and Cheng (1993) conducted a follow-up investigation testing similar connections in compression. The test matrix included varied plate thicknesses, plate size, brace angle orientation, and other variations of the framing members. Yam and Cheng reported that the gusset plate's compressive capacity was almost directly proportional to plate thickness as well as dependent on sway versus non-sway boundary conditions. They also proposed modifying the angle used to the Whitmore effective-width definition from 30 to 45 degrees to more accurately account for the high degree of plate yielding and subsequent load re-distribution that occurs prebuckling. This new definition of width in combination with the equivalent associated column was termed the Modified-Thornton method.

Yamamoto (1988) published testing results on the buckling strength of full-scale gusset plate bridge connections similar to those from his previous study on elastic stress distributions (Yamamoto, 1985). A loading truss was used along with a representative test specimen, as shown in Figure 3. Experimental results were compared to the calculated design buckling strength per guidelines by the Japan Society of Civil Engineers (JSCE 1976). All the 
connections failed because of highly localized buckling surrounding the compression diagonal at loads approximately 2.5 to 3.7 times their design compression capacity. Of note, Yamamoto's paper makes no discussion about the boundary conditions imposed on the connection, although photographs of the failed samples suggest a high degree of out-of-plane constraint was present due to the short length of the members and the presence of large-end plates and stiffeners at the member ends.

Gross (1990) conducted experiments on gusset plate connections for a typical building lateral bracing system. The test specimens included a top and bottom gusset plate on either side of a beam framed into a column subassembly (Figure 4). Parameters of interest were bracing member eccentricity relative to the beam-to-column working-point intersect, and whether a strong or weak axis-column alignment was included in the subassembly. The subassembly was loaded laterally across the two top pins, inducing tension in the top diagonal member and compression in the bottom diagonal member. Two of the three samples tested failed by buckling of the bottom gusset plate, with the third sample failing in block shear in the top gusset plate. Gross found that calculating the gusset plate buckling capacity per AISC Engineering for Steel Construction (1984) yielded values close to the experimental, provided that an effective length factor of $k=0.5$ was used instead of Thornton's $k=0.65$. By decreasing the effective length factor, the calculated compressive capacity is increased, hence accounting for additional strength from post-buckling and plate action in the gusset plate.

\subsection{GUSSET PLATE LOAD RATING METHODS ACCORDING TO FHWA}

After the I-35W bridge collapse in Minneapolis, FHWA released a guidance report detailing the minimum requirements for load rating riveted and bolted gusset plates on bridges 
(FHWA, 2009), Hereinafter referred to as the FHWA Guide, it is based on the latest editions of AASHTO LRFD, LRFR and LFR, where the following strength limit states are addressed: resistance of fasteners, gross-section plate yielding, net-section plate fracture, and both tensile and compressive resistance. In this report, only compression failure states of the gusset plate are of interest and therefore are summarized. A gusset plate's buckling capacity is complex and is influenced by the plate's state of stress, boundary conditions and system geometry. The FHWA Guide allows the ultimate factored compressive capacity $\left(P_{r}\right)$ to be calculated as follows per AASHTO LRFD Articles 6.9.2.1 and 6.9.4 in lieu of more rigorous analysis.

Given,

For $\lambda \leq 2.25$, then

$$
\lambda=\left(\frac{k L}{r_{s} \pi}\right)^{2} \frac{F_{y}}{E}
$$

Otherwise:

$$
P_{r}=\phi_{c} 0.66^{\lambda} F_{y} A_{s}=\phi_{c} 0.66^{\lambda} F_{y} w_{l} t
$$

where:

$$
P_{r}=\phi_{c} \frac{0.88 F_{y} A_{s}}{\lambda}=\phi_{c} \frac{0.88 F_{y} w_{l} t}{\lambda}
$$

$k=$ effective length factor

$L=$ Whitmore effective length (see Figure 2)

$r_{s}=$ Radius of gyration $=\sqrt{I_{g} / A_{g}}$

$w_{l}=$ Whitmore effective width

$\phi_{c}=$ resistance factor for members in compression $=0.9$

It is left to the engineer's judgment to select an appropriate effective length factor $k$, based on the anticipated boundary conditions of the gusset plate (i.e., whether sway or non-sway conditions exist). In non-sway conditions the $K$ values range from 0.65 to 1.0 and for sway conditions they range from 1.2 to 2.0. AASHTO LRFD also places an upper limit of the length-to-thickness ratio of $2.06 \sqrt{E / F_{y}}$ for the design of unsupported edges of gusset plates to prevent gusset plate buckling, but is not required by the FHWA Guide when evaluating existing connections. 


\subsection{PREVIOUS GUSSET PLATE NUMERICAL MODELS}

Many of the aforementioned studies developed analytical models based on the finite element method in conjunction with their experimental work. The following is a summary of previous methods used in the literature to model gusset plate stress distributions and failures.

Davis (1967) was among the early users of numerical methods to investigate gusset plate stresses in the elastic range, where he replicated Whitmore's findings analytically in his thesis research. Vasarhelyi (1971) also employed finite element analysis on stress distributions across critical planes of the gusset plates he tested experimentally. Vasarhelyi reported close agreement between analytical and experimental results that corroborated findings by Whitmore, but Vasarhelyi did not provide specific details to the analytical approach.

More recent numerical models have been developed using Abaqus finite element software to model tensile and compressive failure states. Walbridge et al. (2005) presented a model to investigate gusset plate failure states under monotonic tension, compression and cyclic loading. The model was based upon previous analytical models developed by Yam and Cheng (1993), which were used to model gusset plate buckling capacity. Abaqus S4R shell elements were used to model the gusset plate. Both a perfect elasto-plastic and isotropic strain-hardening material model were examined. Load was delivered through two splicing members on each side of the gusset plate; with the bolt connections modeled as either rigid beam elements, or as onedimensional spring elements to incorporate load displacement behavior of the fasteners. Bolt holes were not explicitly modeled in the gusset plate. The model was calibrated with experimental data from Rabinovitch and Cheng (1993) and Yam and Cheng (1993).

Walbridge found that the perfect elasto-plastic material model produced better predictions of ultimate tensile strength, whereas the isotropic strain-hardening model tended to 
over-predict ultimate tensile strength. Walbridge hypothesized this may be due to the exclusion of bolt holes in the model, and that the excess material along the block shear failure planes contributed to the model's overstrength. Buckling capacity was significantly affected by the magnitude of initial out-of-plane distortion introduced in the gusset plate prior to loading, as well as the state-of-boundary conditions imposed on the splicing members. It was also found that incorporating load-displacement behavior of the fasteners had little effect on the predicted global load-displacement behavior of the plate, or the predicted ultimate strength in tension and compression.

Sheng et al. (2002) used a model analogous to Walbridge's model to conduct a parametric study on gusset plate buckling strength. Among the parameters considered included the effects of unsupported edge length, degree of rotational restraint imposed on the brace member, and the stiffness and length of the brace member. Sheng's model showed that increased unsupported edge length, increased rotational restraint, decreased brace member flexural stiffness and increased brace member length, all decreased the gusset plate's buckling capacity.

Following the I-35W Bridge collapse in Minneapolis, a detailed finite-element model was constructed to elucidate on the hypothesis that collapse was initiated at an under-designed gusset plate, and is described by Liao et al. (2011). A global model of the entire bridge was developed using the software SAP 2000 to determine the load demands on the U10 connection through the bridge's service life. A connection-level model of the U10 connection was developed using Abaqus. The gusset plate was modeled using C3D8 (linear brick element) elements from the Abaqus element library. Member stubs were included in the connection model. Rivets and their corresponding holes were explicitly modeled at the L9/U10 diagonal, represented by rigid 
cylindrical shells that transferred load through contact interaction to the rivet holes in the gusset plate. Rivets on the remaining sections were modeled with rigid beam elements through the hole centers. The contact interaction definition between the rivets and bolt holes neglected tangential friction. The model represents the highest degree of complexity in a gusset plate connection reported in the literature, containing approximately 120,000 elements per gusset and was run on an IBM Power4 supercomputer at the University of Minnesota Supercomputing Institute.

Conclusions from the FEA study corroborated the forensic and design review investigations by the NTSB (2008), namely that a significant portion of the U10 gusset plates may have already been yielded at the time of collapse. The added construction weight, combined with insufficient strength at the U10 node, were the main contributors to the bridge's collapse. Liao also suggested that the interaction between compression and shear may have played an important role in the failure and recommended further study.

\subsection{SUMMARY}

The gusset plate tensile capacity is generally governed by block shear. Although equations for calculating block shear differ slightly between Hardish and Bjorhovde (1985), AISC Specifications, and AASHTO, they all are capable of adequately predicting gusset plate tensile capacity with varying levels of conservatism. The various methods for the evaluation of gusset plate buckling capacity have the same general approach, namely that the gusset plate is reduced to an equivalent column based on rule-of-thumb guidelines such as the Whitmore section and an assumed effective-length factor. However, appropriate definitions for Whitmore section, effective length and effective-length factor are still subject to debate, as seen from the numerous formulations presented, in order to align calculated buckling capacity with experimental results. Also, the magnitude of out-of-plane imperfection in the gusset plates are 
not incorporated into design or load-rating procedures per the FHWA Guide, which may have a significant impact on buckling capacity. 


\subsection{GUSSET CONNECTION EXPERIMENTAL PROGRAM (OREGON STATE UNIVERSITY)}

Six large-scale gusset plate connection tests were conducted at Oregon State University in the Structural Engineering Research Laboratory. All six specimens failed due to sway buckling at the base of the diagonal compression member. Details of the specimen design, test setup, instrumentation, experimental methods, results, and discussions are described in the following sections.

\subsection{EXPERIMENTAL DESIGN AND SETUP}

The overall geometry for the experimental setup was inspired by connection U10 from the I-35W Bridge in Minnesota. This is the connection reported to have failed and which prompted the professional community's interest in gusset plate performance and this research program. The experimental program focused on the response of an isolated double-sided gusset plate connection typical of truss bridges. While the experimental setup is similar to the U10 connection, it is not a replica of the actual connection and was modified to meet certain laboratory testing limitations. An overall elevation view of the setup is shown in Figure 5. The connection is composed of two gusset plates which have five members framing into them, representing the geometry of a typical truss. The member designations are M1, M2, M3, M4 and M5, as seen in Fig. 5. The setup utilizes a strong-wall and strong-floor on which a reaction frame was erected to allow reaction forces of over 1 million pounds to be generated in the setup. To model lateral resistance typical from floor beams and wind bracing, a lateral brace was positioned on one side of the connection in line with the work point of the joint.

In order to ensure that the gusset plates failed due to instability at the compression diagonal, it was necessary to design the members and reaction frame to preclude alternative 
failure mechanisms. Members were designed according to the LRFD design provisions prescribed in the AISC Steel Construction Manual, $13^{\text {th }}$ Edition. With the exception of M1, all members were HSS shapes, though not all the same size. Members M2, M4 and M5 were HSS $20 \times 12 \times 5 / 8$, with the strong-axis bending oriented in the plane of the truss, while member M3 was HSS 12x12x3/8. All tube sections were made of A500 steel. Member M1 was a built-up box member composed of A36 steel plates (Figure 7) with the strong-axis bending oriented in the plane of the truss. The lateral brace consisted of a pair of back-to-back angles, which acted as links as shown in Figure 9. The lateral brace was connected using slotted connections at the gusset plate and pinned at the reaction frame. The braces allowed vertical translations but restricted out-of-plane deformation at the work point. Members M1 and M2 were connected to the reaction frame. Member M1 was connected using four (4) 1-inch-diameter bolts connected to the reaction frame. Member M2 was connected using two (2) 1/2-inch-thick plates (one on each side), which were each fastened to the reaction frame with six (6) 1-inch-diameter bolts. Each plate was connected to the member with 36 3/4-inch-diameter bolts. Member M4 was connected to the reaction frame using a high-strength spherical bearing that provided a true pin connection with no rotational restraint.

Two different members were used for the compression diagonal member, M4. The first member M4 and HSS section, as described above, were relatively stiff. The second M4 section was designed so that the out-of-plane flexural stiffness was reduced by an order of magnitude from the "stiff" HSS section. The "soft" member M4 consisted of back-to-back MC18x58 channel sections (Figure 8), which provided approximately the same cross-sectional area (same axial stiffness) and strong-axis second moment of area, $I$, while providing just $7 \%$ of the weakaxis second moment of area of the HSS member M4. By orienting the member so that weak-axis 
bending occurred in and out of the plane of the truss, the effects of out-of-plane compression diagonal stiffness on sway buckling capacity could be evaluated.

The gusset plates used in each test were identical in size and shape, with the exception of thickness, and are detailed in Figure 6. Specimens 1, 2 and 4 were 1/4-inch-thick, Grade A36 steel plates, and specimens 3, 5 and 6 were 3/8-inch-thick, Grade A36 steel plates. The connections to the truss members were all bolted with 3/4-inch-diameter A325 bolts. All bolts were tightened using a pneumatic impact wrench, with the exception of those at the M4 connection. The bolts in the M4 connection were tightened to a relatively low $100 \mathrm{ft}-\mathrm{lbs}$ to enable bearing behavior instead of slip critical behavior. This is more representative of older plates with riveted connections, whereby forces are transferred between the member and plate through bearing. The gusset plates were fabricated using $\mathrm{CNC}$ equipment and all bolt holes in the plates were drilled.

Three actuators were used in the setup and included two 500-kip actuators and one 220kip actuator. The actuator sizes were chosen based on the design forces in the I-35W bridge for which each member was sized. The 220-kip actuator was positioned over the vertical member (M3). The first 500-kip actuator was positioned vertically over member M4. The second 500kip actuator was positioned horizontally in line with member M5. This large actuator was used to induce compressive force in the chord. Henceforth, the actuators will be referred to by their associated member when referenced (i.e., the actuator positioned over member M4 will be referred to as the "M4 actuator"). 


\subsubsection{Instrumentation}

Four different sensor types were used to capture the behavior of the gusset plates and members as well as the reaction frame. Uniaxial strain gages were placed on all members except M3 (not enough length available to instrument) to capture axial forces and bending moments in the members. Uniaxial strain gages were also applied to the gusset plate to capture bending and membrane stresses at the free edges of the gusset plate by positioning gages on each side of the plate at the same location. On the gusset plate surface, $45^{\circ}$ strain rosettes were used to determine stress magnitudes and orientations along critical paths identified as A-A, B-B and C-C (shown in Figure 26). Relative displacement between the edge of the gusset at each connection and the work point was measured with displacement sensors attached to the work point and each member. Local slip between the members and gusset plate was measured with displacement sensors placed at the edges of the gusset at each member connection. Out-of-plane displacement was measured using displacement sensors attached to the free edge of the gusset between members M4 and M5 and also at the work point. Global system displacement in the downward direction was measured with displacement sensors attached between the work point and laboratory strong floor. For each test, data were collected and archived using a commercially available data acquisition system. After testing, the data were reduced and are reported subsequently. As the test program evolved, some sensors were deemed inconsequential and were not used in later tests. The instrumentation plans for all tests is shown in Figure 10-Figure 15.

In addition to the discrete displacement sensors described above, a digital image correlation (DIC) system was used to monitor global movements of the critical plate area where M4 framed into the joint on one the west side of the connection. The use of DIC also allowed 
measurement of the initial imperfections in the gusset plates prior to loading. These initial imperfections are shown for each specimen in Figure 16. An example of the progressive motion of the west plate of specimen 2 during loading of the gusset is shown in Figure 17. In this figure, the final buckled shape at failure is not scaled the same as the other images and is shown to illustrate the progression of out-of-plane deformation.

\subsubsection{Loading Protocols}

Two separate loading protocols were used in the test series. Protocol 1 was used for specimen 1 and specimen 3 and deployed all three actuators in the setup. The loading was broken down into cycles, and each cycle used progressively larger loads proportioned between M3, M4 and M5, based on the I-35W design load proportions for the truss members. Each cycle followed these steps:

1. All actuators at zero

2. Load M4 actuator

3. Hold M4 + Load M3

4. Hold M4 + Unload M3

5. Hold M4 + Load M5

6. Hold M4 + Unload M5

7. Hold M4 + LoadM3 + Load M5

8. Unload all actuators in reverse order from Step 6

For specimen 1, the load cycles followed the values shown in Table 1, and for specimen 3 the load cycles followed the values shown in Table 2. The rate at which the loads were applied 
varied throughout the duration of each test. At low loads in the elastic range a rate of $1 \mathrm{kip} / \mathrm{sec}$ was used, and when load magnitudes became large the rate was increased to $2 \mathrm{kip} / \mathrm{sec}$.

The other loading protocol, protocol 2, was used in the other tests and was a monotonic

loading using the M4 actuator only. The actuator was loaded at a constant rate of $1 \mathrm{kip} / \mathrm{sec}$ until failure of the gusset plates. This protocol was used for specimens 2, 4, 5 and 6 .

\subsubsection{Development of M4 Brace Stiffness for Test Program}

In order to assess the role of the compression diagonal member out-of-plane stiffness on the sway behavior and strength, the member stiffness was changed for different specimens. To rationally establish the compression diagonal proportions, existing steel truss bridges across the country were examined to determine common diagonal compression member stiffnesses observed in practice. The stiffness of the compression diagonals was determined by calculating the weak-axis moment of inertia, $I$, from drawings of the built-up cross sections. Member length, $l$, was also taken from the drawings. Modulus of elasticity, $E$, was assumed to be 29,000 ksi. The translational stiffness, $k_{t}$, and rotational stiffness $k_{r}$ were computed assuming the same boundary conditions for each member considered as:

$$
\begin{aligned}
& k_{t}=\frac{E I}{l^{3}} \\
& k_{r}=\frac{E I}{l}
\end{aligned}
$$

where:

$k_{t}=$ translational stiffness (kip/in)

$k_{r}=$ rotational stiffness (kip-in)

$E=$ modulus of elasticity (ksi)

$I=$ moment of inertia $\left(\right.$ in $\left.^{4}\right)$

$l=$ length of member (in.) 
To ensure no regional design bias in the selection of the diagonal stiffness, six different bridges were evaluated from different parts of the country. The bridges and results of the comparison are shown in Table 4. The average member translational stiffness in the steel truss bridges evaluated was $0.55 \mathrm{kip} / \mathrm{in}$. For the back-to-back channel section used for M4, the stiffness was $1.31 \mathrm{kip} / \mathrm{in}$. and is higher than that observed in the bridge database considered. The closest in situ value was $1.29 \mathrm{kip} / \mathrm{in}$. for member M15-L16 on the I-275 Bridge over the Ohio River in Kentucky. The average member rotational stiffness in the set of steel truss bridges evaluated was $271,000 \mathrm{kip} / \mathrm{in}$. This is much closer to the HSS brace stiffness used in the experimental program, which had a rotational stiffness of 224,000 kip/in. This shows that for laboratory tests that must deploy artificial member cross sections and lengths (often necessary for cost and facility constraints), the resulting specimens have out-of-plane stiffness properties that are unrealistically large. The effects of this high member stiffness on sway buckling are uncertain and have not previously been considered experimentally. In the present set of tests, the two M4 configurations considered were able to model the translational stiffness or the rotational stiffness of in situ bridges, but not both simultaneously. This explicit consideration of member stiffness on connection behavior and strength is a unique feature of the test program.

\subsubsection{Calibration of Strain Gages on Member M4 for Axial Force Calculation}

To accurately represent the axial force data gathered from strain gages located on member M4, it was necessary to calibrate the gages on both the soft and stiff cross sections. The stiff brace was calibrated using a separate actuator that was not subject to the system losses of the test setup caused by the reaction frame. The brace was placed vertically below the actuator and centered in all directions so that bending would not be induced. The strain gage readings 
were averaged across all the gages to obtain force. A linear fit was used to calibrate the strain gages with the load cell readings. Calibration of the soft brace was done using the M4 actuator in the test setup. The diagonal member was placed vertically under the crossbeam. A load cell was placed at the bottom of the diagonal member so that the member load could be measured directly. Like that for the stiff section, a linear fit was applied to the strain data and correlated with the direct applied load cell measurements. Both calibrations are shown in Appendix B. All axial force data presented in this report are the member forces calibrated in this way.

\subsection{EXPERIMENTAL RESULTS}

All six gusset plate specimens exhibited sway buckling failure modes at the M4 location. Specimen 1 buckled away from the out-of-plane brace and all other specimens buckled towards the out-of-plane brace (two specimens were forced to buckle toward the brace). This showed some limited bias in the test setup. The buckled shapes of each specimen after failure are shown in Figure 23 along with the predicted FEA buckled shape. The experimental results are described by buckling capacity, compressive force in the compression diagonal versus out-ofplane displacement of the gusset plate, plate stress distributions, and bending strains in the M4 compression diagonal cross section. The experimental findings are compared with the predicted strength using the FHWA Guide. The measured stress in the plate is compared with the Whitmore effective width and Modified-Thornton methods. Table 5 shows the experimental test matrix with salient specimen characteristics as well as key results including: plate thickness, loading protocol, maximum initial out-of-plane imperfection, out-of-plane displacement at failure, axial load in member M4 at failure, average Whitmore stress at failure, and the ratio of 
observed stress in the M4 direction to the Whitmore stress and Modified-Thornton stress at corresponding loads.

\subsubsection{Compression Diagonal force-Plate Out-of-plane Displacement}

The compression diagonal (M4) force versus out-of-plane displacement at the free edge of the gusset plate is most descriptive of the overall behavior of the connection. For each specimen, the out-of-plane displacement data were collected at the midpoint of the vertical free

edge of the gusset plates as well as at the work point of the gusset plates. The rigid body motion of the overall connection assembly as captured at the work point of the gusset was projected to the free edge of the gusset by assuming a linear projection from the base of the reaction frame through the work point and out to the free edge of the gusset. This rigid body motion was removed from the displacements observed at the midpoint of the free edge of the gussets to obtain the out-of-plane displacement of the free edge relative to the truss members. The curves exhibited load stiffening at the beginning of each test, which was removed using a linear fit of the elastic portion of the curve (once it became linear), and then projecting the linear elastic portion to the x-axis. The entire curve was then shifted so that the line crossed the origin. Figure 19 shows the compression diagonal (M4) force versus out-of-plane displacement at the free edge behavior during failure cycles for each specimen. Specimen 1 is shown as a backbone curve because it failed during unloading of the M5 actuator (this is described in more detail subsequently).

Three parameters were seen to influence the compression diagonal (M4) force versus outof-plane displacement at the free edge behavior most significantly: combination loading, initial out-of-plane imperfection, and compression diagonal flexural stiffness. Specimen 1 provided the 
most insight into the effects of member combination loading on connection capacity. Two figures help explain the observed behavior of specimen 1: Figure 20 shows the M4 load versus free edge displacement behavior for all load cycles, and Figure 21 shows the final load cycle with the different load steps detailed. For each load cycle, additional out-of-plane displacement was introduced to the system (as observed at the work point) by the application of loads from the M3 and M5 actuators. As the M3 and M4 forces were increased, the compression stresses in the plate reduced, even while the axial force in member M4 was maintained. In the final load cycle, M4 was loaded to the target value without failure and then M3and M5 loads were applied. The M3 and M5 loads created slightly more additional out-of-plane displacement of the system while decreasing the compression stress in the plate. Then, when both M3 and M5 loads were removed and the axial force in M4 remained unchanged, the compressive stress in the gusset increased and with the slightly increased out-of-plane deformation of the system (induced by application of the M3 and M5 loads), the gusset plates buckled. When compared with specimen 2, which had all the same parameters but was loaded monotonically using only the M4 actuator, the buckling load increased by 10\% from 291 kips for specimen 1 to 325 kips for specimen 2 .

The effects of initial imperfections were most evident in specimens 3,5 and 6 . In specimen 3 , the capacity of the actuators was not sufficient to buckle the plates when the specimen contained only as-built initial imperfections on the order of about $100 \%$ of the plate thickness seen in Table 5. In order to buckle the specimen, additional imperfections were required. To increase the plate imperfections, a hydraulic ram was used to push the plates laterally out-of-plane at the center of the free edge as shown in Figure 18. This simulated the lowest buckling mode for the connection (as described in the numerical modeling chapter). Using this approach, an additional imperfection of $102 \%$ of the plate thickness was imposed, 
which was sufficient to produce failure given the force capacity of the available hydraulic loading system. Figure 22 shows the results during tests with the as-built initial imperfection. Here the first results was for the as-built imperfections where the specimen did not fail, while the second curve shows the final loading cycle which produced sway buckling failure (after an additional out-of-plane imperfection of $102 \%$ of the plate thickness). The same behavior was observed for specimens 5 and 6 (soft brace M4). Both of these specimens had $3 / 8$-inch-thick plates with the flexurally soft M4 cross section and used the monotonic loading protocol. However, specimen 6 had an additional initial out-of-plane imperfection of $98 \%$ imposed on the free edge to compare with the findings of specimen 3. A reduction in capacity of $14 \%$ was observed for specimen 6 (498 kips) compared with specimen 5 (579 kips). This shows that the strength reduction was not as significant for the flexurally soft M4 cross section as compared to that of the stiff M4 cross section.

Finally the effect of the M4 compression diagonal stiffness was observed in the load versus out-of-plane displacement behavior at the free edge. In both the $1 / 4$-inch and $3 / 8$-inch-thick plates, the sway buckling capacity was significantly reduced when the soft-brace section was used instead of the stiff-brace section. Specimens 2 and 4 show a $21 \%$ reduction in capacity for the $1 / 4$-inch plates while specimens 3 and 6 show a $9 \%$ reduction in capacity for the $3 / 8$-inch plates (these specimens had approximately $100 \%$ plate-thickness imperfections imposed prior to testing). While specimen 5 showed a higher buckling capacity than specimen 3 , the effects of initial imperfection were more dominant than the effects of brace stiffness for the thicker plates. This difference in behavior can be explained through member-plate interactions in the numerical studies described later. 


\subsubsection{Bending strains in member M4}

Compression diagonal-gusset plate interactions were observed in the bending behavior of member M4. Bending strains were extracted from the uniaxial strain gages that were placed at cross sections of the member to measure the member axial, shear and bending. The measured strain distributions for member M4 are shown in figures 25 and 25 for the flexurally stiff and soft diagonals, respectively. The strain profiles show both axial and bending strains. The axial strain was removed as the average of the strains at the instrumented cross sections. The resulting strains are from bending. The observed strain profiles at the midpoint of the member were obtained directly from strain gage data gathered during testing. The expected strain at the plate-member interface was projected based on a linearly extrapolated moment profile along the length of the member with the spherical pinned bearing connection having zero bending strain. The difference in the two different stiffness compression diagonals is clearly evident in the aforementioned figures. In specimens 1, 2 and 3, where the stiff brace was used, there is very little bending observed. Specimen 3 shows some bending due to the much higher loads needed to buckle the 3/8-inch-thick plates. However, this bending strain was very small when compared with that observed for specimens 4, 5 and 6 . In the specimens where the soft M4 was used, bending strains at the midpoint of the member was clearly evident, and the projected profiles at the platemember interface actually indicate some tensile stress in the member. The strains show bending of the diagonal that provides less restraint to the plate, thereby reducing the effective stiffness of the system and lead to lower buckling load. 


\subsubsection{Stress distribution}

The experimental tests allowed characterization of the stress distribution in the gusset plates and comparison with previously reported archival findings. Three different paths were used to describe the stress distribution throughout the plate and are shown in Figure 26. Each path corresponds to a path typically used to assess plate strength. Plane A-A corresponds to the shear plane located just above the bottom chord of the connection, path B-B corresponds to the Whitmore effective width, $w$, and path C-C corresponds to the effective column length, $L_{2}$, as described by Thornton (Yam and Cheng 1993).

In order to fairly represent the axial stress in the plate from strains measured using the strain rosettes, it was necessary to determine when the effects of bending began to contaminate the strain-gage measurements. A strain-gaged location was used to determine this threshold. The sensor was identified as gage R2 as seen in the instrumentation plans of figures 10-Figure 15. This sensor was offset slightly from the midpoint of the Whitmore width along path C-C and was chosen due to the high stresses and bending that occurred at this location. The strain-gage values were reduced to provide stress values oriented in the direction of member M4 so that they could be compared with the Whitmore stress. Two different normalizations were performed to establish the threshold where bending in the plate begins to become significant and the straingage readings are not representative of the axial plate stresses. The gusset plate stress oriented in the M4 direction, $\sigma_{4}$, were normalized with respect to the maximum Whitmore stress (computed as the maximum member force divided by the Whitmore section) and plotted against normalized M4 axial compressive force values, $\mathrm{F} / \mathrm{F}_{\max }$ and are shown in Figure 27. The gusset plate stress in the M4 direction is shown in Figure 28 normalized with respect to the corresponding Whitmore stress for each member force value and plotted against the normalized M4 axial compressive 
force values. In these figures, specimen 4 showed significantly higher stresses relative to the Whitmore stress and exhibited bending early in the test. From the observed results it was determined that the plate membrane stress distributions were maintained between $0.3 \mathrm{~F}_{\max }$ to $0.6 \mathrm{~F}_{\max }$. The lower stresses are not characteristic because they are sensitive to noise, imperfections and nonuniform bearing/contact between the fasteners and plates.

For all specimens, stresses were determined in the global x, global y, global xy (shear) and principal directions, as well as von Mises stresses. For paths B-B and C-C, they were further determined in the direction of member M4 to correspond with the Whitmore stress direction and Thornton's effective column direction. Results between the range of $0.3 \mathrm{~F}_{\max }$ and $0.6 \mathrm{~F}_{\max }$ for specimens 1, 2 and 4 (1/4-inch plates) are shown in figures 29-Figure 35. Results between the range of $0.3 \mathrm{~F}_{\max }$ and $0.6 \mathrm{~F}_{\max }$ for specimens 3,5 and $6(3 / 8$-inch plates $)$ are shown in figures 36Figure 35 . For the $1 / 4$-inch-thick plates, specimens 1 and 2 are similar for all stress directions. This is expected since both tests were identical, with the exception of the loading protocol. When compared with specimen 4 however, differences were observed. In general, specimen 4 exhibited similar trends to those of specimens 1 and 2, with differences observed in the stress magnitudes. For plane A-A and path $\mathrm{C}-\mathrm{C}$, the stresses tended to be smaller for specimen 4 in all directions. Further, the stress in the global-x direction on plane A-A did not follow the same pattern as that observed for specimens 1 and 2. For path B-B, the magnitudes tended to be larger than specimens 1 and 2, especially at the center of the path, which corresponds to the midpoint of the Whitmore width. As described earlier, specimen 4 exhibited higher bending stresses than the other specimens. Bending is likely the cause of this difference in stress distribution, and the early bending (out-of-plane distortion) resulted in a relatively low failure load. 
For the $3 / 8$-inch-thick plates, specimens 3 and 6 were similar. Although the two tests used different M4 brace sections, the effects seen in the 1/4-inch-thick plates with different brace stiffness were not as evident. The same trend of the soft brace having slightly smaller magnitudes than the stiff brace was observed, but the differences were smaller, generally below 3 ksi. The reason for the smaller differences was the externally applied initial imperfection. By inducing greater initial imperfection the influence of the bracing member stiffness is reduced, resulting in similar stress magnitudes and distributions. This also explains the difference in stresses reported from specimen 5 in relation to specimens 3 and 6 . Specimen 5 had only as-built imperfections and exhibited lower variations in plate stresses across all the stress paths and directions.

In addition to the stresses reported in the range of $0.3 \mathrm{~F}_{\max }$ and $0.6 \mathrm{~F}_{\max }$ of the member force, the effects of combination loading (loading protocol 1) were observed by comparing specimens 1 and 3. For specimen 3, results are reported before additional imperfection was applied for better comparison to specimen 1. The load cycle chosen for reporting stresses corresponds to the load cycle that most closely matched $0.6 \mathrm{~F}_{\max }$. For specimen 1 , the load cycle chosen was 175 kips - 42 kips - 164.5 kips (actuator loads M4 - M3 - M5, respectively), and for specimen 3 the load cycle was 300 kips -72 kips -282 kips. Stresses are shown for the load cases of M4 only, M4 and M5, and M4, M3 and M5. In general, the stresses in each specimen followed the same trends with larger magnitudes in specimen 3 . The plots show that different member load combinations definitely affect the stress distribution in the plate, especially the addition of M5. The addition of M5 to M4 caused plate stresses to increase in nearly every direction, with the exception of shear stresses. The addition of M3 did not have the same effect on magnitudes as the addition of M5; however, it did reduce the stress in the M4 direction at the 
midpoint of the Whitmore section back to levels corresponding to M4-only loads. This also helps to explain why specimen 1 failed in unloading as the M3 load was removed.

\subsubsection{Comparison of stresses to Whitmore and Modified-Thornton methods}

The most common formulation used to describe the stress magnitude in a gusset plate is the Whitmore method. The method assumes the maximum stress can be estimated as the member force divided by an effective plate area having a width determined based on an assumed dispersion angle of $30^{\circ}$. This was illustrated previously in Figure 2. The experimentally measured gusset plate stress magnitudes were compared with the Whitmore method. The theoretical Whitmore stress was calculated as the applied compression member (M4) force divided by the cross-sectional area of the gusset plate. The effective area was computed as the Whitmore effective width $\mathrm{x}$ gusset plate thickness. The M4 force level was set equal to $60 \%$ of the collapse load $\left(0.6 \mathrm{~F}_{\max }\right)$ to minimize the influence of significant plate bending in the measured results. This value was compared with the measured maximum principle stress in the plate, measured at strain-gage location R2 (see Fig. 14 for example). This strain gage was centered at the end of the compressive diagonal member. The theoretical and measured maximum compressive stresses are shown in Table 5. As seen in this table, the mean ratio of the maximum compressive stress (from the plate strain gages) to theoretical stress (member load/theoretical

Whitmore area) was 1.26. Data from specimens 3 and 6 were not used for this assessment due to bending stresses produced by the large imposed out-of-plane deformations for these tests. This indicates that, on average, the actual maximum compressive gusset plate stresses were larger than those predicted by the Whitmore method. However, the stress distributions across the Whitmore section were not uniform as discussed below. 
Most engineers apply the Whitmore section in design and analysis by considering it to be the cross section of an equivalent column. To consider this, the experimentally measured gusset plate strains (from rosettes R1, R2 and R3) were transformed to show the plate stresses oriented in the member M4 direction along the Whitmore width. The stress distribution in the direction of member M4 across path B-B was non-uniform for all specimens, as shown in figures 35-42. Because the stress distribution was non-uniform, comparisons were made considering average plate stress in the direction of member M4 and maximum plate stress in the direction of member M4 along the Whitmore width (path B-B). Average gusset plate stresses along path B-B were determined by averaging the measured stresses in the gusset plate oriented in the M4 direction when the M4 force was equal to $60 \%$ of the collapse load $\left(0.6 \mathrm{~F}_{\max }\right)$. The gusset plate stress values along path B-B were normalized with respect to theoretical Whitmore stresses and are also shown in Table 5. The mean ratio of average stress (from plate strains) to theoretical stress (member load/theoretical Whitmore area) was 0.65 . The mean ratio of maximum stress (from R2 measured in the direction of member M4) to theoretical Whitmore stress was 1.14. Data from specimens 3 and 6 were not used in these assessments because the bending stresses produced by the large imposed out-of-plane deformations affected the strain measurements. These results showed that the average gusset plate stresses across the Whitmore section were approximately $57 \%$ of the maximum stress. This may help explain the conservative outcomes when using the Whitmore method to predict gusset plate connection buckling strengths.

Another method that uses a different assumed stress distribution in the gusset plate is the Modified-Thornton method (Yam and Cheng, 1993). This method assumes a larger dispersion angle of $45^{\circ}$ as compared to the $30^{\circ}$ angle used by Whitmore. The original formulation by Yam and Cheng considered only the overall strength rather than the local plate stresses. However, to 
compare with the application of Whitmore as described in the previous paragraph, the plate stresses in the member M4 direction were evaluated considering the $45^{\circ}$ dispersion angle. Both average and maximum gusset plate stresses along path B-B were determined when the M4 force was equal to $60 \%$ of the collapse load $\left(0.6 \mathrm{~F}_{\max }\right)$. The gusset plate stress values in the member M4 direction along path B-B were normalized with respect to theoretical Modified-Thornton stresses (taken as the M4 load/(Modified-Thornton width*gusset plate thickness)) and are shown in Table 5. The mean ratio of average stress (from plate strains) to theoretical stress (member load/theoretical Modified-Thornton area) was 0.54 . It should be noted that strain gages R1 and R3 are at the end of the Whitmore section and to estimate the stresses at the ends of the Modified-Thornton section the plate stresses were linearly extrapolated. Due to the non-uniform stress distribution in the plate, the results showed that as the plate stresses were considered over a larger area, the average stress decreased. The average plate stresses were lower for the ModifiedThornton approach than that observed for the Whitmore approach. The mean ratio of maximum stress (from R2 measured in the direction of member M4) to the theoretical Modified-Thornton stress was 1.40. These results showed that the Modified-Thornton method predicted a lower maximum stress than the Whitmore method. Whitmore more closely predicted the value of the maximum stress with the actual plate stress being higher than that predicted. Whitmore also better predicted the average stress on the effective area with the actual average plate stress being lower than that predicted. Data from specimens 3 and 6 were not used in the above assessments because the bending stresses produced by the large imposed out-of-plane deformations influenced the strain measurements. 


\subsubsection{Comparison of Experimental Results to FHWA Guide}

Currently, the FHWA Guide is the protocol used by transportation agencies to evaluate gusset plates. Of interest to this work is the effectiveness of the FHWA Guide in predicting buckling strength of gusset plates. Buckling strength is computed as described previously using Eqns. 2-1 through 2-3. A key parameter in these calculations is the effective length factor, $K$. The FHWA Guide describes appropriate values of $K$ for sway buckling as 1.2 to 2.0 depending on boundary conditions. Using the experimental results produced in this research, $K$ values were back-calculated from the measured buckling loads using the following series of equations:

$$
\begin{gathered}
\lambda_{1}=\log _{0.66}\left(\frac{P_{n}}{2 F_{y} A_{g}}\right) \\
\lambda_{2}=\frac{2(0.88) F_{y} A_{g}}{P_{n}} \\
\lambda=\lambda_{1} \\
\lambda=\lambda_{2} \\
\text { If } \lambda_{1}<2.25 \\
\text { If } \lambda_{1} \geq 2.25 \\
K=\frac{r_{s} \pi}{l} \sqrt{\frac{\lambda E}{F_{y}}}
\end{gathered}
$$

Using Eqns. 3-3 to 3-5, the experimentally predicted $K$ values were computed and are shown in Table 6. As seen in Table 6, the experimentally determined $K$ values were well below those thought to be applicable to sway-buckling of gusset plates. In addition to the experimental $K$ values, the critical buckling loads were estimated using the FHWA Guide and compared with the experimental results. Results of these comparisons are also shown in Table 6 and show that the FHWA Guide underestimated the capacity of the connections in this experimental program.

Based on these results, the FHWA Guide is quite conservative and the equivalent column analogy for plate bucking does not adequately account for the plate buckling behavior of the connection. The capacity of the specimens was four times greater for the $1 / 4$-inch-thick plates (very slender plates) and 2.5 times greater for the $3 / 8$-inch-thick plates when compared with the 
predicted values. The experimental $K$ values were 0.54 to 0.61 for the $1 / 4$-inch-thick plates and 0.73 to 0.80 for the $3 / 8$-inch-thick plates. These values are all less than 1.0 , which is the theoretical value for sway-buckling conditions considering the plate as an equivalent column. The effects of the compression diagonal flexural stiffness were also evident in the backcalculated experimental $K$ values. In the 1/4-inch-thick plates, the effective length factor increased 0.06 from specimen 2 to specimen 4 and in the 3/8-inch-thick plates, the effective length factor increased 0.04 from specimen 3 to specimen 6 when only the M4 stiffness was varied.

\subsubsection{Modeling of member-connection interaction}

In order to account for plate behavior in evaluation of the sway-buckling capacity, it is necessary to consider member-connection interaction. Considering an equivalent column approach, a stepped column model is used to demonstrate the member-connection interaction as shown in Figure 50. In this figure, the member is represented by the long think line and the gusset plate is represented by the short thick line. The figure also illustrates the extreme bounds of the compression member stiffness with an intermediate point between them. The effective stiffness of the plate is then determined based on the stiffness of the member, where 2.0 represents a very soft member and values less than 1.0 represents a very stiff member. Based on the eigenvalue buckling load for the stepped column (considering the relative stiffness of the connection and member as well as the length of the connection relative to the member $\alpha$ ), the plate equivalent length factor $\mathrm{K}$ was determined as shown in Fig. 51. The interaction relationship is still subject to the limitations of the column analogy for the problem space, but it 
demonstrates how relative member and plate stiffnesses affect "plate" buckling capacity and shows the need to consider the system behavior.

\subsection{CONCLUSIONS FROM EXPERIMENTAL TESTS}

Six large-scale gusset plate tests were conducted at Oregon State University to produce new data on the behavior and capacity of gusset plates with sway-buckling response. The parameters considered in the experimental program were plate thickness, initial out-of-plane imperfection, compression member out-of-plane stiffness, and member-load combinations. Variation of the diagonal compression member out-of-plane flexural stiffness was unique to the testing program. The effectiveness of the Whitmore section, Modified-Thornton approach and FHWA Guide to accurately predict behavior and capacity of gusset plates in sway-buckling failure modes was evaluated. All six specimens failed due to sway buckling of the diagonal compression member connection. The key findings are summarized below:

- The out-of-plane flexural stiffness of the diagonal compression member influenced the buckling capacity of the gusset plates and demonstrated that as the member stiffness reduced, gusset plate buckling strength decreased.

- The interaction between the member stiffness and relative plate stiffness on sway buckling was also shown analytically with the stepped column analogy. These interactions may need to be considered in future design and load-rating guidelines to accurately predict sway-buckling capacity of the system (member-connection interaction).

- Member-load combinations that increased the compression stress in the plates and increased out-of-plane deformations reduced the capacity of the gusset plate connections. 
The incremental out-of-plane displacements were not fully recoverable upon unloading of the truss members in the experimental setup.

- Initial imperfection equivalent to plate thickness decreased the buckling capacity of the gusset plates and reduced the influence of the diagonal compression member flexural stiffness on plate buckling.

- The Whitmore section predicted the principle compressive stress in the gusset plate within $14 \%$. The average measured principle compressive stresses were larger than those predicted by the Whitmore method.

- The distribution of stresses across the Whitmore effective width were non-uniform and the experimentally measured average stress magnitudes showed that both Whitmore and Modified-Thornton methods overestimated the magnitude of average stress in the gusset plate.

- Using the methodology in the FHWA Guide, the experimentally computed $K$ values were less than 1.0 and showed that values below unity can be used to analyze gusset plates dominated by sway buckling. While this appears theoretically erroneous, it is a result of the flawed column analogy used to model the plate buckling behavior.

- Using the FHWA Guide example $K$ value of 1.2, the capacity of the experimental specimens was underestimated by factors of 2 to 4 . 


\subsection{NUMERICAL MODELING (PORTLAND STATE UNIVERSITY)}

\subsection{OBJECTIVES}

The primary goal of this effort is to develop a calibrated FEA model capable of evaluating gusset plate stresses and ultimate strength limit states. Experimental data from ongoing research at Oregon State University was provided to validate the connection model. A secondary objective was to develop a gusset connection model such that at a future date could be readily adapted to analyze multiple connection geometries while minimizing the development process. This was realized by utilizing the Abaqus scripting environment to automate a significant portion of the model development, thereby aiding in existing parametric studies and building in the capability for rapid analysis across multiple connection in future studies.

\subsection{GUSSET CONNECTION MODEL DESCRIPTION}

The connection-level gusset plate model was developed using Abaqus Version 6.9. The experimental test setup and FEA model are shown in Figure 52. The connection consists of a bottom chord (M1 and M5), a vertical chord (M3), and two diagonal chords (M2 and M4). M1 and M2 are fixed on the experimental load frame and actuators are attached to M3, M4 and M5, each capable of delivering compressive loads. Global boundary conditions were imposed at the ends of each member such that they reflected the conditions found in the experimental tests.

Bolts were modeled as a one-dimensional rigid beam element that ties all degrees of freedom between the two connected nodes, where the nodes correspond to the bolt hole centers on adjoining plate surfaces. In Abaqus, this is achieved by using a rigid multi-point constraint (MPC) element positioned at the bolt-hole centers between two connected surfaces. The 
decision to model bolts using MPC elements, along with a detailed discussion of various methods for modeling bolt-load transfer in shear, can be found in work by Kay (2011).

Members were modeled with a combination of wire and extruded shell features, with the transition occurring where the members overlapped the gusset plates (Figure 53). The beam-toshell junction for each member was rigidly tied to form a continuous member. Partitions were created on the shell portion of the member to define vertices corresponding to bolt-hole centers. The actuator load capacities, along with the boundary conditions, are illustrated in Figure 54 . Note that the ends of M3 and M5 were also restrained out-of-plane in the FEA model although it is not shown in Figure 54.

An isotropic hardening material model was used for the gusset plates, which requires true stress-strain data derived from coupon tests (Table 3). Inspection of the gusset plate mill certs from all tests reported $\mathrm{F}_{\mathrm{y}}$ and $\mathrm{F}_{\mathrm{u}}$ values within $10 \%$ of the coupon data. Material for the members was modeled as perfectly elastic, with a Young's modulus of 29,000 ksi. This was justified since the members from the experimental specimens were designed to remain elastic under all foreseen loading conditions. Modeling the members as perfectly elastic increased computational efficiency and ensured that failure always occurred in the gusset plate.

The gusset plates were modeled as shells in order to avoid the additional development time and computational requirements associated with three-dimensional modeling. S4 and S3 elements were selected from the Abaqus element library for the shell portions of the model. The $\mathrm{S} 4$ shell element is a rectangular element and the $\mathrm{S} 3$ element is a triangular element; both are fully integrated, finite-membrane-strain shell elements suitable for large-strain analysis (Simulia 2010). The B31 element was selected for the beam portions of the model, which uses a 
Timoshenko beam formulation with a linear interpolation function and is suitable for both stout and slender beams (Simulia 2010).

A stress convergence trial was conducted to determine the gusset plate mesh necessary to converge on stresses under elastic loads. Von Mises stress, $\mathrm{s}_{\mathrm{xx}}, \mathrm{s}_{\mathrm{yy}}$ and $\mathrm{s}_{\mathrm{xy}}$ were monitored at nodes spaced along planes A and B, with each node corresponding to positions of strain gages from experimental tests. The subscripts refer to stress in the global $\mathrm{x}$, global y and shear stress in the xy plane, respectively. Convergence was defined as the point where stress change due to increased number elements was less than 5\%. Convergence plots for von Mises, $\mathrm{s}_{\mathrm{xx}}, \mathrm{s}_{\mathrm{yy}}$, and $\mathrm{s}_{\mathrm{xy}}$ stresses from sample points on planes A and B are available in Appendix C. Both von Mises and $\mathrm{s}_{\mathrm{xy}}$ stresses converged rapidly and satisfied the convergence criteria with gusset plate meshes of 2892 elements and 6082 elements, respectively. Convergence was more problematic at sampling points $\mathrm{A} 3$ and $\mathrm{B} 2$ for $\mathrm{s}_{\mathrm{xx}}$, and sampling point $\mathrm{A} 3$ for $\mathrm{s}_{\mathrm{yy}}$ due to their locations in high-stress zones on the gusset plate. However, the majority of sampling points converged rapidly. It was ultimately determined that a mesh of approximately 6,000 elements per gusset plate was sufficient for monitoring stresses at the most of sampling points in the elastic range, which is roughly equivalent to elements with one-inch sides.

\subsection{NUMERICAL ANALYSIS METHODS}

The three primary metrics chosen to evaluate the gusset connection were elastic stresses and gusset plate buckling capacity at the M4 diagonal member.

\subsubsection{Elastic Stress Analysis}

Gusset plate stresses due to member loading were analyzed with the specific goals of mapping gusset plate stress contours and identifying changes in the stress profile due to different loading patterns. The Abaqus Static-General step module was used to run the analysis. No initial out-of- 
plane distortions were introduced into the model for the elastic stress analysis. Loading of the gusset plate was delivered by members M3, M4 and M5 such that gusset plate stresses were kept in the elastic range. Three load sets were selected for analysis and are shown in Table 7. Global trends were tracked quantitatively across critical stress planes to make comparisons between analytical and experimental values.

\subsubsection{Buckling Capacity Analysis}

Buckling capacity at compression diagonal M4 was considered, per the experimental program at Oregon State University. The Abaqus Static-Riks step module was used to run the buckling capacity analysis, which applies an implicit-based direct stiffness approach and is capable of analyzing systems with high geometric and material non-linearity, coupled with a modified Riks algorithm to track the load-displacement path of the system through successive increments (Simulia 2010). The modified Riks method works well for analyzing unstable systems, such as buckling, where negative stiffness conditions may occur as the solution progresses, and is a valid approach assuming loading is smooth and can be scaled with a single parameter (Simulia 2010). A detailed discussion on the analysis selection method can be found in Kay (2011).

Load was induced in the connection by applying a vertical displacement of 0.5 inches in the global y direction until failure, in order to simulate the testing conditions used at Oregon State University. Preliminary numerical tests showed that the axial load and global behavior of the model were extremely close to when the displacement was applied axially along the member. Initial out-of-plane distortion was introduced as a scaled first-mode buckling shape in order to initiate buckling behavior in the model. For the Static-Riks method, a displacement criterion of 
two inches out-of-plane displacement at the gusset vertical free edge was used to halt the analysis.

The effect of gusset plate mesh refinement on global behavior was also checked for convergence by looking at the elastic buckling load from an eigenvalue buckling analysis and load-displacement behavior. Refer to Appendix C for global behavior convergence plots. It was determined by inspection that a mesh of approximately 6,000 elements was adequate for capturing global connection behavior, roughly equivalent to elements with one-inch sides.

\subsection{ANALYTICAL RESULTS AND EXPERIMENTAL VALIDATION}

Analytical results from the gusset connection elastic stress, buckling capacity and tensile capacity analyses are summarized below, followed by a comparison with experimental findings.

\subsubsection{Elastic Stresses}

A qualitative examination of the analytical stress contours is presented in Figure 57, showing stresses induced by a 100 kip compressive load at M4. The numerical results show that shear stress is the dominant stress along plane $\mathrm{A}$, whereas compressive $\mathrm{s}_{\mathrm{xx}}$ and $\mathrm{s}_{\mathrm{yy}}$ stresses were dominant along plane B. A tension stress zone can also be seen along the M2 diagonal.

Direct comparisons between analytical and experimental stresses were made along Planes A and B (figures 59-63) due to preloading at M3 and M5, and revealed numerous differences between the analytical and experimental values. One major distinction lies between analytical and experimental stress. Analytical stress from the model output is in the form of membrane stresses and represents an averaged stress across the plate thickness, whereas the experimental stress is derived from strain gages that recorded the outer plate surface. Also, out-of-plane distortions can potentially color the experimental data due to bending stresses induced in the plate. 
Von Mises and $\mathrm{s}_{\mathrm{xy}}$ stresses provided the closest correlation between analytical and experimental values, with peak values occurring approximately midway along planes $\mathrm{A}$ and $\mathrm{B}$. The trend that von Mises stress increases on the left side of plane A and decreases on the right side of plane A due to preloading from M5 and M3 was also observed for analytical and experimental values. Von Mises stresses on plane B shared a common profile between analytical and experimental results, although the experimental data was more sensitive to change due to preloading than the analytical data did.

The strongest correlation between the analytical and experimental results was seen in Figure 63, which plots von Mises profile changes to increased compressive load at M4 along planes A and B, respectively. An increase in load caused linear increases in the von Mises stress profiles for both the analytical and experimental along plane A. A similar trend occured along plane B, although not as close as with Plane A. This result is expected since loading of the gusset plate was kept within the elastic range.

\subsubsection{Buckling Capacity}

Load-displacement data was used to assess buckling predictions between the numerical and experimental, where the load is the axial force in M4, and out-of-plane displacement is measured at the midpoint of the gusset free edge between M4 and M5, as illustrated in Figure 55. Table 8 summarizes the experimental specimens 1 through 6 , along with analytical/experimental (A/E) ratios and back-calculated values for $K$ per the FHWA Guide. A/E ratios are to show analytical deviations from the experimental values, where $\mathrm{A} / \mathrm{E}$ values less than 1.0 indicate a conservative prediction and $\mathrm{A} / \mathrm{E}$ values greater than one indicate a non-conservative prediction. The numerical post-buckling shape was the same for each model case, and is shown along with 
the experimental buckled shapes from specimens 1 through 6 in Figure 23. The load versus outof-plane displacement behavior is shown in comparison to the model prediction at varied initial out-of-plane imperfections in figures 64-69.

\subsection{CONCLUSIONS AND MODELING RECOMMENDATIONS}

Connection-level FEA analysis was shown to be an effective method for evaluating the strength of steel bridge gusset plate connections, including member interactions. The model presented here has been validated with experimental tests conducted at Oregon State University. From a load-rating perspective, connection-level FEA models are appealing due to their relatively rapid development time compared to developing a global bridge model. For the connection considered here, the FEA model using MPC bolts proved to be the most efficient in assessing compressive capacity of the experimental tests, with reasonable accuracy. Although this study only examined one M4 portion of the gusset plate for strength limit states, the FEA development methods can be easily generalized to the evaluation of failure states at different portions of the gusset plate, as well as different connections.

Recommendations for further study are as follows:

1) The work presented in this report focused on gusset plate buckling capacity due to loading a single diagonal chord (M4) with minimal loadings from the horizontal (M5) and vertical (M3) chords, which is not representative of in situ loading conditions for an in-service gusset connection. Investigating the effects of M4 buckling capacity due to various pre-loadings from M3 and M5 would help quantify this relationship.

2) Fasteners in the analytical model were idealized as rigid members in this study in order to focus on failure states of the gusset plate itself. However, fastener behavior may contribute 
to gusset plate behavior. Implementation of fastener load-displacement behavior into the bolt model would extend the model's capabilities of detecting fastener-related failure states.

3) Connection-level models are well-suited to evaluate capacity for individual member connections. However, a means of delivering loads that are more representative in situ conditions to the connection-level model have not been considered. Analyzing the connection-level model as part of a more complex truss could provide additional insight into connection behavior, and reveal more complex failure states beyond those outlined in the FHWA Guide. 


\subsection{FIGURES}

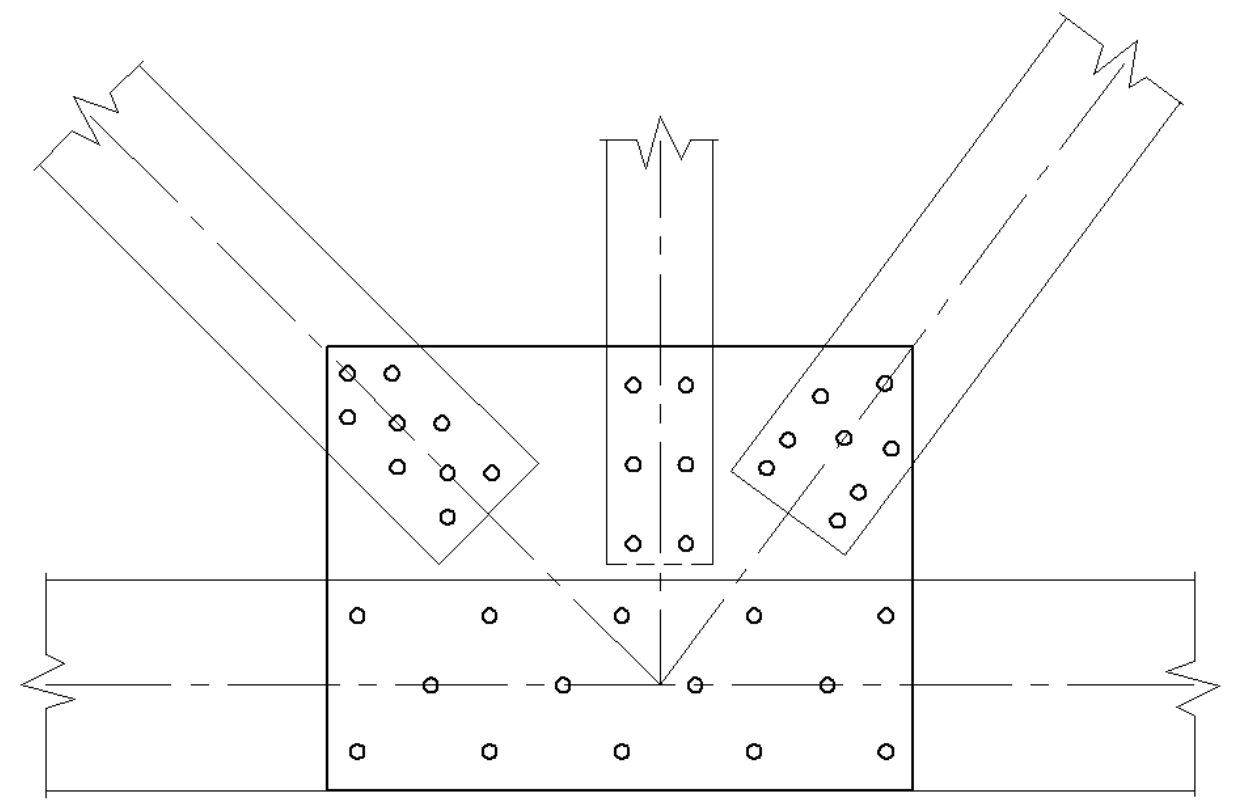

Figure 1: Warren truss gusset plate connection tested by Whitmore (1957)

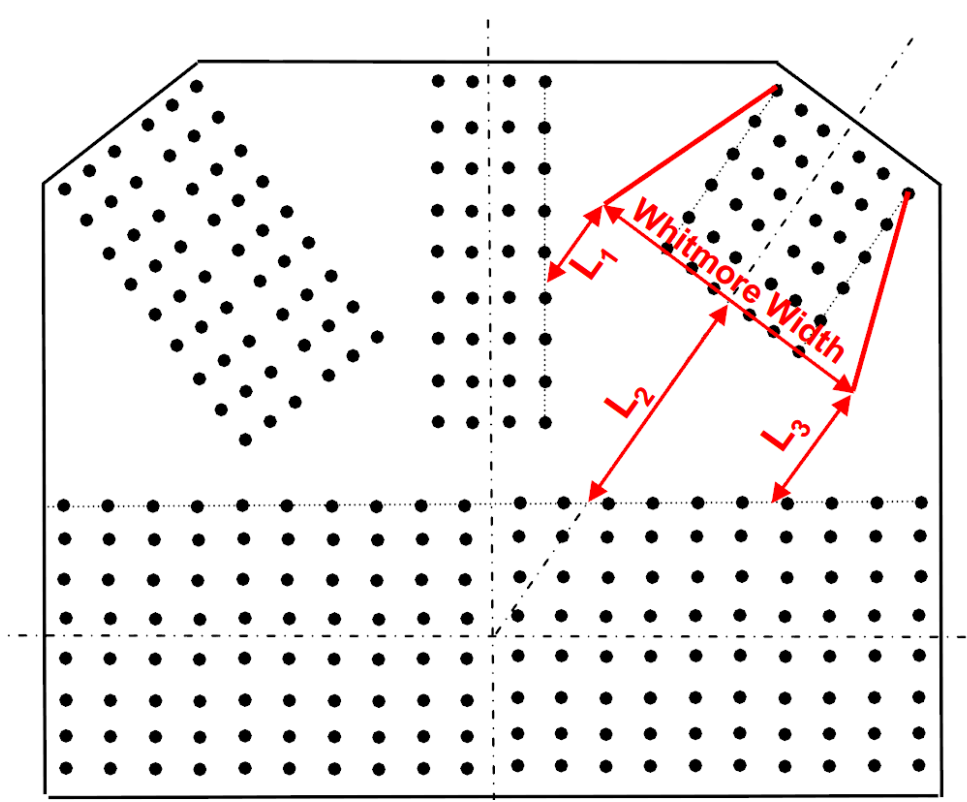

Figure 2: Whitmore effective width and length definitions for member region of gusset plates (NTSB, 2008) 


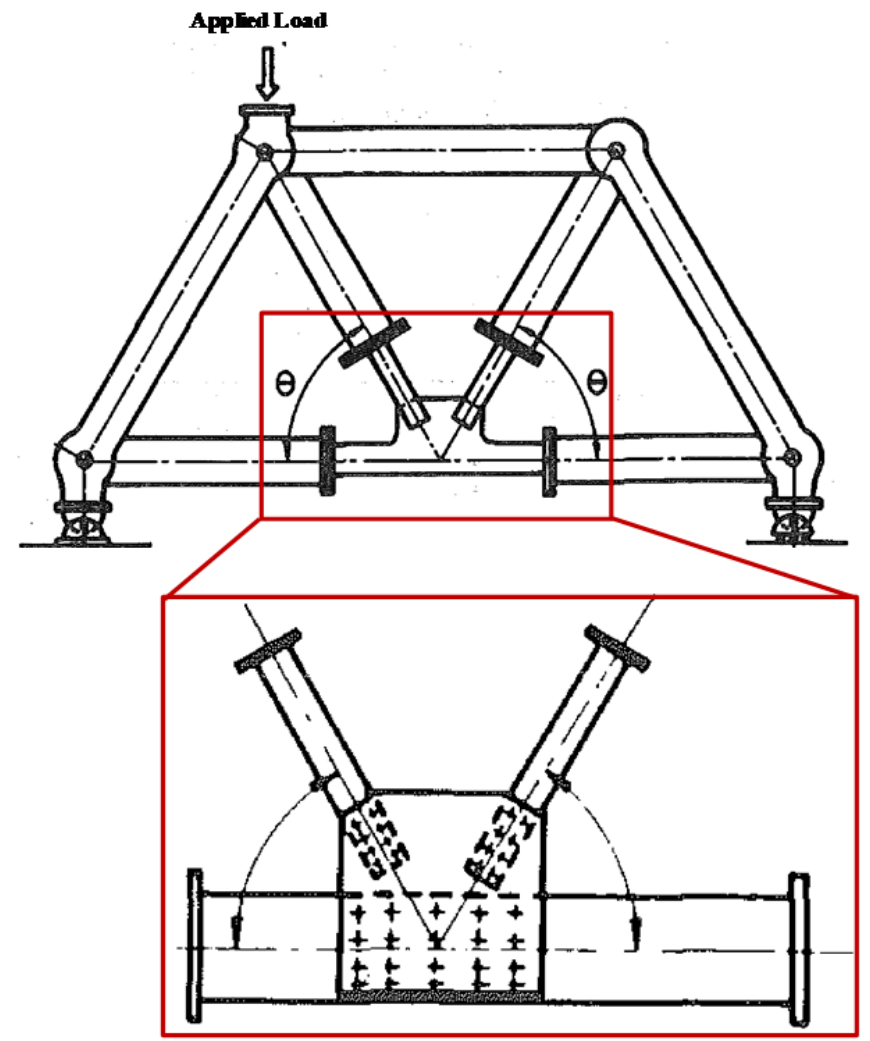

Figure 3: Test frame and gusset plate connection (Yamamoto, 1988)

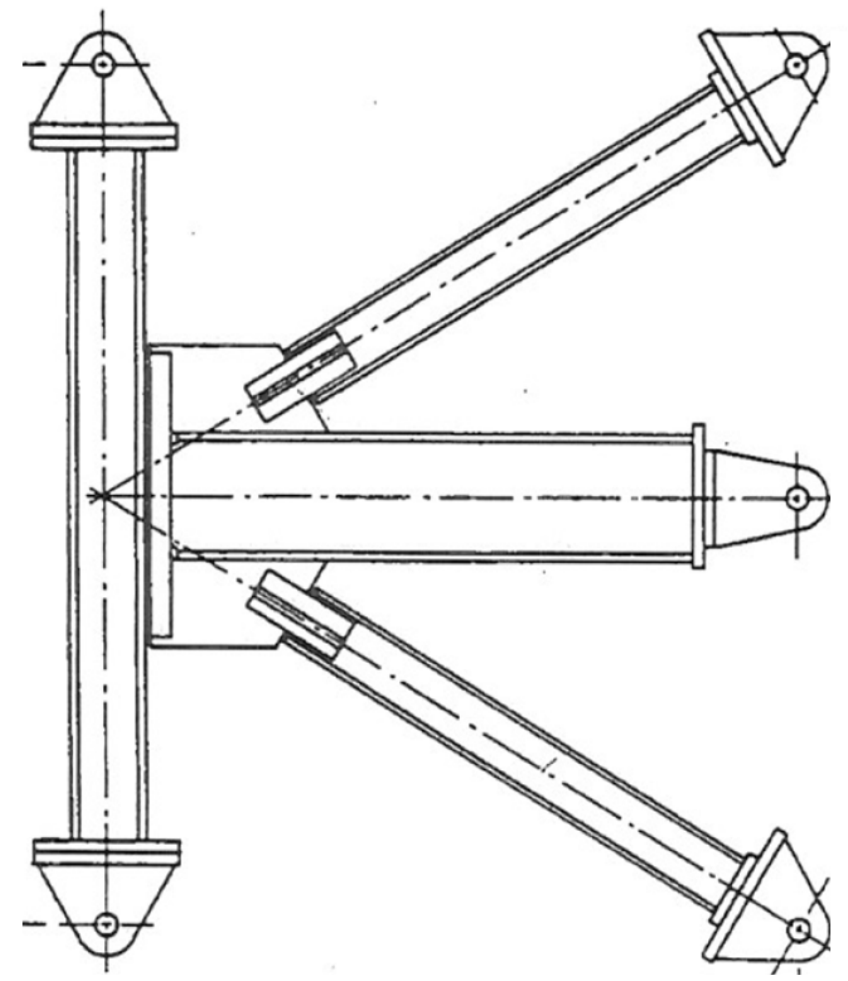

Figure 4: Gusset plate test specimen assembly (Gross, 1990) 


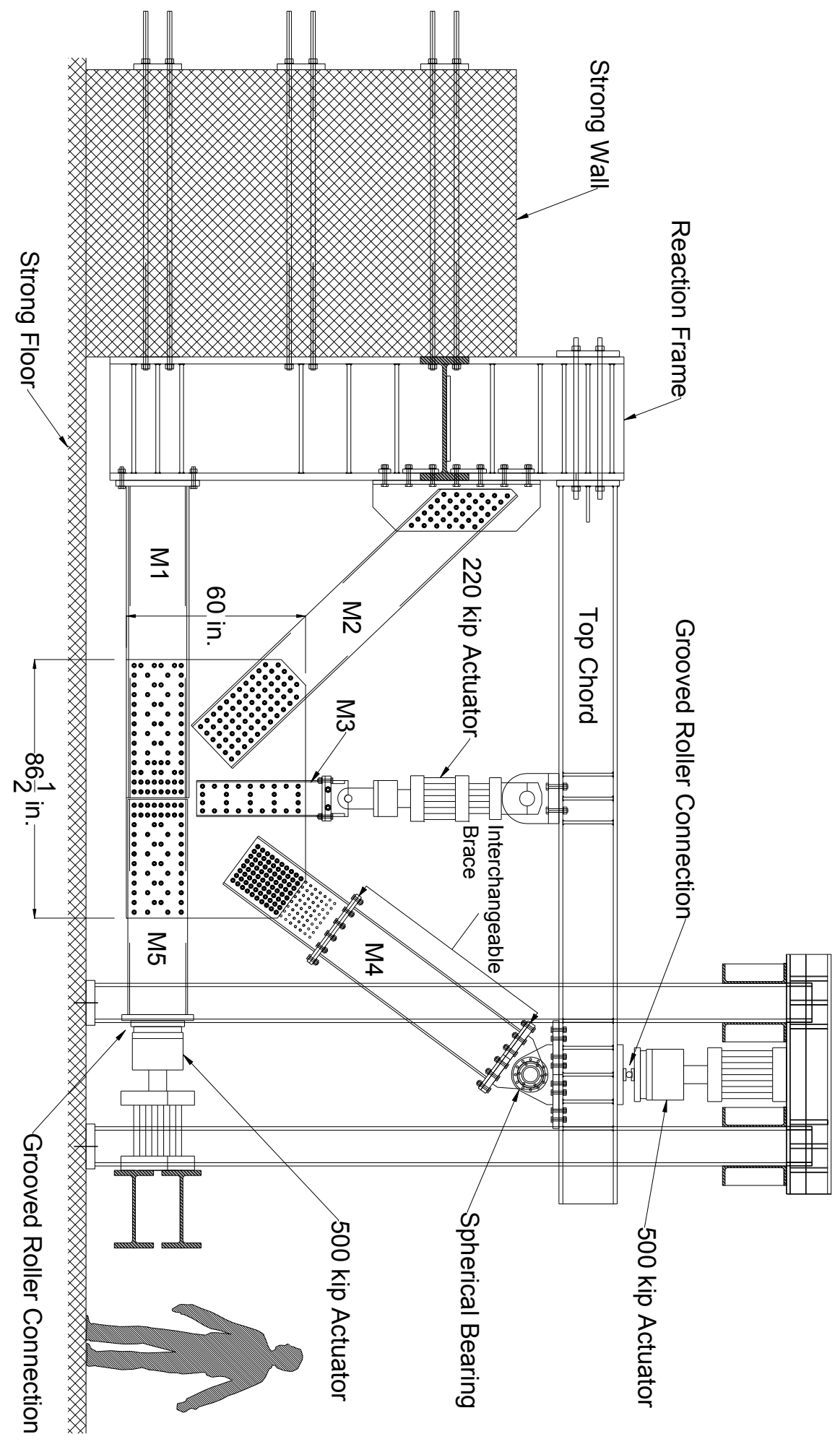

Figure 5: OSU Gusset plate test specimen assembly 


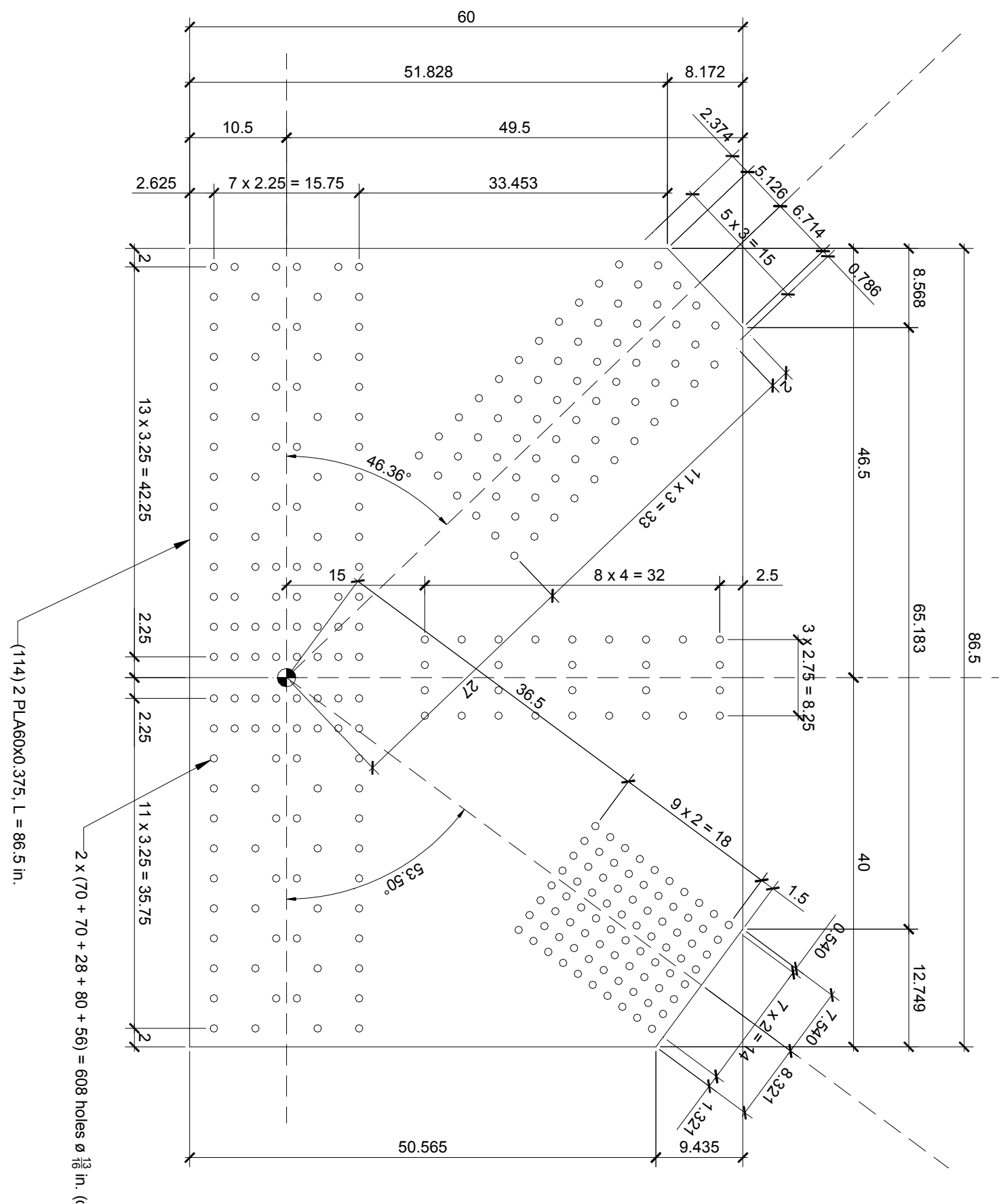

Figure 6: Plate dimensions and bolt patterns (all dimensions in inches or degrees) 


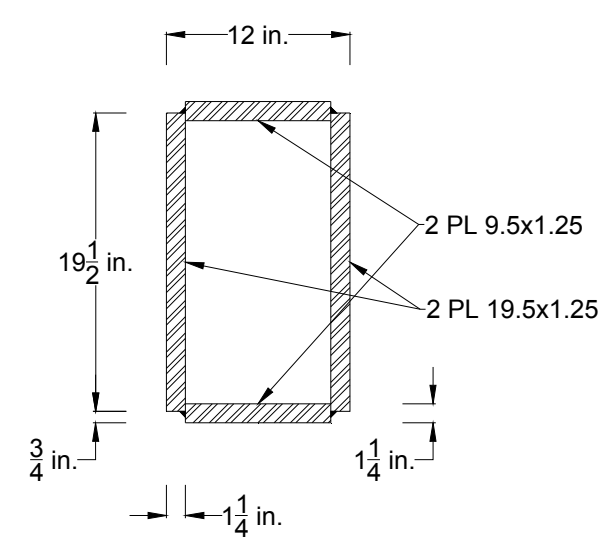

Figure 7: M1 cross section

Stiff Brace (Tests 1, 2, \& 3)

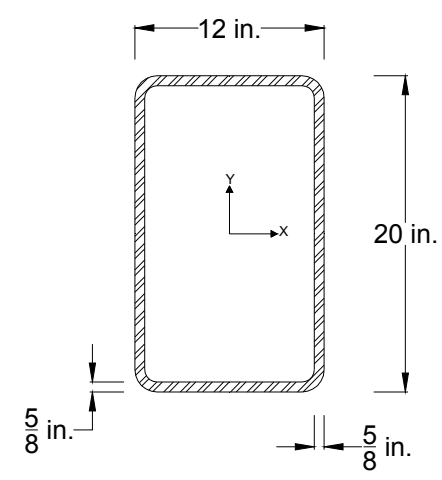

HSS $20 \times 12 \times 5 / 8$
Soft Brace (Tests 4 \& 5)

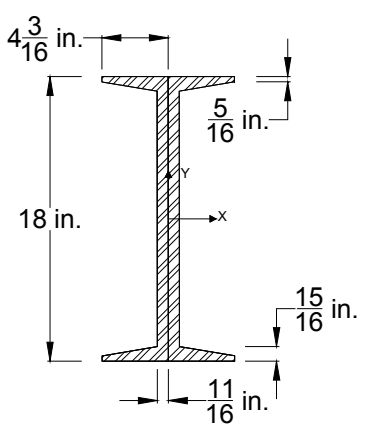

Back-to-back MC 18x58

Figure 8: M4 cross sections for stiff and soft braces

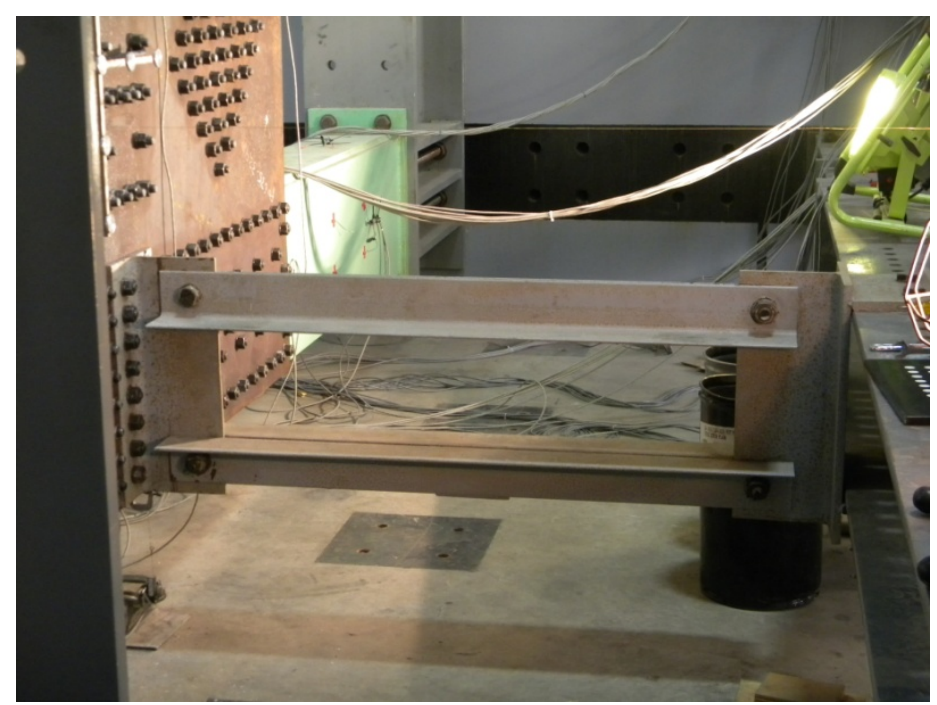

Figure 9: Floor diaphragm 

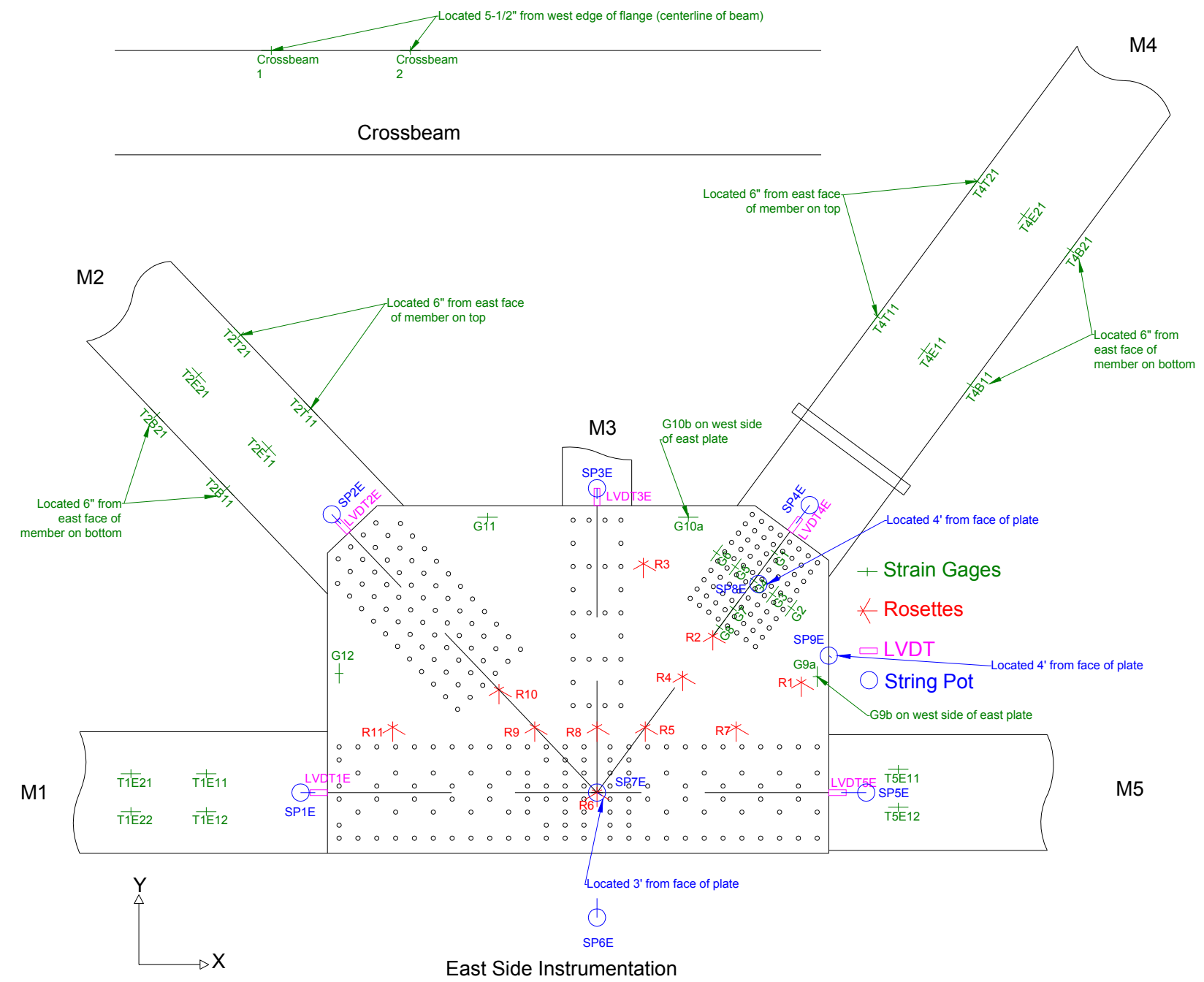

Figure 10: Instrumentation plan - Test 1 


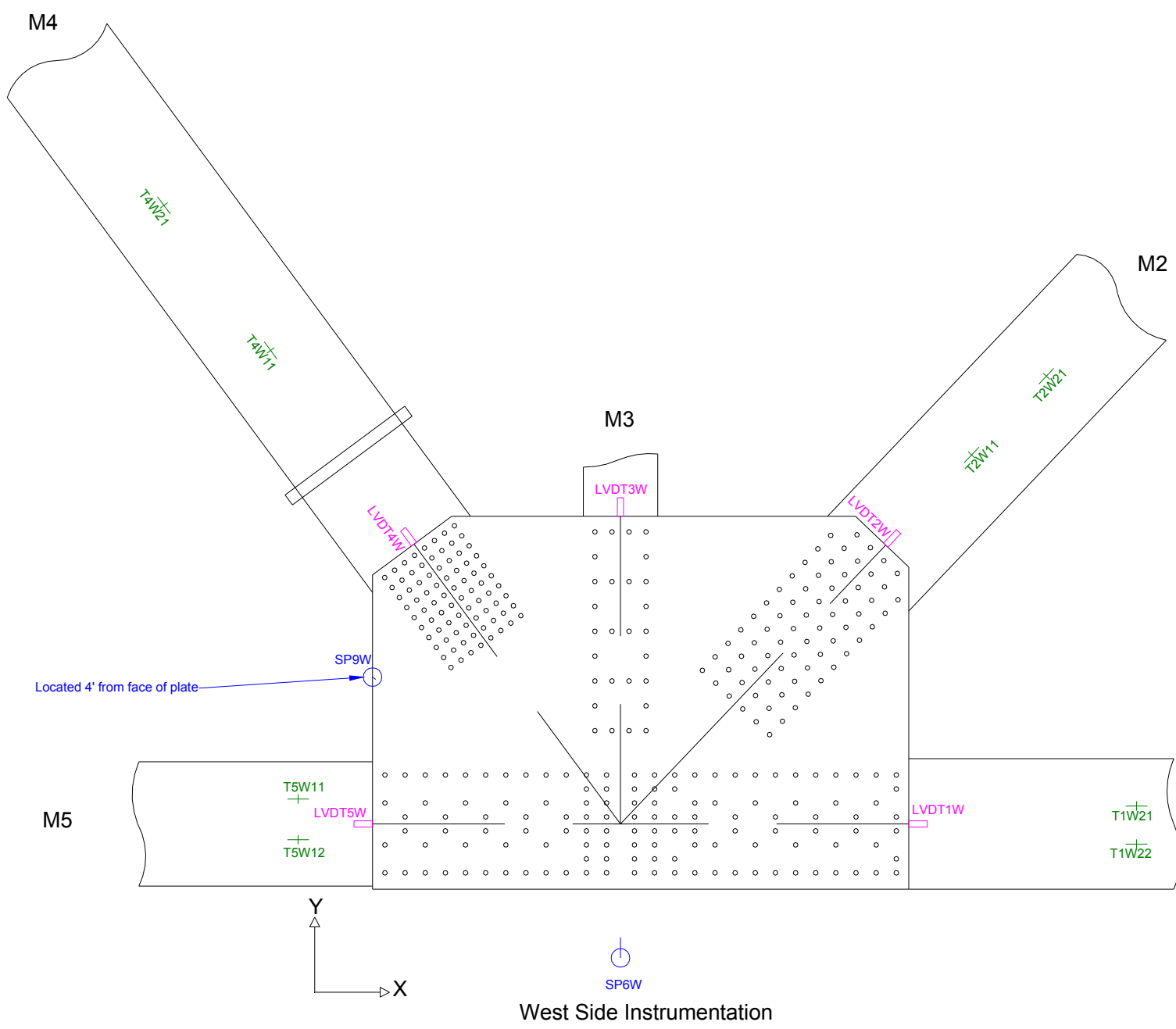

Figure 11: Instrumentation plan continued - Test 1 


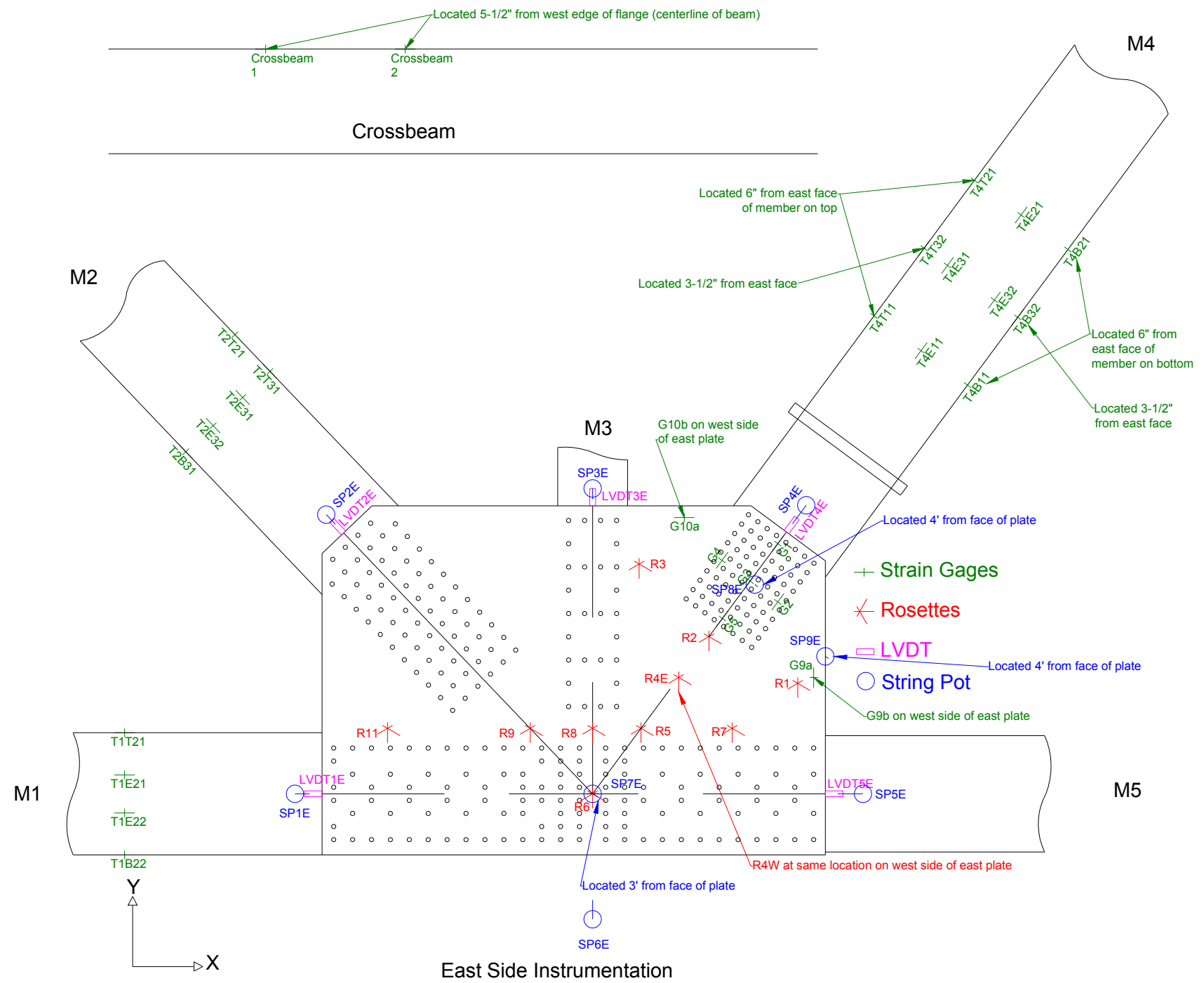

Figure 12: Instrumentation plan - Test $2 \& 3$ 


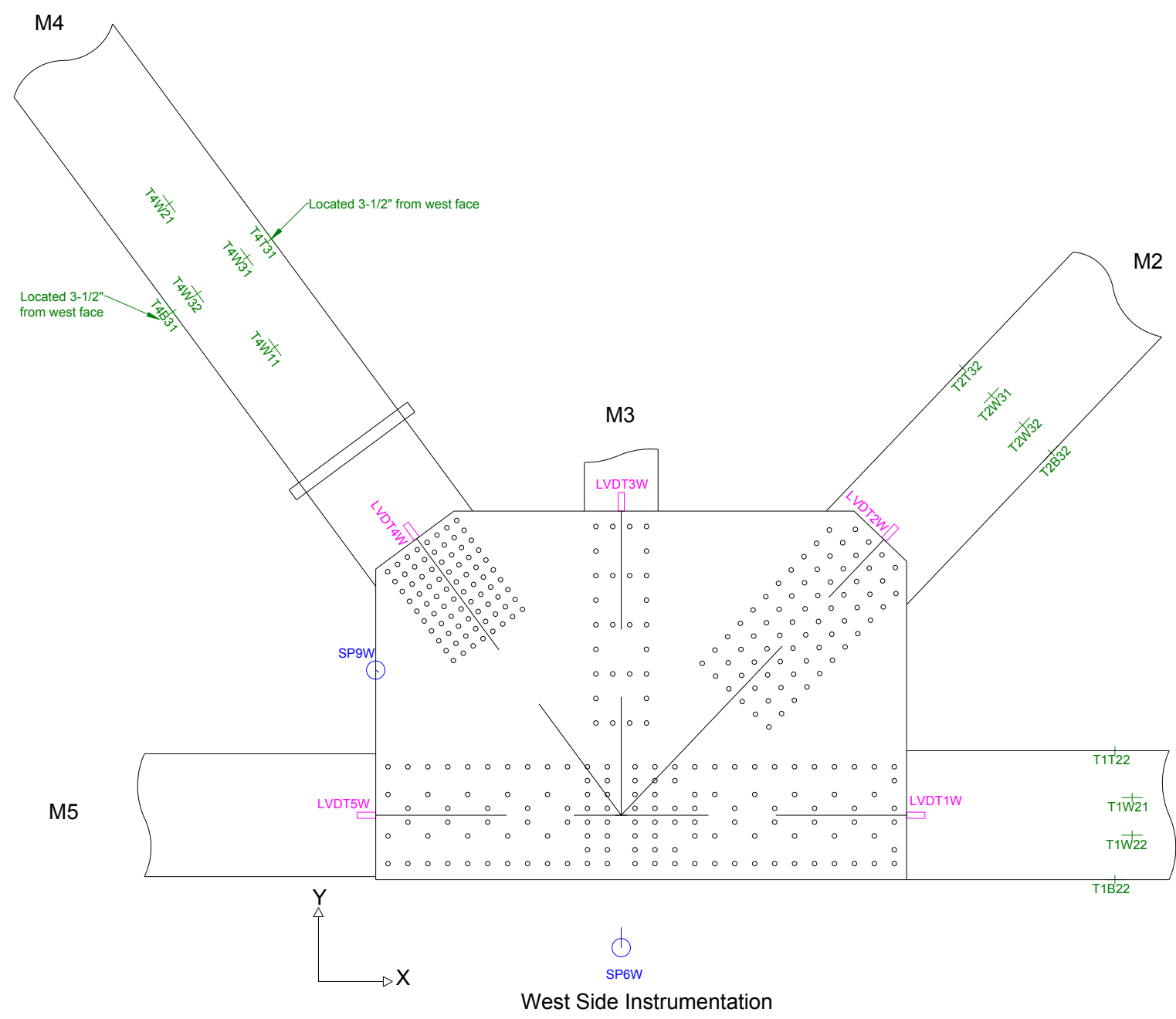

Figure 13: Instrumentation plan continued - Test $2 \& 3$ 

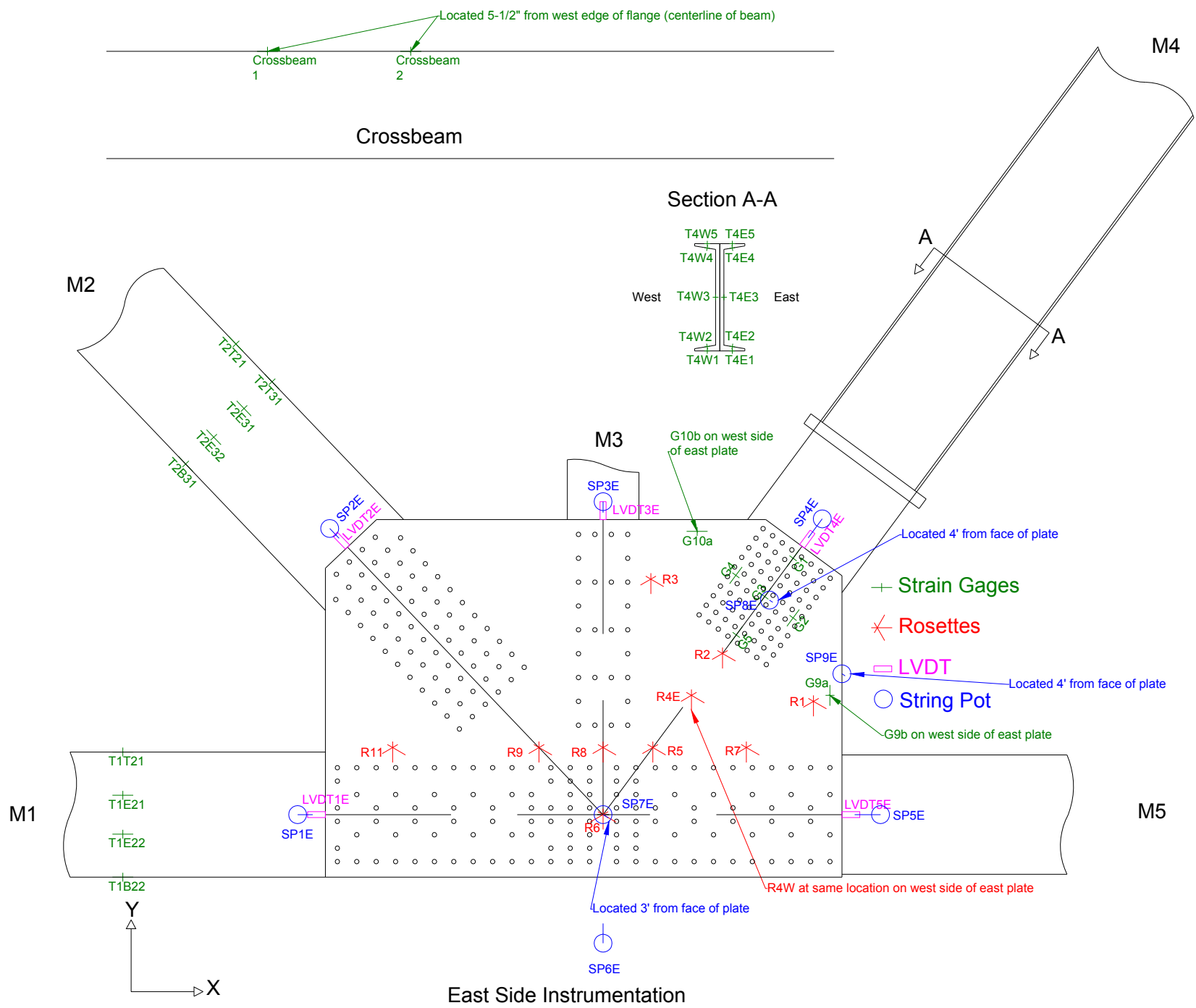

Figure 14: Instrumentation plan - Test 4, 5, \& 6 


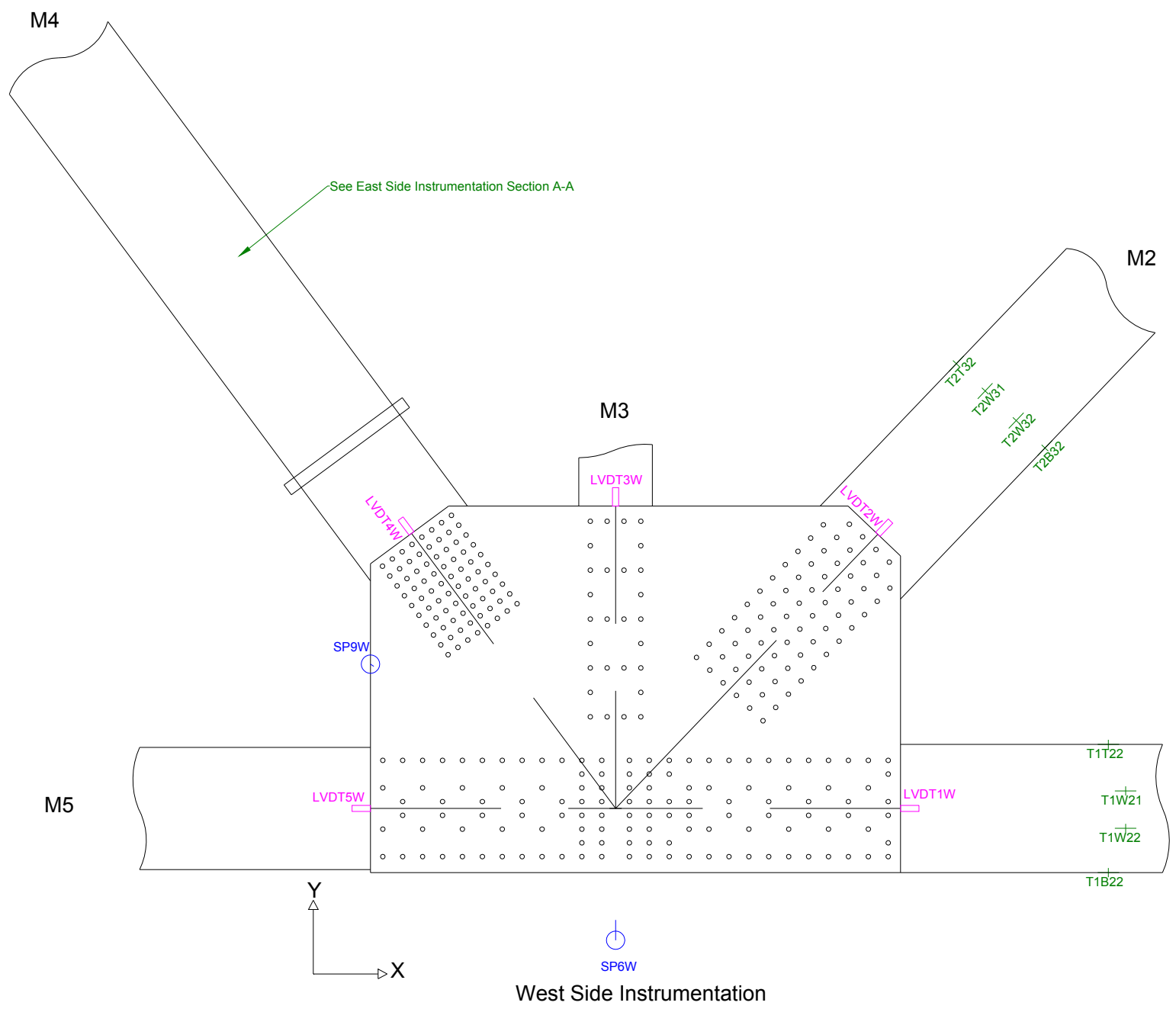

Figure 15: Instrumentation plan continued - Test 4, 5, \& 6 


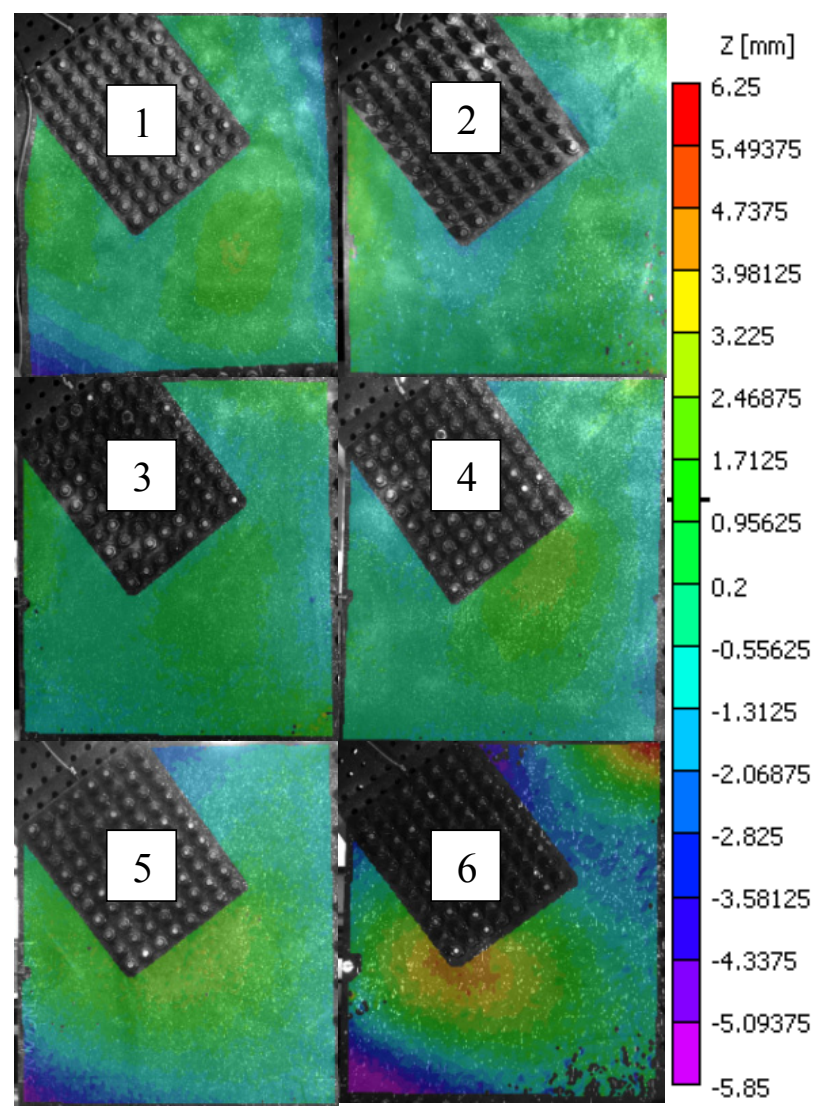

Figure 16: DIC measured initial out-of-plane imperfections (prior to imposed deformations on specimens 3 and 6) 


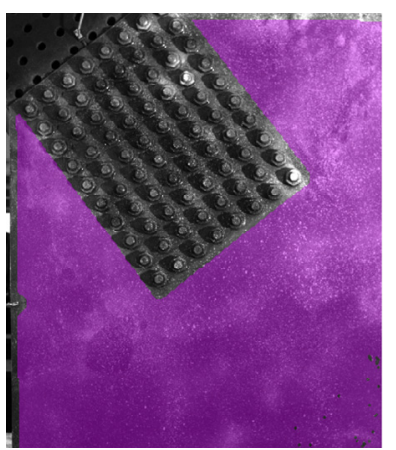

0 kip

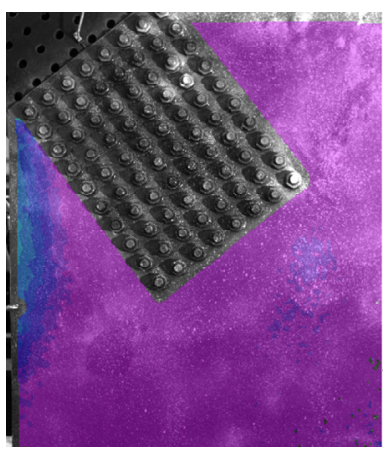

100 kip

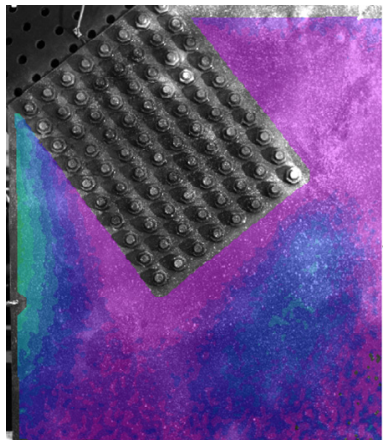

175 kip

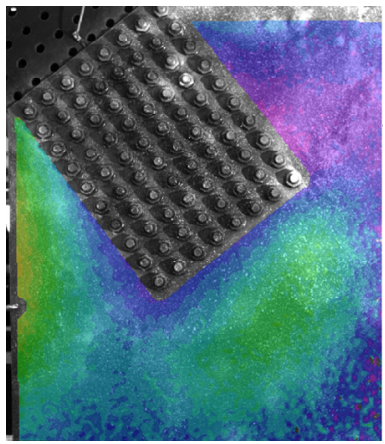

250 kip

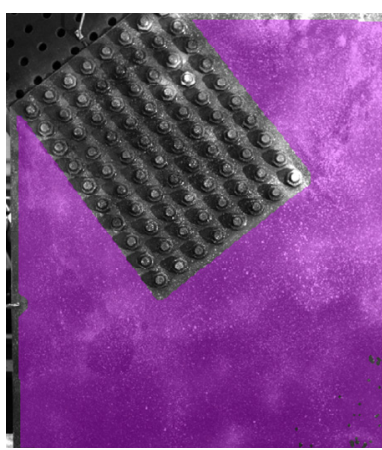

25 kip

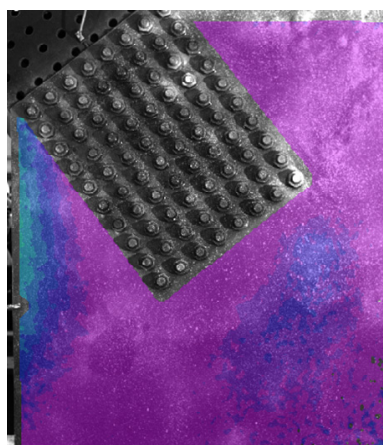

125 kip

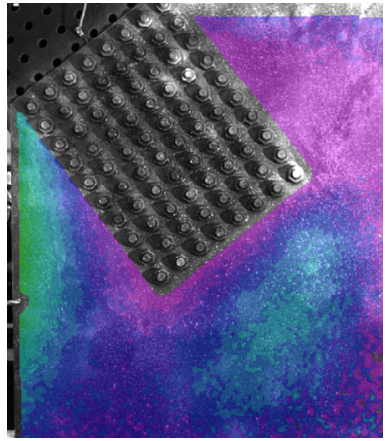

200 kip

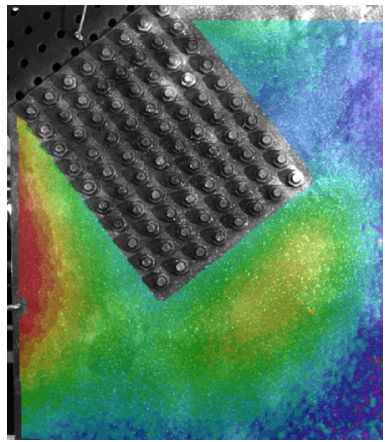

275 kip

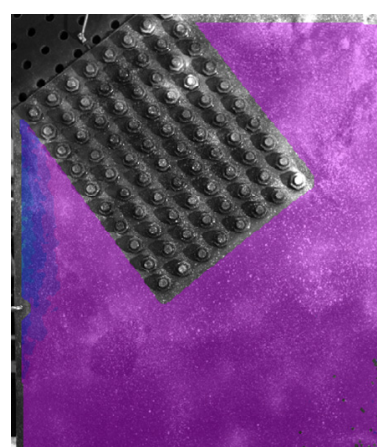

$\mathrm{Z}$ [mm]

6.90

6.47

6.04

5.61

5.18

4.74

75 kip

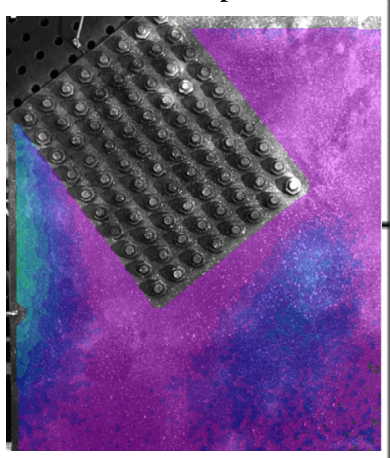

4.31

3.88

3.45

3.02

2.59

2.16

1.73

1.29

150 kip

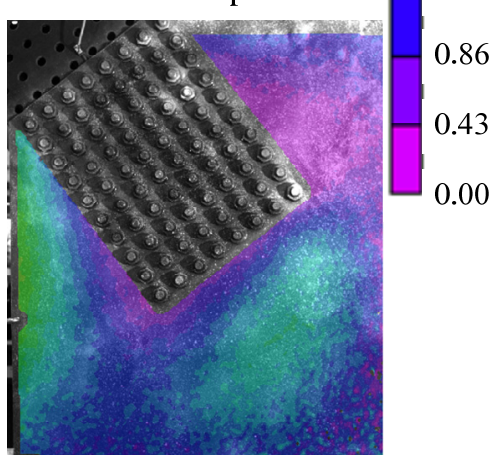

225 kip

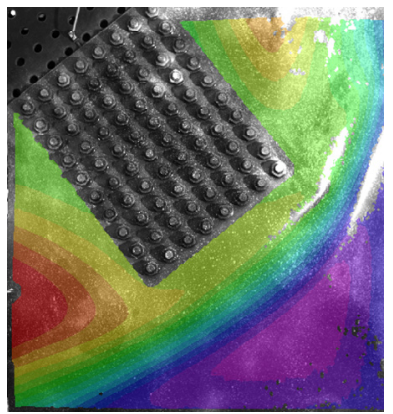

Failure

Figure 17: DIC measured out-of-plane displacement of specimen 2 at incremental load steps throughout test (Failue image is not scaled and has limits of -18 to $122 \mathrm{~mm}$ ) 


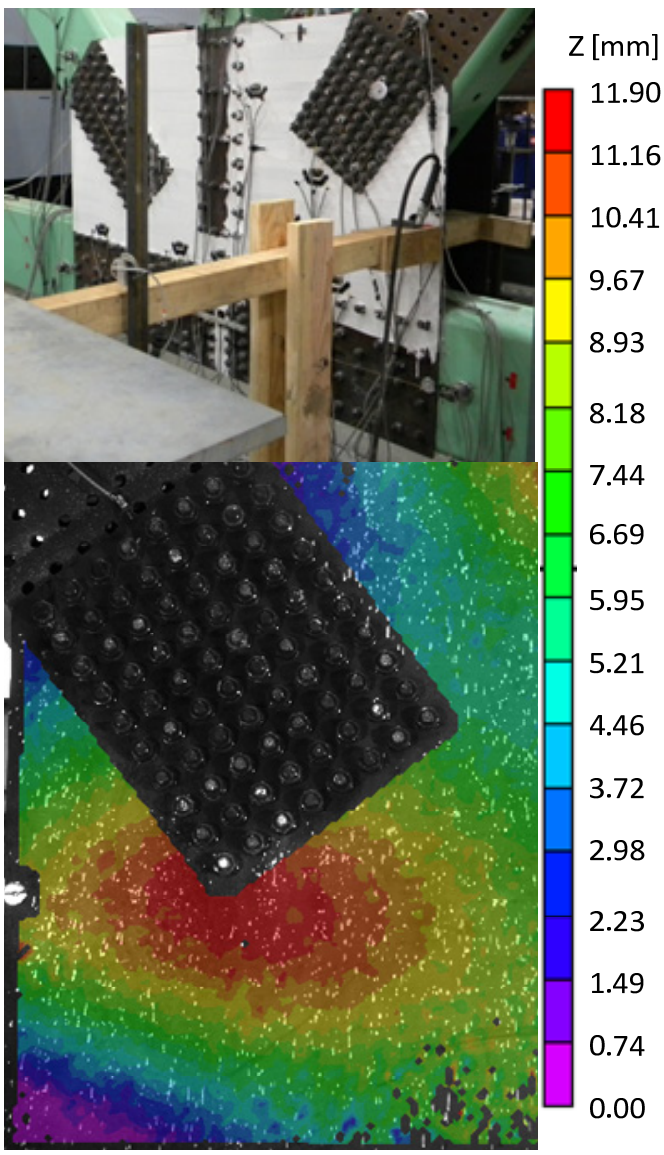

Figure 18: Hydraulic ram setup for imposing initial imperfections and DIC measured imposed imperfections across plate for specimen 6

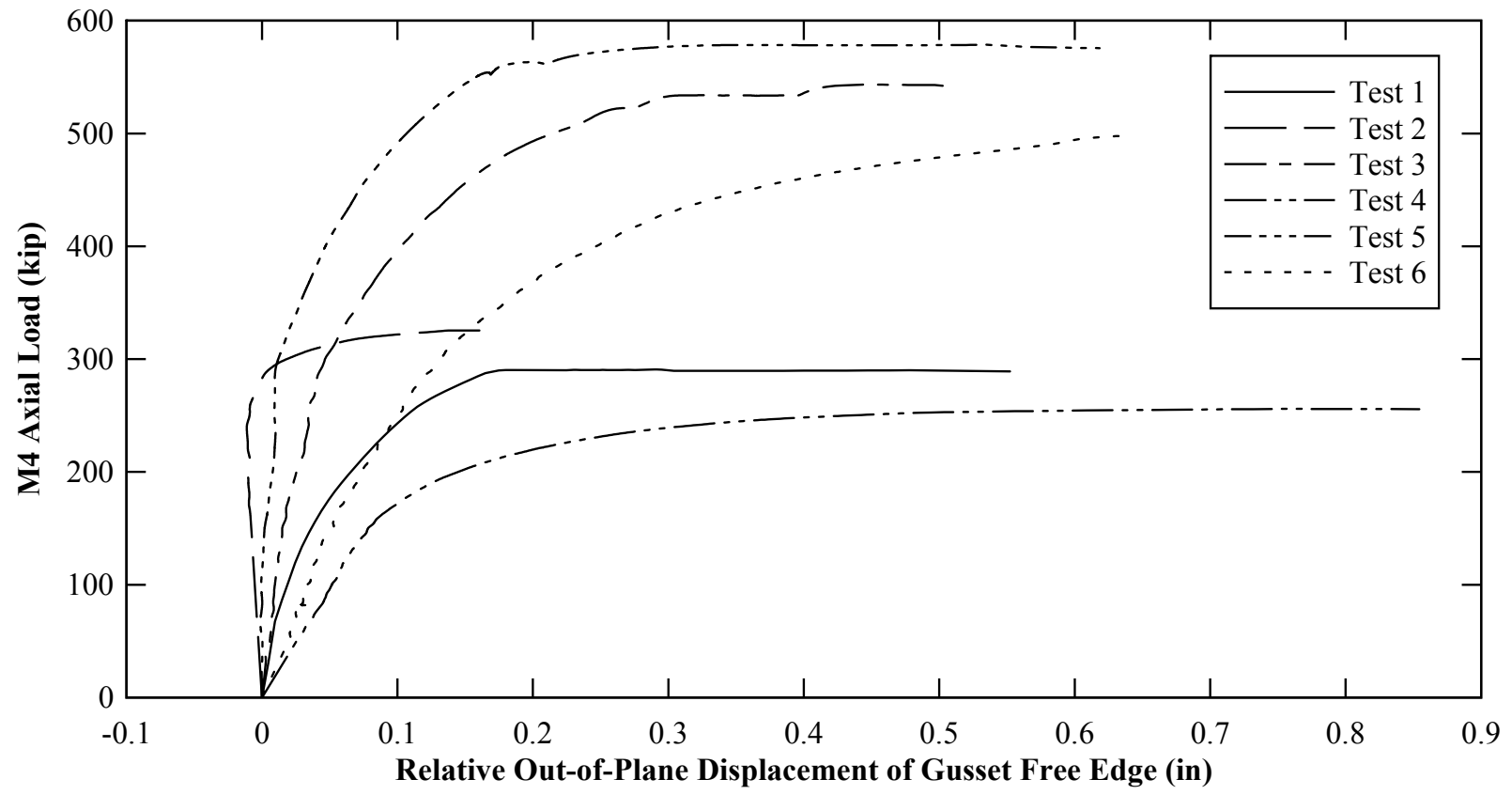

Figure 19: Load v Out-of-Plane displacement for all tests 


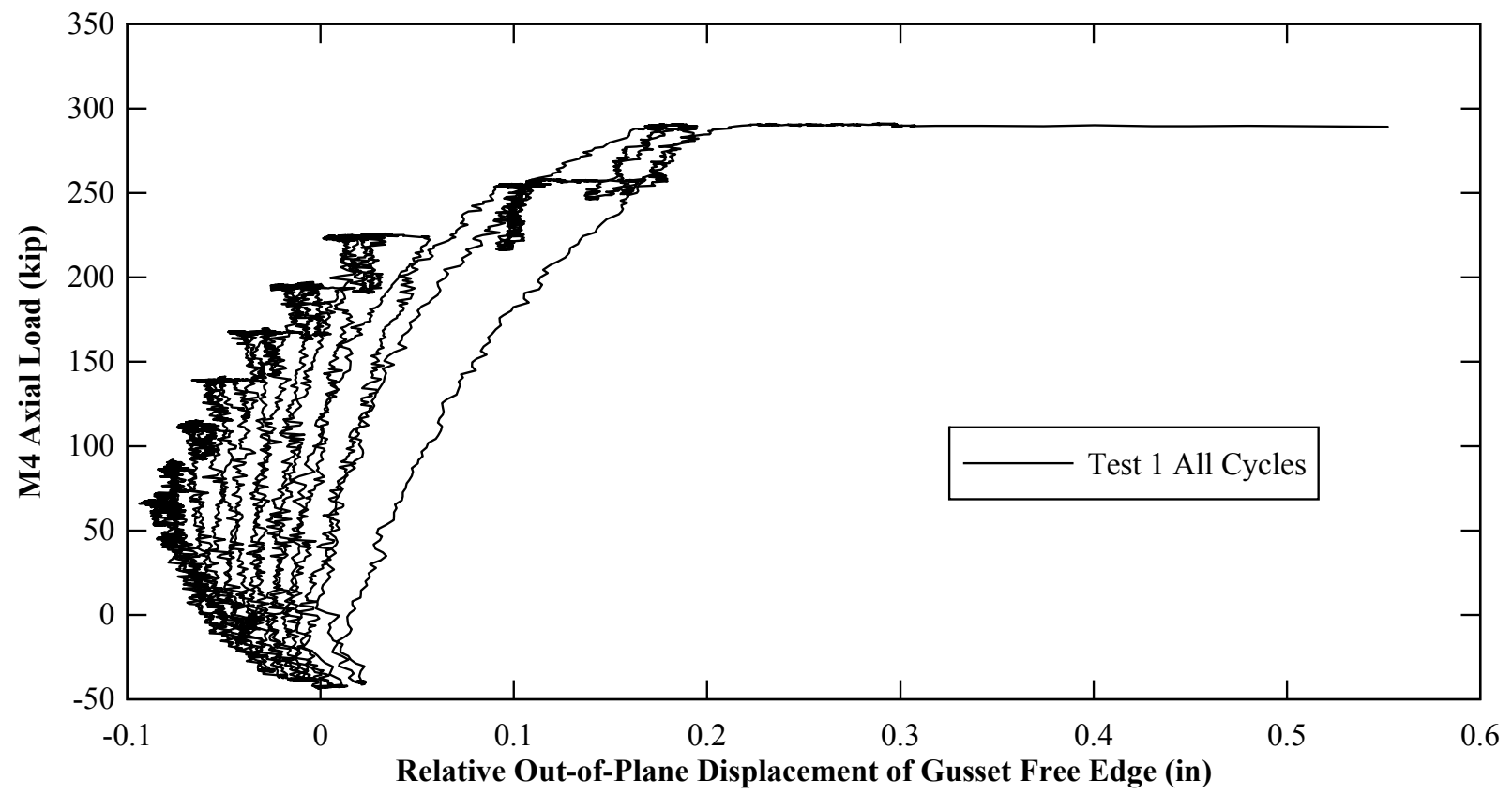

Figure 20: Test 1 Load $v$ out- of plane displacement for all cycles

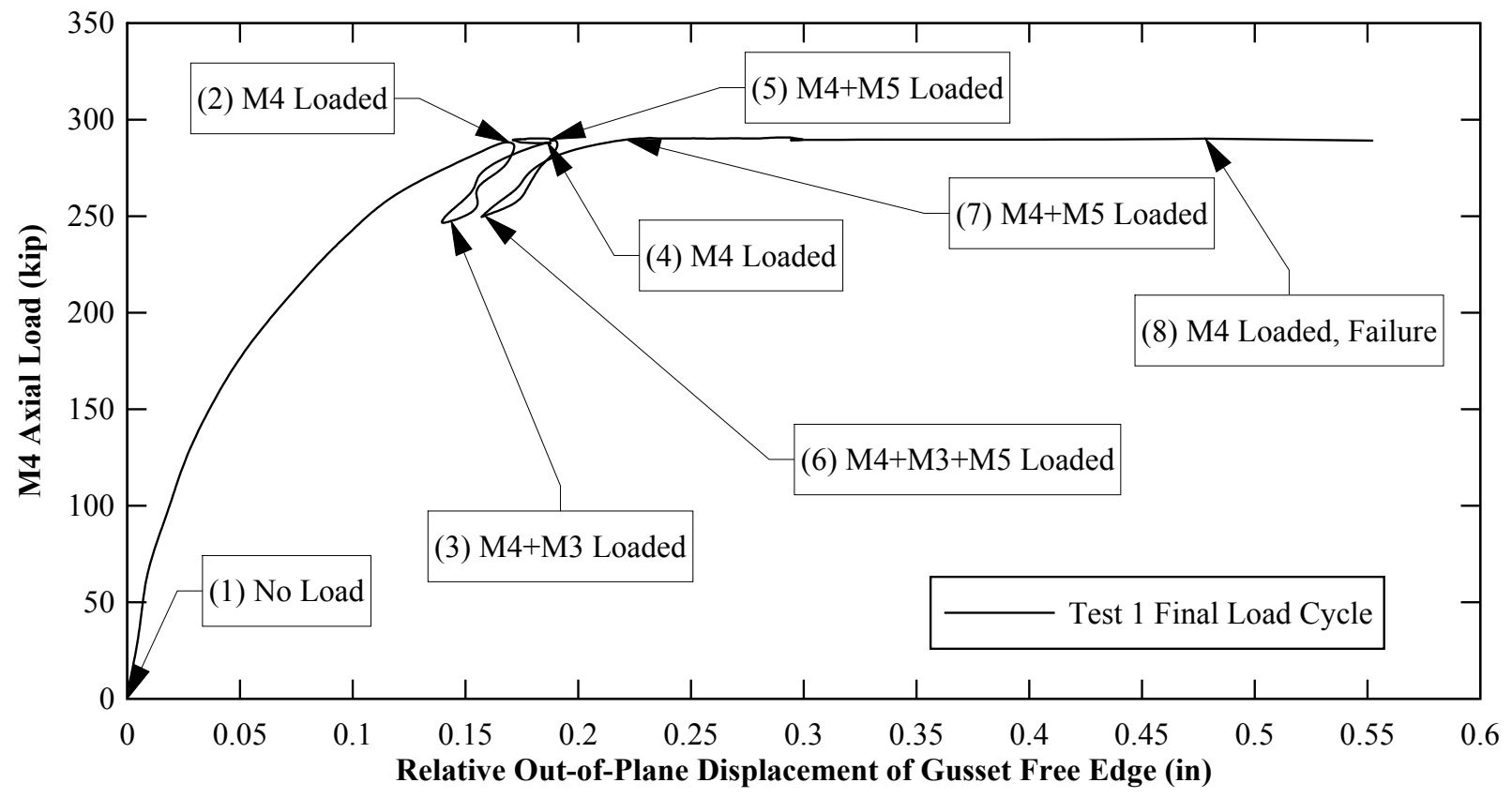

Figure 21: Test 1 Load $v$ displacement for final cycle. (\#) shows step in load cycle. 


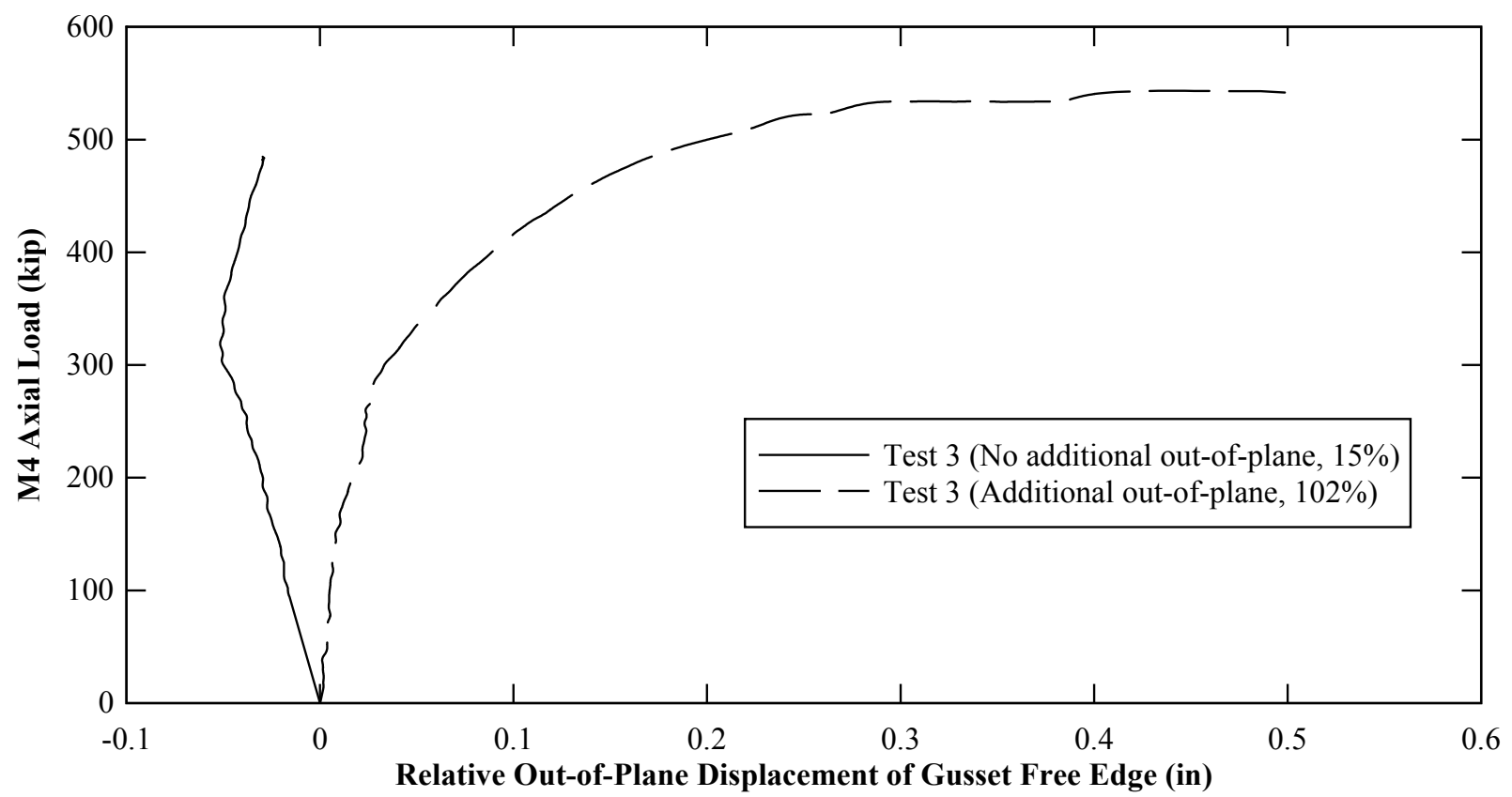

Figure 22: Test 3 load $v$ displacement with initial and final out-of-plane imperfections 

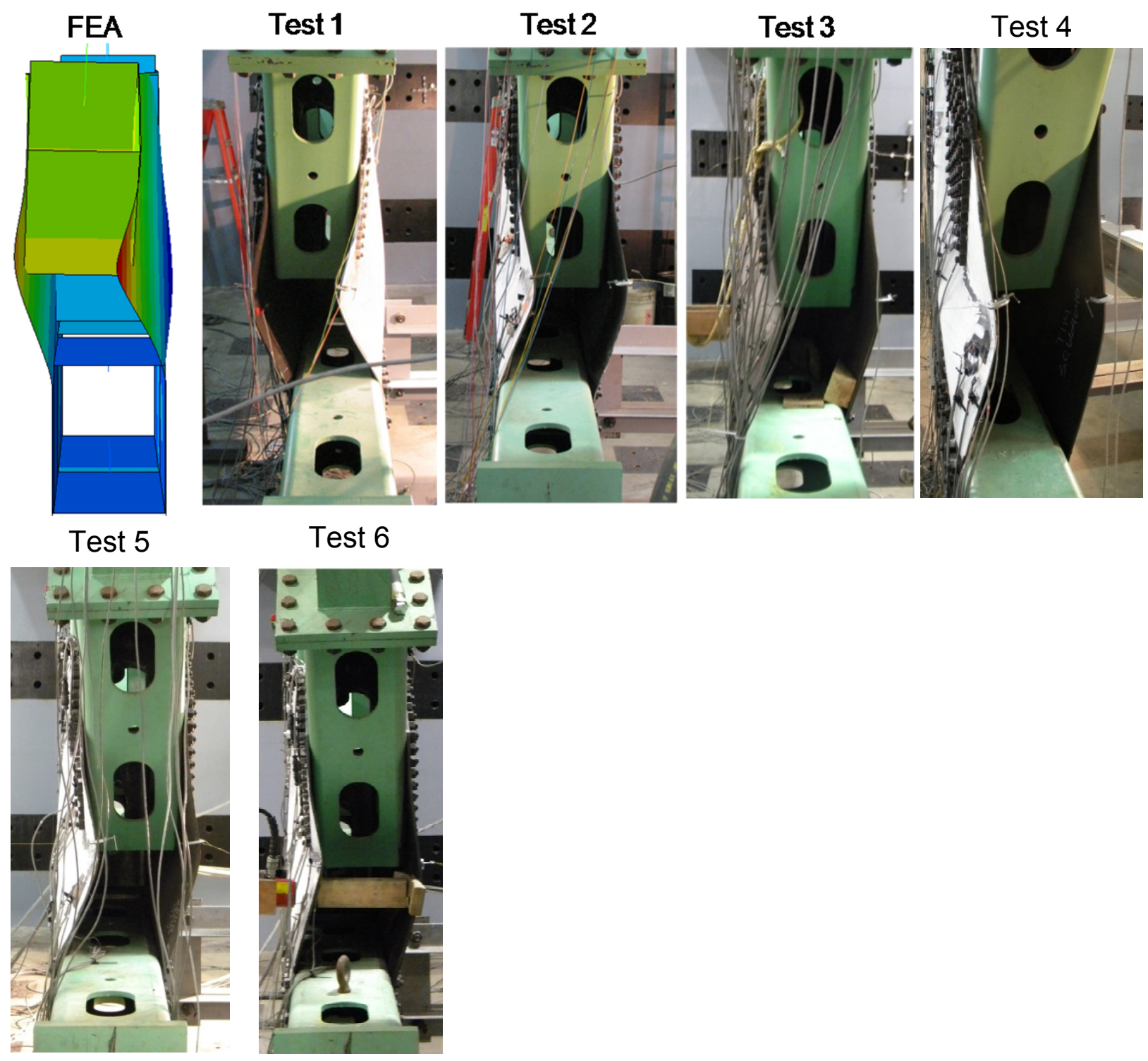

Test 6

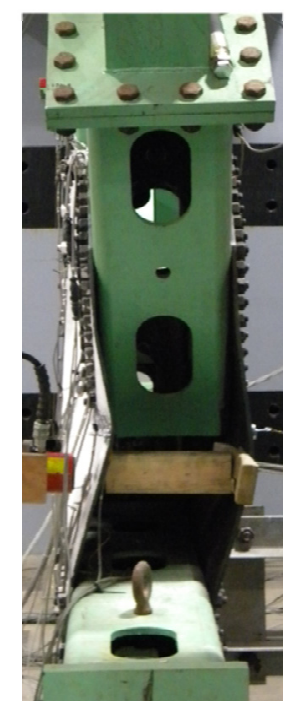

Figure 23: Post-buckling shapes 
Strain Profiles for M4 Stiff Brace at Failure Load.

(Drawings are top view of member M4 and bending

is in the out-of-plane direction.)

Test 1
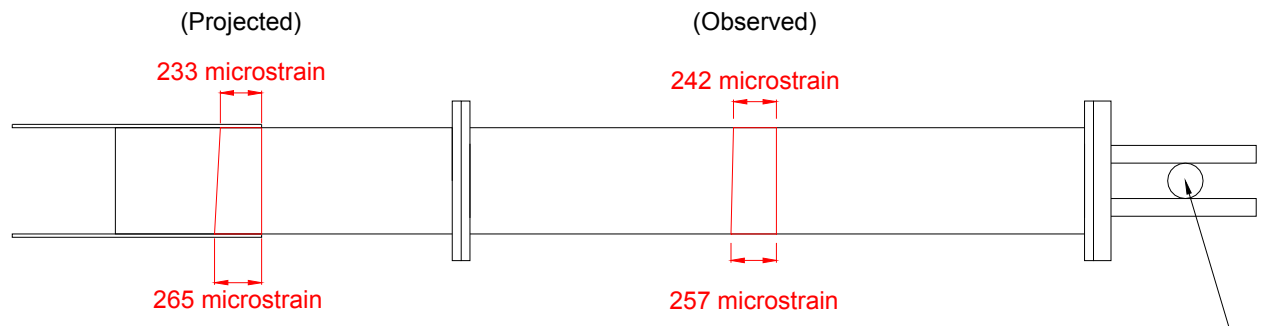

Test 2

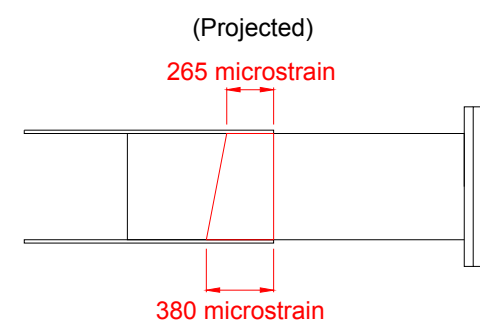

(Observed)

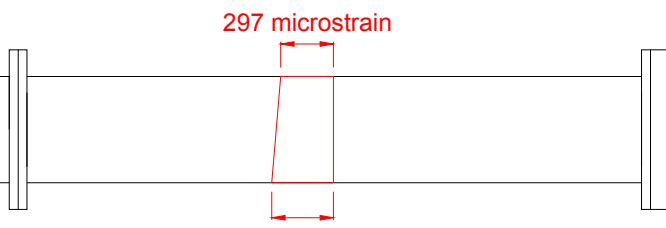

297 microstrain

348 microstrain

Test 3
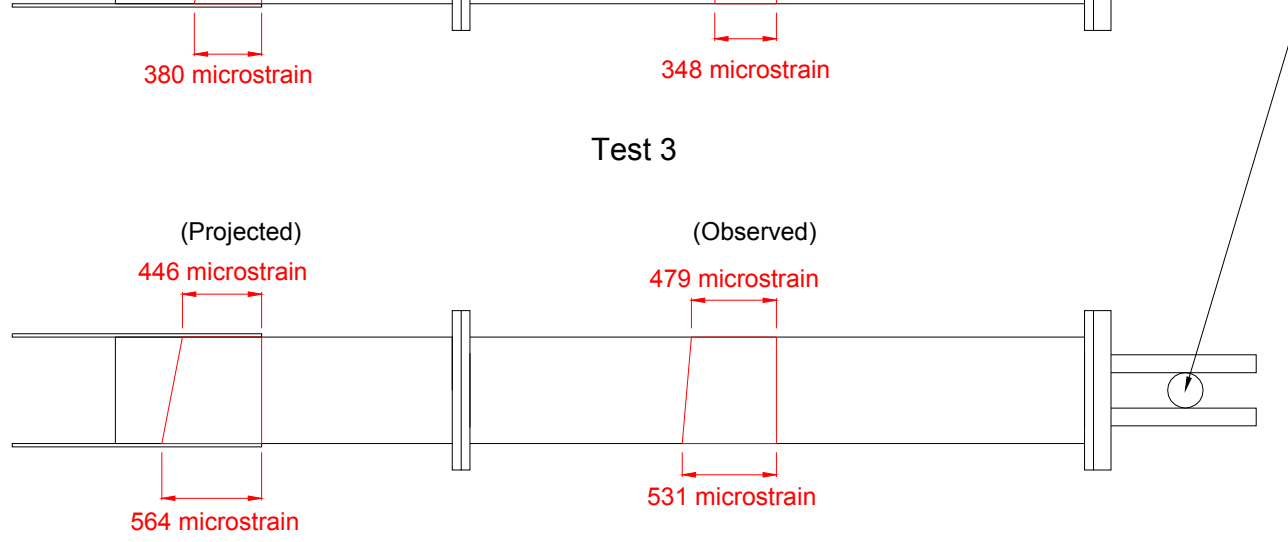

Spherical Bearing

Pin Connection

(No Bending Strain)

Figure 24: Strain Profiles for M4 Stiff brace showing out-of-plane bending of the member ( $+=$ Compression, $-=$ Tension $)$ 
Strain Profiles for M4 Soft Brace at Failure Load.

(Drawings are top view of member M4 and bending

is in the out-of-plane direction.)

Test 4

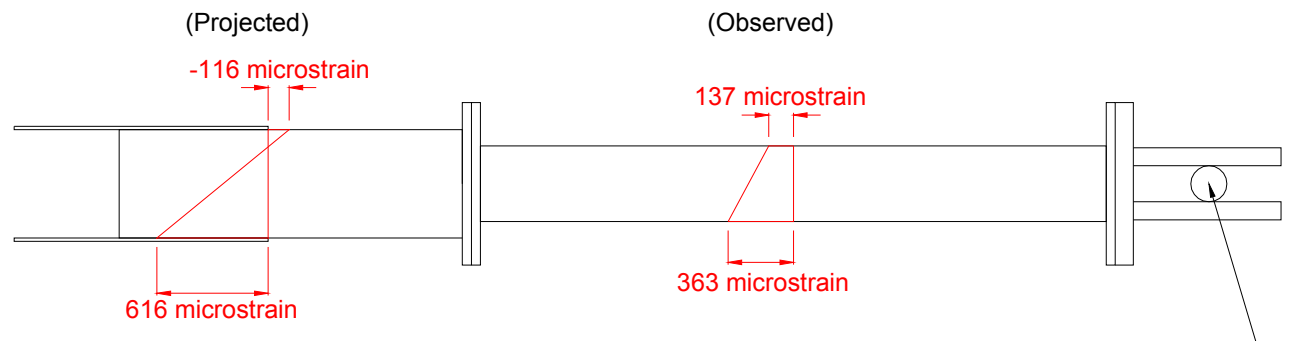

Test 5

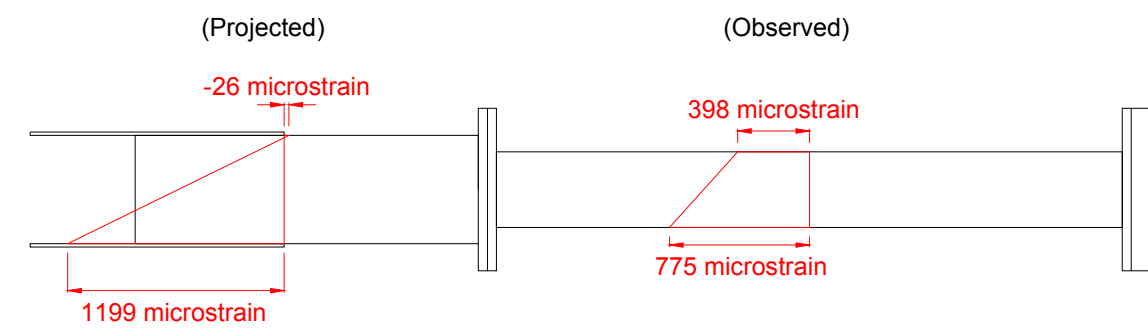

(Observed)

Test 6

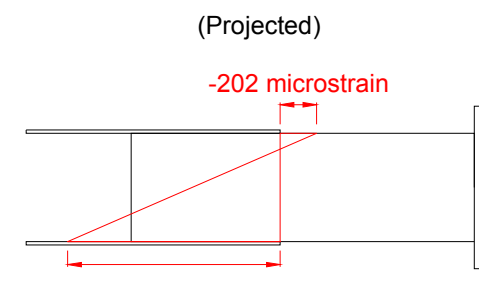

1177 microstrain

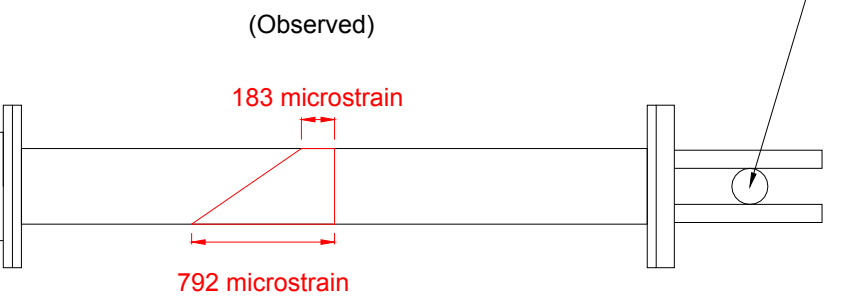

792 microstrain

Figure 25: Strain Profiles for M4 Soft brace showing out-of-plane bending of the member (+ = Compression, $-=$ Tension) 


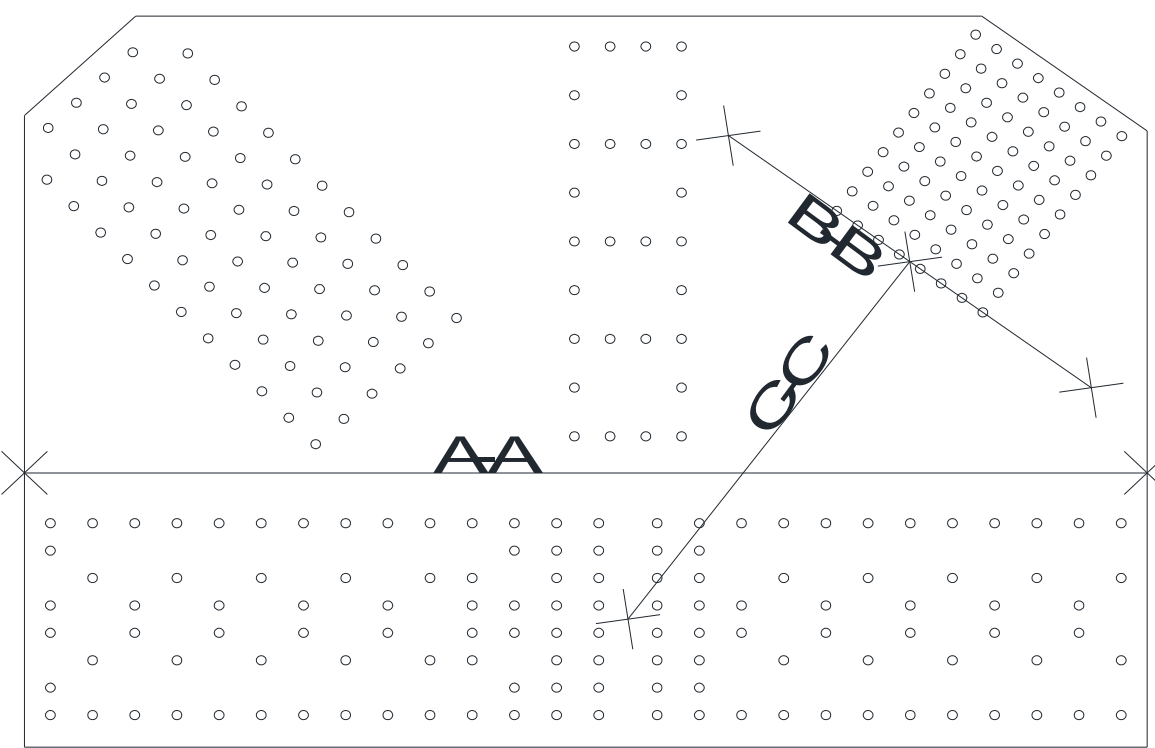

Figure 26: Plane A-A, Path B-B, \& Path C-C used to interpret plate stresses

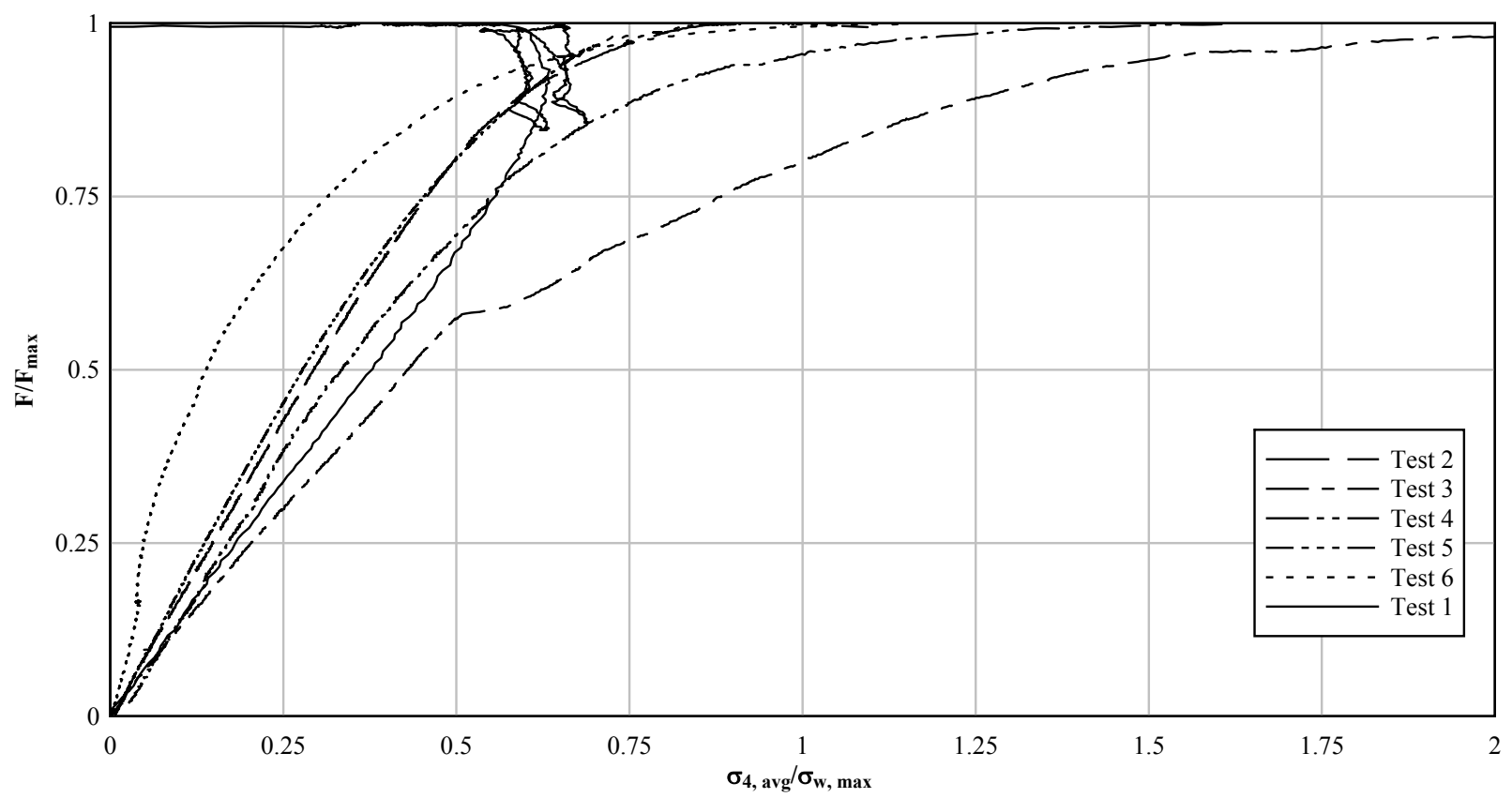

Figure 27: Average stress across Whitmore width in M4 direction normalized to maximum theoretical Whitmore stress 


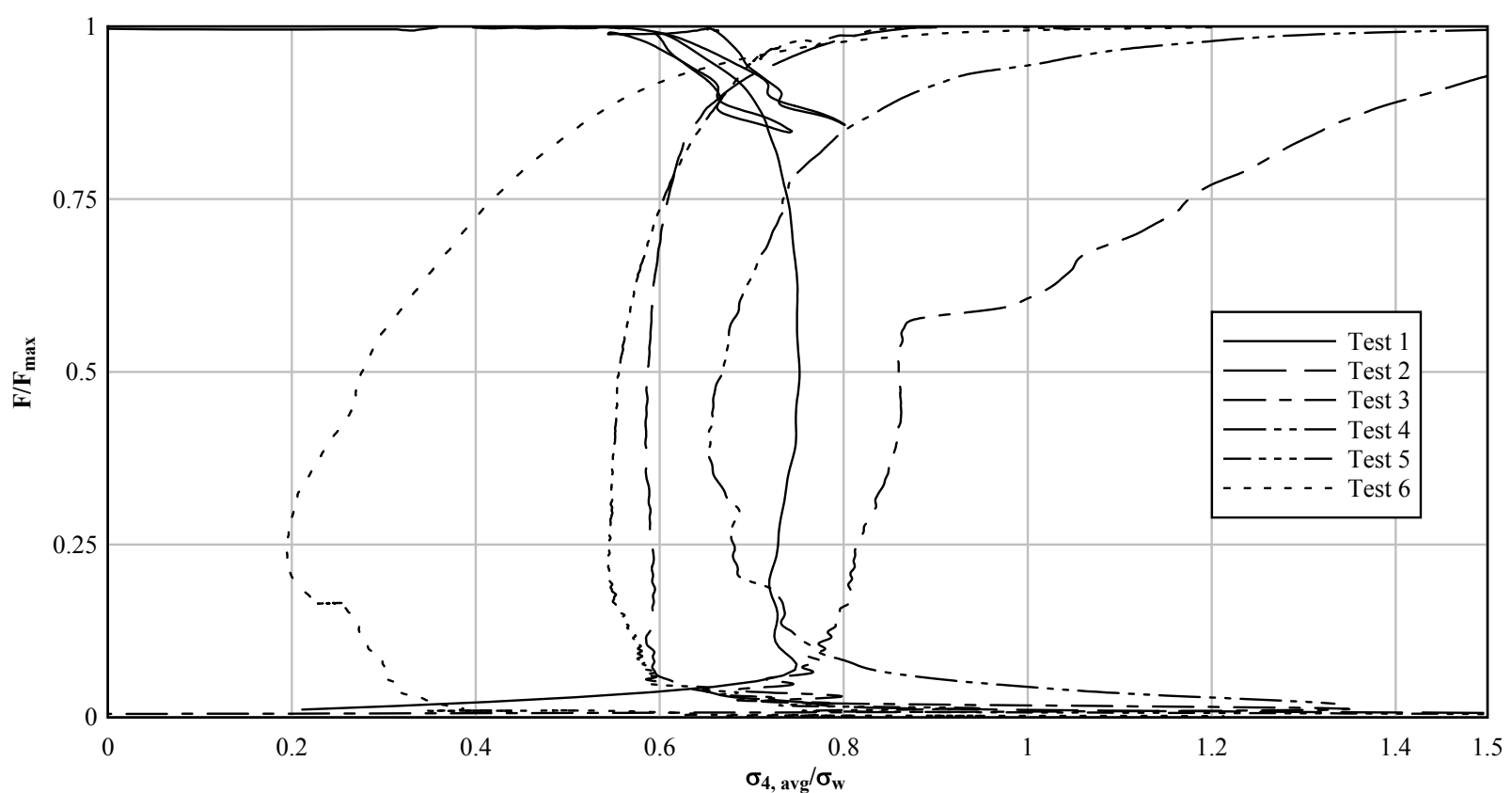

Figure 28: Average stress across Whitmore width in M4 direction normalized to theoretical Whitmore stress at corresponding M4 axial load

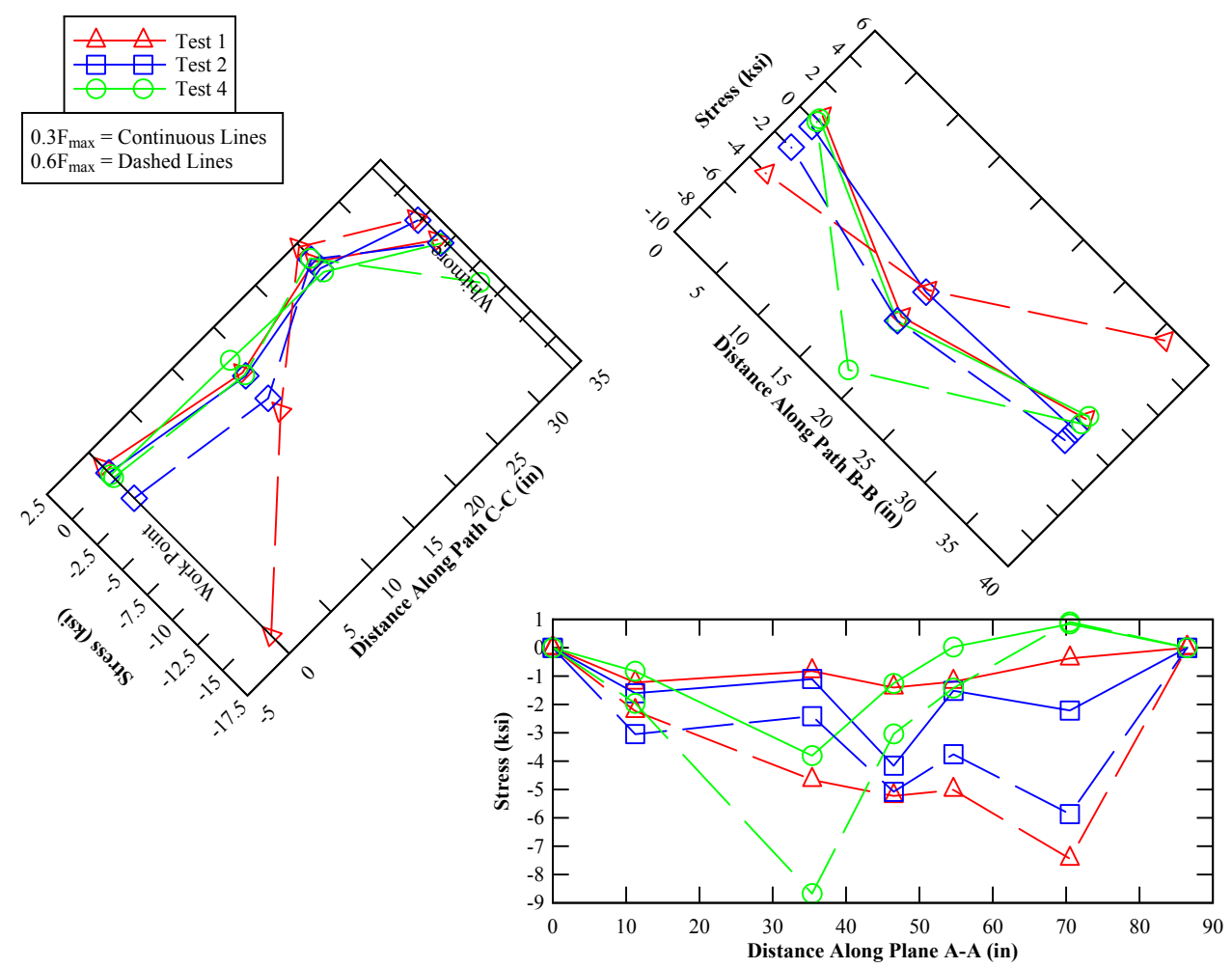

Figure 29: 1/4-inch plates, stress in global $x$ direction $(+=$ Tension, $-=$ Compression $)$ 


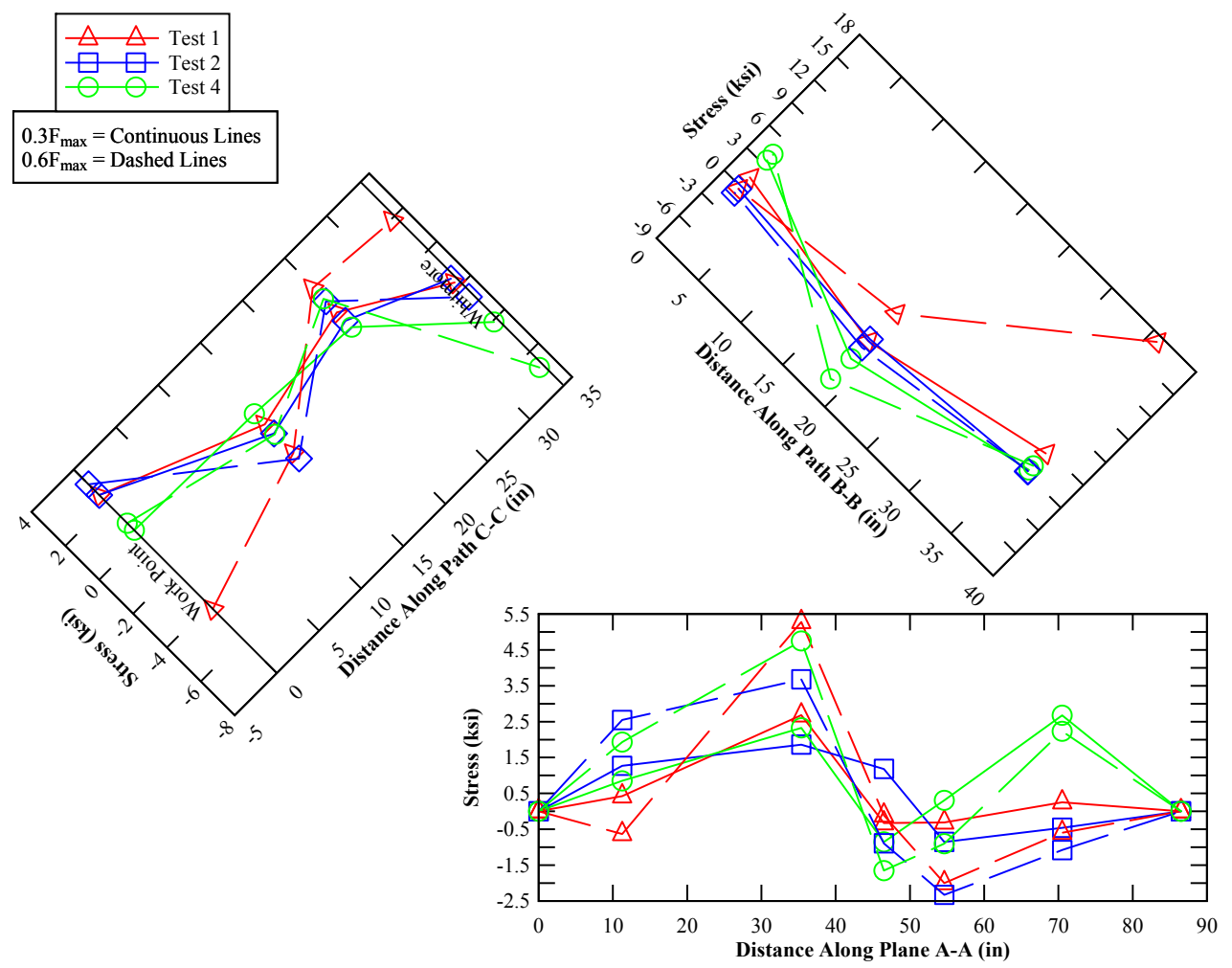

Figure 30: 1/4-inch plates, stress in global y direction $(+=$ Tension, $-=$ Compression)

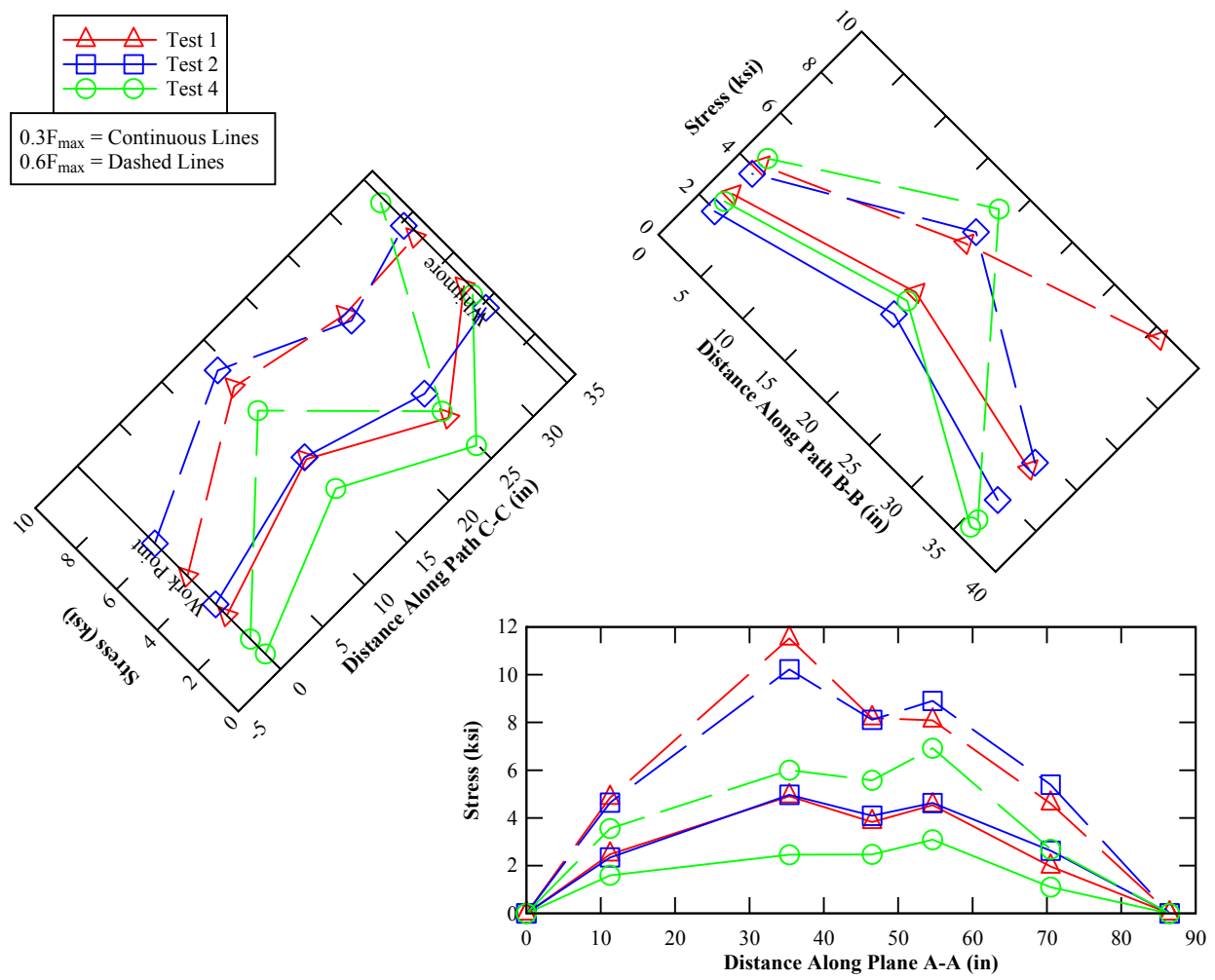

Figure 31: 1/4-inch plates, shear stress in global xy direction 


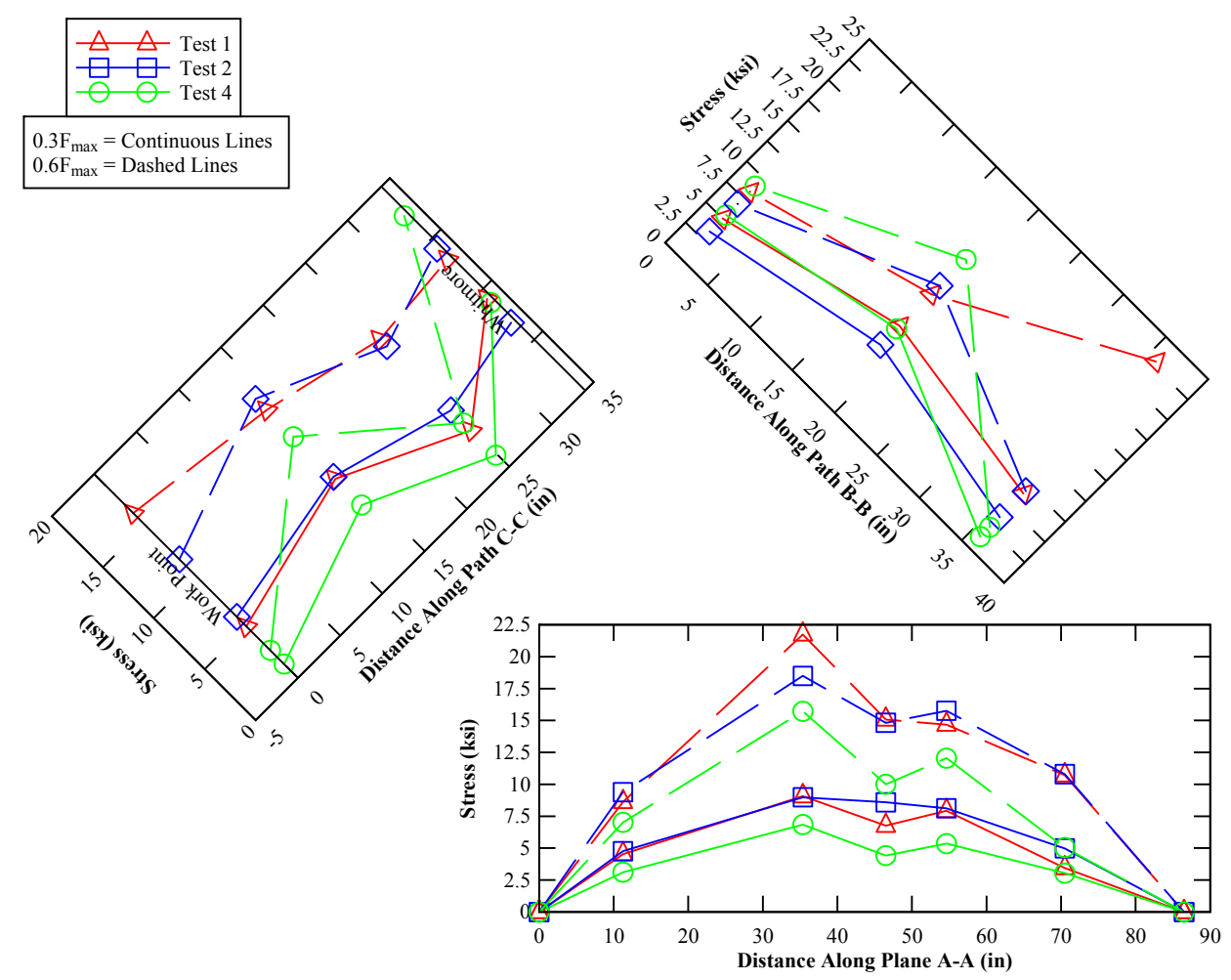

Figure 32: 1/4-inch plates, von Mises stress

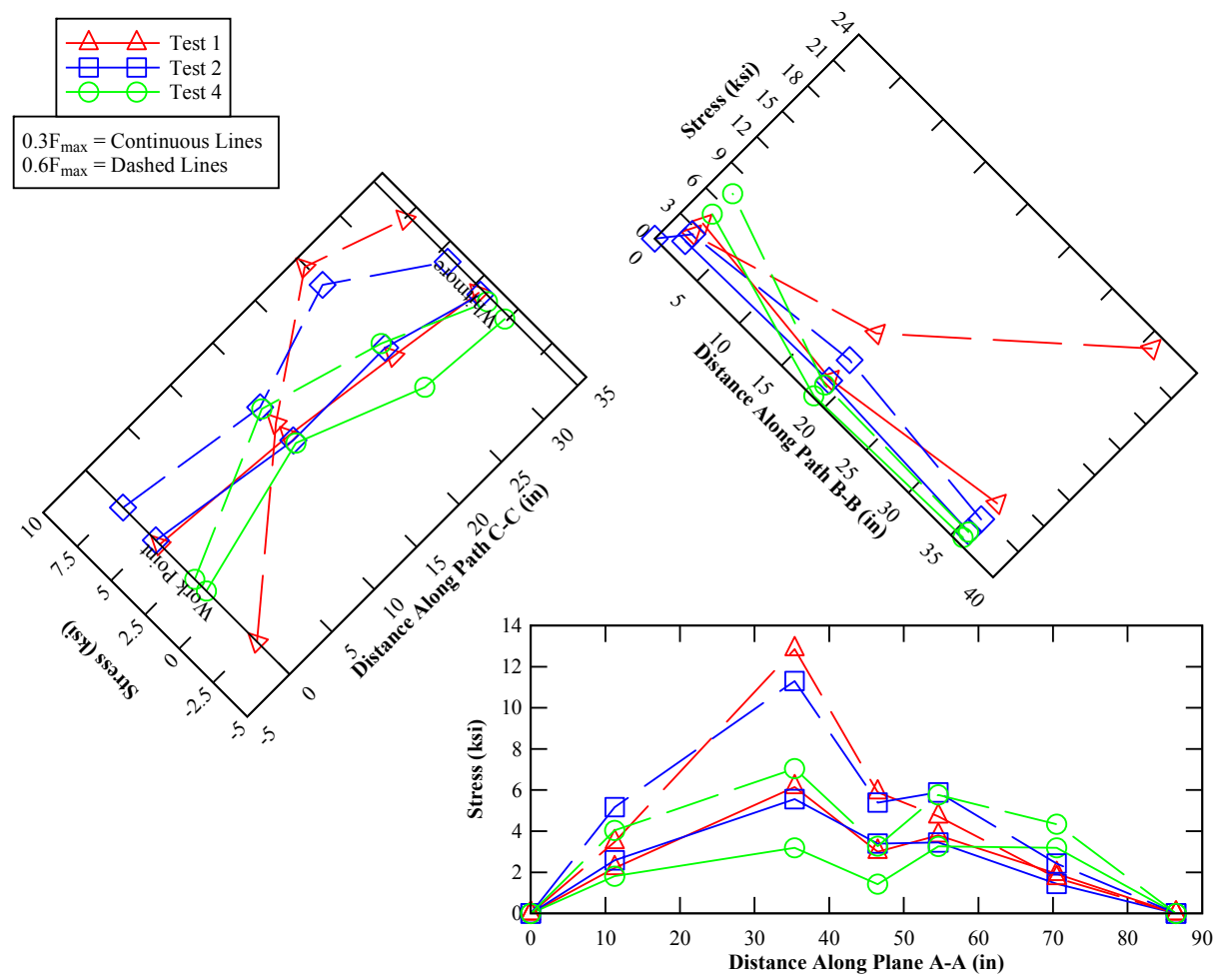

Figure 33: 1/4" plates, 1st principle stress (+ = Tension, - = Compression) 


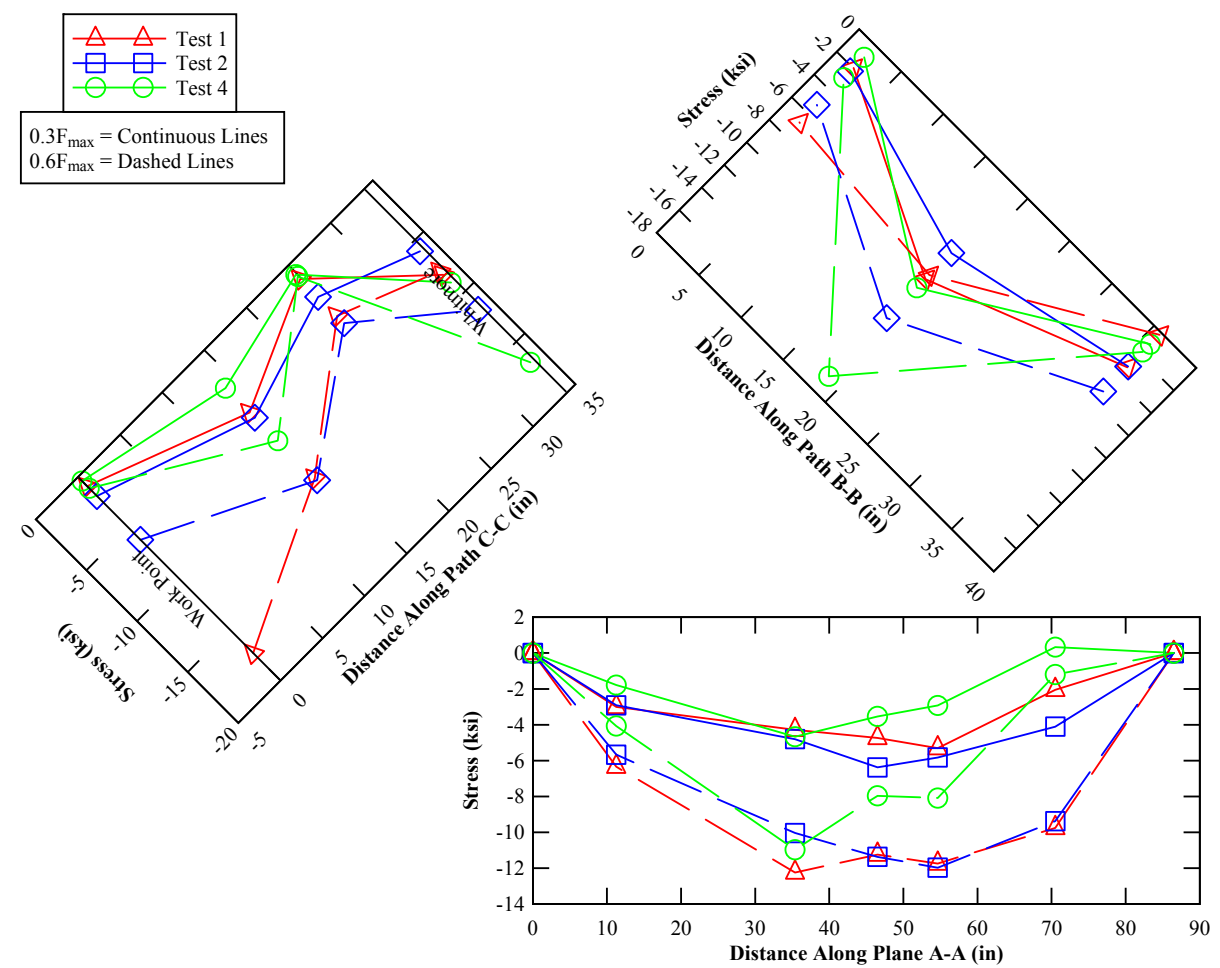

Figure 34: 1/4-inch plates, 2 nd principle stress $(+=$ Tension, $-=$ Compression)

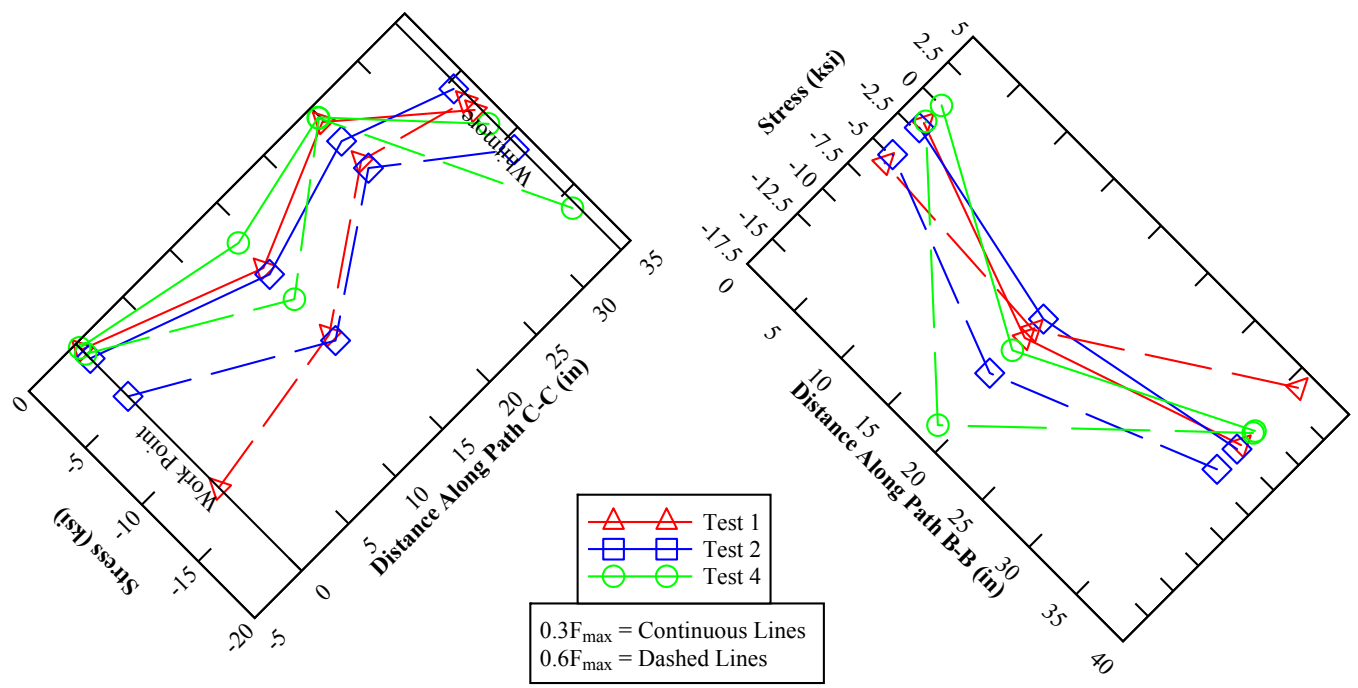

Figure 35: 1/4-inch plates, stress in M4 direction, path B-B and C-C only $(+=$ Tension, $-=$ Compression $)$ 


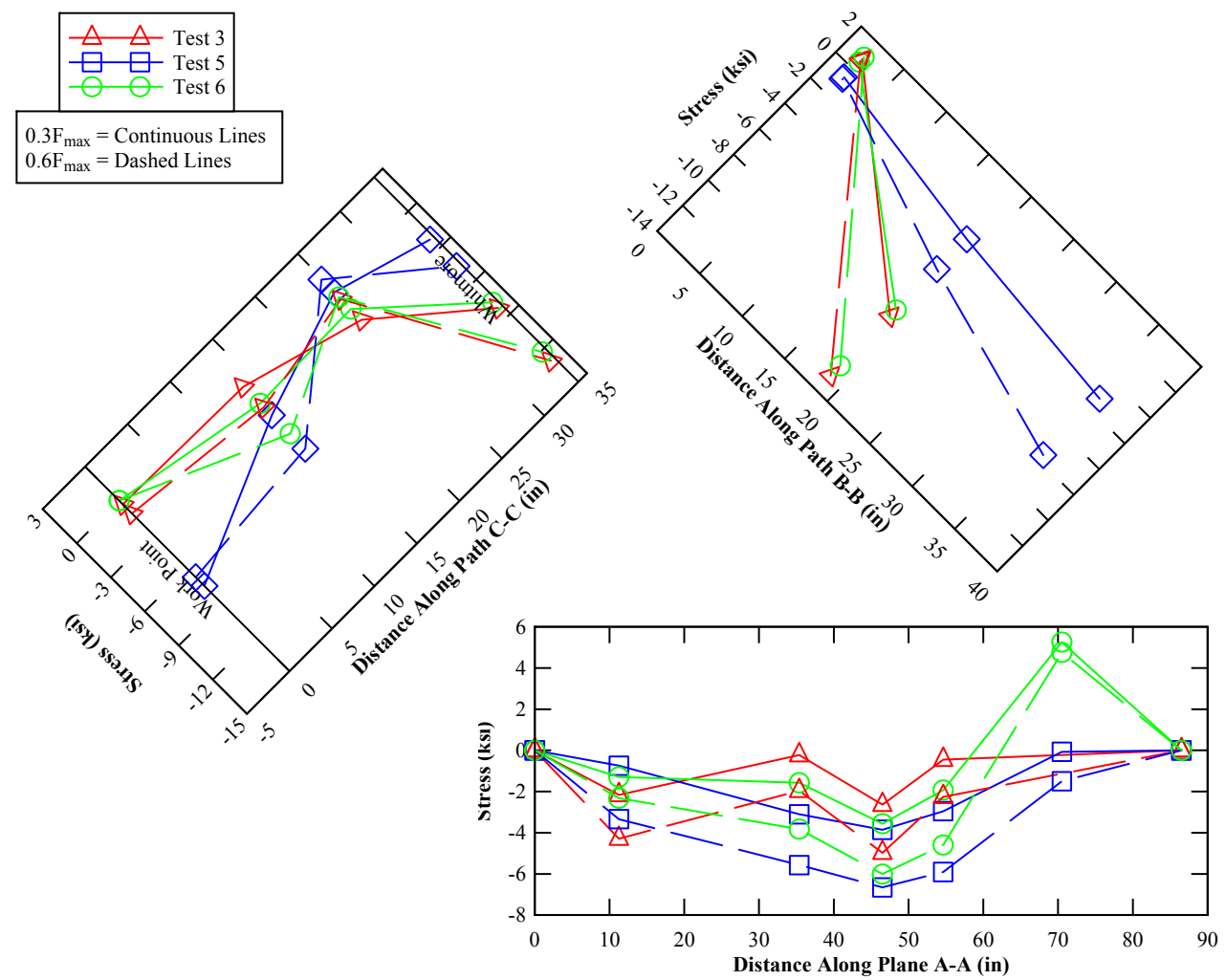

Figure 36: 3/8-inch plates, stress in global $x$ direction $(+=$ Tension, $-=$ Compression) 


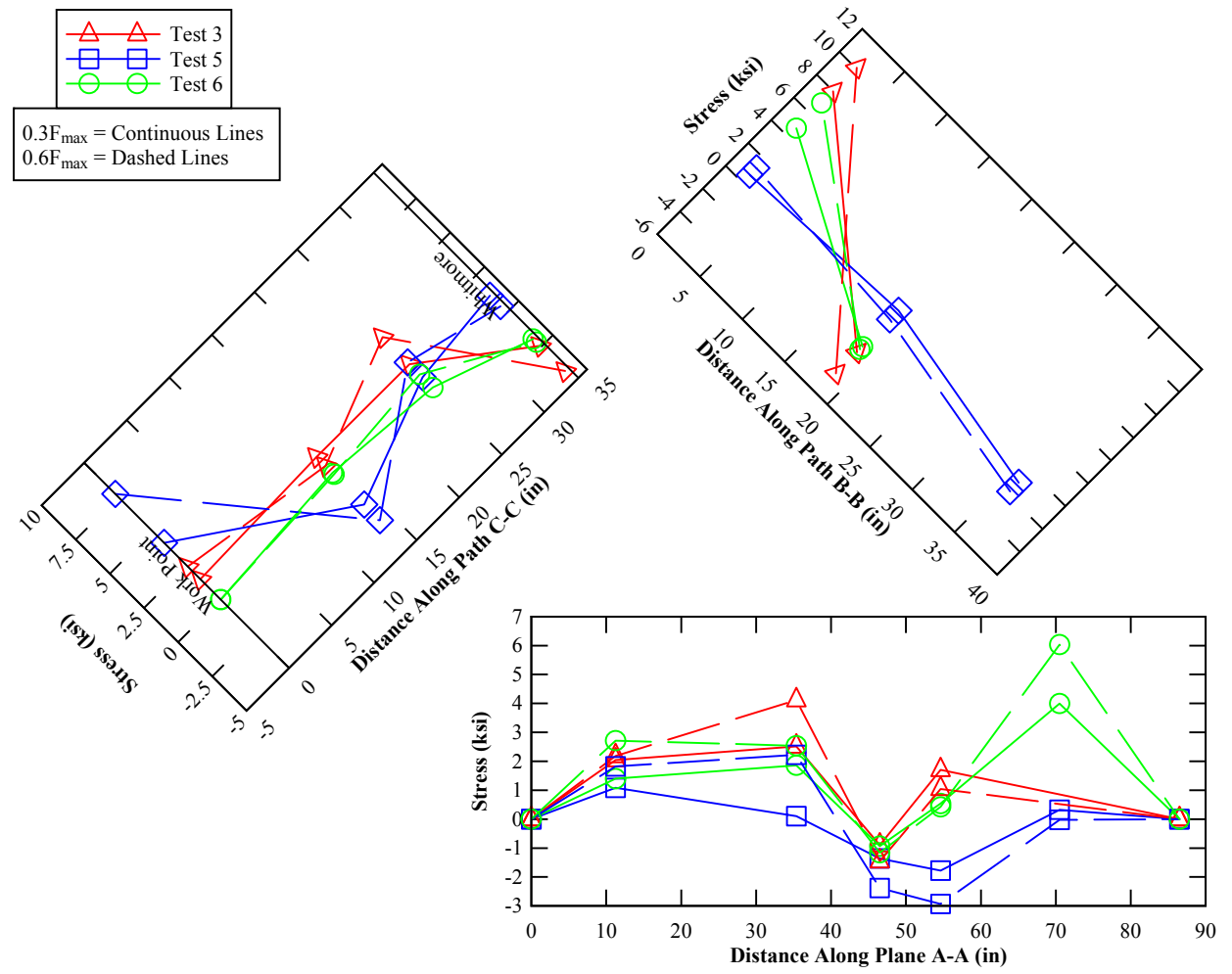

Figure 37: 3/8-inch plates, stress in global y direction $(+=$ Tension, $-=$ Compression $)$

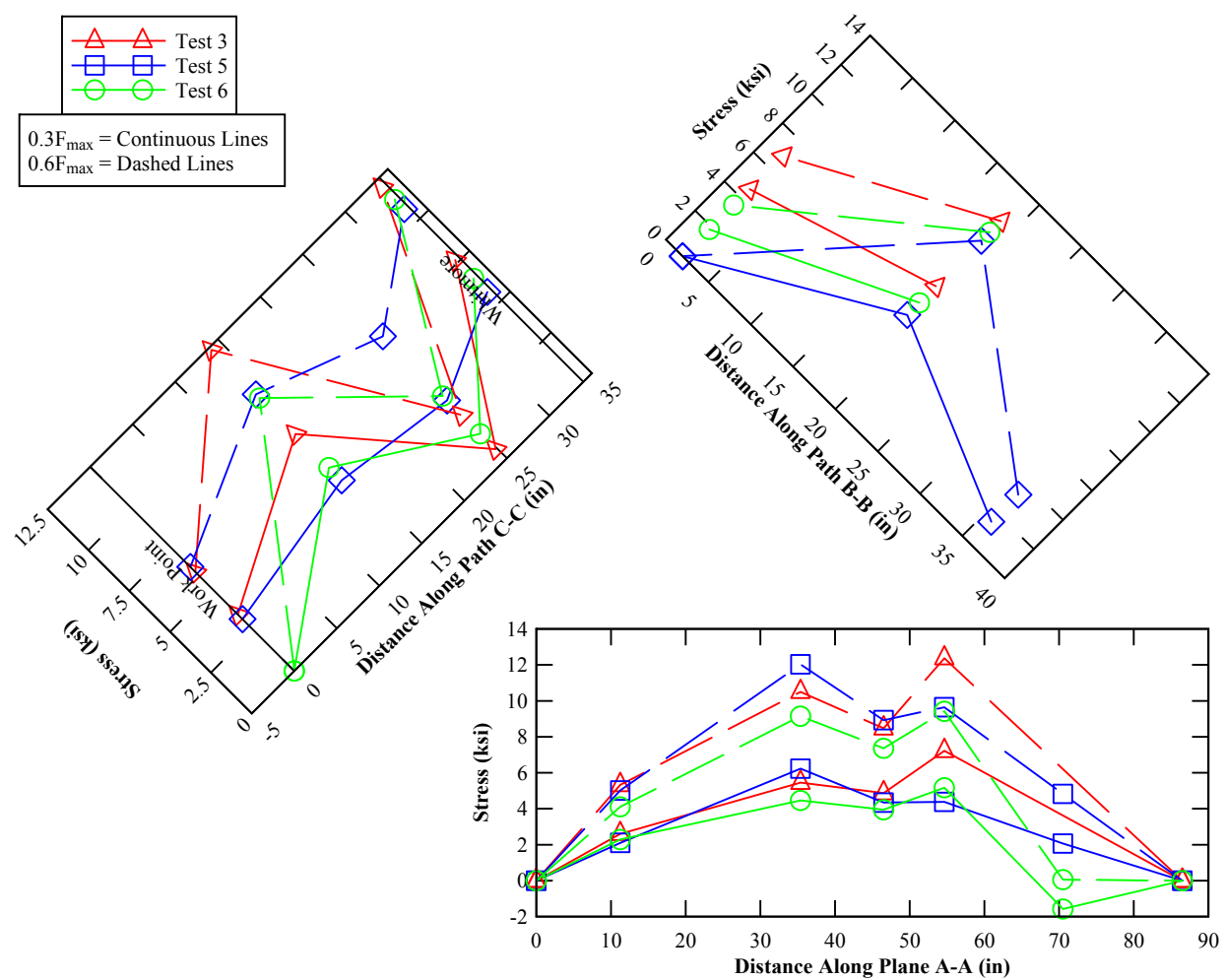

Figure 38: 3/8-inch plates, shear stress in global xy direction 


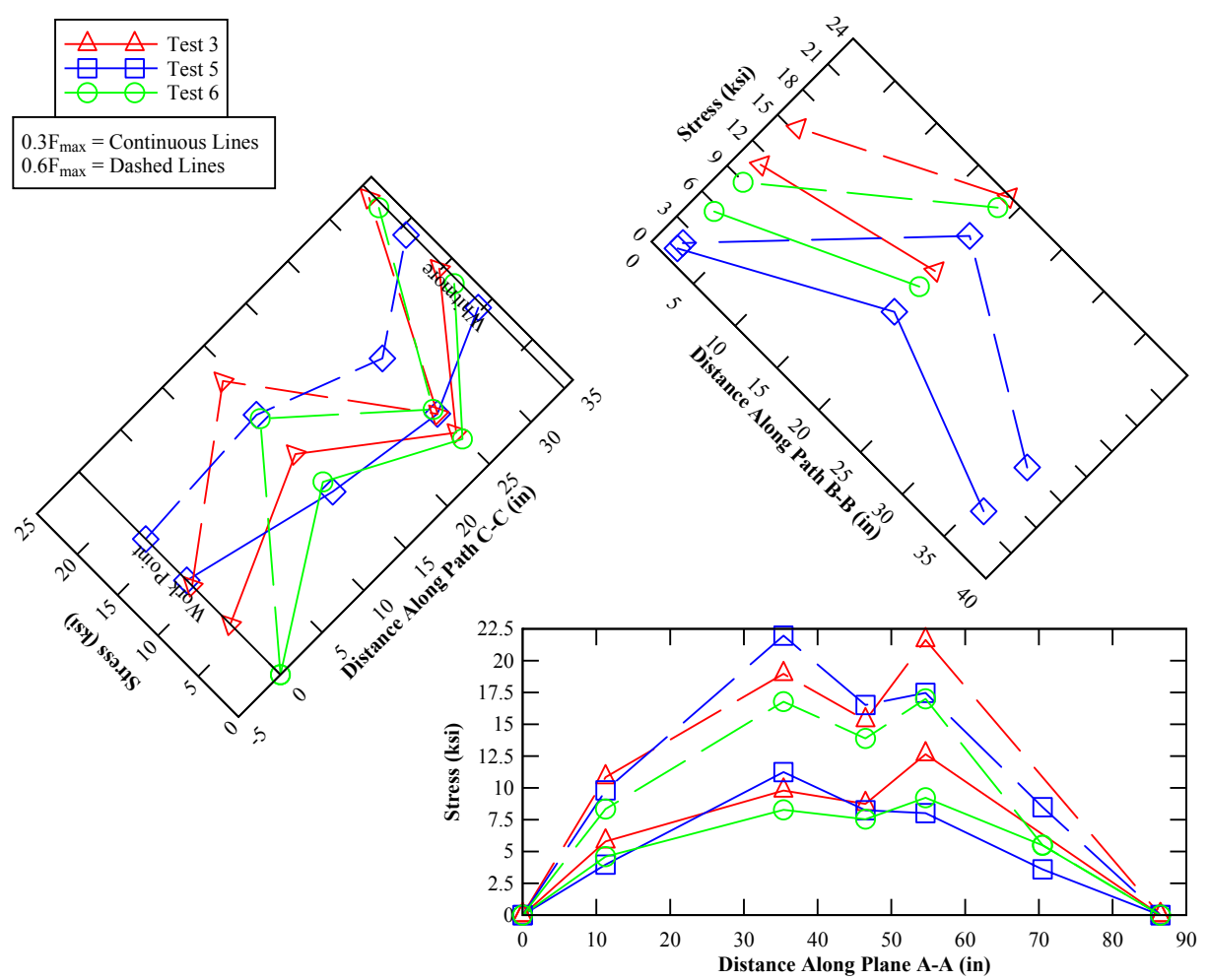

Figure 39: 3/8-inch plates, von Mises stress

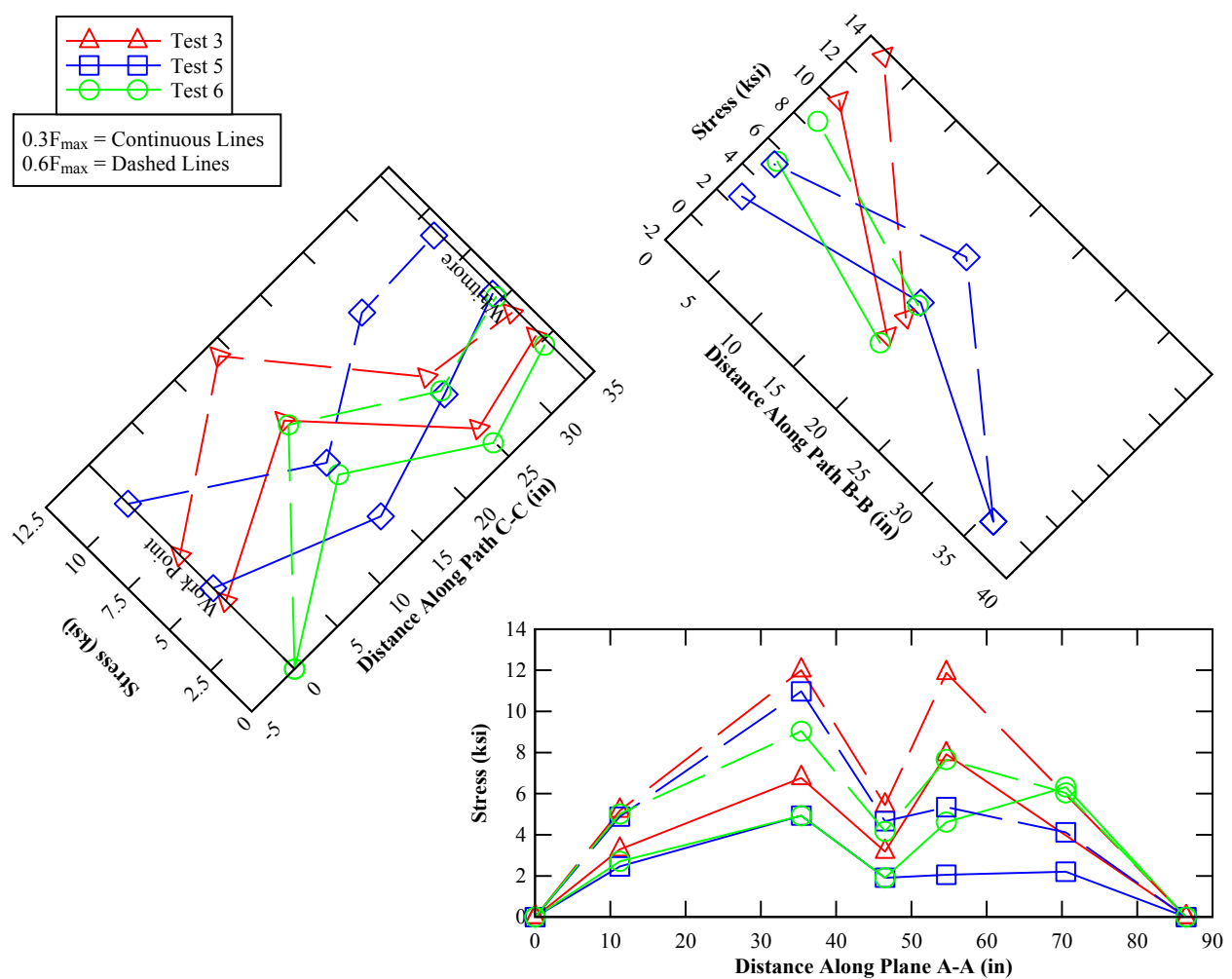

Figure 40: 3/8" plates, 1st principle stress $(+=$ Tension, $-=$ Compression $)$ 


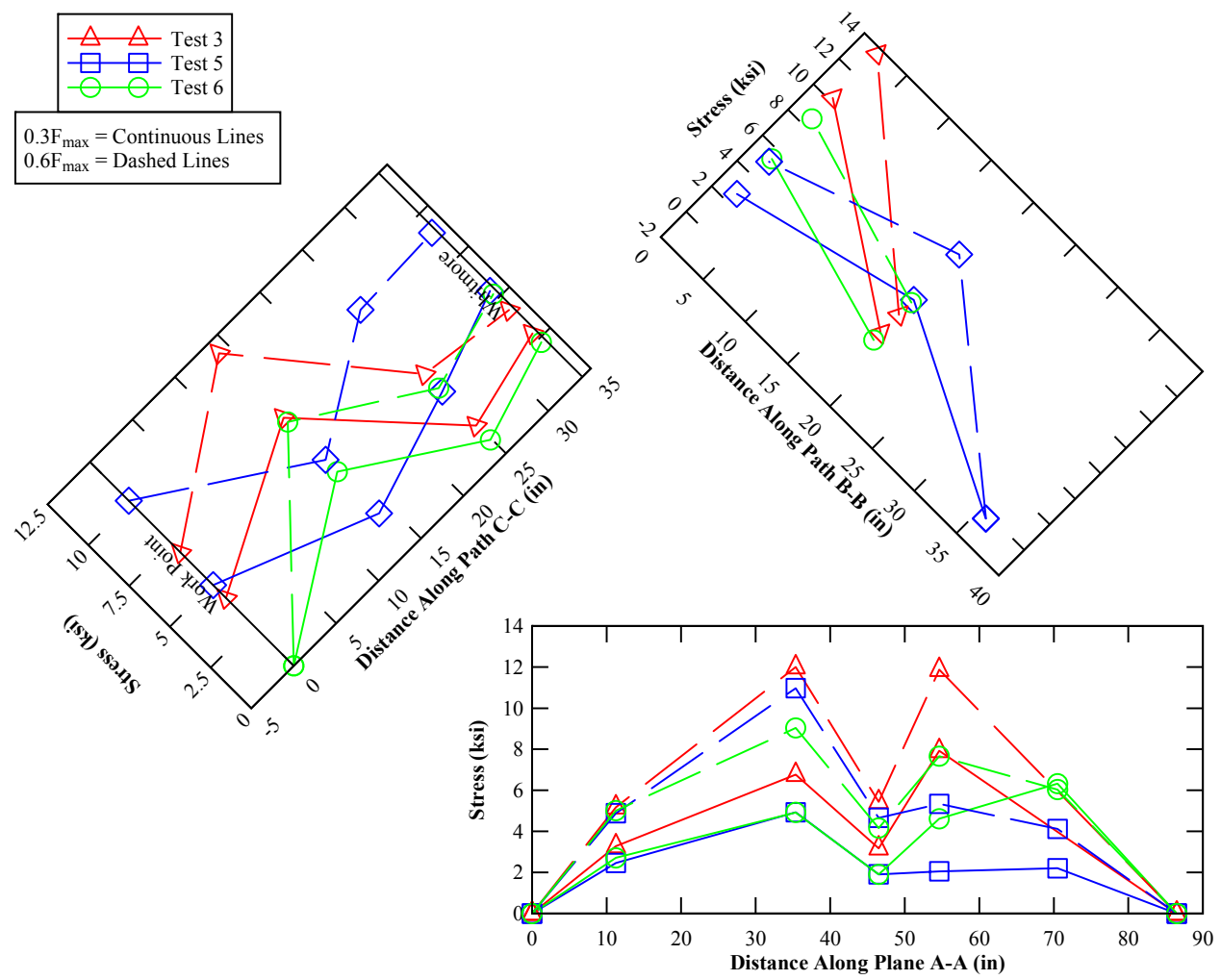

Figure 41: 3/8-inch plates, 2nd principle stress ( $+=$ Tension, - = Compression)

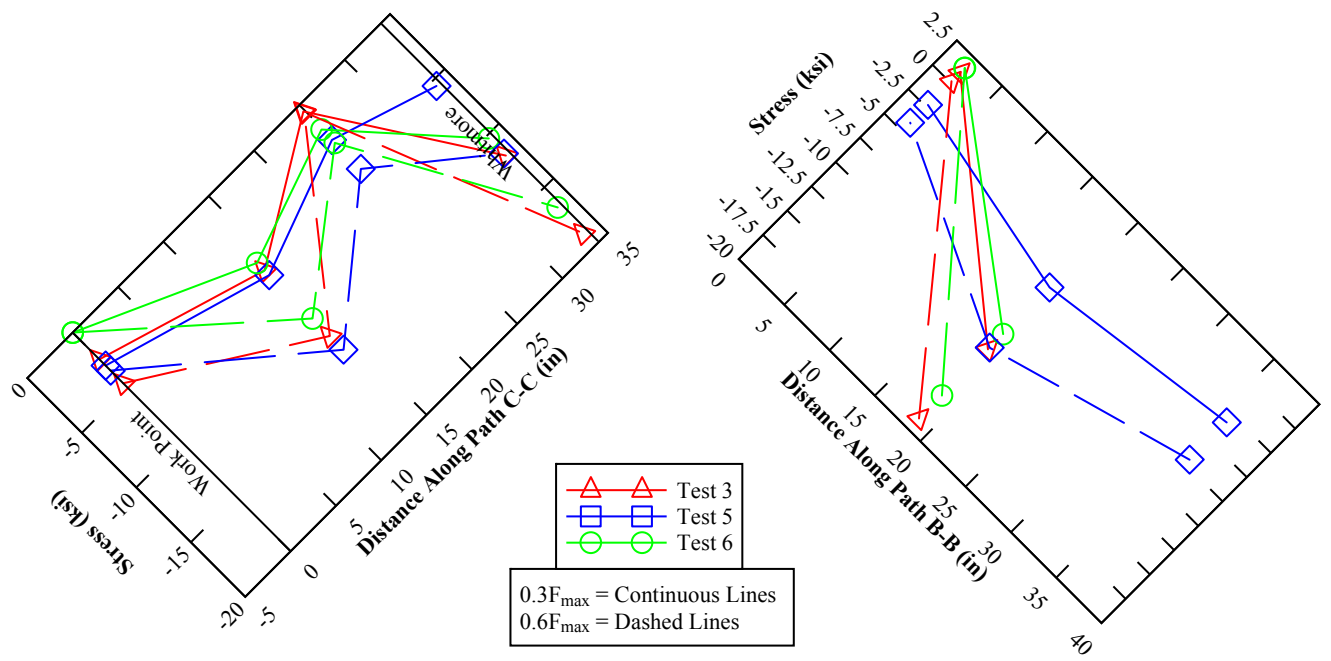

Figure 42: 3/8-inch plates, stress in M4 direction, paths B-B and C-C only ( $+=$ Tension, $-=$ Compression) 


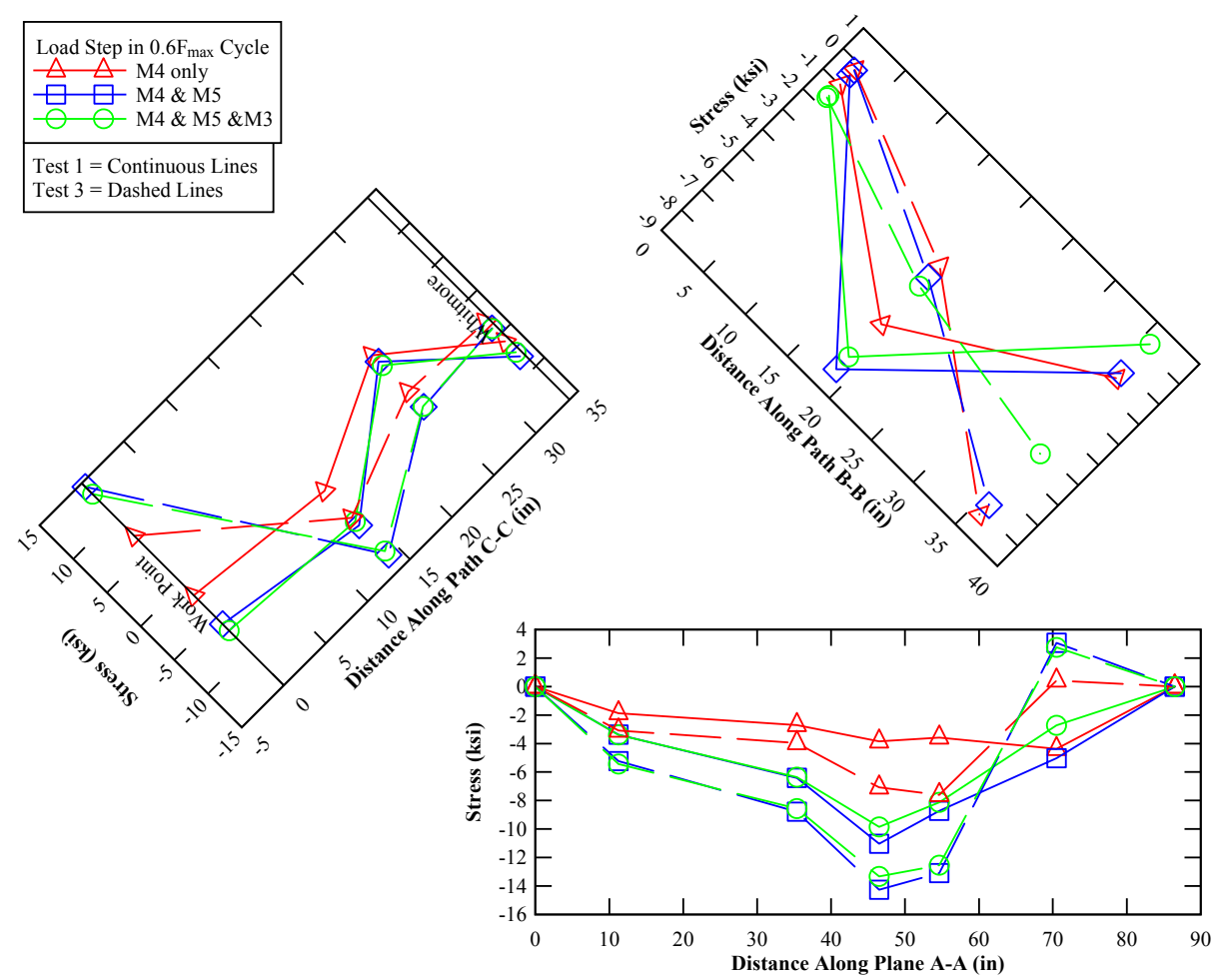

Figure 43: Combination loading, stress in global $x$ direction $(+=$ Tension, $-=$ Compression $)$

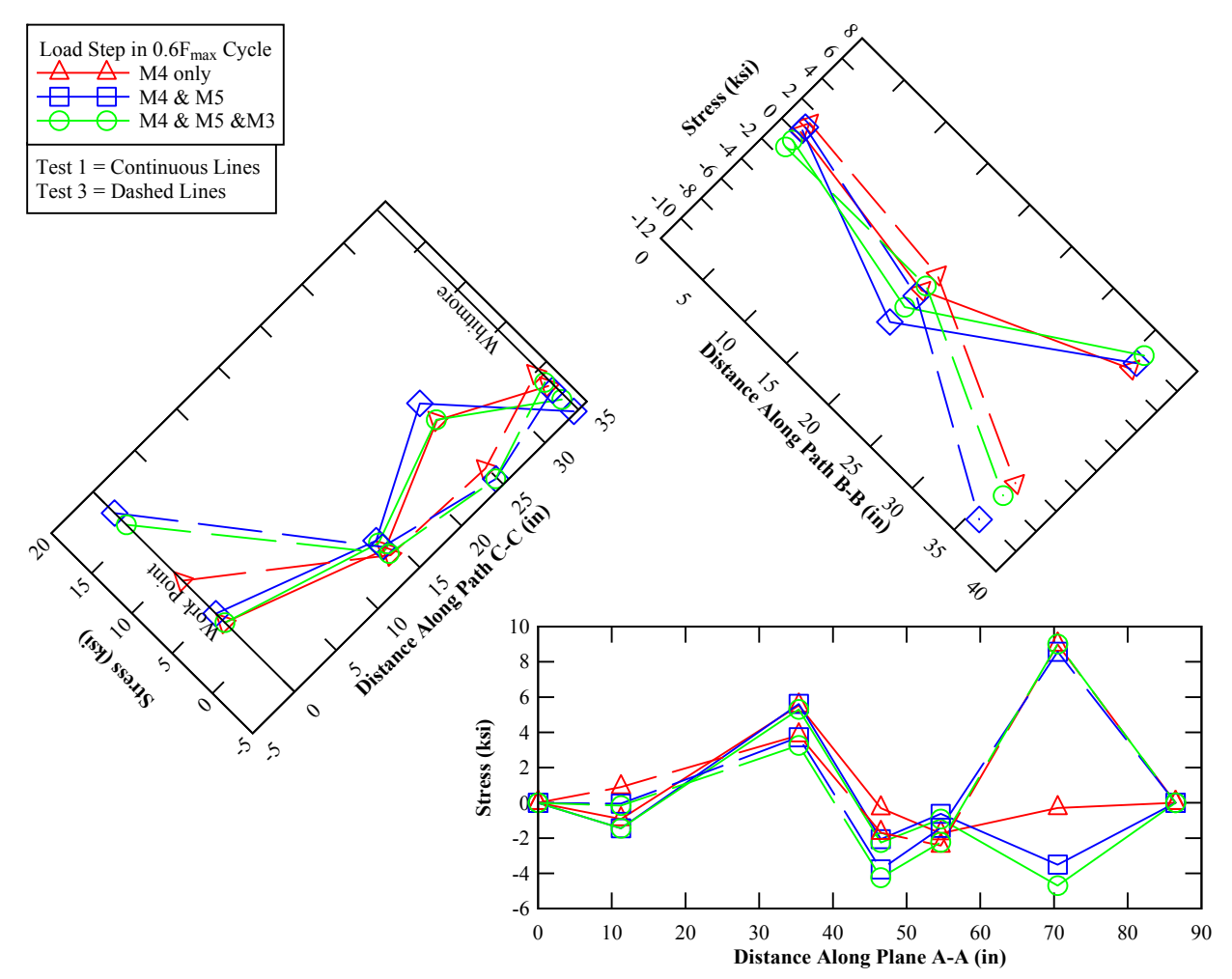

Figure 44: Combination loading, stress in global y direction $(+=$ Tension, $-=$ Compression $)$ 


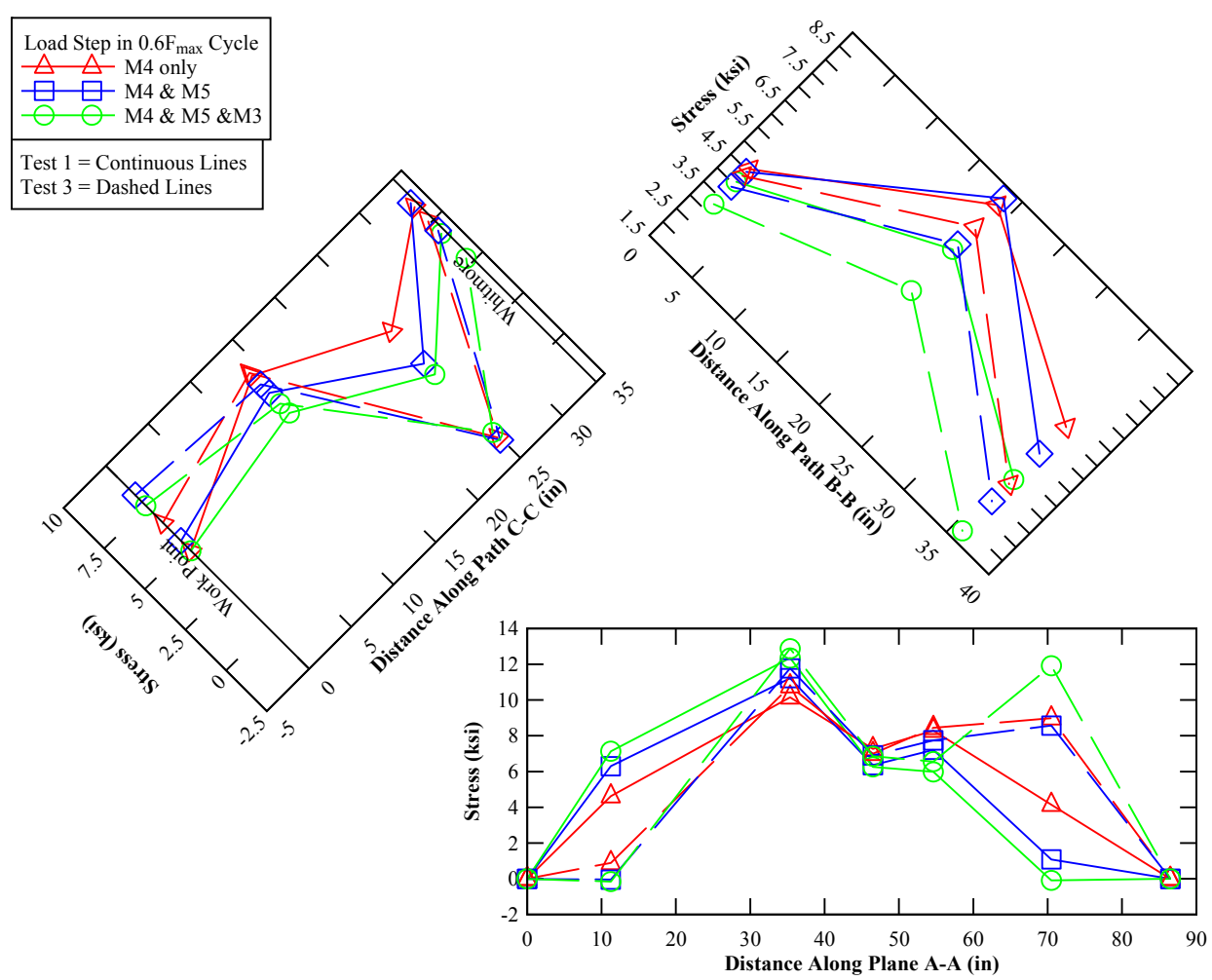

Figure 45: Combination loading, shear stress in global xy direction

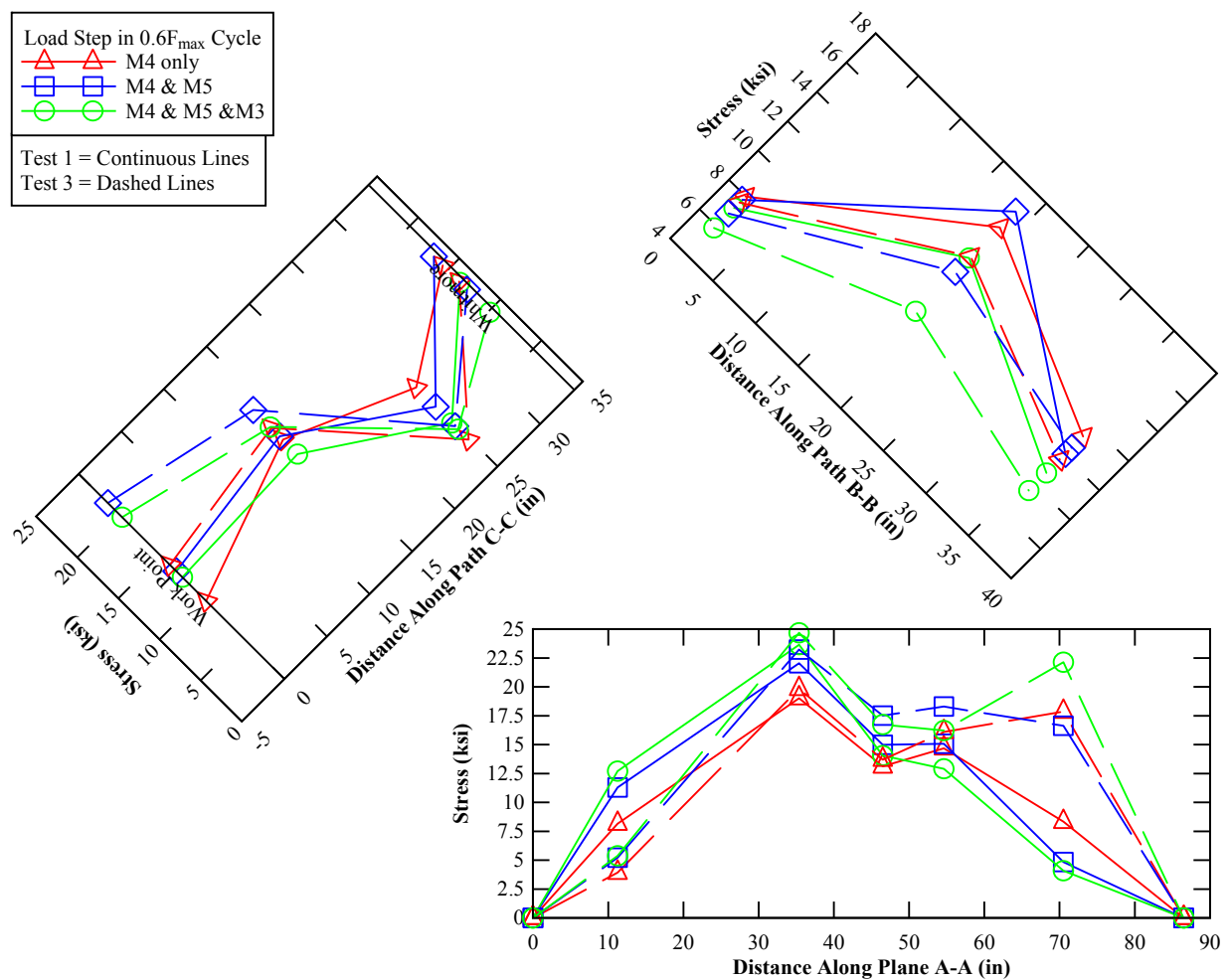

Figure 46: Combination loading, von Mises stress 


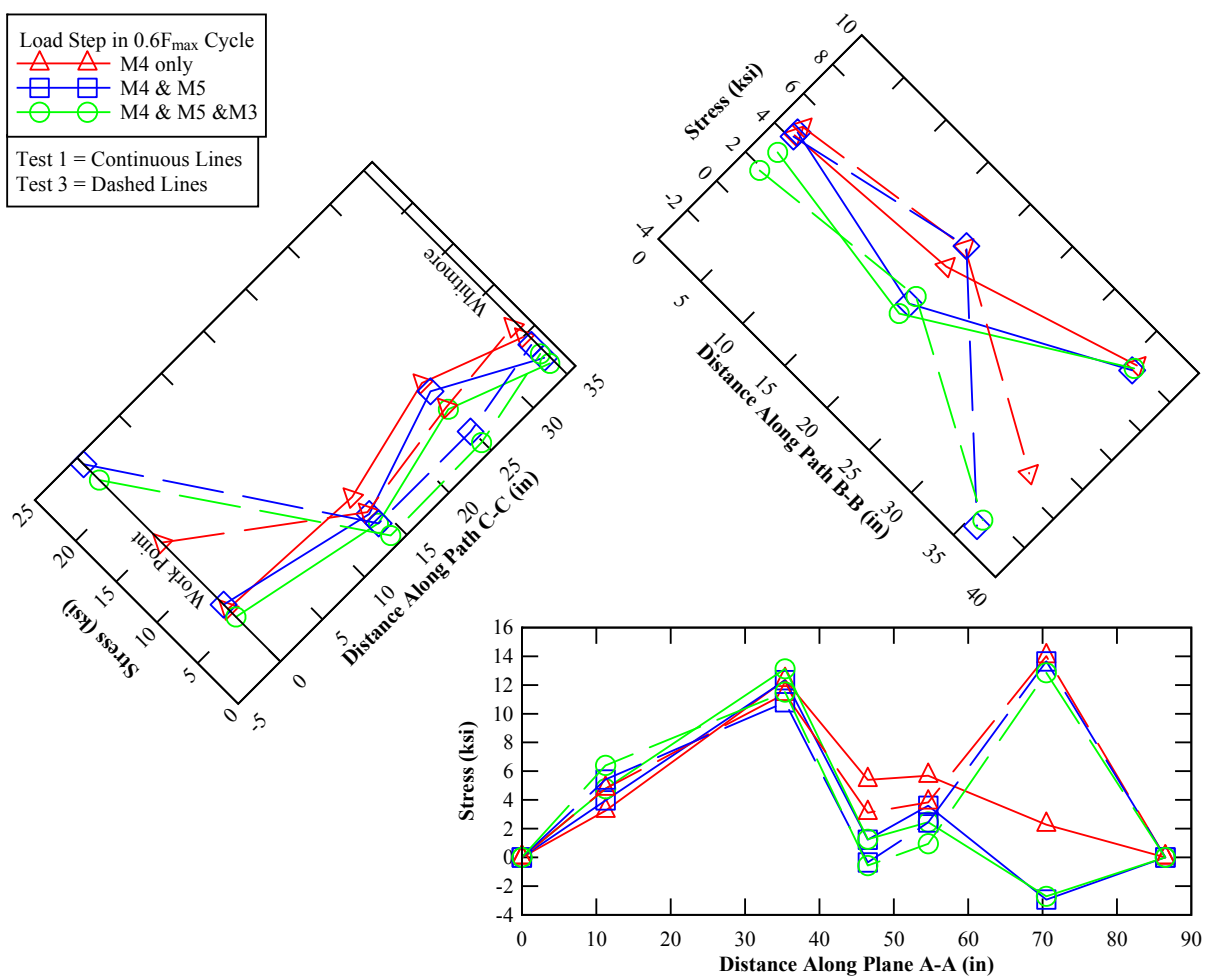

Figure 47: Combination loading, 1 st principle stress $(+=$ Tension, $-=$ Compression $)$

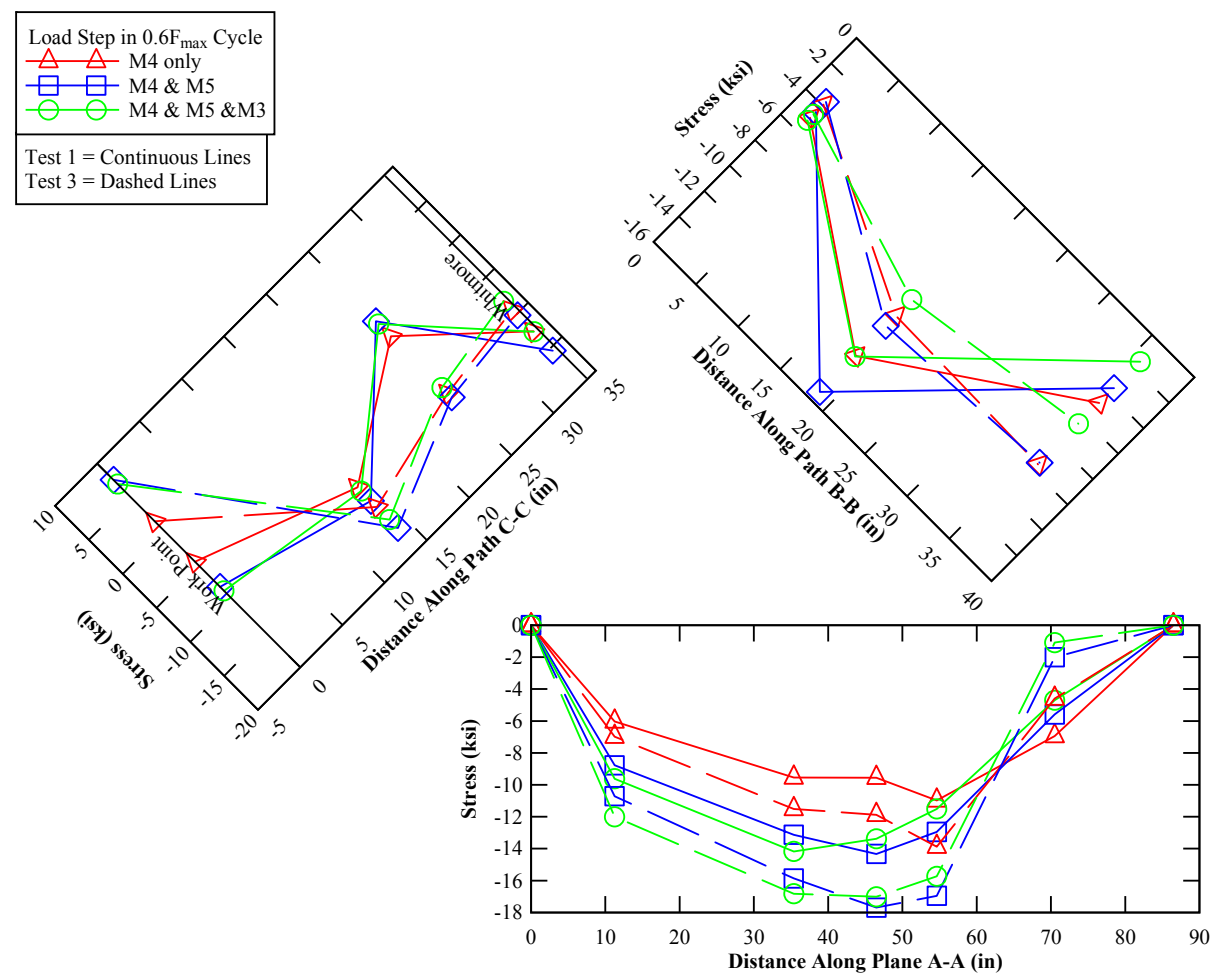

Figure 48: Combination loading, 2nd principle stress $(+=$ Tension, $-=$ Compression) 


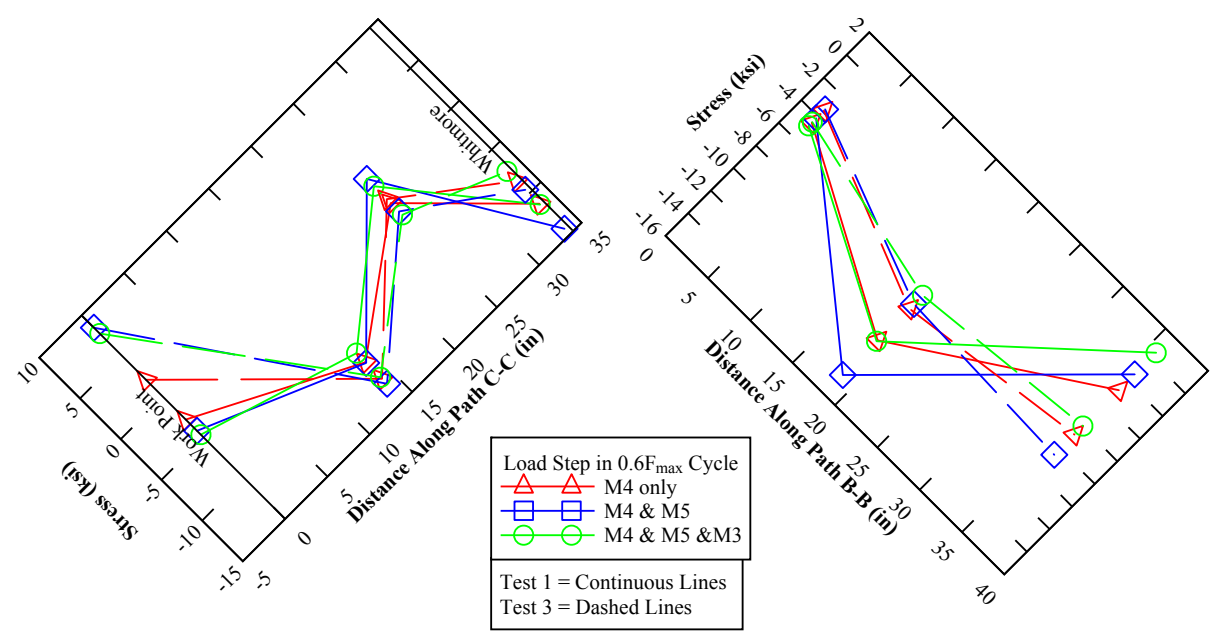

Figure 49: Combination loading, stress in M4 direction, paths B-B and C-C only $(+=$ Tension, $-=$ Compression)

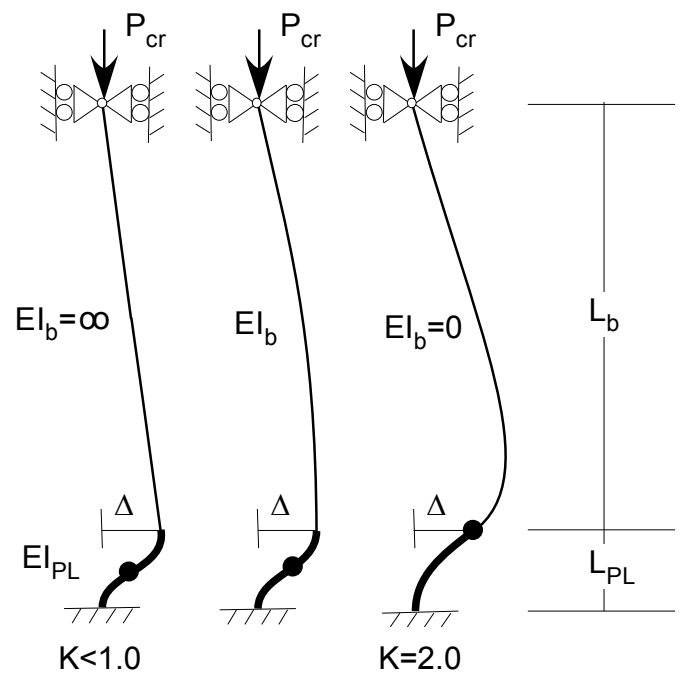

- Member - Connection $\bullet$ Inflection point

Figure 50: Stepped column analogy for member-plate interaction system 


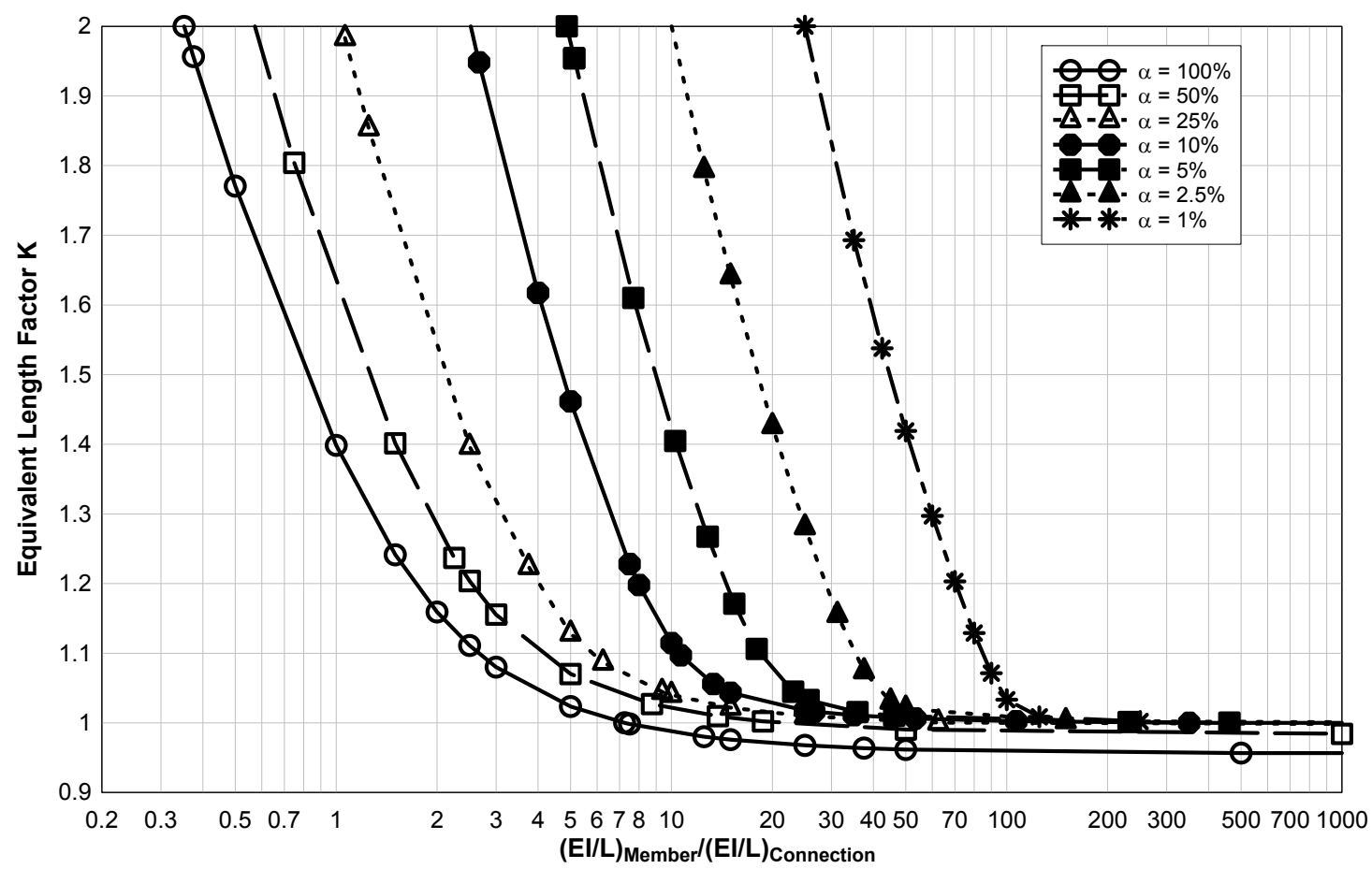

Figure 51: System interactions for buckling of a stepped column showing member interaction on connection equivalent length factor, $\alpha=\mathbf{L}_{\text {connection }} / \mathbf{L}_{\text {member }}$ 


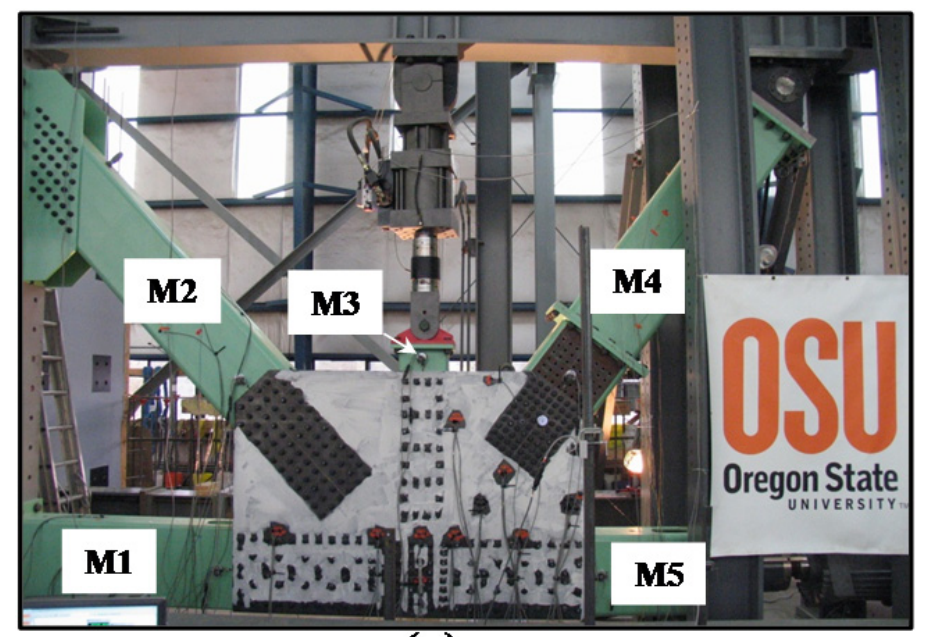

(a)

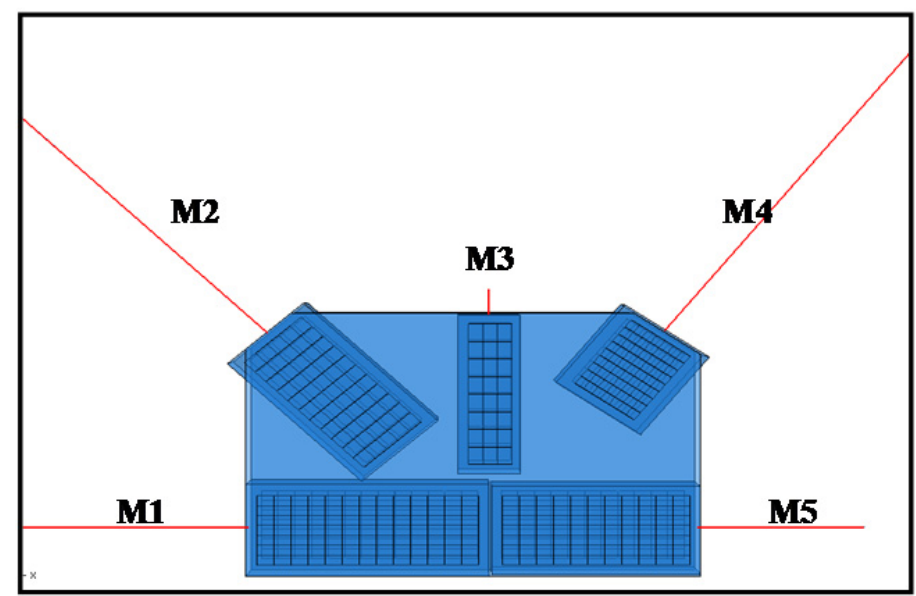

(b)

Figure 52: (a) experimental setup and (b) FEA model assembly 


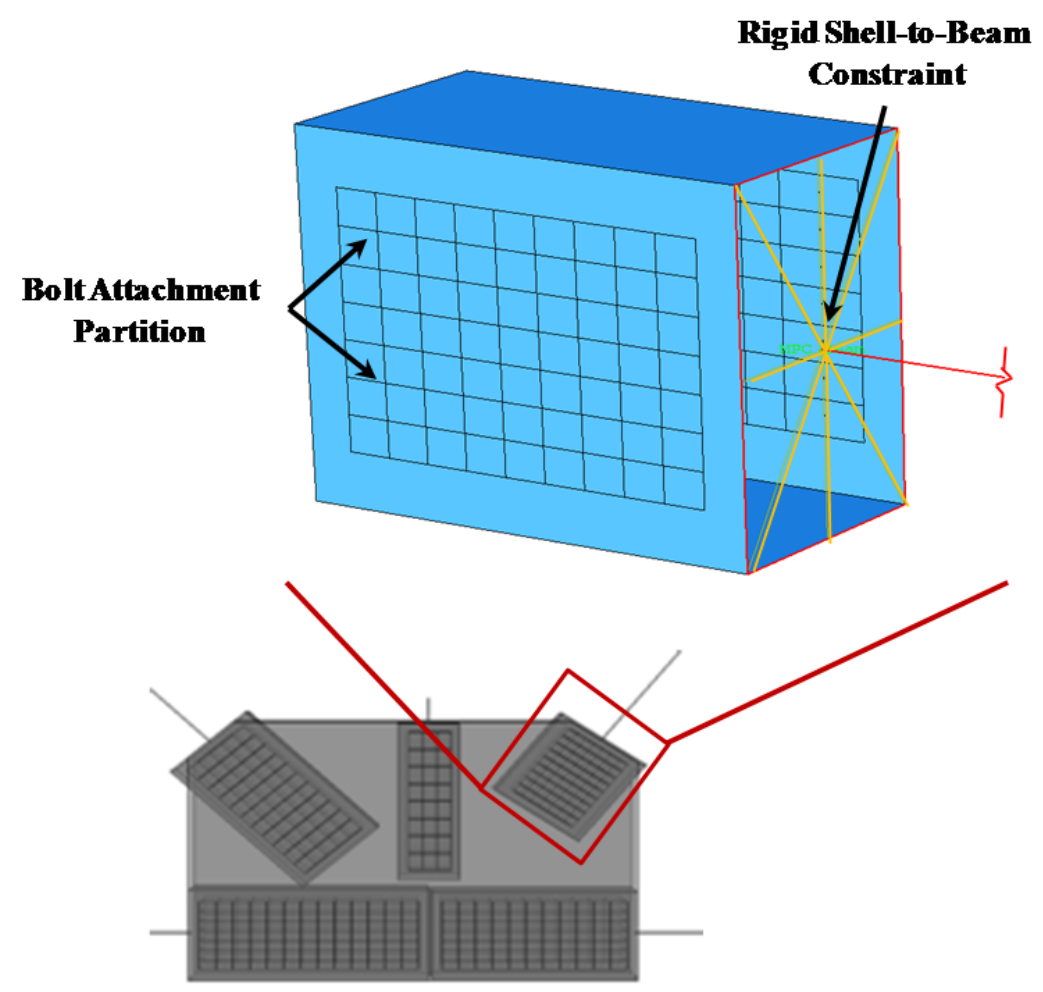

Figure 53: Gusset plate connection member modeling

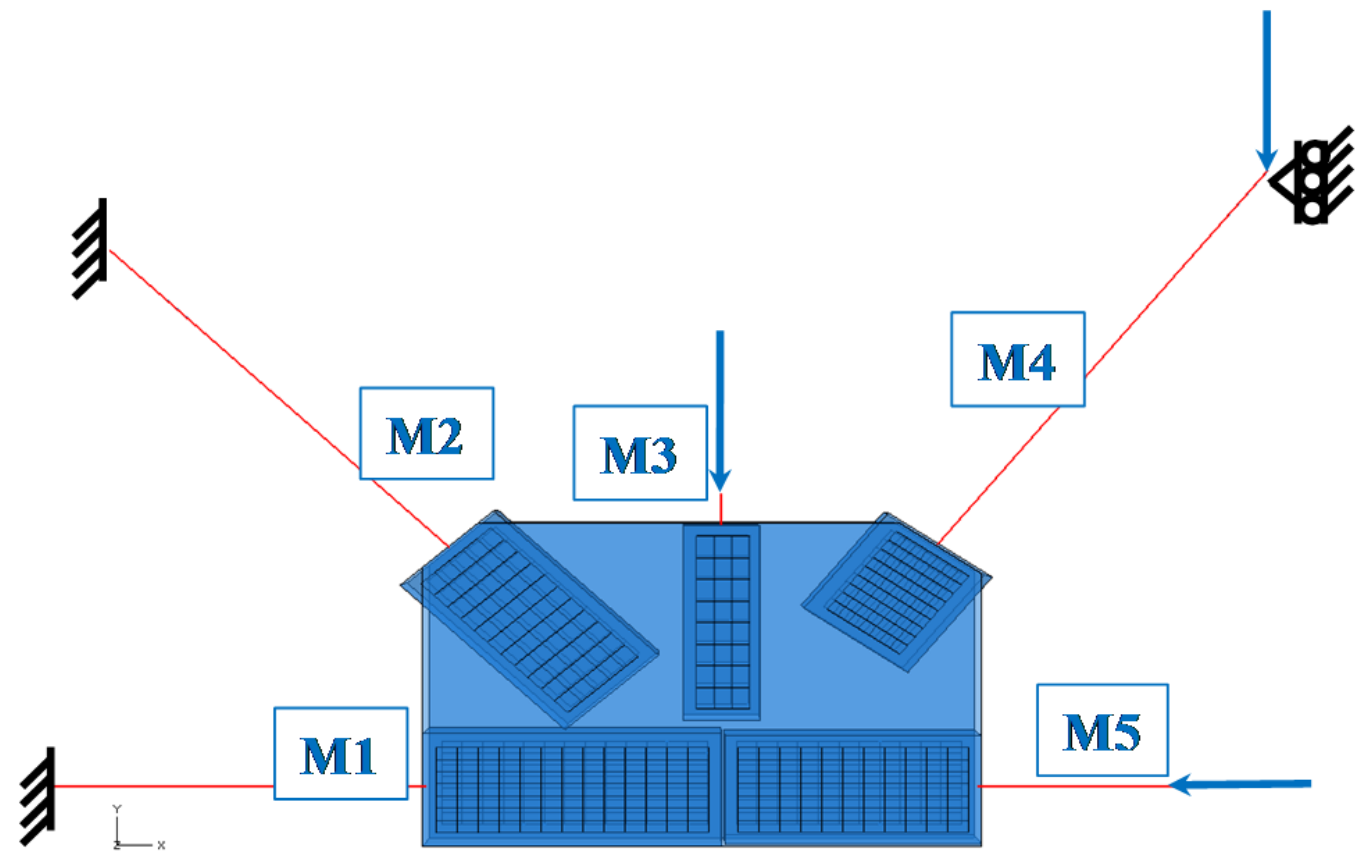

Figure 54: Boundary conditions and locations of applied loads for gusset plate connection model 


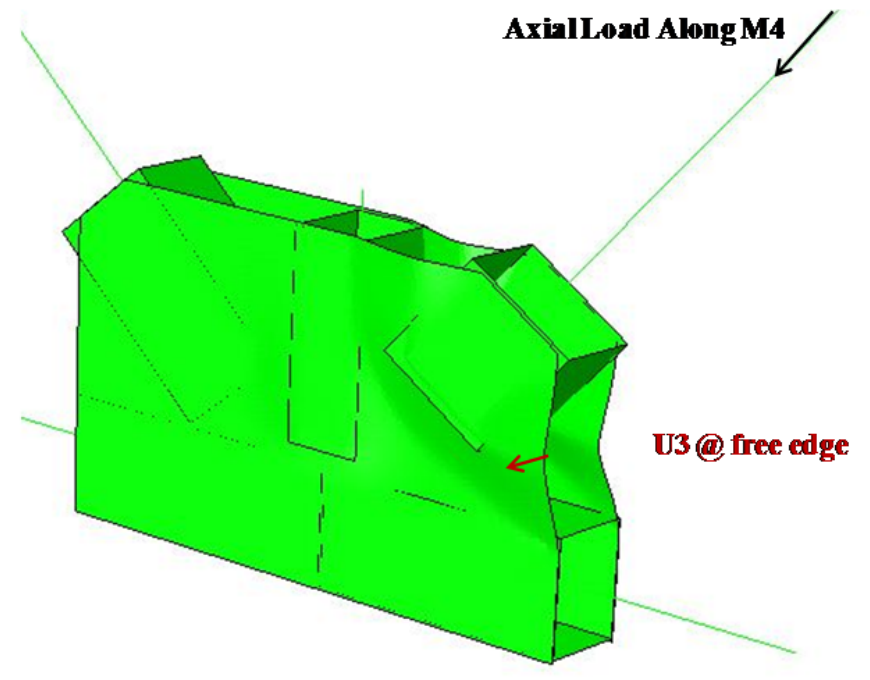

Figure 55: Measurements used to construct gusset connection model load-displacement plots
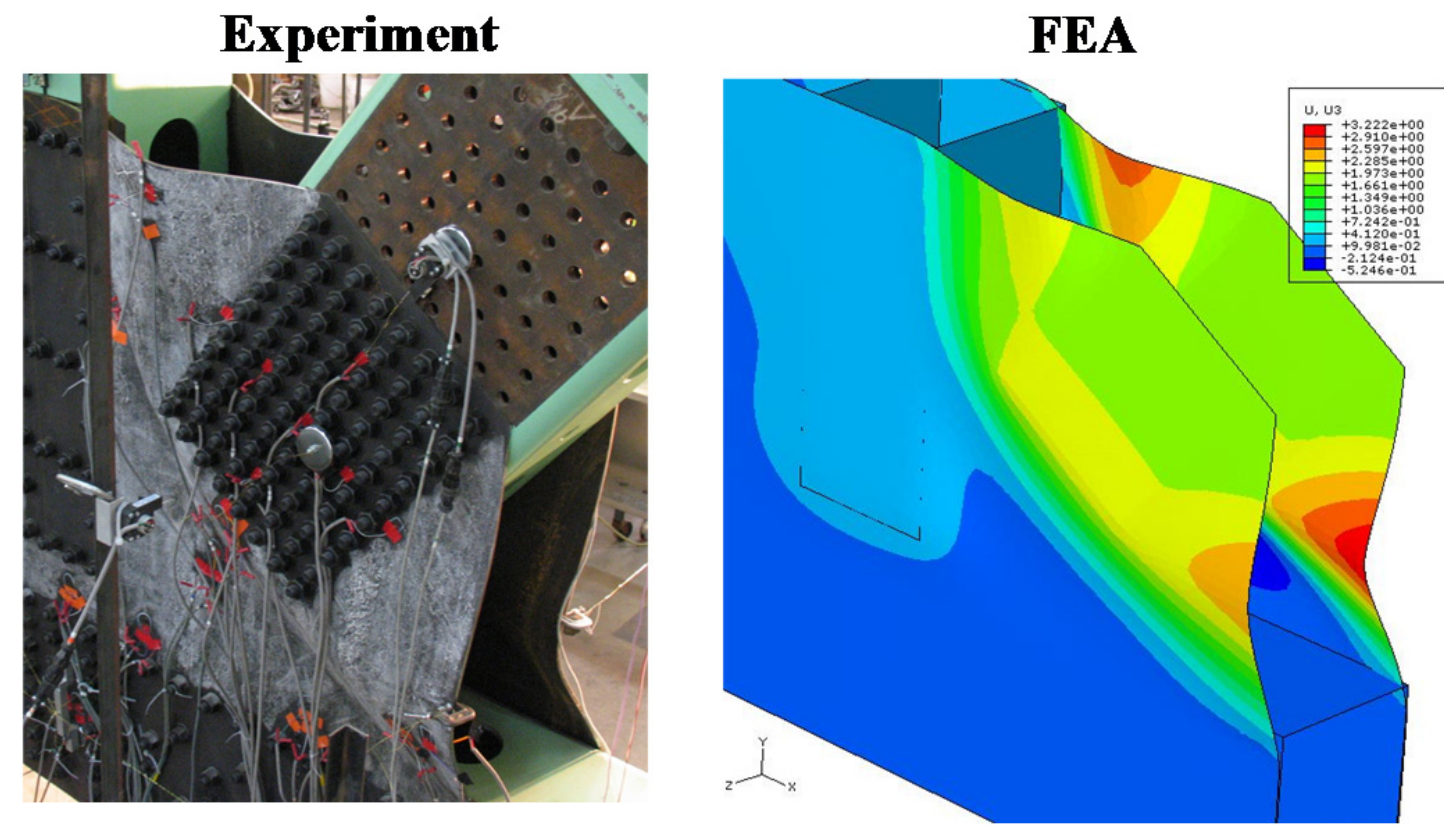

Figure 56: Experimental and numerical buckled shape - Test 1 


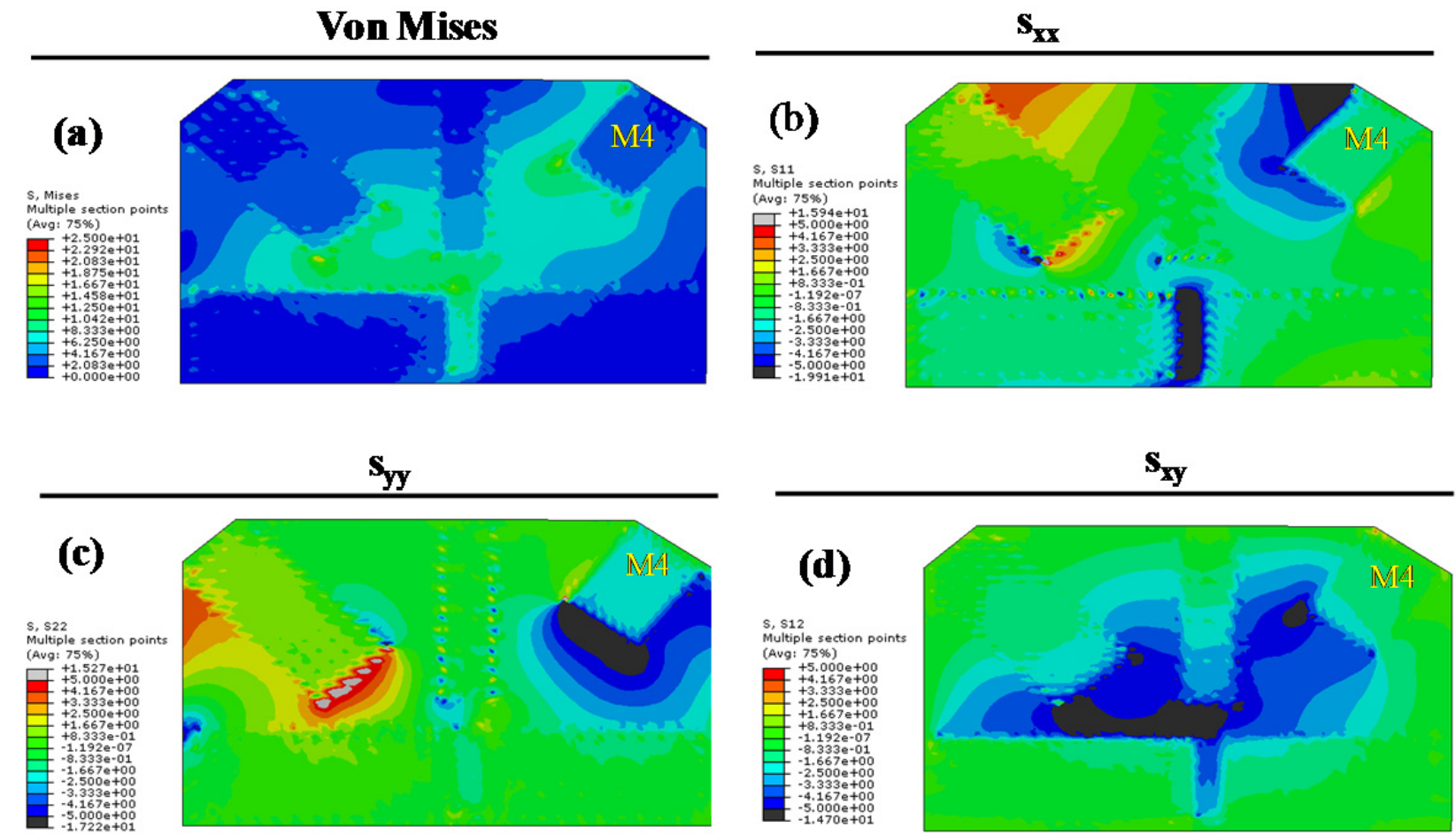

Figure 57: Stress contours from 100 kip axial load along M4, (a) von Mises stress, (b) $s_{x x}$ stress, (c) $s_{y y}$ stress and (d) $s_{x y}$ stress

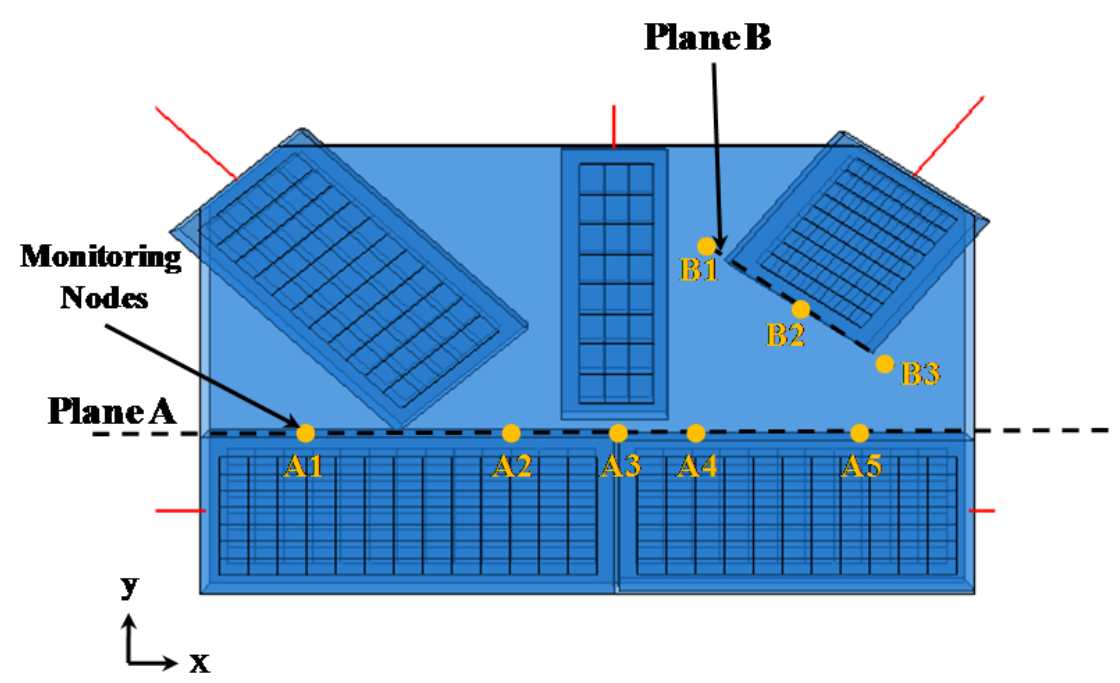

Figure 58: Stress planes and sample points used for elastic stress analysis 


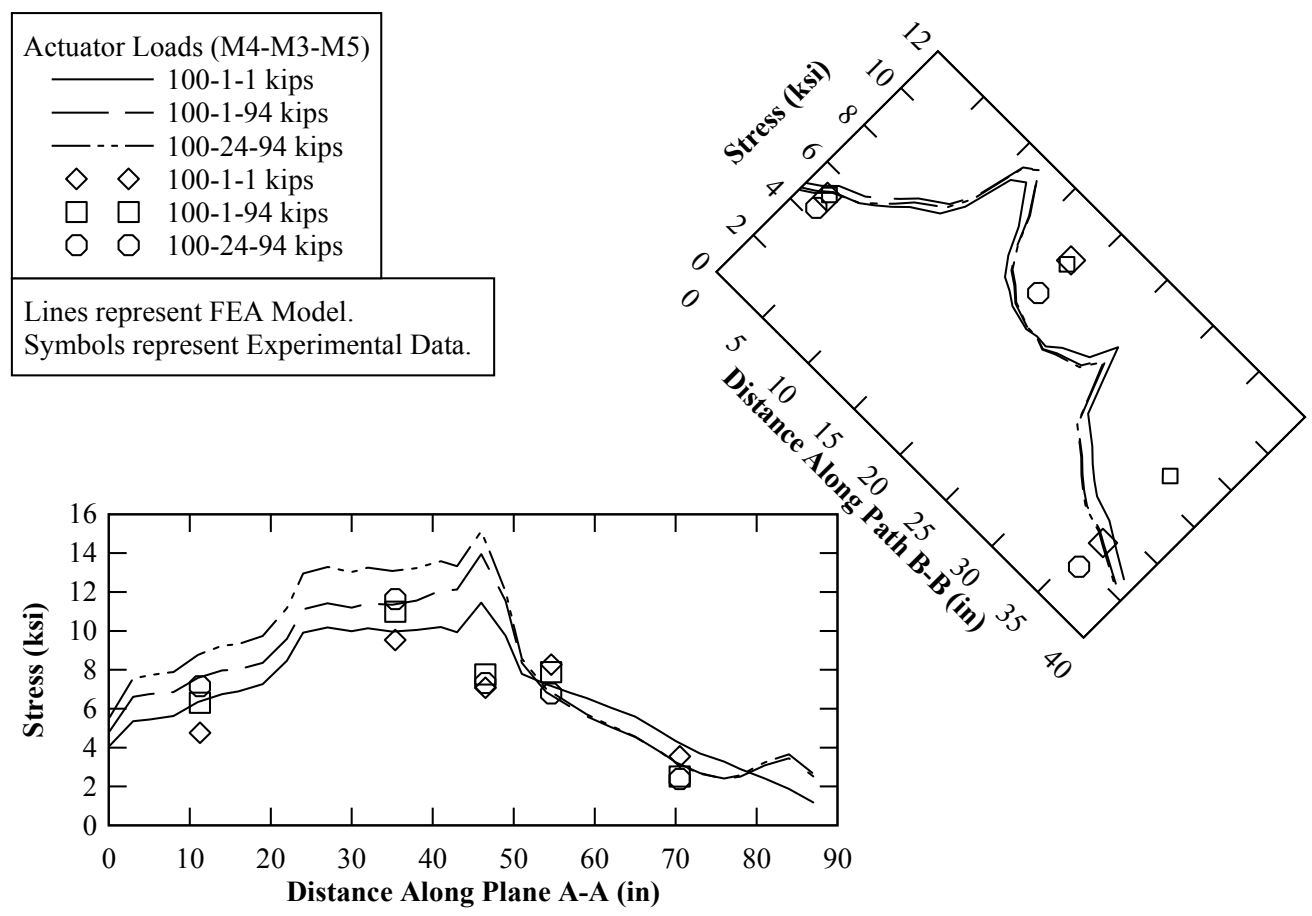

Figure 59: Specimen 1 vs FEA Model, von Mises stress

$$
\begin{aligned}
& \text { Actuator Loads (M4-M3-M5) } \\
& \text { - 100-1-1 kips } \\
& \text { - - 100-1-94 kips } \\
& \text { - - - 100-24-94 kips } \\
& \diamond \diamond \text { 100-1-1 kips } \\
& \square \quad \square \quad \text { 100-1-94 kips } \\
& \text { ○ } \bigcirc \text { 100-24-94 kips }
\end{aligned}
$$

Lines represent FEA Model. Symbols represent Experimental Data.
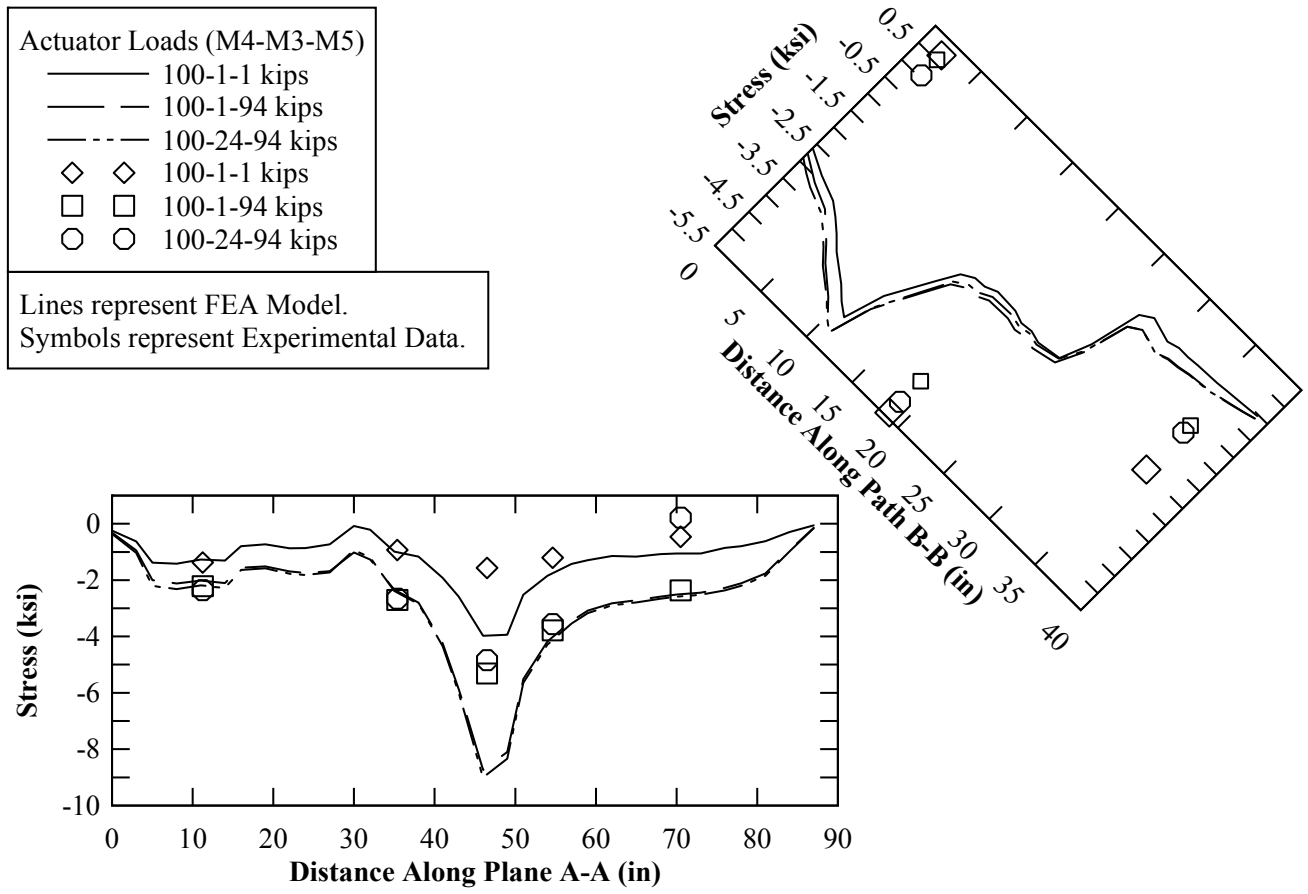

Figure 60: Specimen 1 vs FEA Model, stress in global $x$ direction 


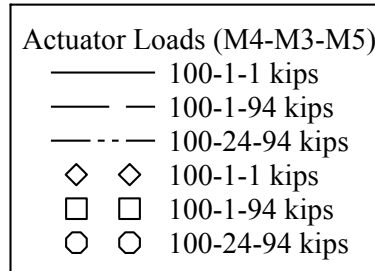

Lines represent FEA Model. Symbols represent Experimental Data.

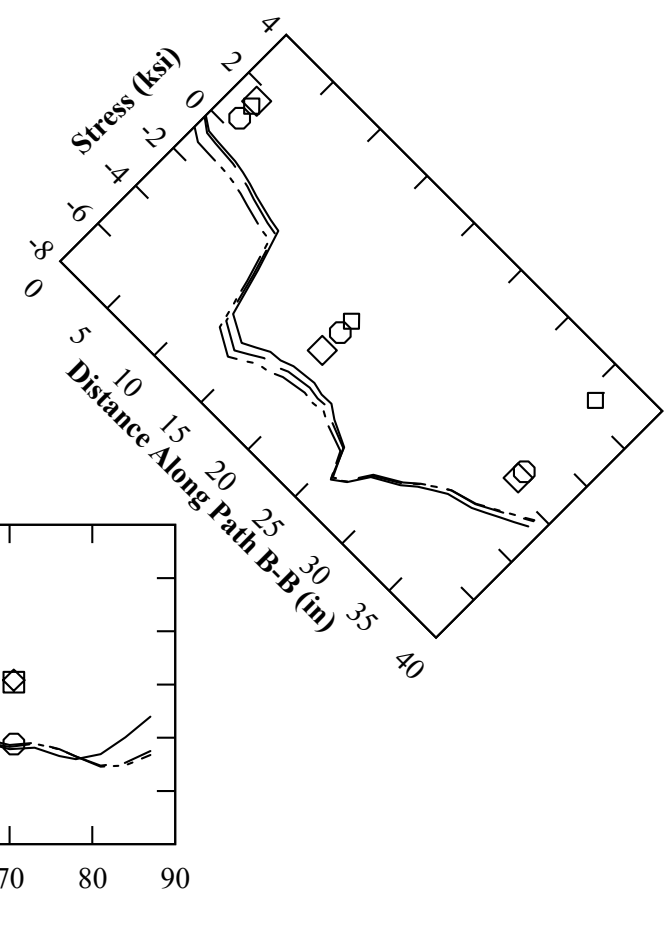

Figure 61: Specimen 1 vs FEA Model, stress in global y direction

$$
\begin{gathered}
\text { Actuator Loads (M4-M3-M5) } \\
-\quad 100-1-1 \text { kips } \\
-\quad-100-1-94 \text { kips } \\
\hdashline-100-24-94 \text { kips } \\
\diamond \diamond 100-1-1 \text { kips } \\
\square \quad \square \quad 100-1-94 \text { kips } \\
\bigcirc \quad \bigcirc \quad 100-24-94 \text { kips }
\end{gathered}
$$

Lines represent FEA Model.

Symbols represent Experimental Data.

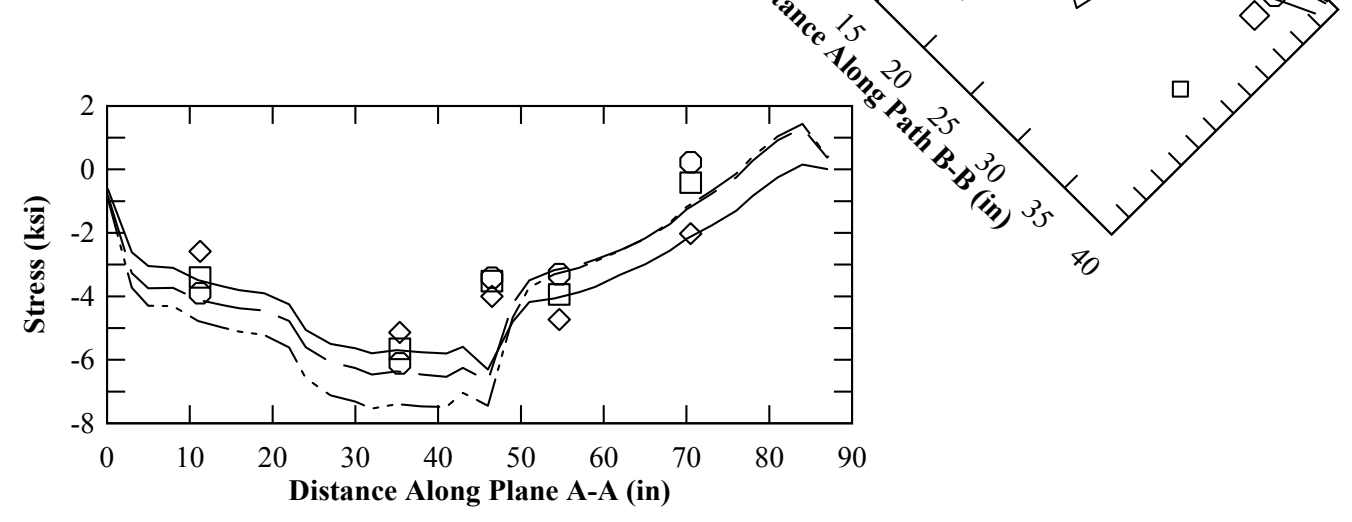

Figure 62: Specimen 1 vs FEA Model, shear stress in global xy direction 


$$
\begin{gathered}
\text { Actuator Loads (M4-M3-M5) } \\
-100-1-1 \text { kips } \\
-\quad-175-1-1 \text { kips } \\
--1250-1-1 \text { kips } \\
\diamond \diamond 100-1-1 \text { kips } \\
\square \quad \square \quad 175-1-1 \text { kips } \\
\bigcirc \quad 0 \quad 250-1-1 \text { kips }
\end{gathered}
$$

Lines represent FEA Model.

Symbols represent Experimental Data.

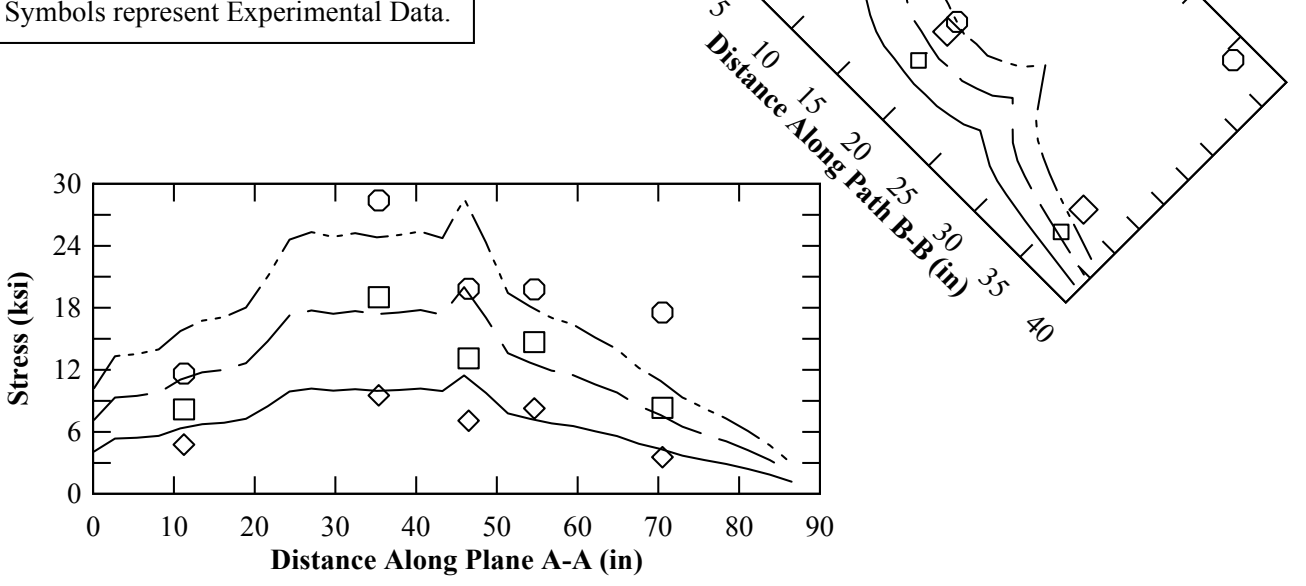

Figure 63: Specimen 1 vs FEA Model, von Mises stress for M4 loaded to different magnitudes

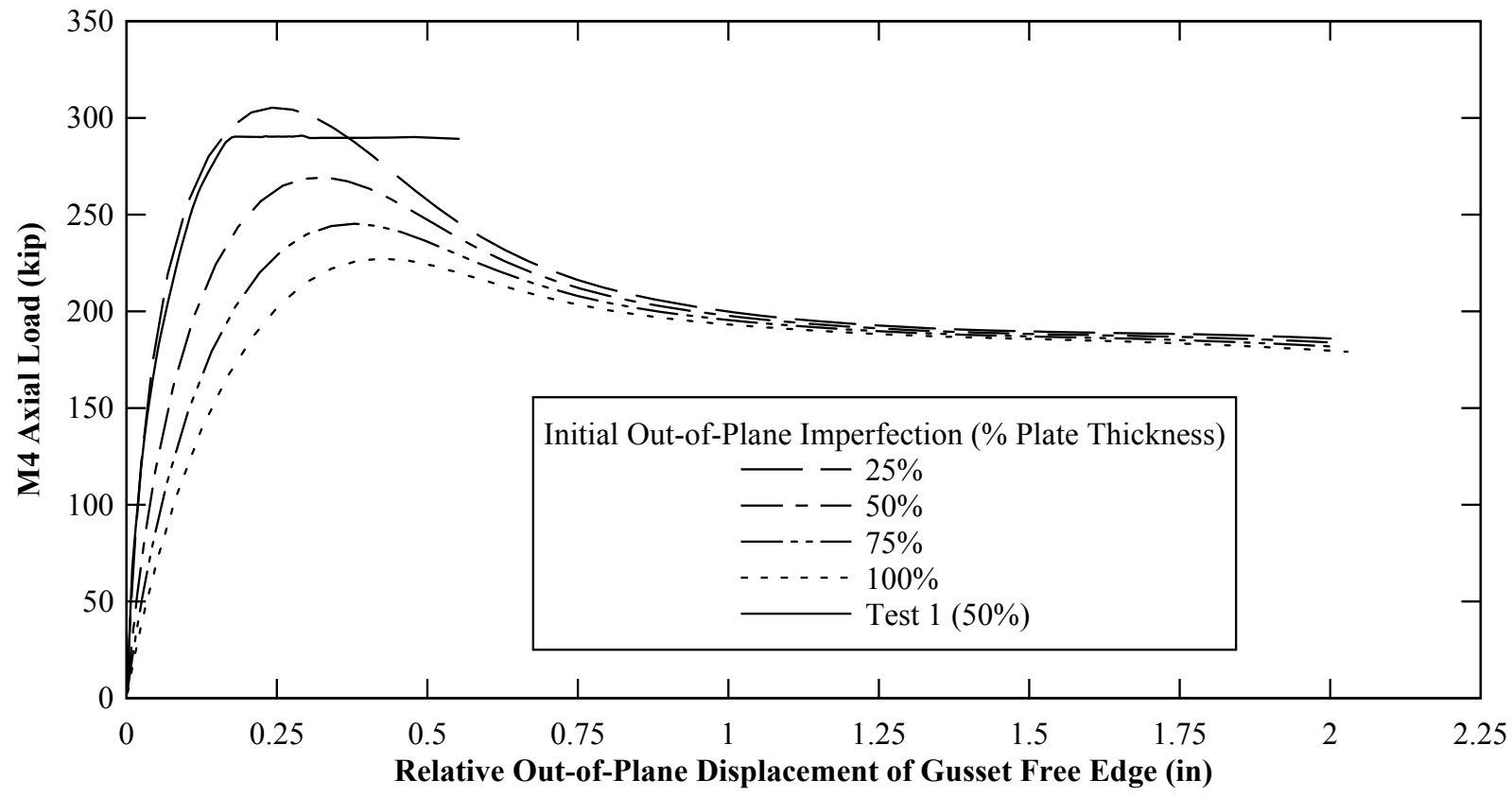

Figure 64: Test 1 Experimental results vs. Analytical results at different levels of initial imperfection 


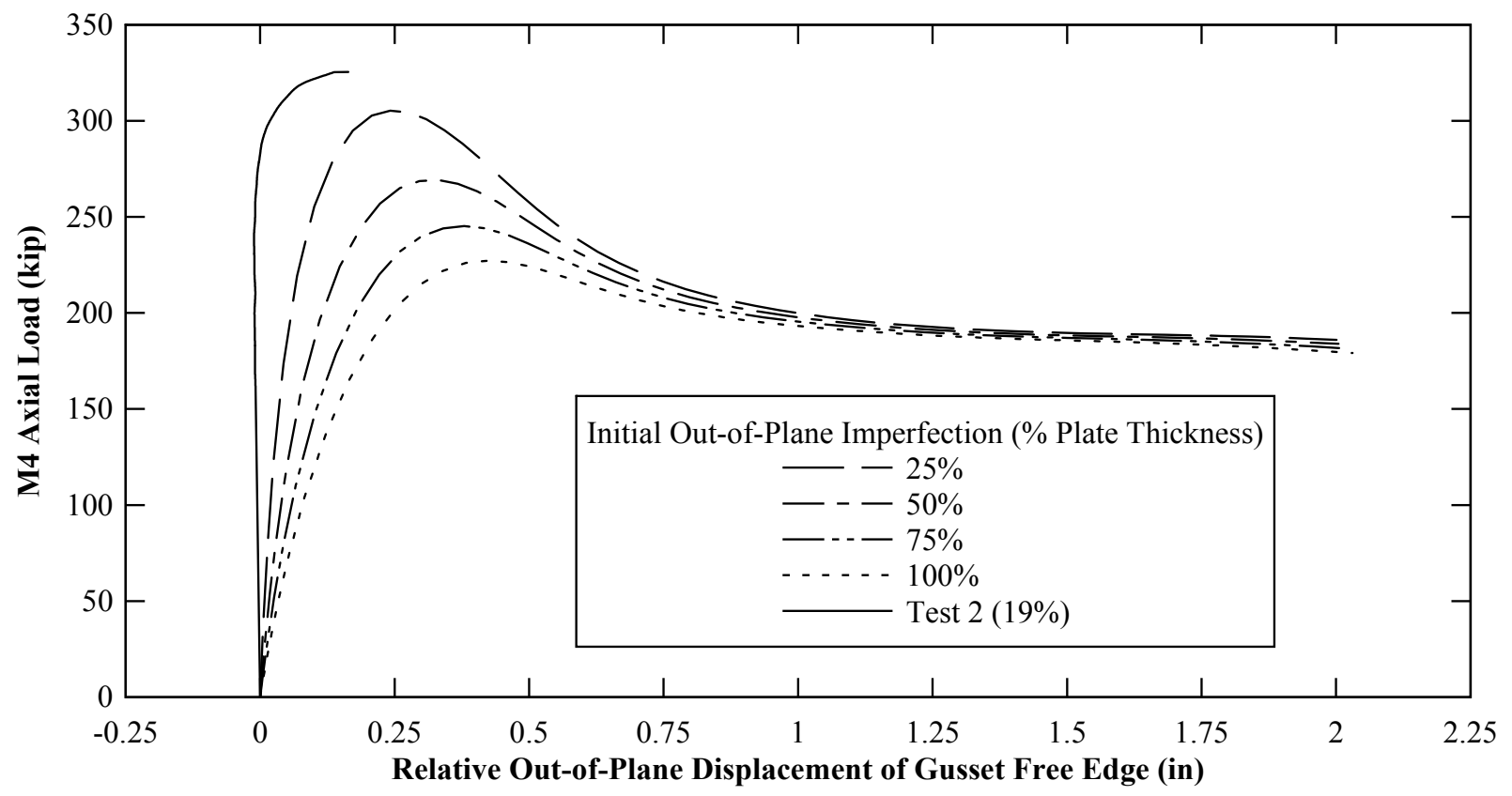

Figure 65: Test 2 Experimental results vs. Analytical results at different levels of initial imperfection

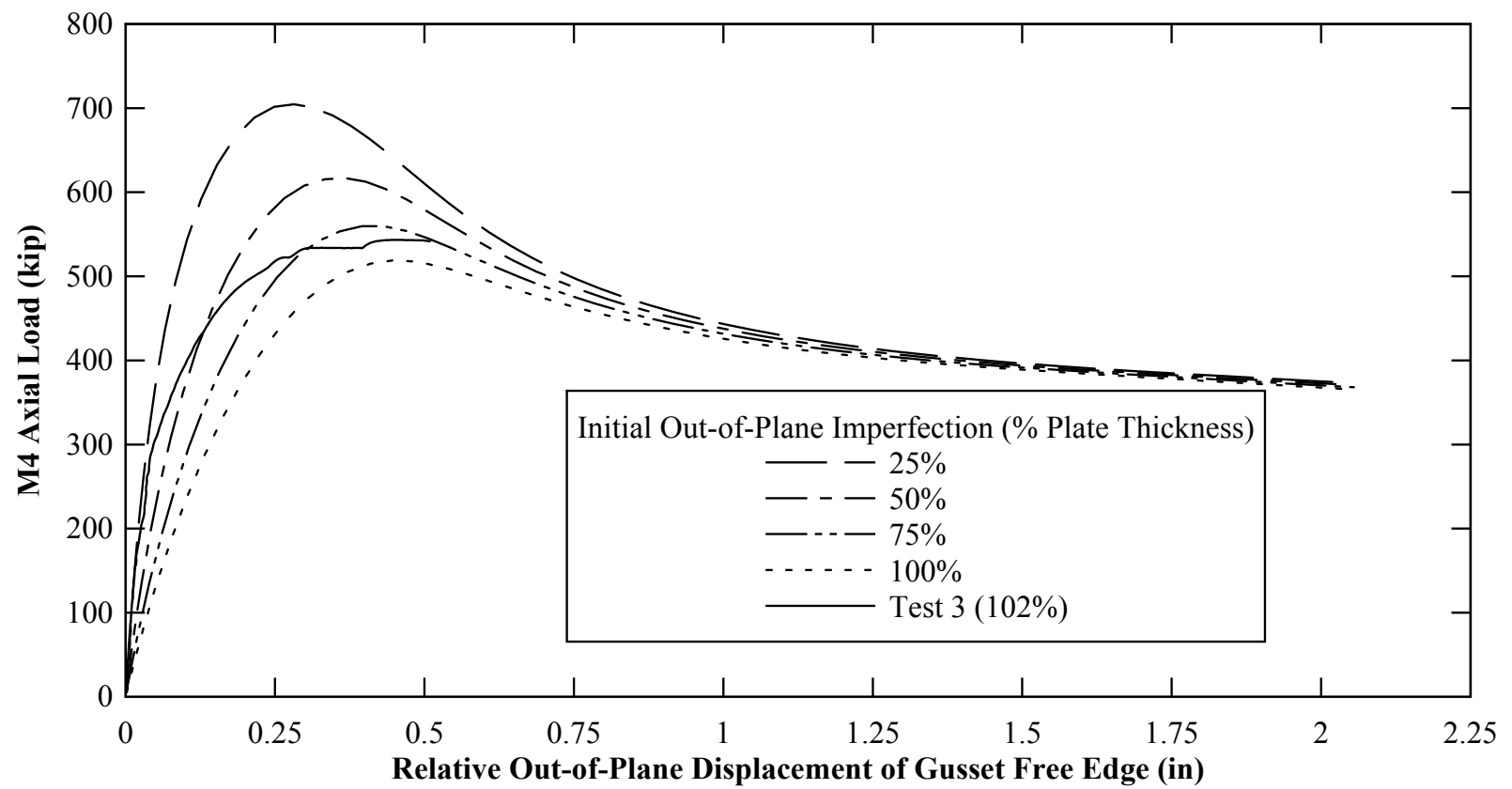

Figure 66: Test 3 Experimental results vs. Analytical results with different initial imperfections 


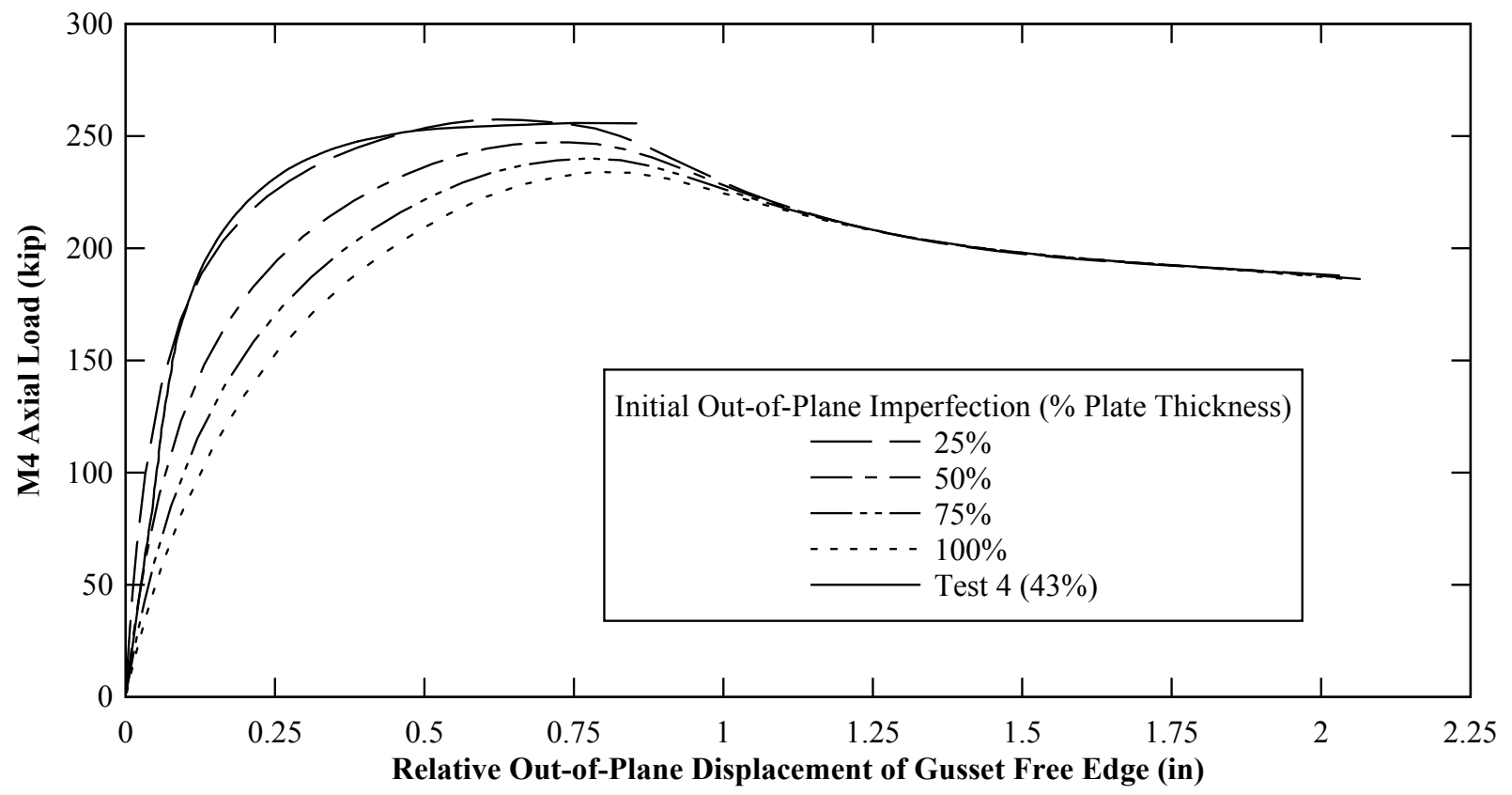

Figure 67: Test 4 Experimental results vs. Analytical results with different initial imperfections

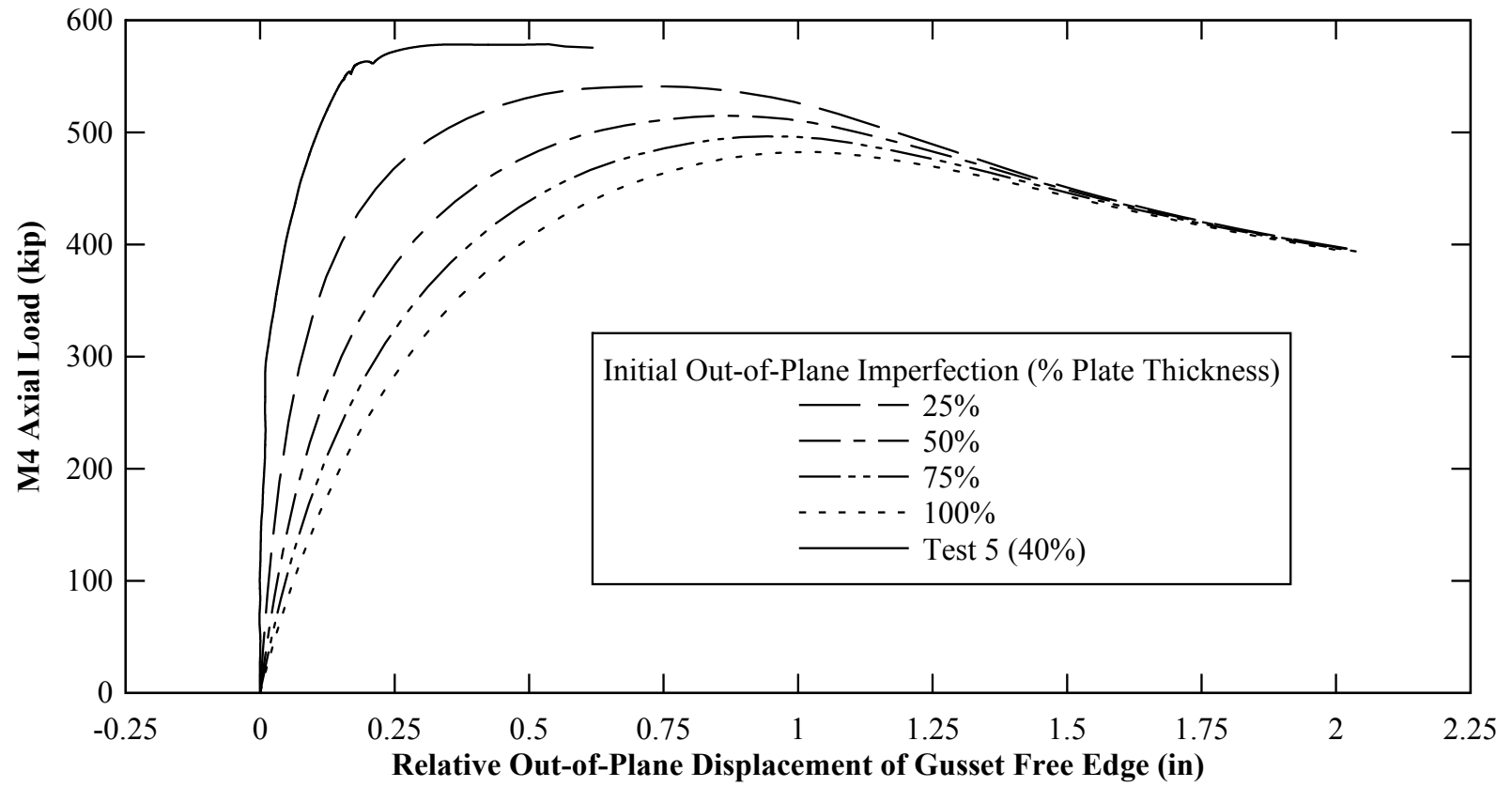

Figure 68: Test 5 Experimental results vs. Analytical results with different initial imperfections 


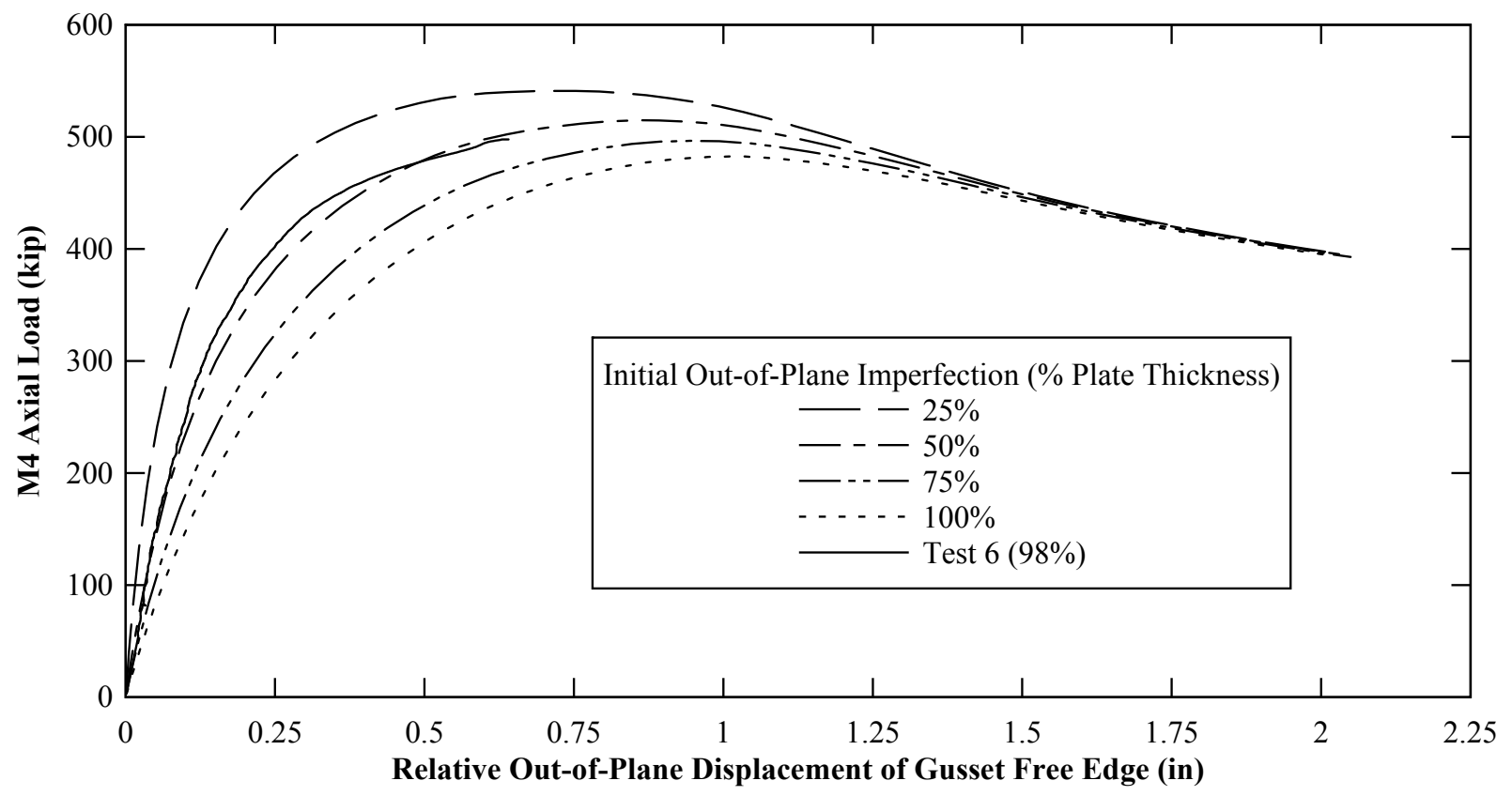

Figure 69: Test 6 Experimental results vs. Analytical results with different initial imperfections 


\subsection{TABLES}

Table 1: Load sets used in Oregon State Gusset Connection Test 1

\begin{tabular}{|c|c|c|c|}
\hline \multirow[b]{2}{*}{ Load Set Label } & \multicolumn{3}{|c|}{$\begin{array}{l}\text { Compressive Load } \\
\text { (kip) }\end{array}$} \\
\hline & M4 & M3 & M5 \\
\hline $1: 1: 1$ & 1 & 1 & 1 \\
\hline $25: 1: 1$ & 25 & 1 & 1 \\
\hline $25: 6: 1$ & 25 & 6 & 1 \\
\hline $25: 1: 23.5$ & 25 & 1 & 23.5 \\
\hline $25: 6: 23.5$ & 25 & 6 & 23.5 \\
\hline $50: 1: 1$ & 50 & 1 & 1 \\
\hline $50: 12: 1$ & 50 & 12 & 1 \\
\hline $50: 1: 47$ & 50 & 1 & 47 \\
\hline $50: 12: 47$ & 50 & 12 & 47 \\
\hline $75: 1: 1$ & 75 & 1 & 1 \\
\hline $75: 18: 1$ & 75 & 18 & 1 \\
\hline $75: 1: 70.5$ & 75 & 1 & 70.5 \\
\hline $75: 18: 70.5$ & 75 & 18 & 70.5 \\
\hline $100: 1: 1$ & 100 & 1 & 1 \\
\hline $100: 24: 1$ & 100 & 24 & 1 \\
\hline $100: 1: 94$ & 100 & 1 & 94 \\
\hline $100: 24: 94$ & 100 & 24 & 94 \\
\hline $125: 1: 1$ & 125 & 1 & 1 \\
\hline $125: 30: 1$ & 125 & 30 & 1 \\
\hline $125: 1: 117.5$ & 125 & 1 & 117.5 \\
\hline $125: 30: 117.5$ & 125 & 30 & 117.5 \\
\hline$:$ & $:$ & $:$ & $:$ \\
\hline$:$ & $:$ & $:$ & : \\
\hline : & $\begin{array}{c}: \\
\text { Pattern } \\
\text { followed } \\
\text { until } \\
\text { failure }\end{array}$ & : & : \\
\hline
\end{tabular}


Table 2: Load sets used in Oregon State Gusset Connection Test 3

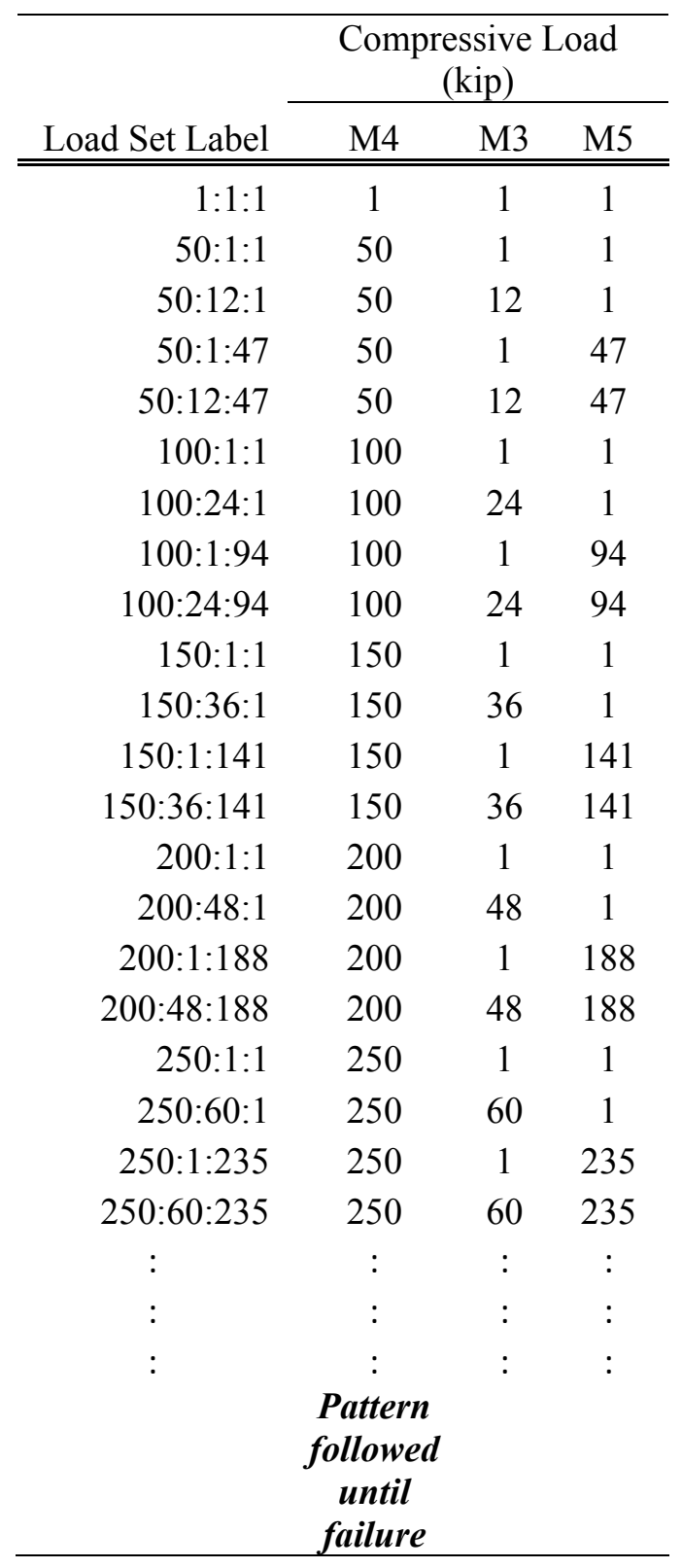


Table 3: Summary of coupon test results per ASTM A370

\begin{tabular}{|c|c|c|c|c|}
\hline Plate \# & $\begin{array}{c}\text { Average } \\
\mathrm{F}_{\mathrm{y}} \\
(\mathrm{ksi}) \\
\end{array}$ & $\begin{array}{c}\text { Standard } \\
\text { Deviation } \\
\end{array}$ & $\begin{array}{c}\text { Average } \\
\mathrm{F}_{\mathrm{u}} \\
(\mathrm{ksi}) \\
\end{array}$ & $\begin{array}{l}\text { Standard } \\
\text { Deviation }\end{array}$ \\
\hline 1 & 47.02 & 1.73 & 72.74 & 0.90 \\
\hline 2 & 45.12 & 1.95 & 68.59 & 0.46 \\
\hline 3 & 45.93 & 0.34 & 67.76 & 0.31 \\
\hline 4 & 45.10 & 1.55 & 69.96 & 0.31 \\
\hline 5 & 46.13 & 0.66 & 67.83 & 0.34 \\
\hline 6 & 46.27 & 0.19 & 67.90 & 0.16 \\
\hline
\end{tabular}

Table 4: Comparison of existing bridge member stiffness

\begin{tabular}{|c|c|c|c|c|c|c|}
\hline Bridge Name & $\begin{array}{l}\text { Member } \\
\text { Number }\end{array}$ & $\begin{array}{c}\text { Member } \\
\text { Shape }\end{array}$ & $\begin{array}{c}\text { Moment of } \\
\text { Inertia, I } \\
\left(\text { in }^{4}\right) \\
\end{array}$ & $\begin{array}{l}\text { Length, } \mathrm{L} \\
(\mathrm{ft})\end{array}$ & $\begin{array}{c}\text { Translational } \\
\text { Stiffness, } k_{\mathrm{t}} \\
\text { (kip/in) }\end{array}$ & $\begin{array}{c}\text { Rotational } \\
\text { Stiffness, } \mathrm{k}_{\mathrm{r}} \\
\text { (kip-in) } \\
\end{array}$ \\
\hline \multirow{2}{*}{ OSU experiment } & M4 (Stiff) & Box & 851 & 9.2 & 18.38 & 224,000 \\
\hline & M4 (Soft) & I-shape & 60.6 & 9.2 & 1.31 & 16,000 \\
\hline \multirow{2}{*}{$\begin{array}{l}\text { I-94 over Little } \\
\text { Calumet, IL }\end{array}$} & L2-U3 & Box & 8367 & 69.5 & 0.42 & 291,000 \\
\hline & L0-U1 & Box & 9737 & 69.5 & 0.49 & 339,000 \\
\hline \multirow{2}{*}{$\begin{array}{c}\text { I-275 over Ohio R., } \\
\text { KT }\end{array}$} & L2-U3 & Box & 8700 & 78.2 & 0.30 & 269,000 \\
\hline & M15-L16 & Box & 12779 & 55.0 & 1.29 & 562,000 \\
\hline \multirow{2}{*}{$\begin{array}{c}\text { Clarion R. Bridge, } \\
\text { PA }\end{array}$} & U6-L5 & Box & 9079 & 61.3 & 0.66 & 358,000 \\
\hline & U12-L13 & Box & 11341 & 58.0 & 0.98 & 472,000 \\
\hline $\begin{array}{l}\text { St. Highway 57, } \\
\text { Watooga R., TN }\end{array}$ & U11-L12 & Box & 3413 & 61.6 & 0.25 & 224,000 \\
\hline \multirow{2}{*}{$\begin{array}{c}\text { Booth Ranch Bridge, } \\
\quad \# 7841 \mathrm{~A}, \mathrm{OR}\end{array}$} & U1-L0 & Box & 1386 & 38.2 & 0.42 & 88,000 \\
\hline & U3-L2 & I-shape & 1116 & 38.2 & 0.34 & 71,000 \\
\hline \multirow{2}{*}{$\begin{array}{l}\text { Caney Fork River, } \\
\text { HWY \#56, TN }\end{array}$} & L1-U2 & I-shape & 1697 & 42.7 & 0.37 & 96,000 \\
\hline & L15-U16 & I-shape & 4850 & 54.3 & 0.51 & 216,000 \\
\hline
\end{tabular}


Table 5: Experimental test matrix with results

\begin{tabular}{lcccccc}
\hline & Test 1 & Test 2 & Test 3 & Test 4 & Test 5 & Test 6 \\
\hline Plate Thickness (in) & 0.25 & 0.25 & 0.375 & 0.25 & 0.375 & 0.375 \\
Loading Protocol ${ }^{\mathrm{a}}$ & 1 & 2 & 1 & 2 & 2 & 2 \\
M4 Brace Section & Stiff & Stiff & Stiff & Soft & Soft & Soft \\
Initial Imperfection & $50 \%$ & $19 \%$ & $102 \%$ b & $43 \%$ & $40 \%$ & $98 \%{ }^{\mathrm{b}}$ \\
[\% thickness (in)] & $(0.12)$ & $(0.05)$ & $(0.38)$ & $(0.11)$ & $(0.15)$ & $(0.37)$ \\
Gusset Free Edge & & & & & & \\
Out-of-Plane & 0.57 & 0.16 & 0.50 & 0.85 & 0.60 & 0.64 \\
Displacement at & & & & & & \\
Failure (in) & & & & & & \\
M4 Axial Load at & 291 & 325 & 545 & 256 & 579 & 498 \\
Failure $(\mathrm{kip})$ & & & & & & \\
$\sigma_{\mathrm{w}}$ at Failure $(\mathrm{ksi})$ & 16.73 & 18.69 & 20.89 & 14.72 & 22.20 & 19.09 \\
$\sigma_{4, \text { avg }} / \sigma_{\mathrm{w}}$ at $0.6 * \mathrm{~F}_{\max }$ & 0.75 & 0.59 & 0.99 & 0.69 & 0.57 & 0.33 \\
$\sigma_{4, \text { avg }} / \sigma_{\mathrm{T}}$ at $0.6 * \mathrm{~F}_{\max }$ & 0.55 & 0.60 & 1.19 & 0.41 & 0.59 & 0.17 \\
$\sigma_{4, \max } / \sigma_{\mathrm{w}}$ at $0.6 * \mathrm{~F}_{\max }$ & 0.99 & 0.94 & 1.04 & 1.79 & 0.85 & 0.91 \\
$\sigma_{4, \max } / \sigma_{\mathrm{T}}$ at $0.6 * \mathrm{~F}_{\max }$ & 1.21 & 1.15 & 1.27 & 2.20 & 1.05 & 1.12 \\
$\sigma_{\mathrm{p}} / \sigma_{\mathrm{w}}$ at $0.6 * \mathrm{~F}_{\max }$ & 1.15 & 1.03 & 1.81 & 1.89 & 0.98 & 1.66 \\
\hline
\end{tabular}

a) 1 = Combination Loading (M4+M3+M5), 2 = Monotonic Loading (M4 only)

b) Artificially applied initial imperfection

c) $\sigma_{\mathrm{w}}=$ average stress in Whitmore section, $\sigma_{\mathrm{T}}=$ average stress in Modified-Thornton section, $\sigma_{4}=$ stress in direction of M4 axial force, $\sigma_{\mathrm{p}}=$ principle compressive stress at midpoint of Whitmore section 
Table 6: Comparison of Experiment to FHWA Guide

\begin{tabular}{|c|c|c|c|c|c|c|}
\hline & Test 1 & Test 2 & Test 3 & Test 4 & Test 5 & Test 6 \\
\hline $\mathrm{t}$ (in) & 0.25 & 0.25 & 0.375 & 0.25 & 0.375 & 0.375 \\
\hline L (in) & 15.53 & 15.53 & 15.53 & 15.53 & 15.53 & 15.53 \\
\hline $\mathrm{w}$ (in) & 34.78 & 34.78 & 34.78 & 34.78 & 34.78 & 34.78 \\
\hline$r_{s}$ (in) & 0.072 & 0.072 & 0.108 & 0.072 & 0.108 & 0.108 \\
\hline Actual $\mathrm{F}_{\mathrm{y}}(\mathrm{ksi})$ & 47.02 & 45.12 & 45.93 & 45.10 & 46.13 & 46.27 \\
\hline $\mathrm{E}(\mathrm{ksi})$ & 29,000 & 29,000 & 29,000 & 29,000 & 29,000 & 29,000 \\
\hline $\mathrm{K}_{\mathrm{FHWA}}$ & 1.2 & 1.2 & 1.2 & 1.2 & 1.2 & 1.2 \\
\hline$\lambda_{\text {FHWA }}$ & 10.96 & 10.52 & 4.76 & 10.51 & 4.78 & 4.79 \\
\hline $\mathrm{P}_{\mathrm{FHWA}}$ (kip) & 66 & 66 & 222 & 66 & 222 & 222 \\
\hline $\mathrm{P}_{\text {experiment }}$ (kip) & 291 & 325 & 545 & 256 & 579 & 498 \\
\hline$\lambda_{\text {experiment }}$ & 2.47 & 2.12 & 1.90 & 2.70 & 1.76 & 2.13 \\
\hline$K_{\text {experiment }}$ & 0.57 & 0.54 & 0.76 & 0.61 & 0.73 & 0.80 \\
\hline $\mathrm{P}_{\mathrm{exp}} / \mathrm{P}_{\mathrm{FH}}$ & 4.43 & 4.95 & 2.46 & 3.90 & 2.61 & 2.25 \\
\hline$\%$ Differ & $343 \%$ & $395 \%$ & $146 \%$ & $290 \%$ & $161 \%$ & $125 \%$ \\
\hline
\end{tabular}

Table 7: Loads used for elastic analysis of gusset connection FEA model

\begin{tabular}{rccc}
\hline & \multicolumn{3}{c}{ Compressive Load (kip) } \\
\cline { 2 - 4 } Load Set Label & M4 & M3 & M5 \\
\hline \hline $100: 1: 1$ & 100 & 1 & 1 \\
$100: 1: 94$ & 100 & 1 & 94 \\
$100: 24: 94$ & 100 & 24 & 94 \\
$175: 1: 1$ & 175 & 1 & 1 \\
$175: 1: 164.5$ & 175 & 1 & 164.5 \\
$175: 42: 164.5$ & 175 & 42 & 164.5 \\
$250: 1: 1$ & 250 & 1 & 1 \\
$250: 1: 235$ & 250 & 1 & 235 \\
$250: 60: 235$ & 250 & 60 & 235 \\
\hline
\end{tabular}


Table 8: Summary of experimental buckling loads and analytical predictions

\begin{tabular}{|c|c|c|c|c|c|c|}
\hline & \multirow{2}{*}{$\begin{array}{r}t_{\text {gusset }} \\
\text { (in) } \\
\end{array}$} & \multirow[b]{2}{*}{ M4 Section } & \multicolumn{2}{|c|}{ M4 Axial Buckling Load } & \multirow[b]{2}{*}{$\mathrm{A} / \mathrm{E}$} & \multirow[b]{2}{*}{$\mathrm{k}$} \\
\hline & & & Experimental (kip) & FEA (kip) & & \\
\hline Test 1 & $1 / 4$ & Standard & 291 & 304.9 & 1.05 & 0.57 \\
\hline Test 2 & $1 / 4$ & Standard & 325 & 304.9 & 0.94 & 0.54 \\
\hline Test 3 & $3 / 8^{a}$ & Standard & 545 & 552.5 & 1.01 & 0.76 \\
\hline Test 4 & $1 / 4$ & Reduced & 256 & 241.4 & 0.94 & 0.61 \\
\hline Test 5 & $3 / 8$ & Reduced & 579 & 522.1 & 0.90 & 0.73 \\
\hline Test 6 & $3 / 8^{\mathrm{a}}$ & Reduced & 498 & 482.6 & 0.96 & 0.80 \\
\hline
\end{tabular}

a) $100 \%$ plate thickness initial imperfection artificially applied prior to loading 


\subsection{BIBLIOGRAPHY}

AISC. Engineering for steel construction. Chicago, 1984.

Bjorhovde, R, and SK Chakrabarti. "Test of Full-Scale Gusset Plate Connections." Journal of Structrual Engineering (ASCE) 111, no. 3 (March 1985): 667-684.

Davis, C. Computer analysis of the stresses in a gusset plate. Masters Thesis, University of Washington, Seattle, 1967.

FHWA. "Load Rating Guidance and Examples for Bolted and Riveted Gusset Plates In Truss Bridges." FHWA-IF-09-014, U.S. Department of Transportation, 2009.

Gross, J. "Experimental study of gusseted connections." AISC Engineering Journal, 1990: 89-97.

Hardin, B. Experimental investigation of the primary stress distribution in the gusset plates of a double plate Pratt truss joint with chord splice at the joint. Engineering Experiment Station Bulliten No. 49, University of Kentucky, Lexington, 1958.

Holt, R, and J Hartmann. Adequacy of the U10 \& U11 gusset plate designs for the Minnesota Bridge No. 9340 (I-35W over the Mississippi River). Federal Highway Administration, 2008.

$\mathrm{Hu}, \mathrm{S}$, and J Cheng. Compressive behaviour of gusset plate connection. Structural Engineering Report No 244, Department of Civil and Environmental Engineering, University of Alberta, Edmonton, 1987.

Irvan, W. Expermental study of primary stresses in gusset plates of a double plate Pratt truss. Engineering Experiment Station Bulliten No. 46, University of Kentucky, Lexington, 1957.

JSCE. Tentative design guildelines of gussetetd truss joints. Japan Society of Civil Engineers, Tokyo, Japan: Sponsored by Honshu-Shikoku Bridge Authority, 1976.

Kay, T. Numerical modeling and analyses of steel bridge gusset plate connections. Masters Thesis, Department of Civil and Environmental Engineering, Portland State University, 2011.

Liao, M, T Okazaki, R Ballarini, A Schultz, and T Galambos. "Nonlinear finite-element analysis of critical gusset plates in the I-35W Bridge in Minnesota." Journal of Structural Engineering 137, no. 1 (2011): 59-68.

NTSB. Corroded gusset plates of Ohio bridges. November 2008. http://www.ntsb.gov/dockets/Highway/HWY07MH024/404914.pdf. 
—. National Transportation Safety Board Safety Recommentation . Janurary 2008. http://www.ntsb.gov/Recs/letters/2008/H08_1.pdf.

Rabinovitch, J, and J Cheng. Cyclic behaviour of steel gusset plate connections. Structural Engineering Report No. 191, Department of Civil and Environmental Engineering, University of Alberta, Edmonton, 1993.

Sheng, N'Yam,C, and V Iu. "Analytical investigation and the design of the compressive strength of steel gusset plate connections." Journal fo Construction Steel Research 58 (2002): 1473-1493.

Simulia. Abaqus Users Manual V. 6.9. Providence, RI: Dassault Systems Simulia, 2010.

Thornton, W. "Bracing connections for heavy construction." AISC Engineering Journal, 1984: 139-148.

Vasarhelyi, D. "Tests of gusset plate models." ASCE Journal of the Structural Division 97, no. ST2 (1972): 665-678.

Walbridge, S, G Gronding, and $\mathrm{j}$ Cheng. "Gusset plate connections under monotonic and cyclic loading." Canadian Journal of Civil Engineering 32 (2005): 981-995.

Whitmore, R. Experimental investigation of stresses in gusset plates. Engineering Experiment Station Bulliten No. 13, University of Tennessee, Knoxville, 1952.

Yam, C, and $\mathrm{j}$ Cheng. Experimental investigation of the compressive behaviour of gusset plate connections. Structural Engineering Report 194, Department of Civil and Environmental Engineering, University of Alberta, Edmonton, 1993.

Yamamoto, K, N Akiyama, and T Okumura. "Elastic Analysis of Gusseted Truss Joints." Journal of Structural Engineering 111, no. 2 (1985): 2545-2564.

Yamamoto, K, N Akyama, and T Okumura. "Buckling strengths of gusseted truss joints." Journal of Structural Engineering 114, no. 3 (1988): 575-590. 


\subsection{APPENDIX A - CONVERGENCE PLOTS}
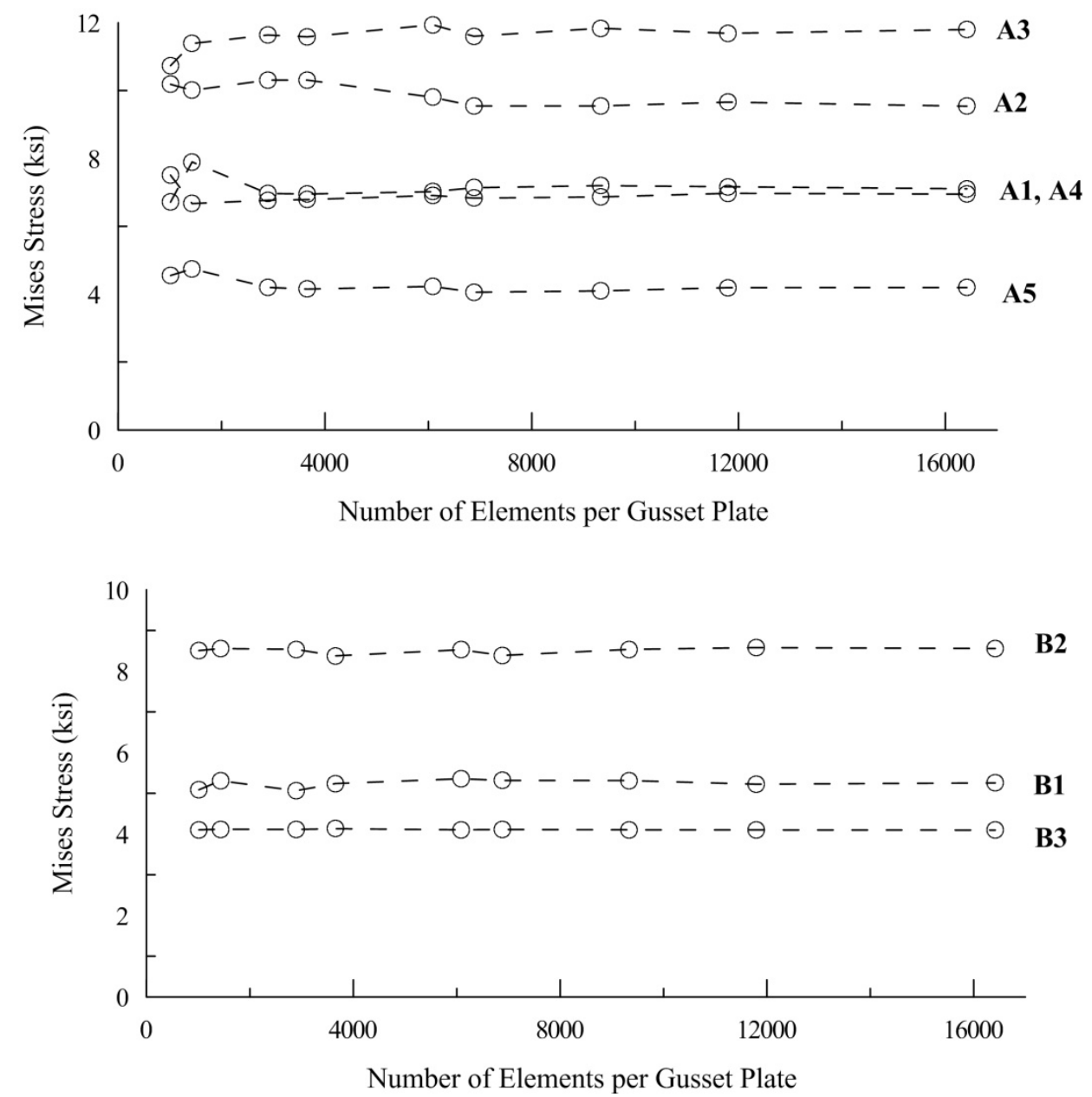

Mises stress convergence plots - Planes A and B 

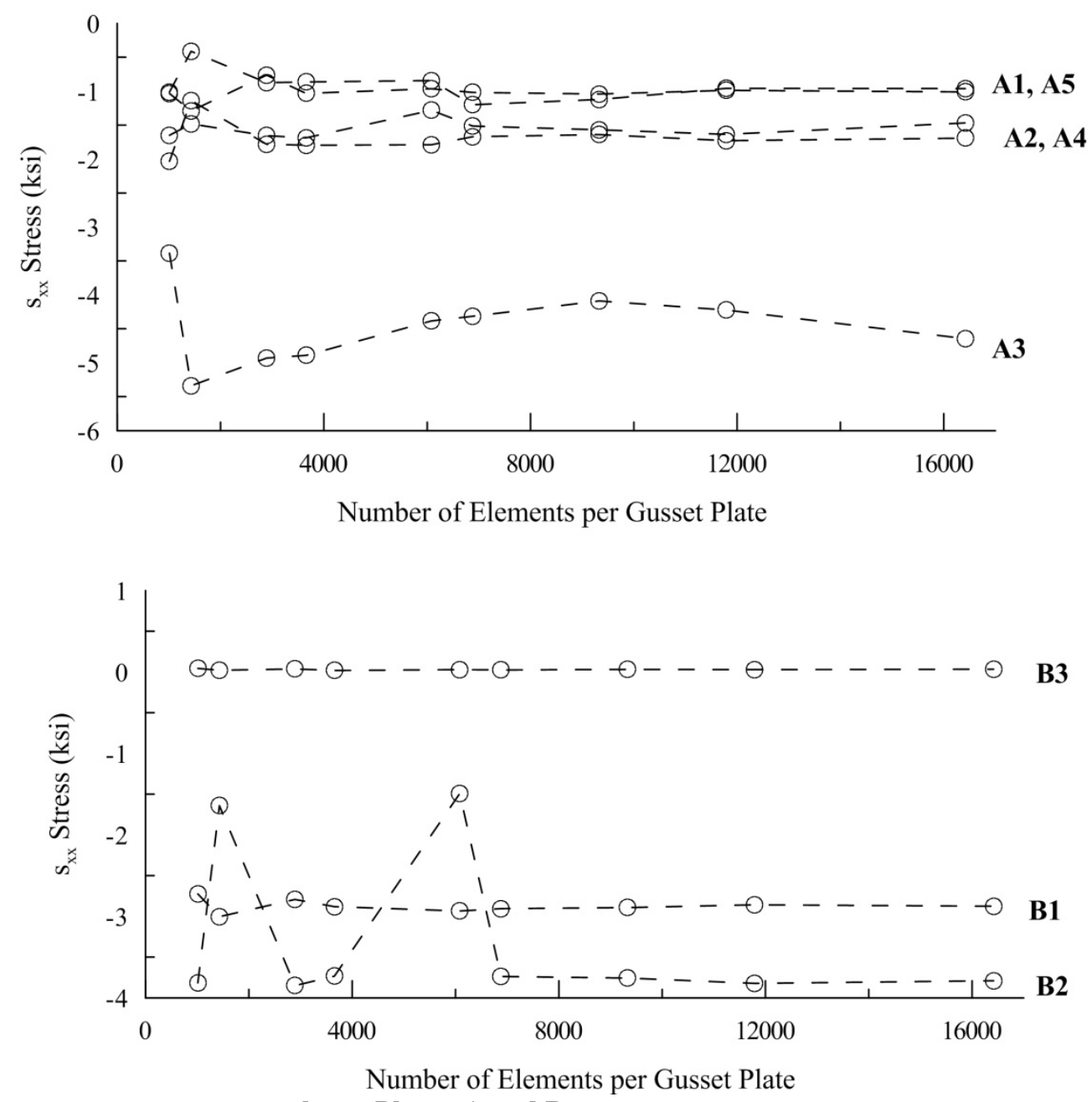
$\mathbf{S}_{\mathrm{XX}}$ stress convergence plots - Planes A and B 

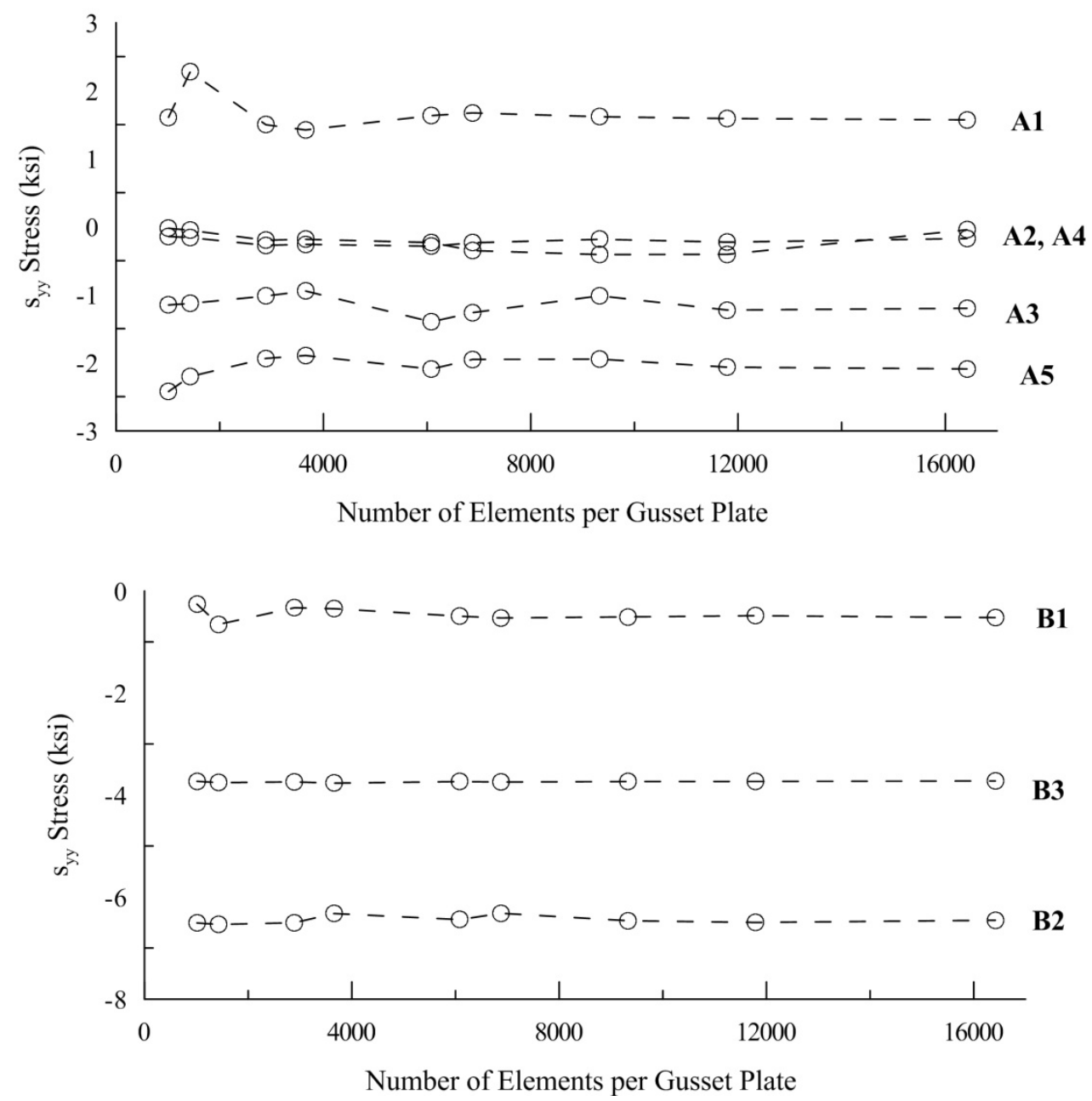
$\mathrm{s}_{\mathrm{yy}}$ stress convergence plots - Planes A and B 

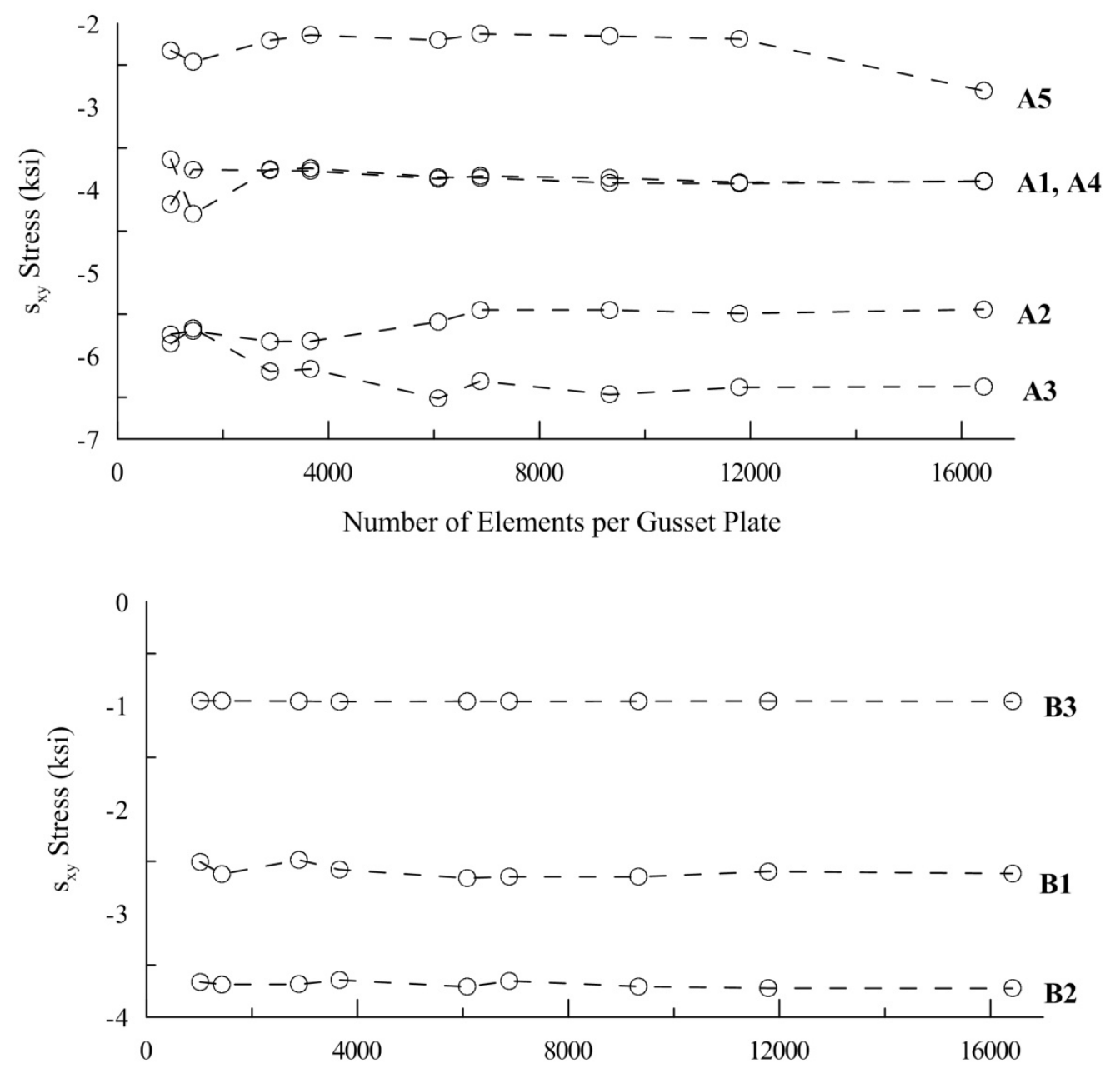

Number of Elements per Gusset Plate $\mathbf{s}_{\mathrm{xy}}$ stress convergence plots - Planes A and B 

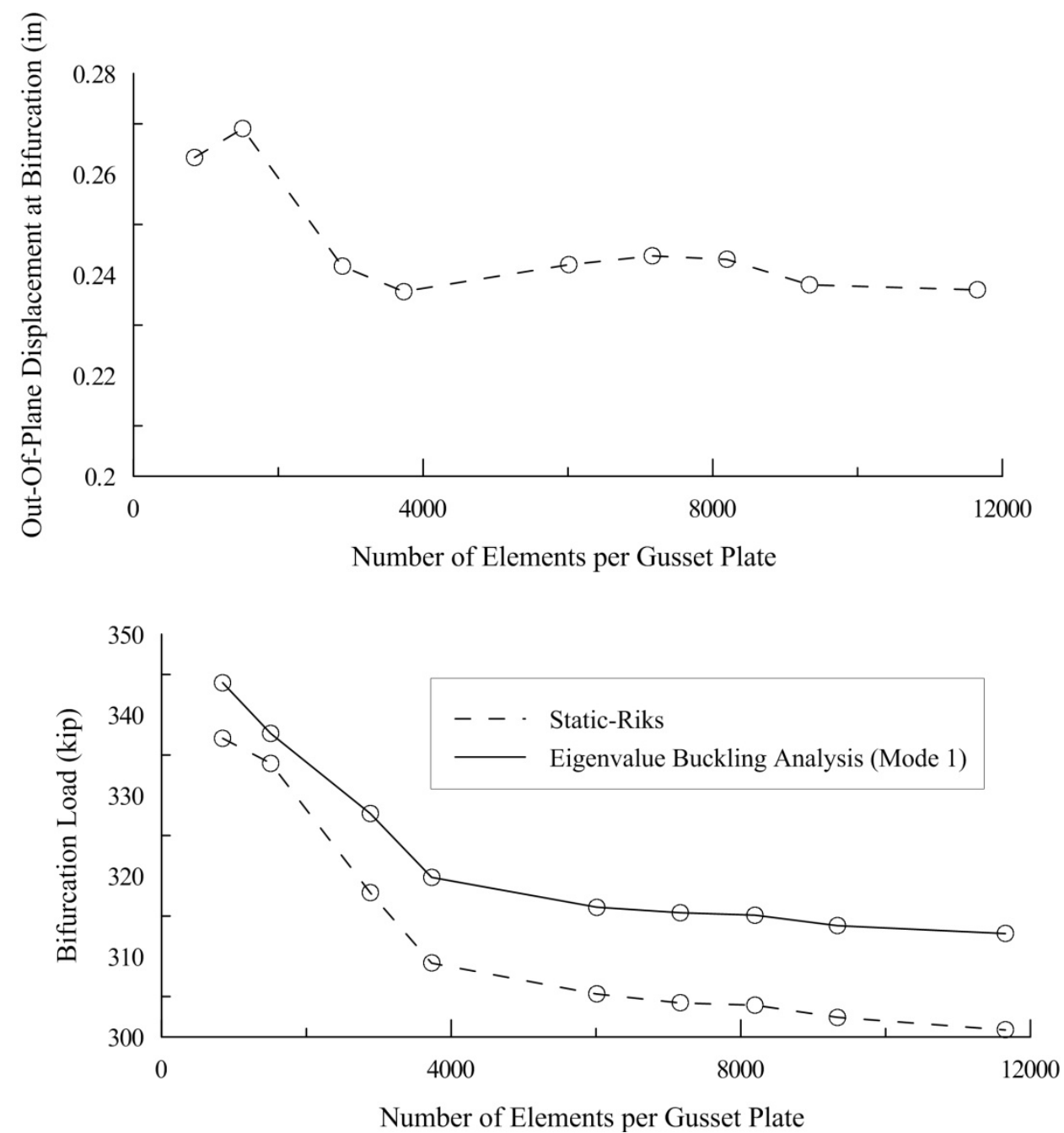

Out-of-plane displacement and bifurcation load convergence plots

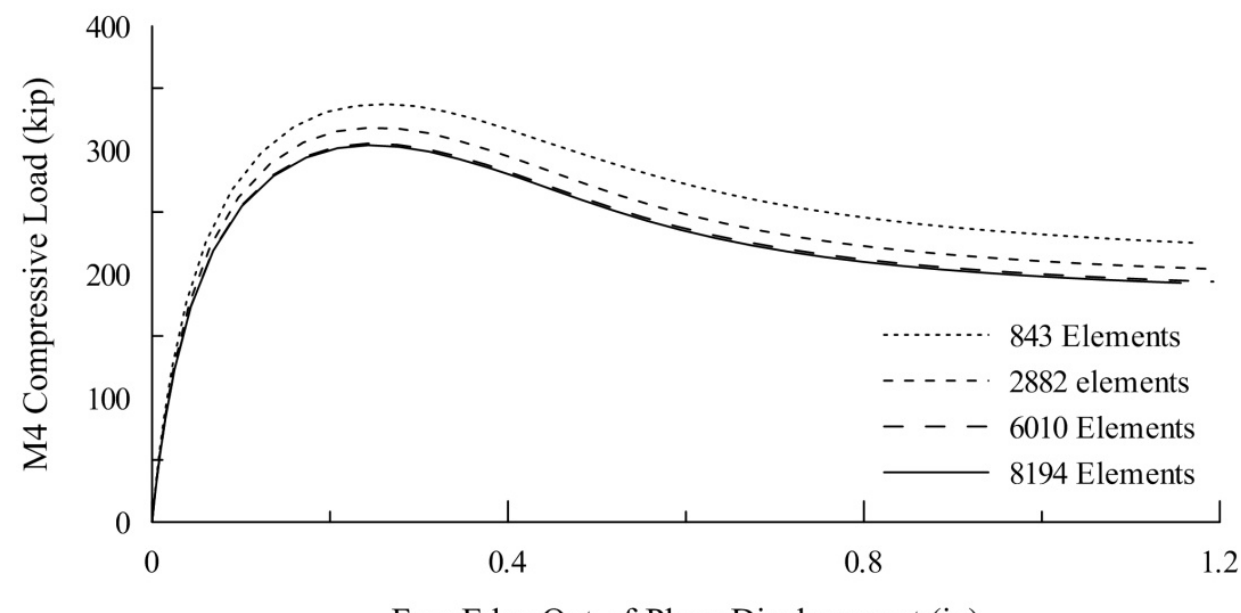

Free Edge Out-of-Plane Displacement (in)

Load-displacement convergence plot 


\subsection{APPENDIX B - ADDITIONAL EXPERIMENT DATA}

\subsection{CALIBRATION OF STRAIN GAGES ON M4}
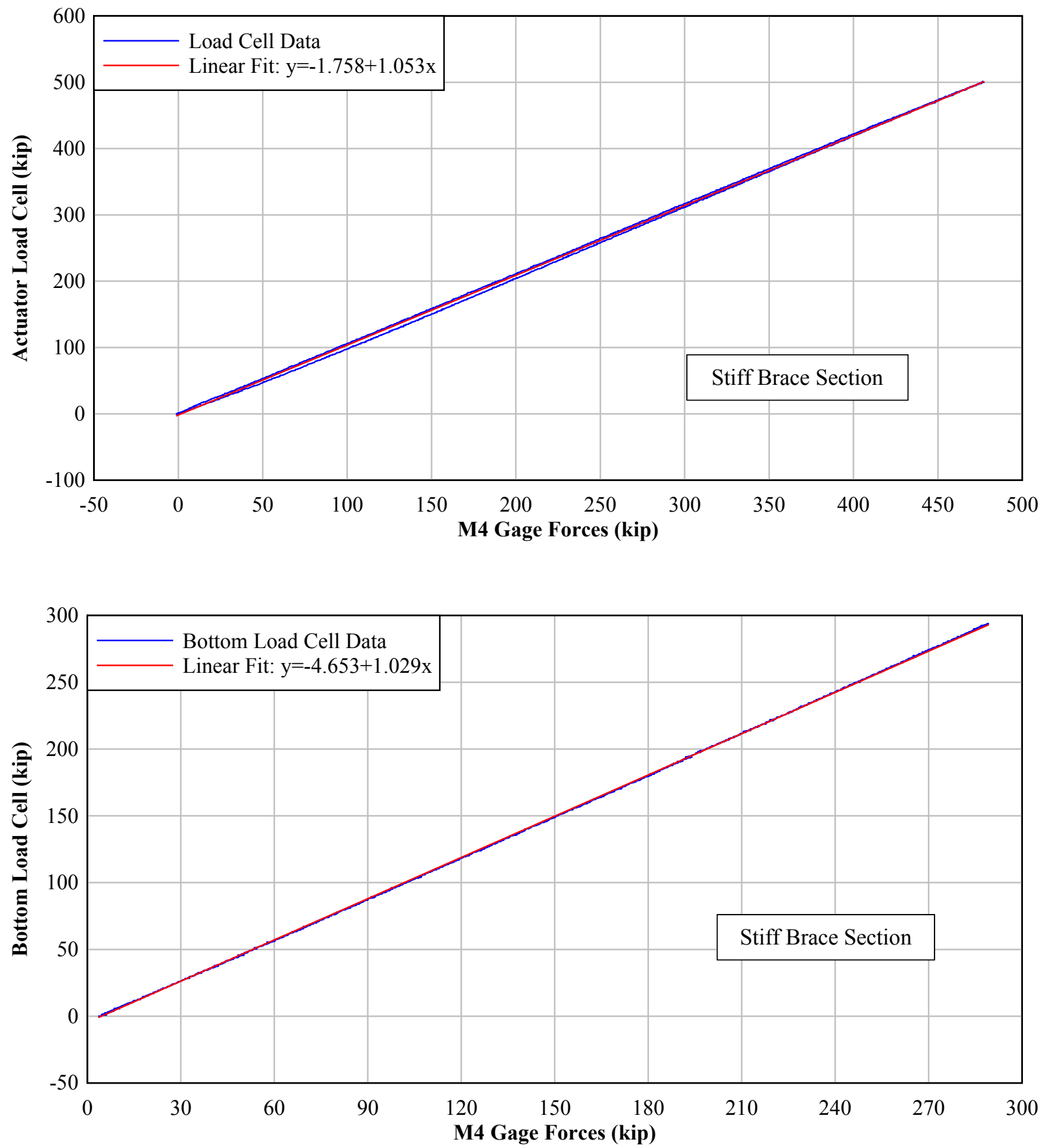


\subsection{TEST 1 DATA}

\subsubsection{Relative Member-to-Gusset Displacement (bolt slip \& work point)}
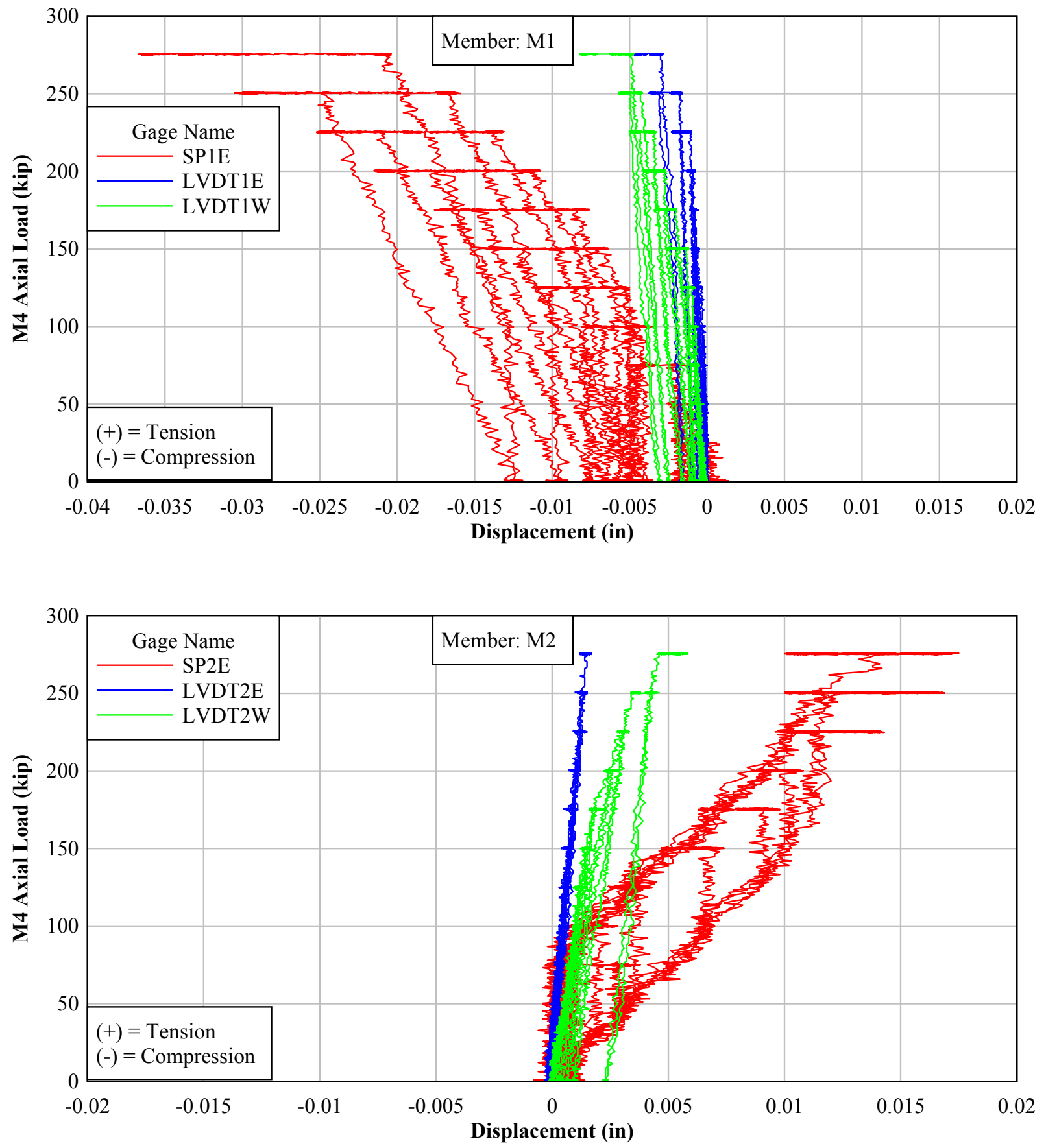

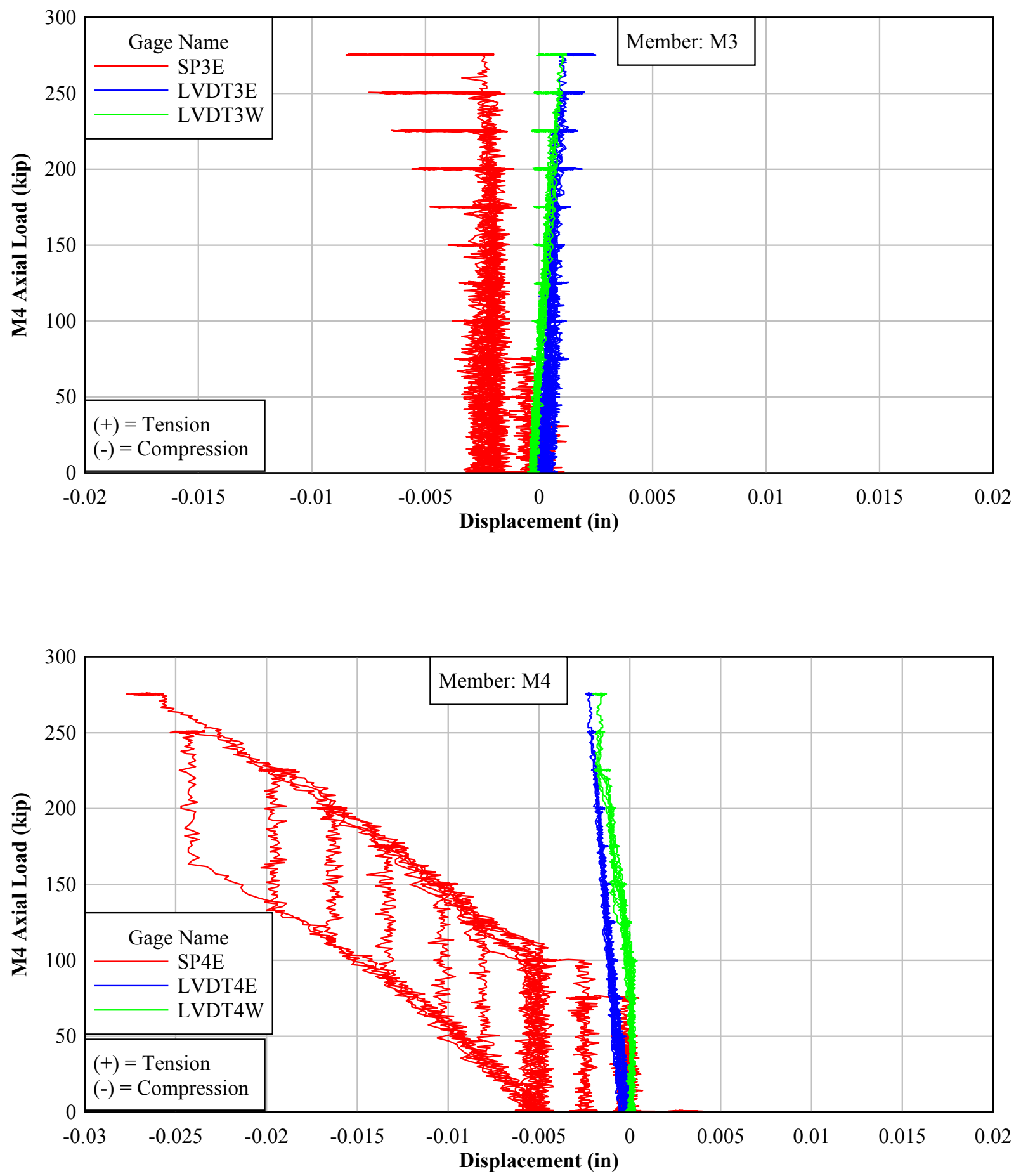


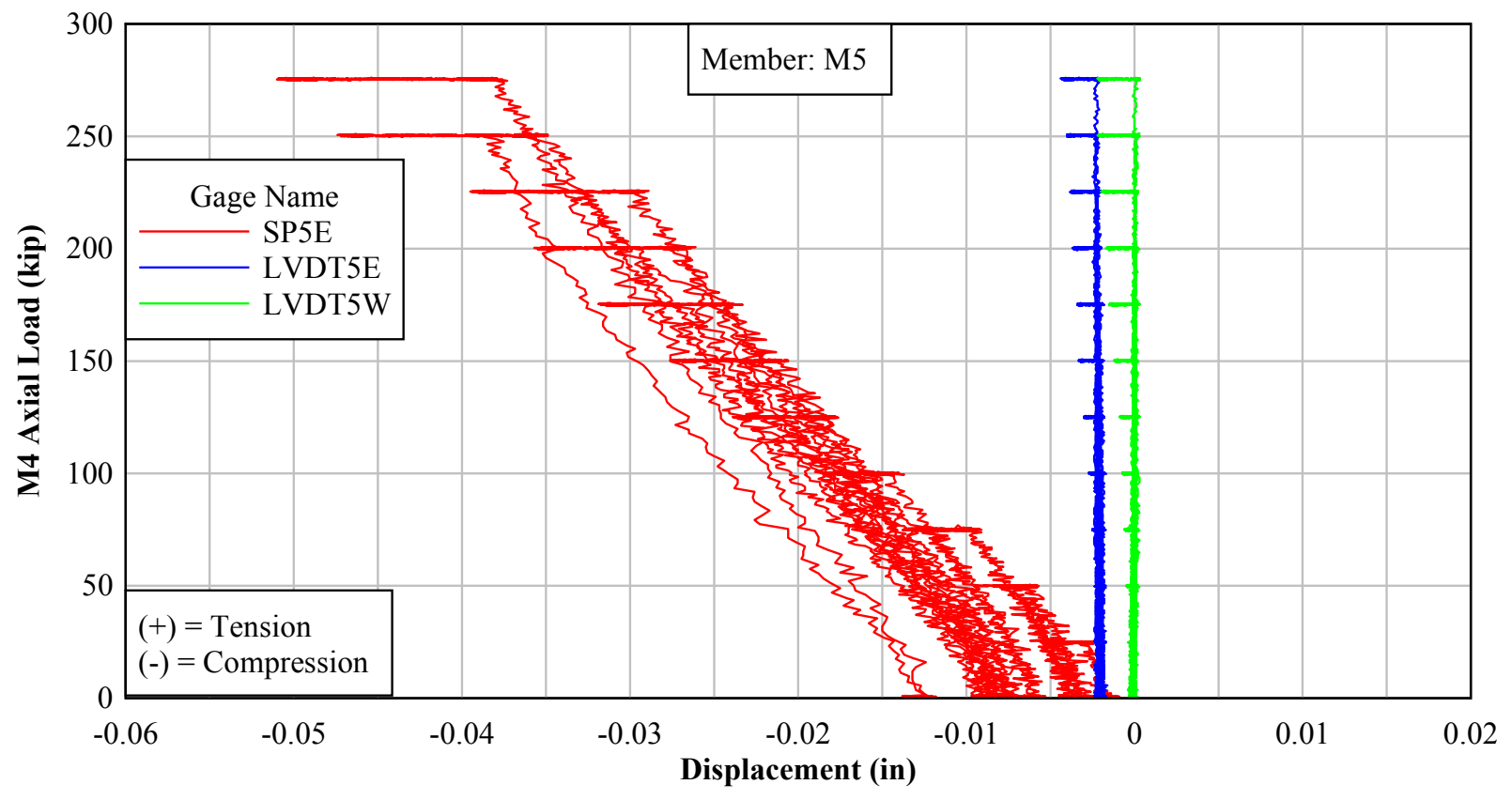

\subsubsection{Gusset Free Edge Strain Versus Load and Displacement}

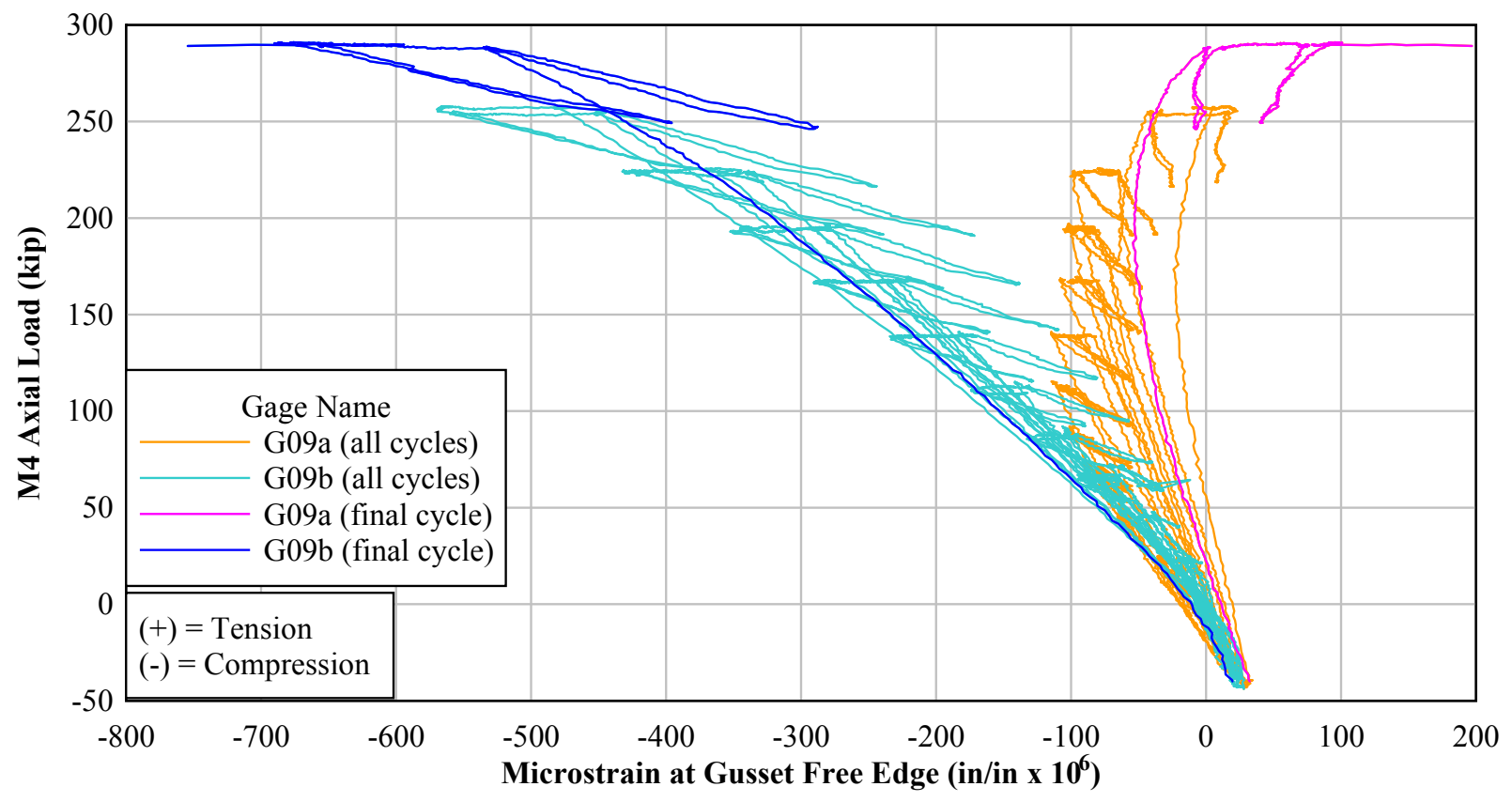




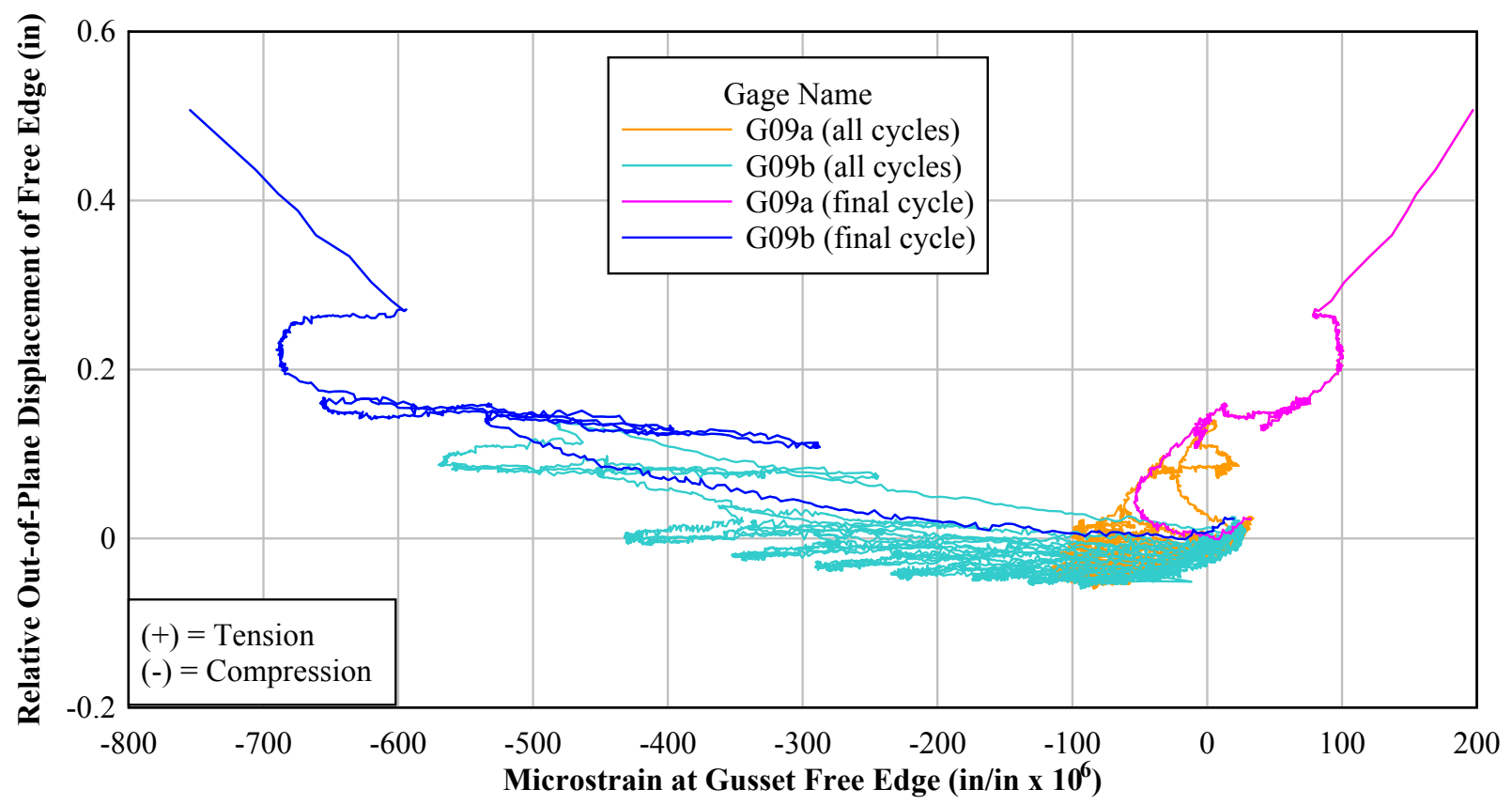

\subsubsection{Strain in M4 Connection Versus Load}

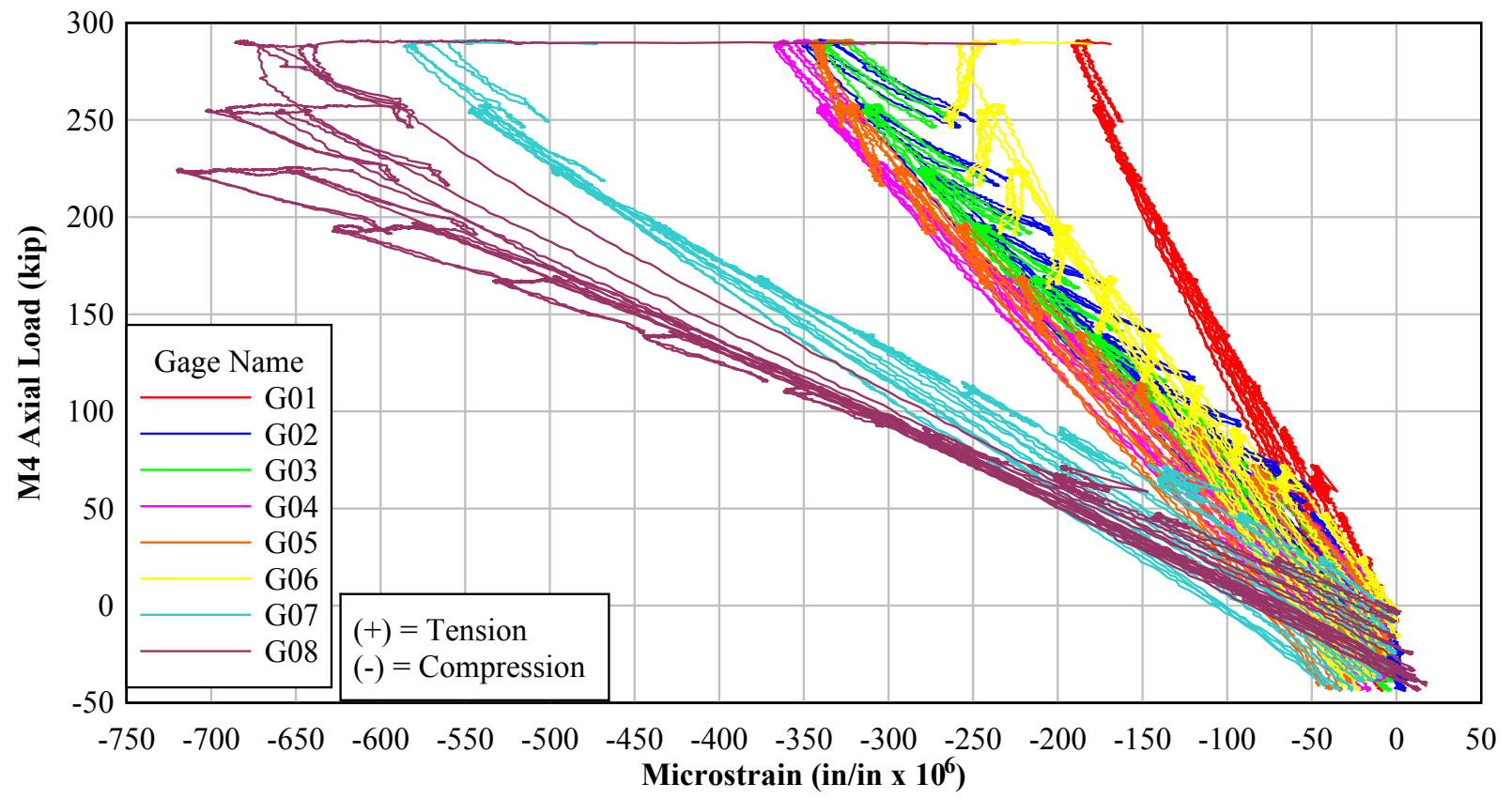




\subsection{TEST 2 DATA}

\subsubsection{Relative Member-to-Gusset Displacement (bolt slip \& work point)}
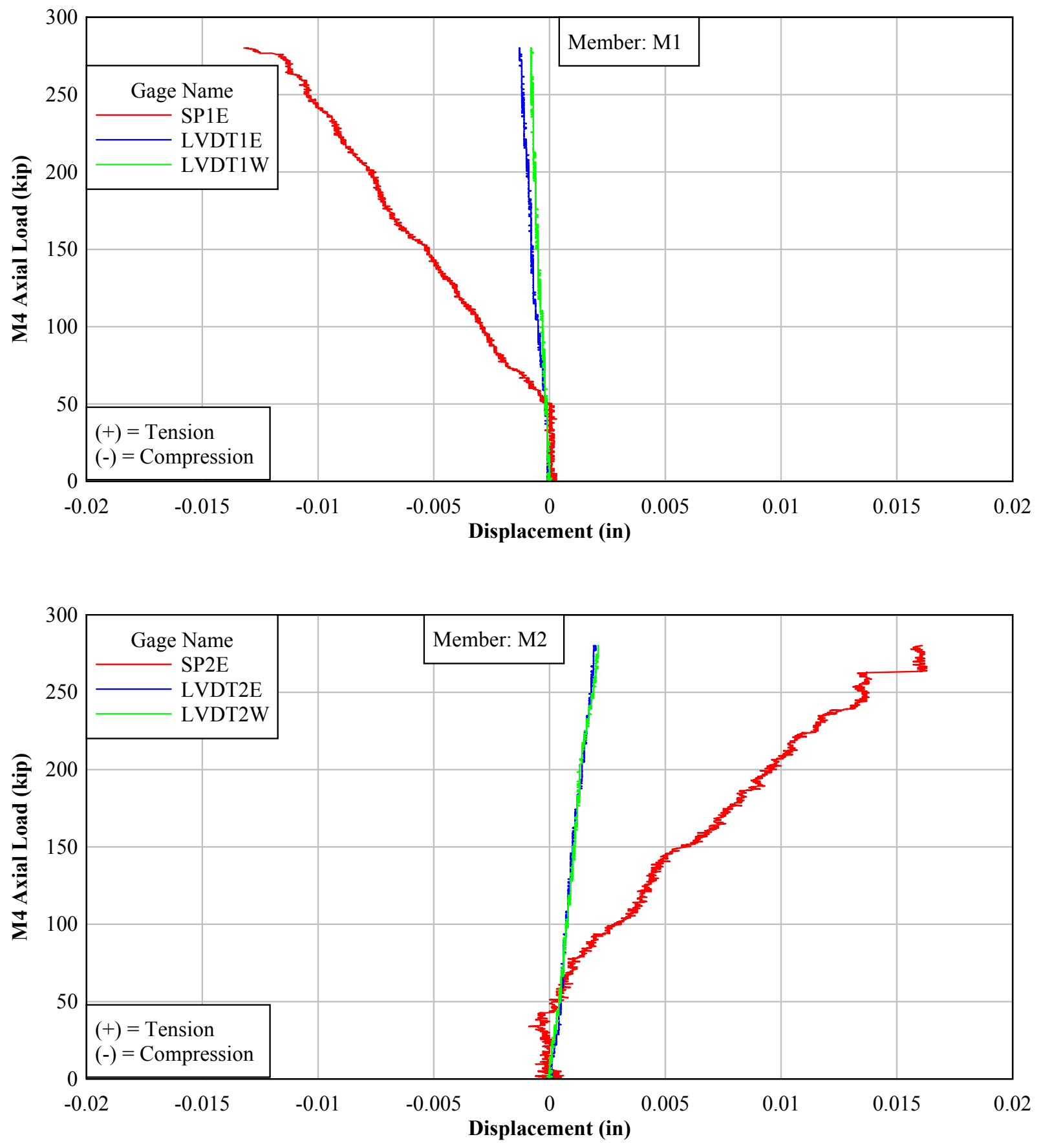

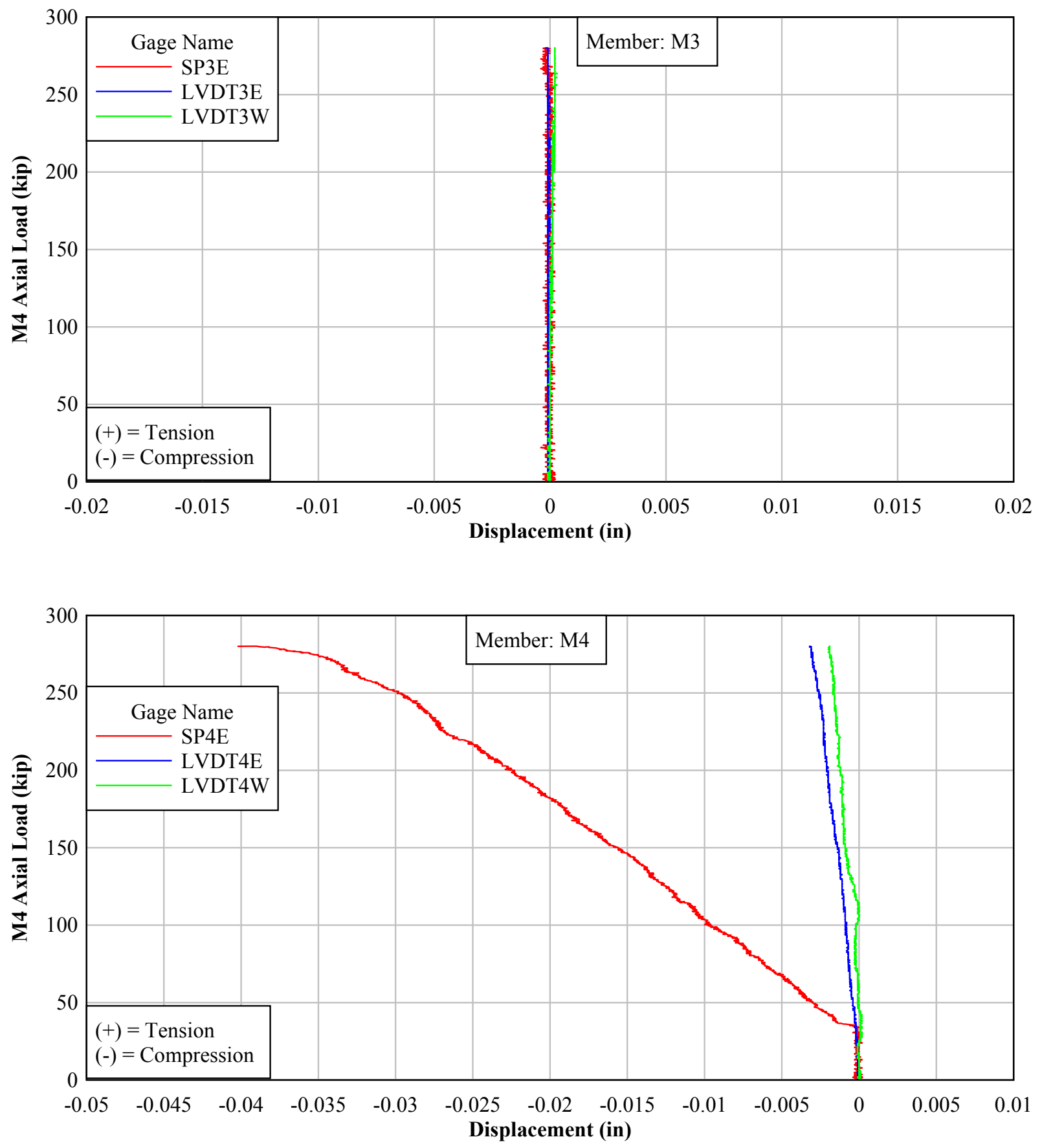


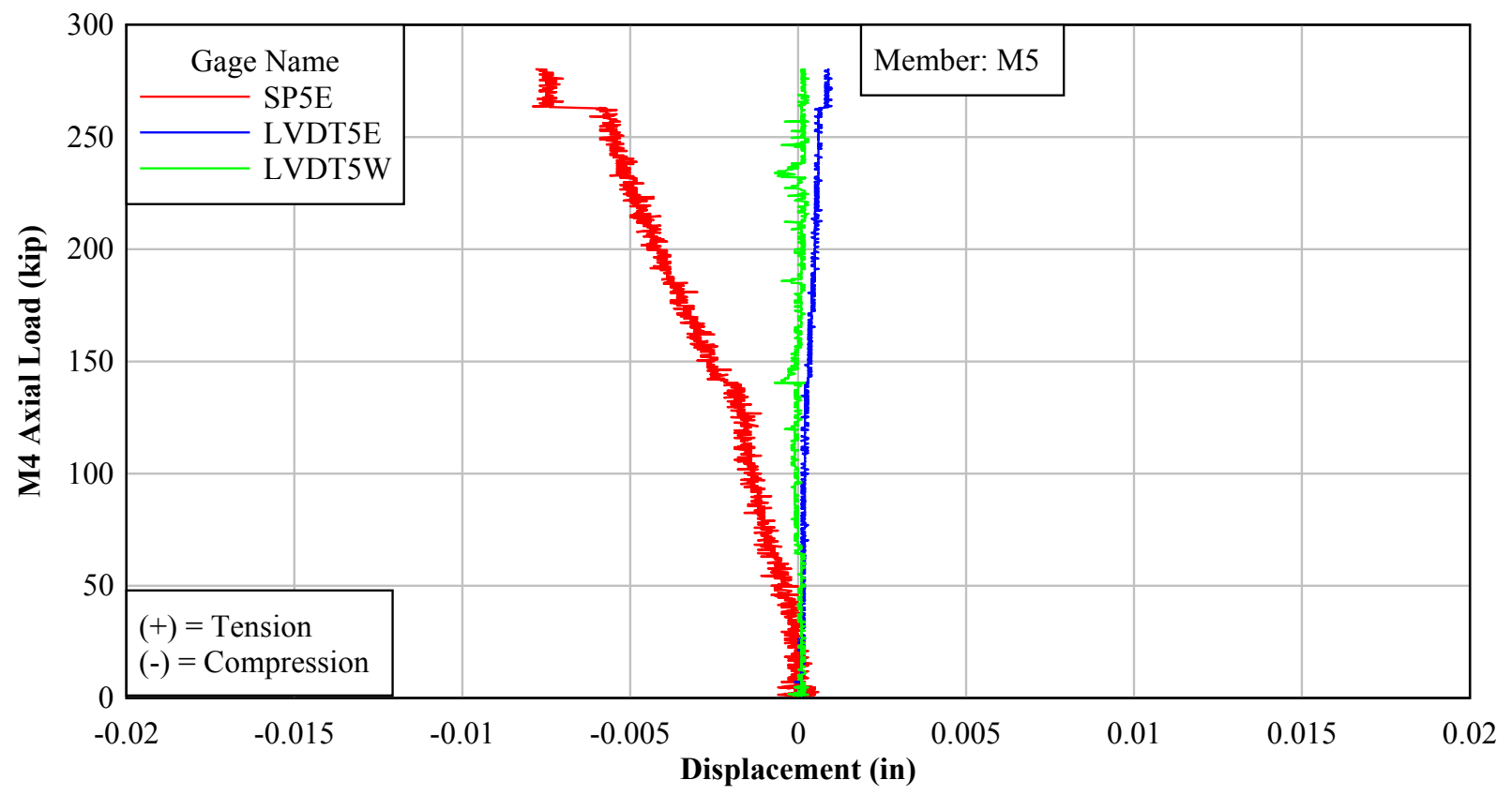

9.3.2 Gusset Free Edge Strain Versus Load and Displacement

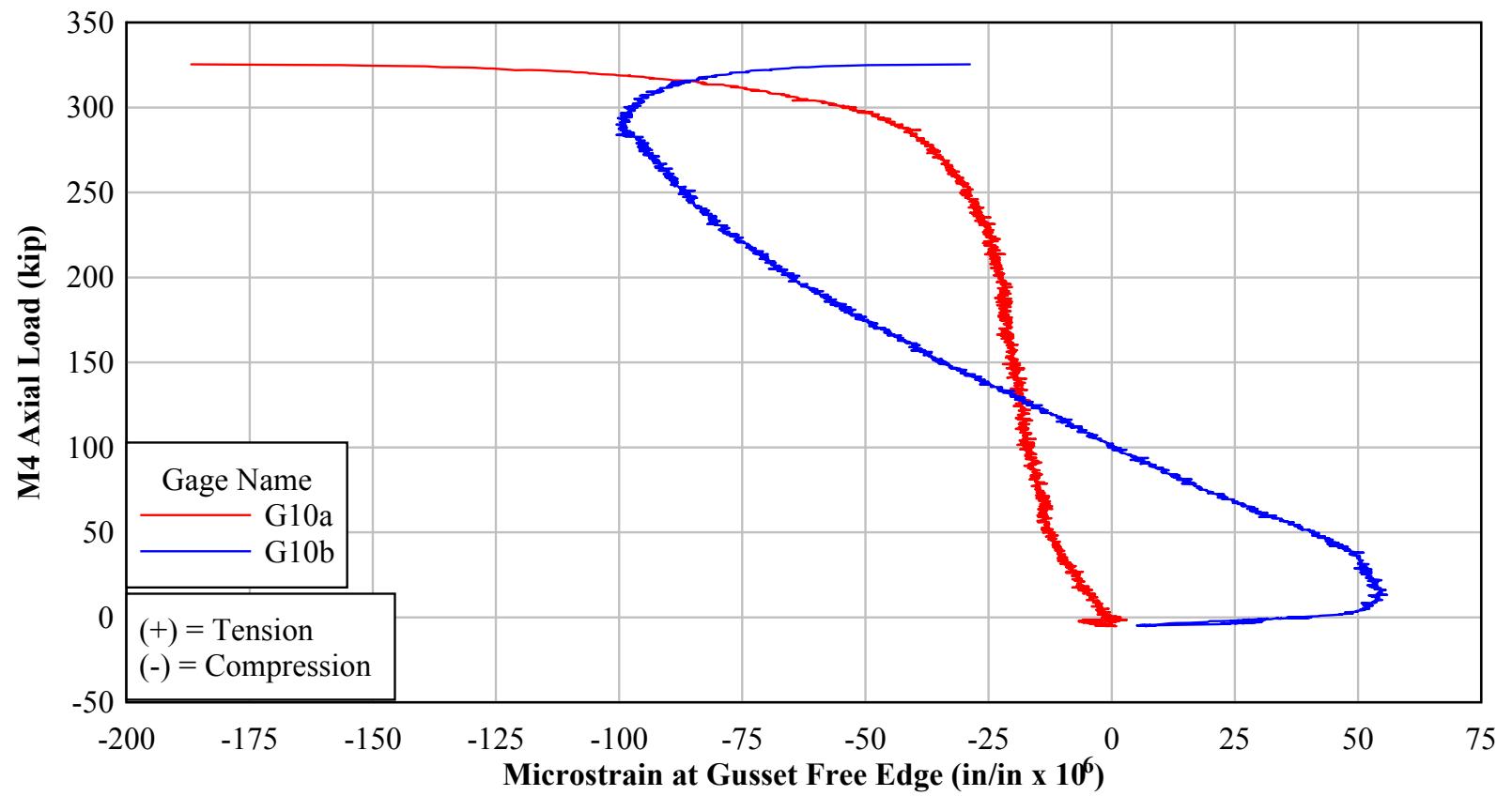




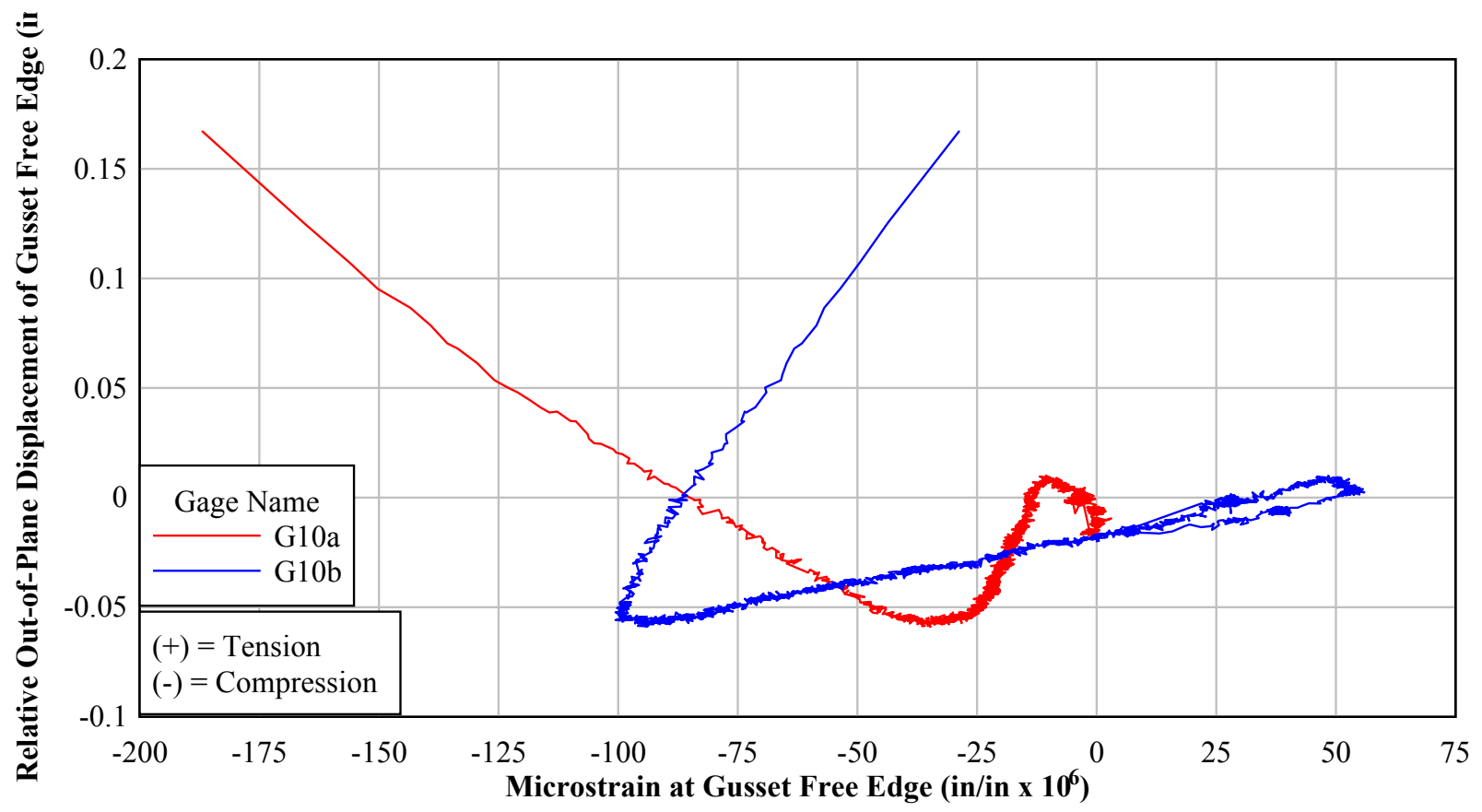




\subsection{TEST 3 DATA}

\subsubsection{Relative Member-to-Gusset Displacement (bolt slip \& work point)}
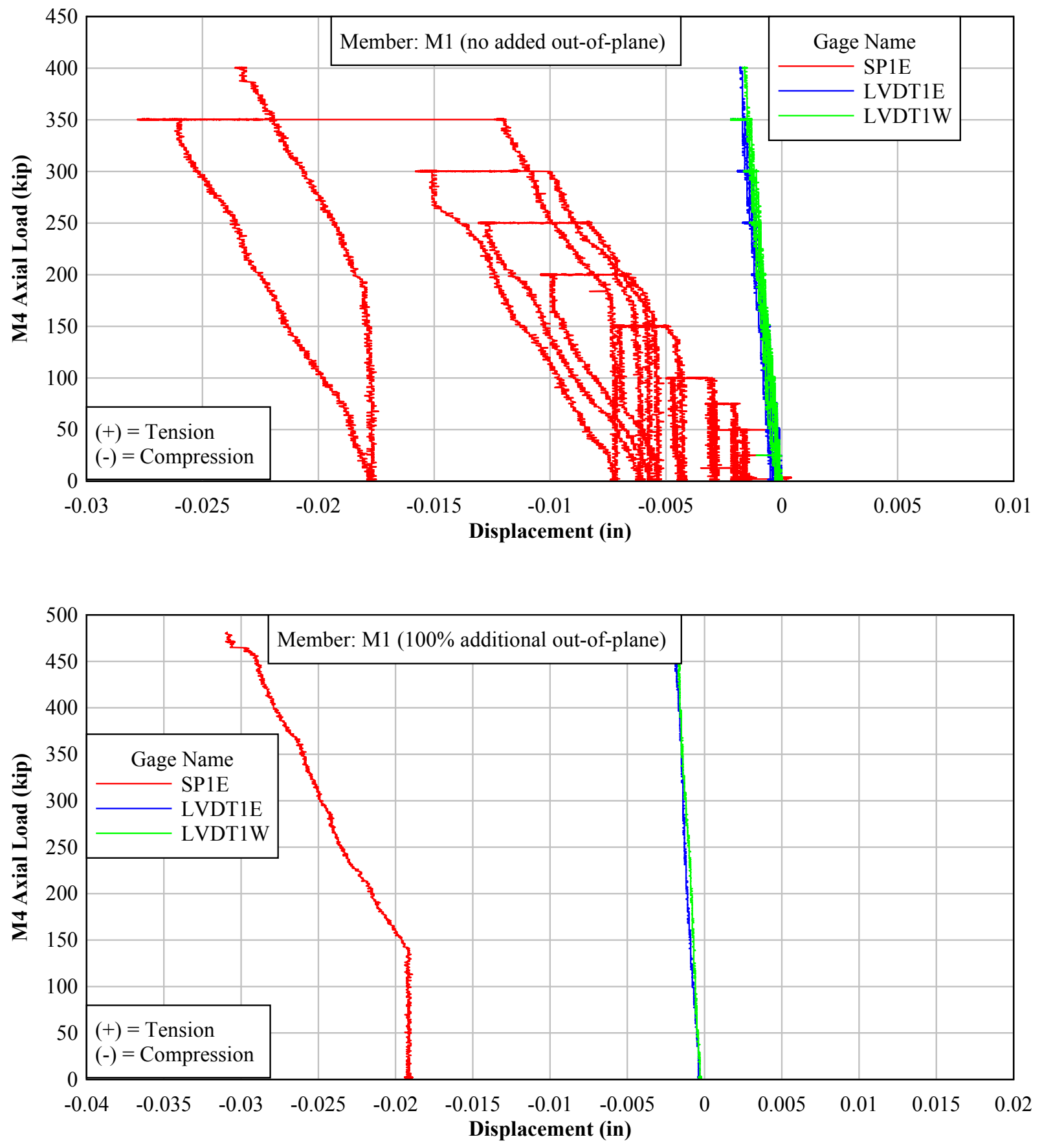

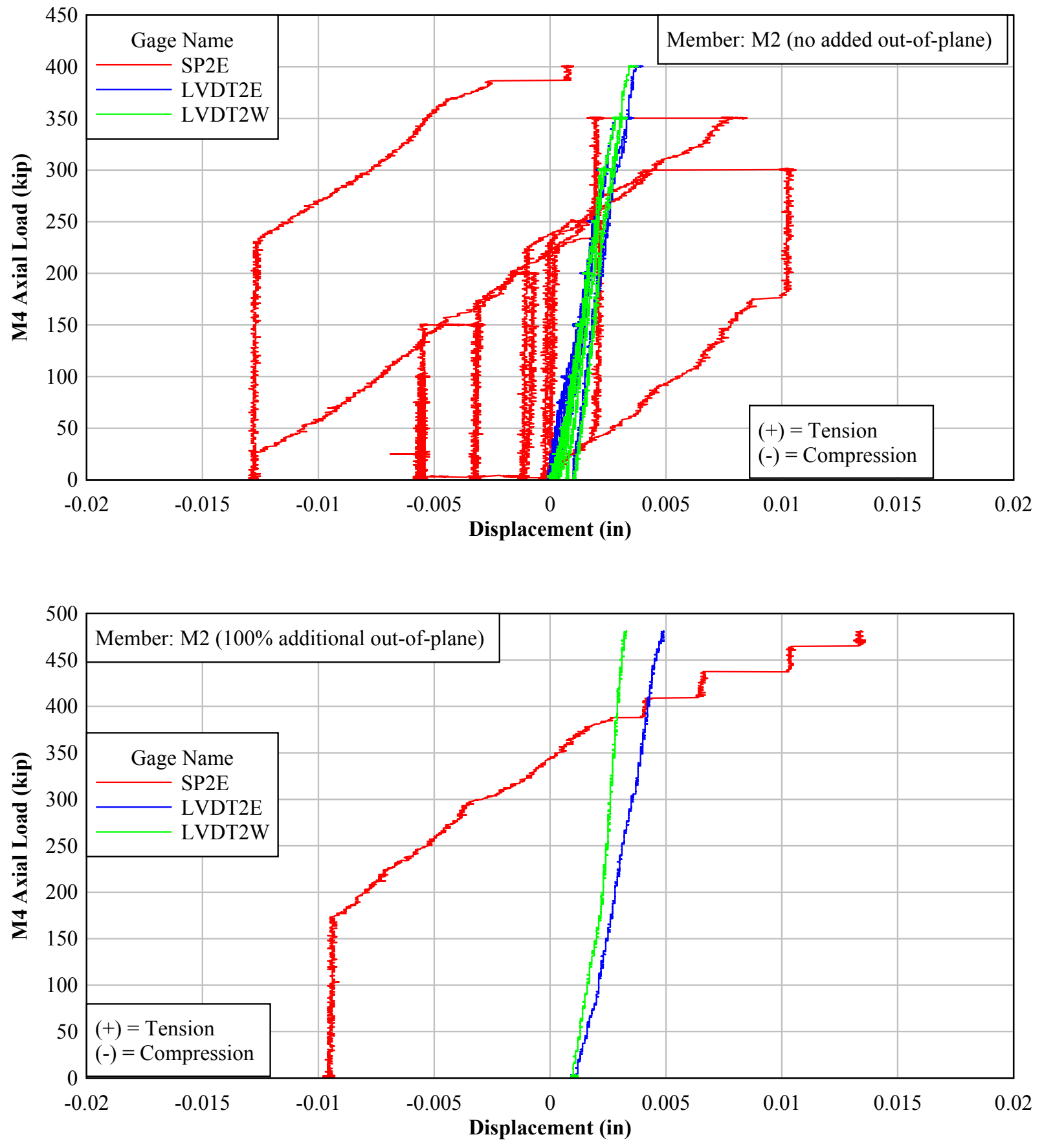

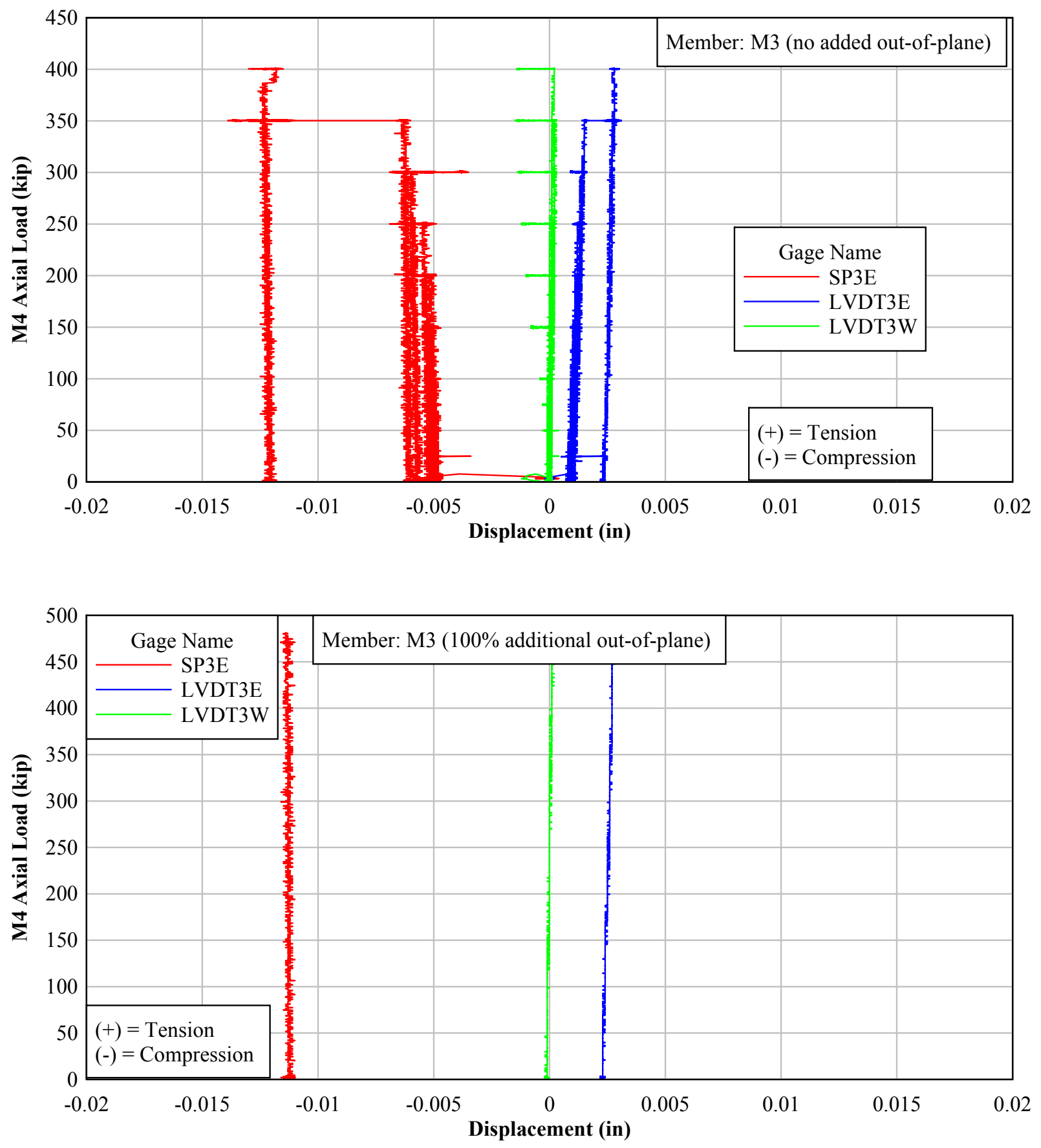

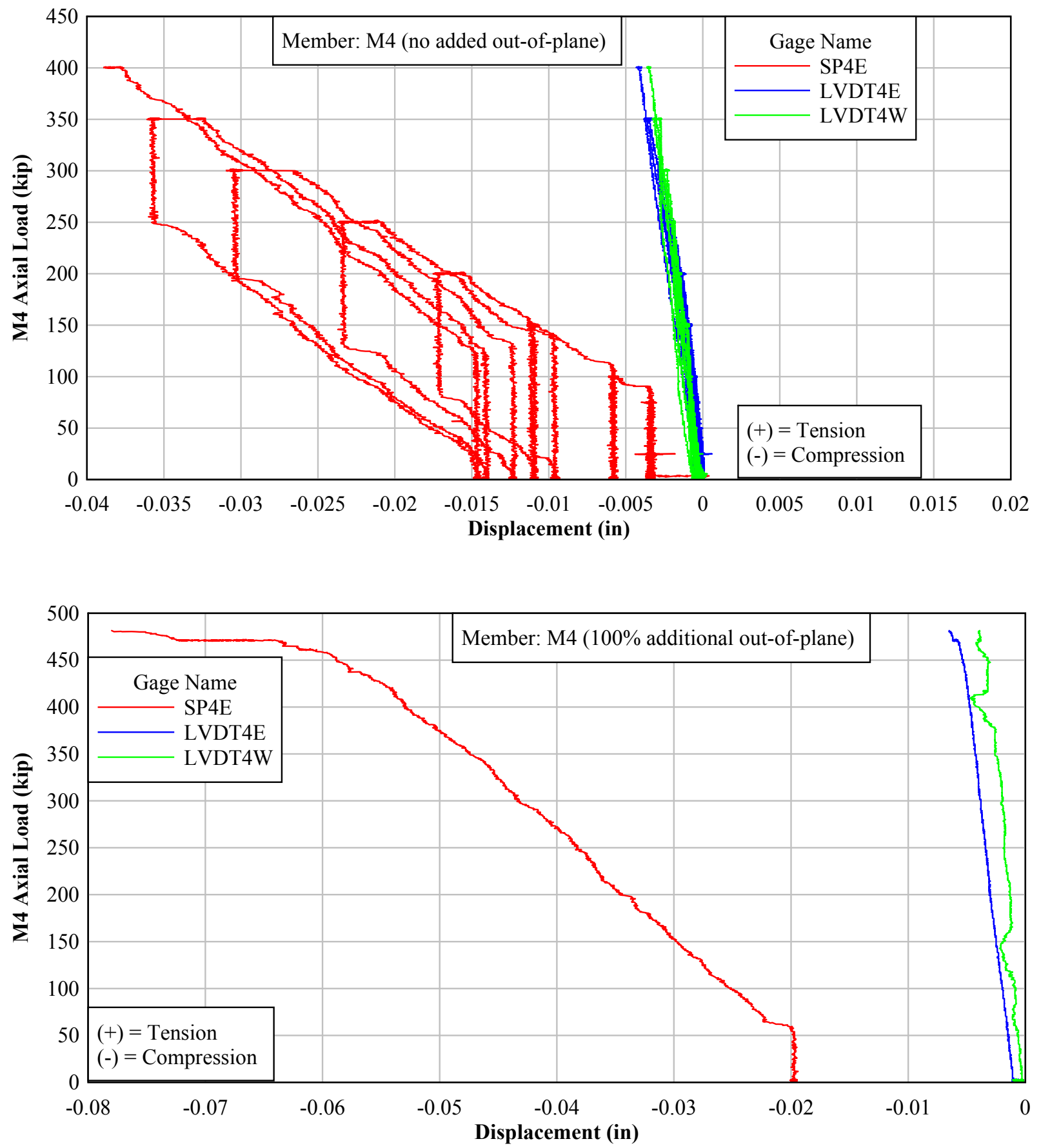

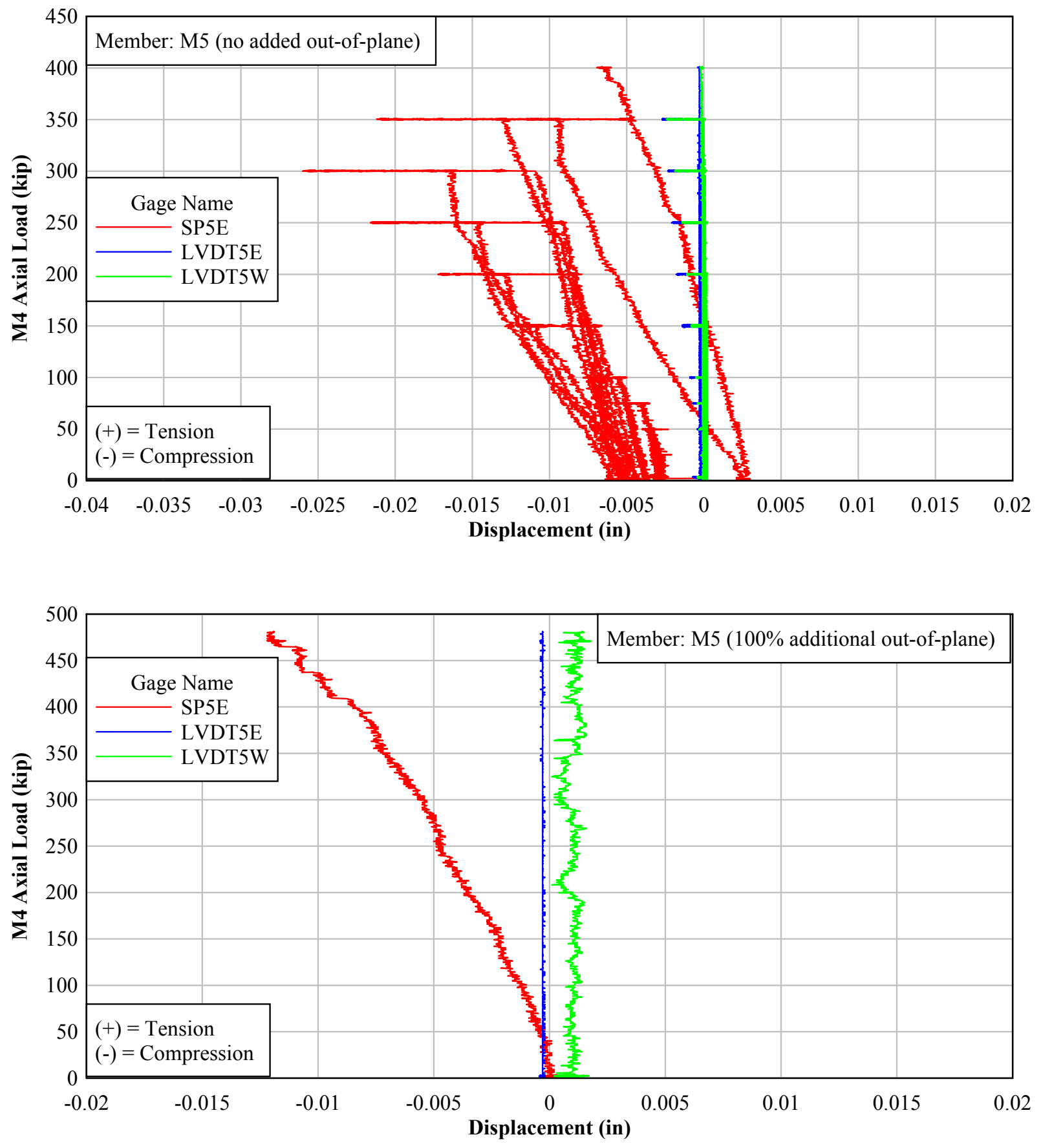


\subsubsection{Gusset Free Edge Strain Versus Load and Displacement}
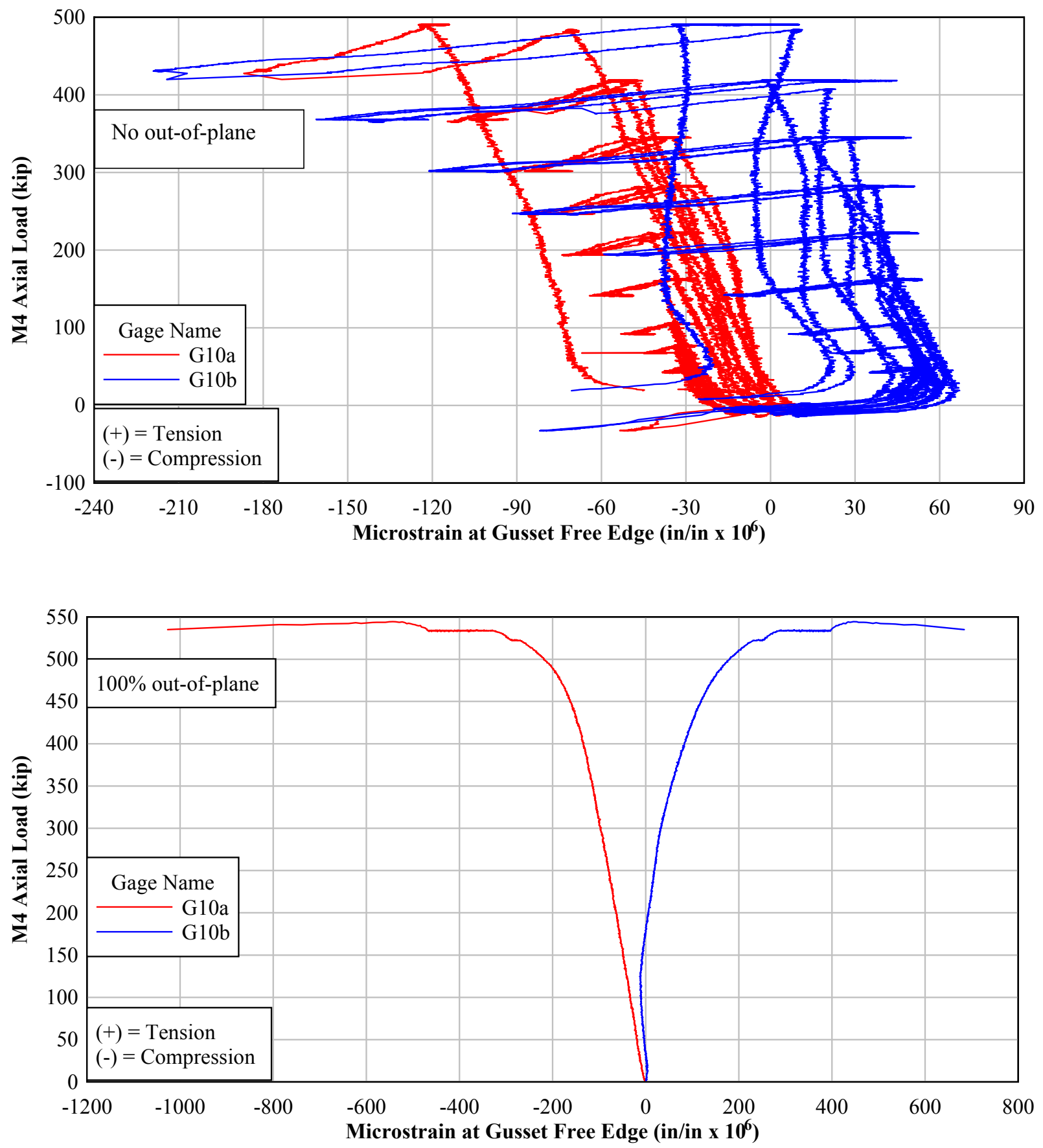

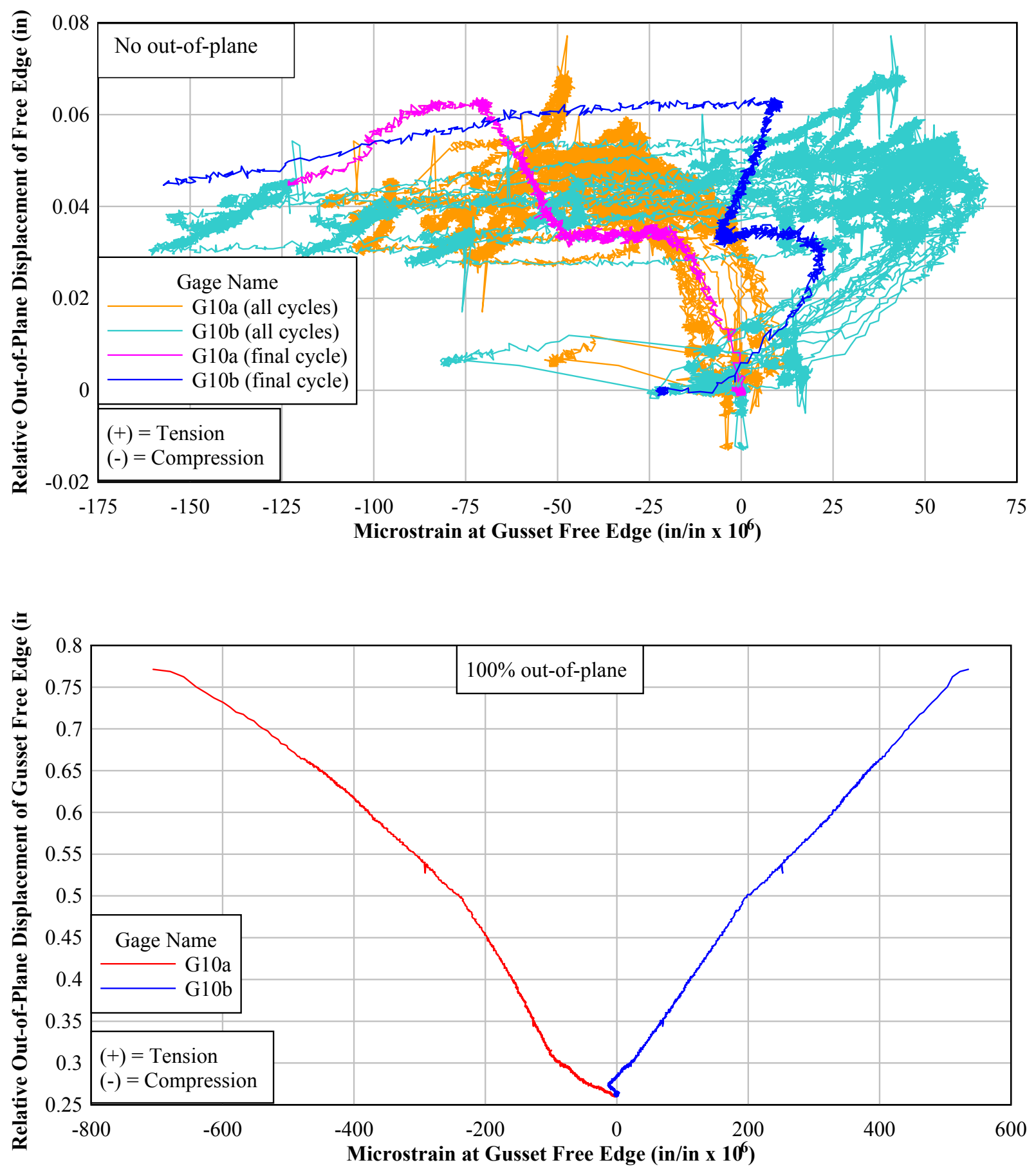


\subsubsection{Strain in M4 Connection Versus Load}

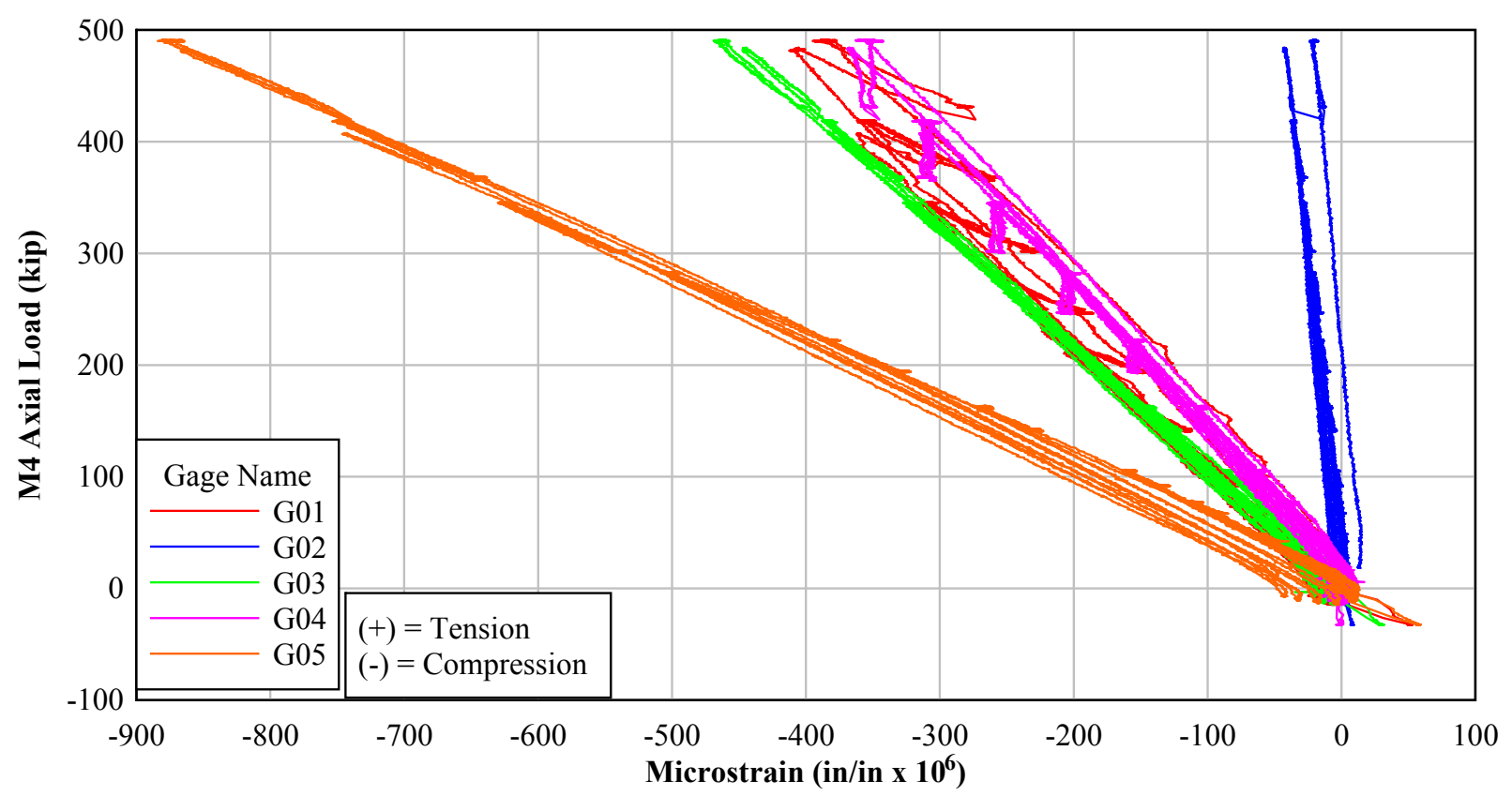




\subsection{TEST 4 DATA}

\subsubsection{Relative Member-to-Gusset Displacement (bolt slip \& work point)}
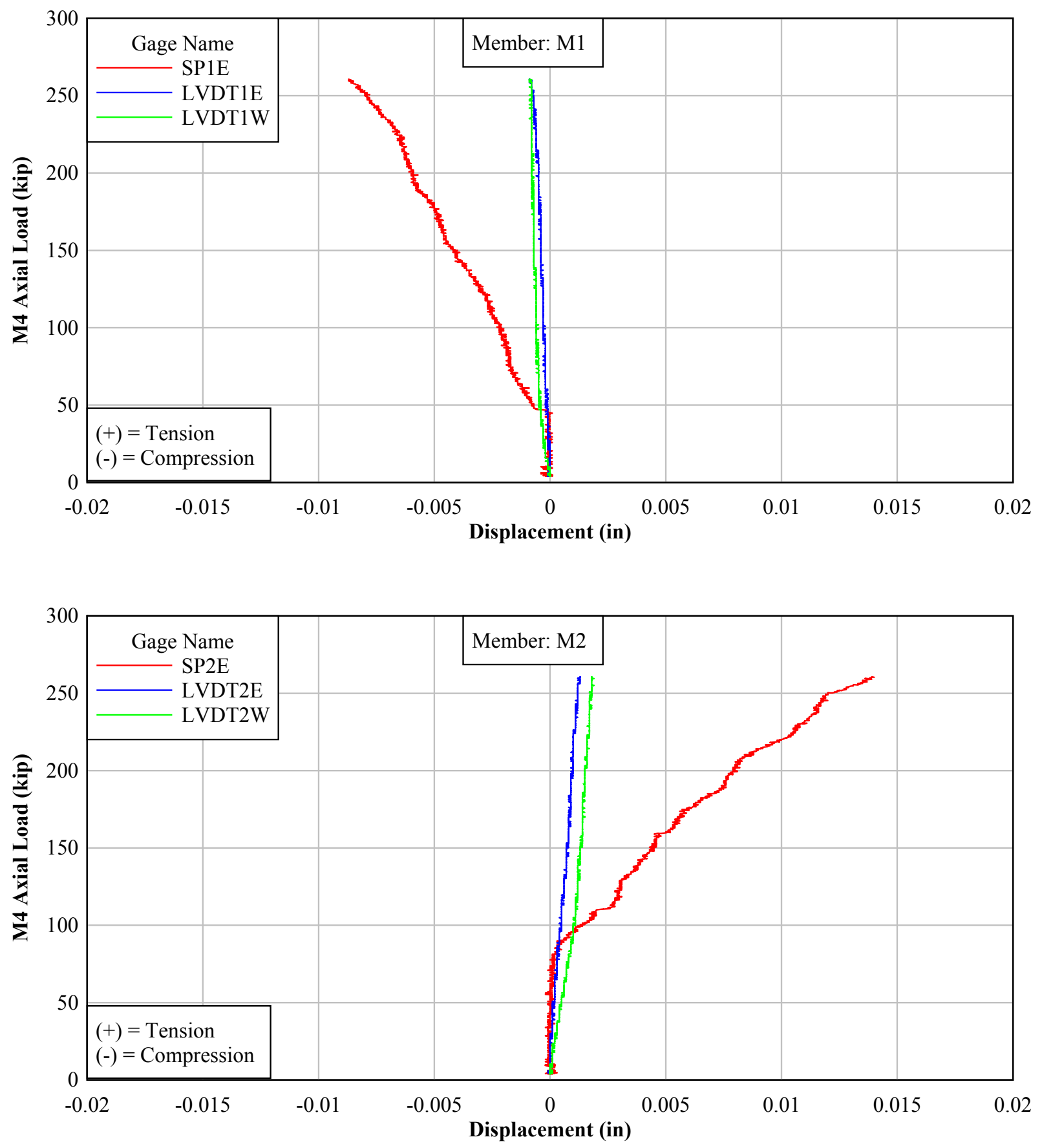

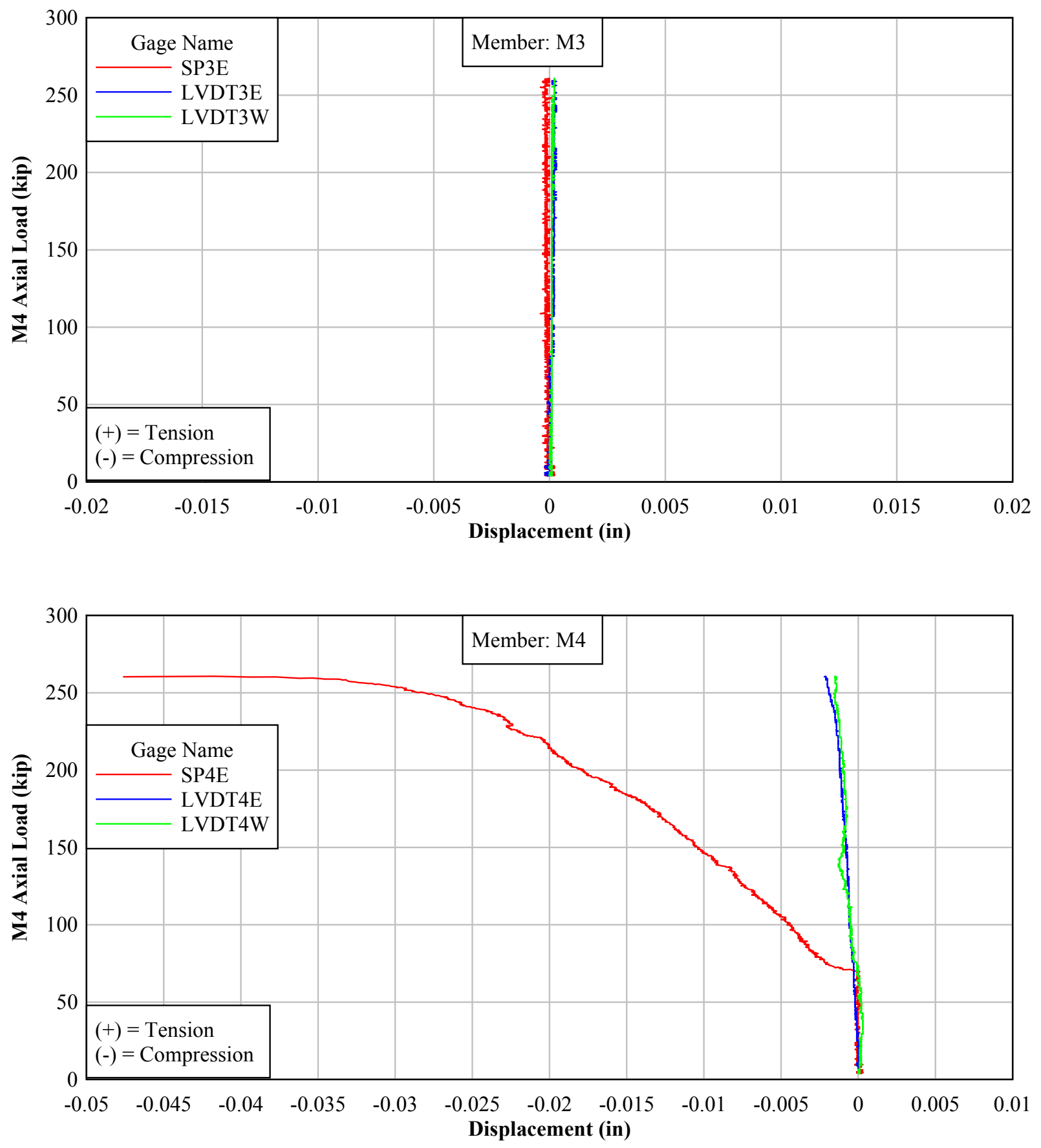


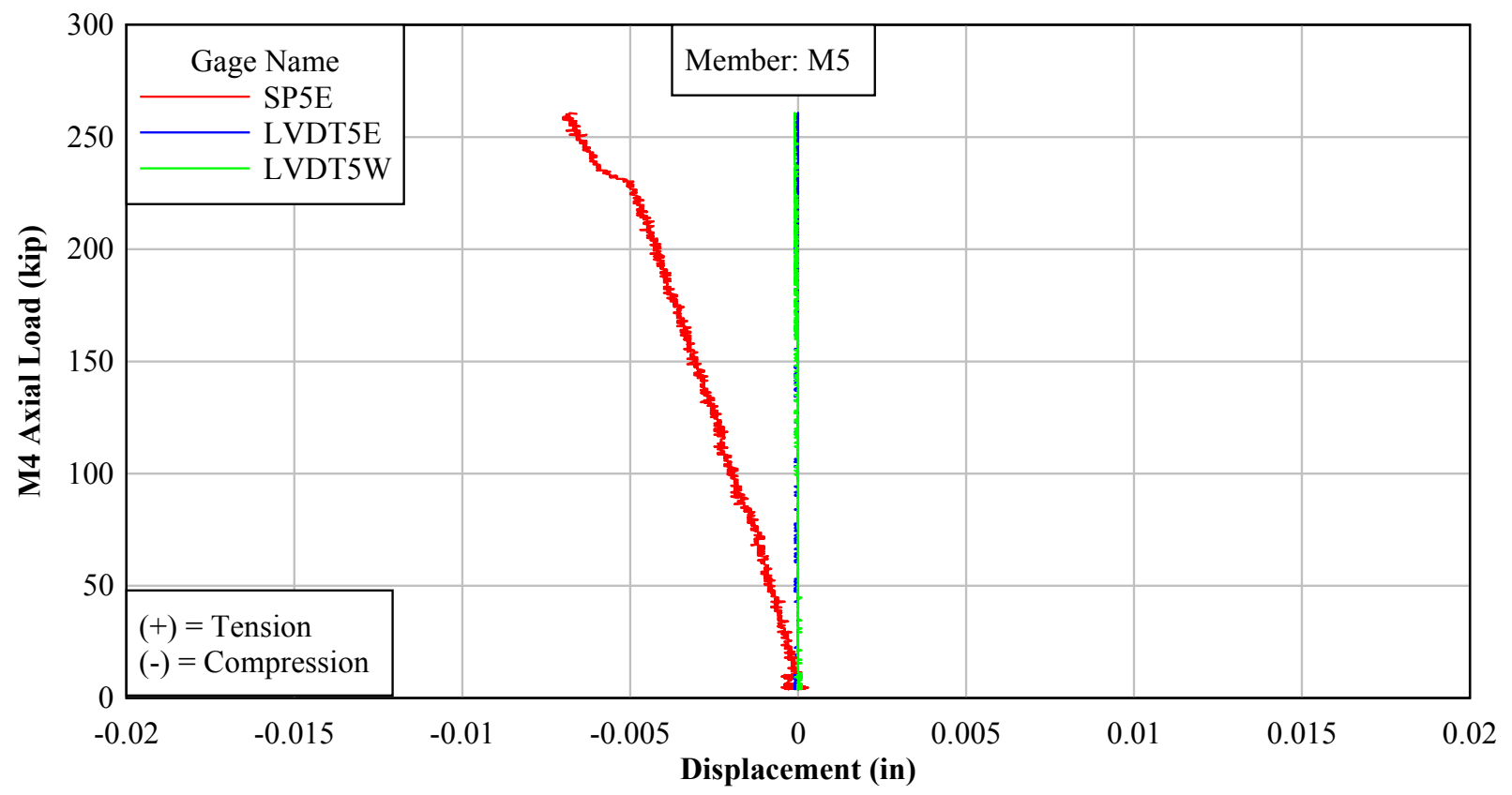

9.5.2 Gusset Free Edge Strain Versus Load and Displacement

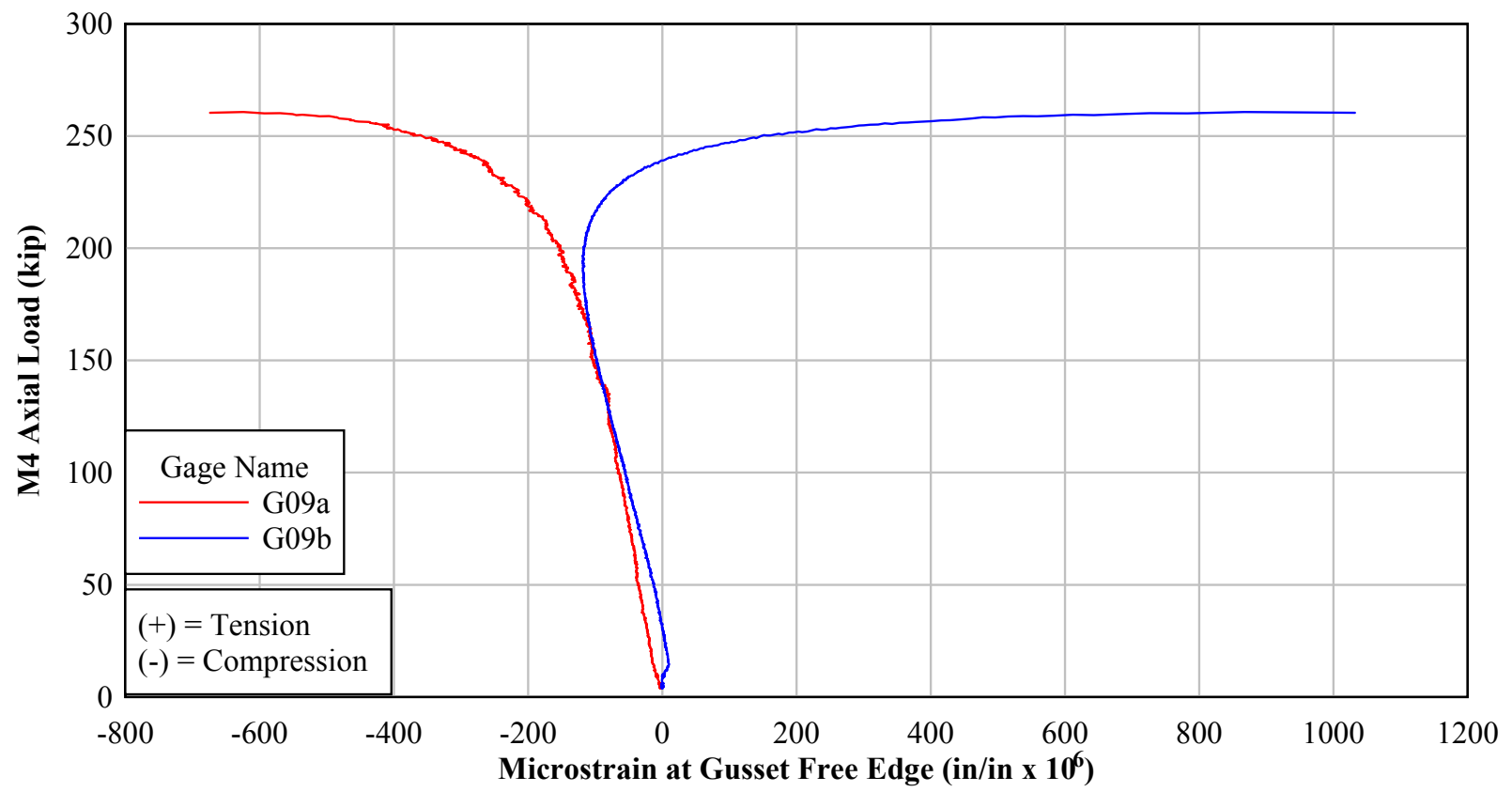




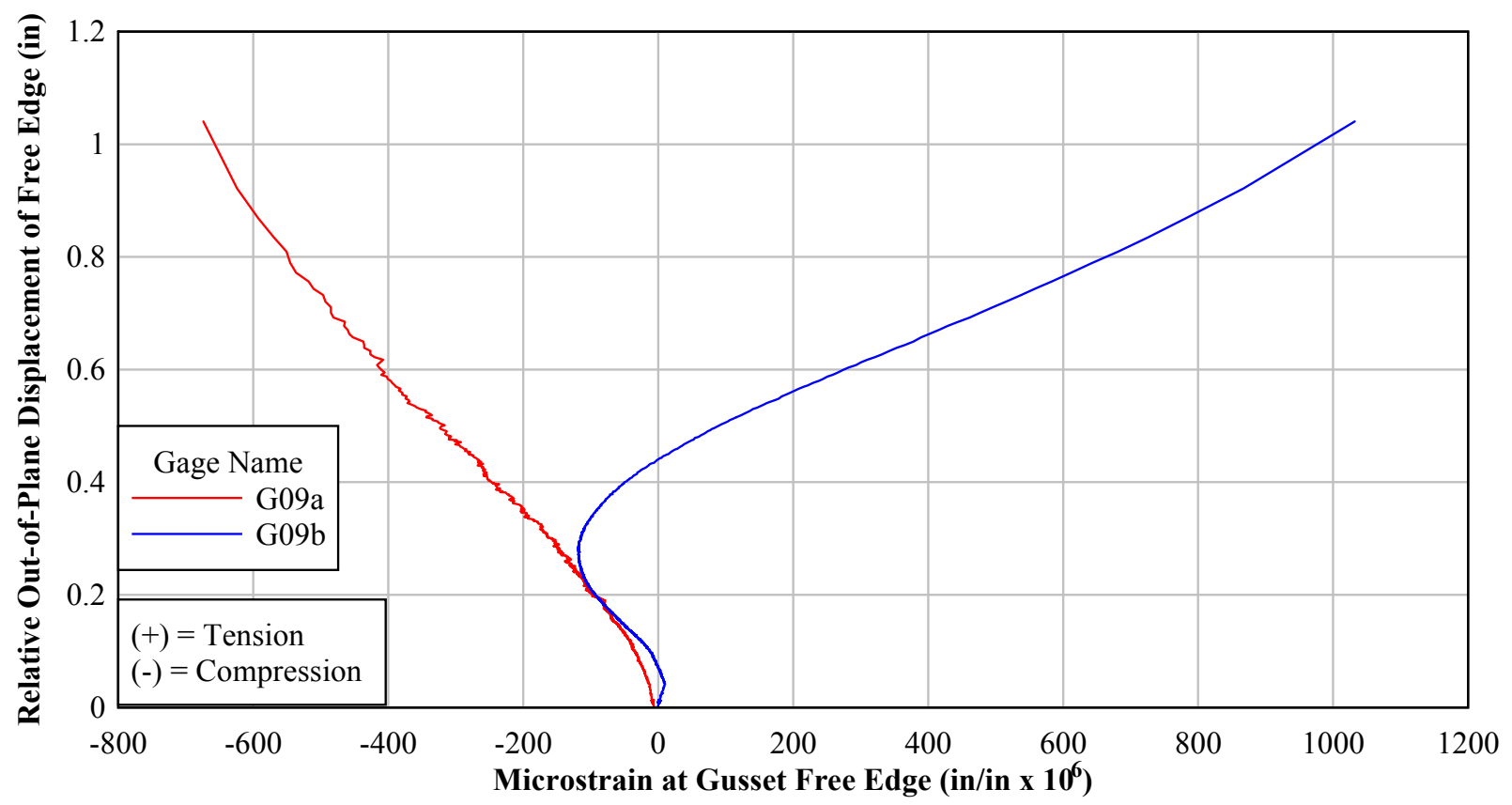

\subsubsection{Strain in M4 Connection Versus Load}

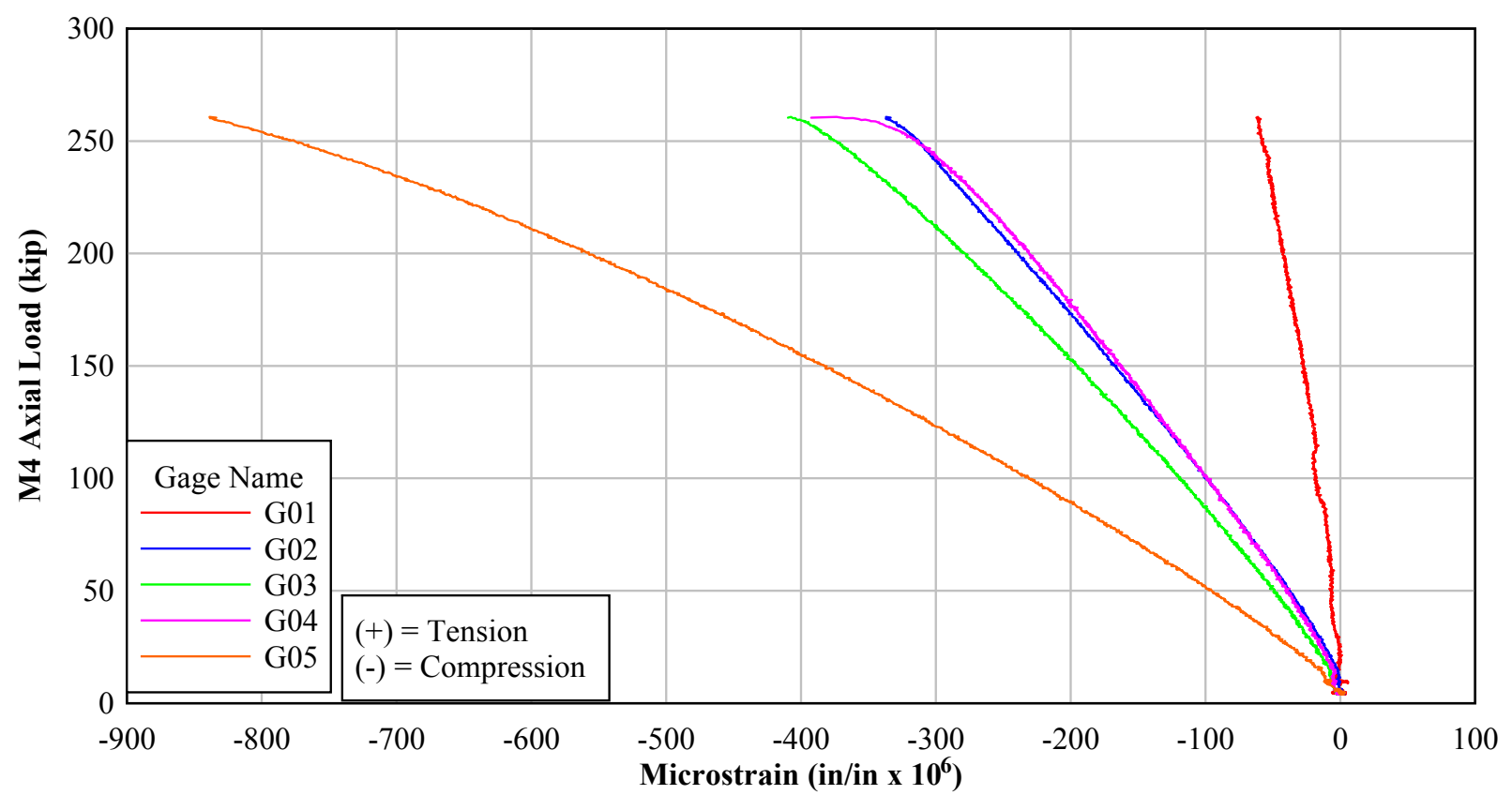




\subsection{TEST 5 DATA}

\subsubsection{Relative Member-to-Gusset Displacement (bolt slip \& work point)}
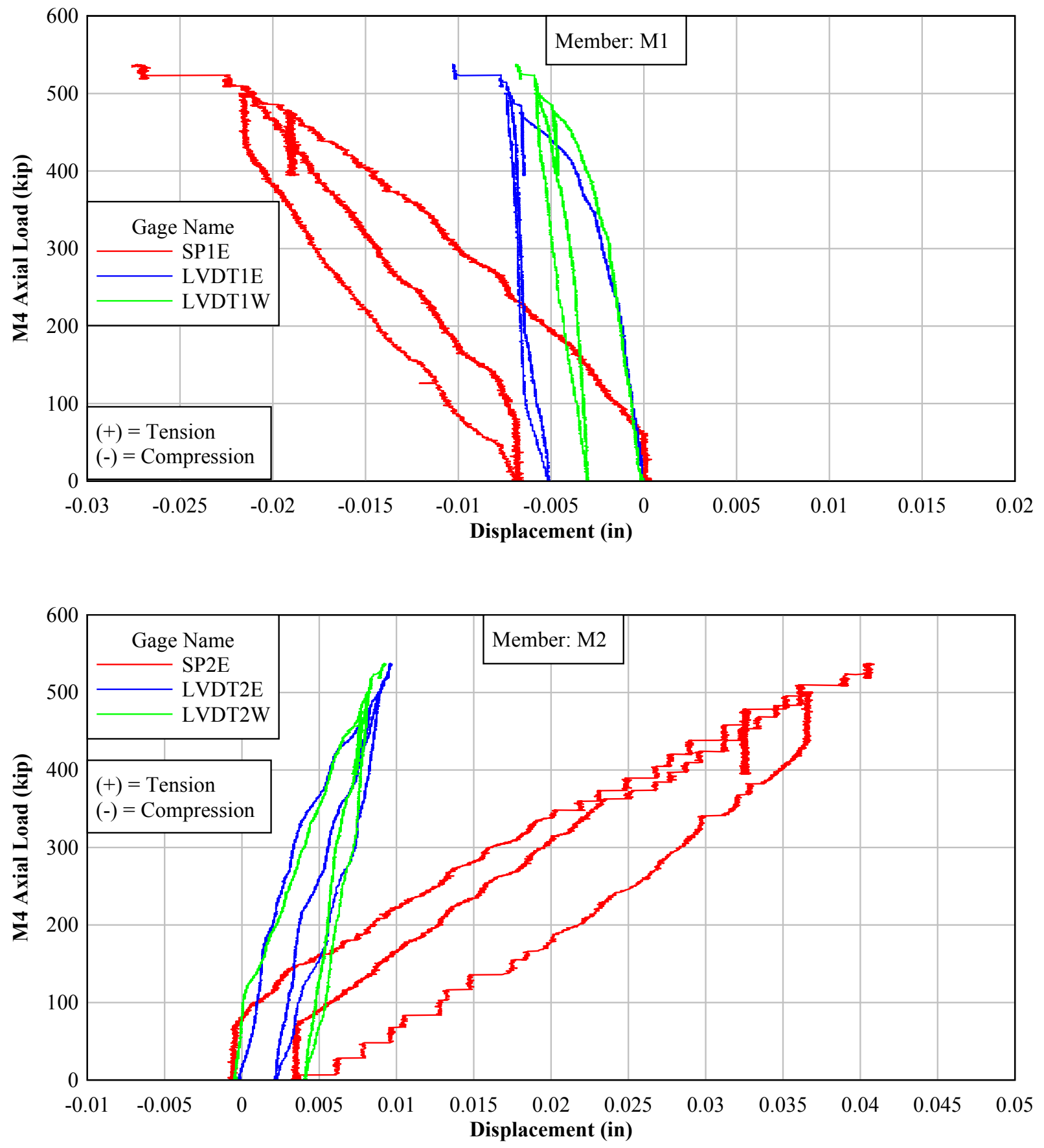

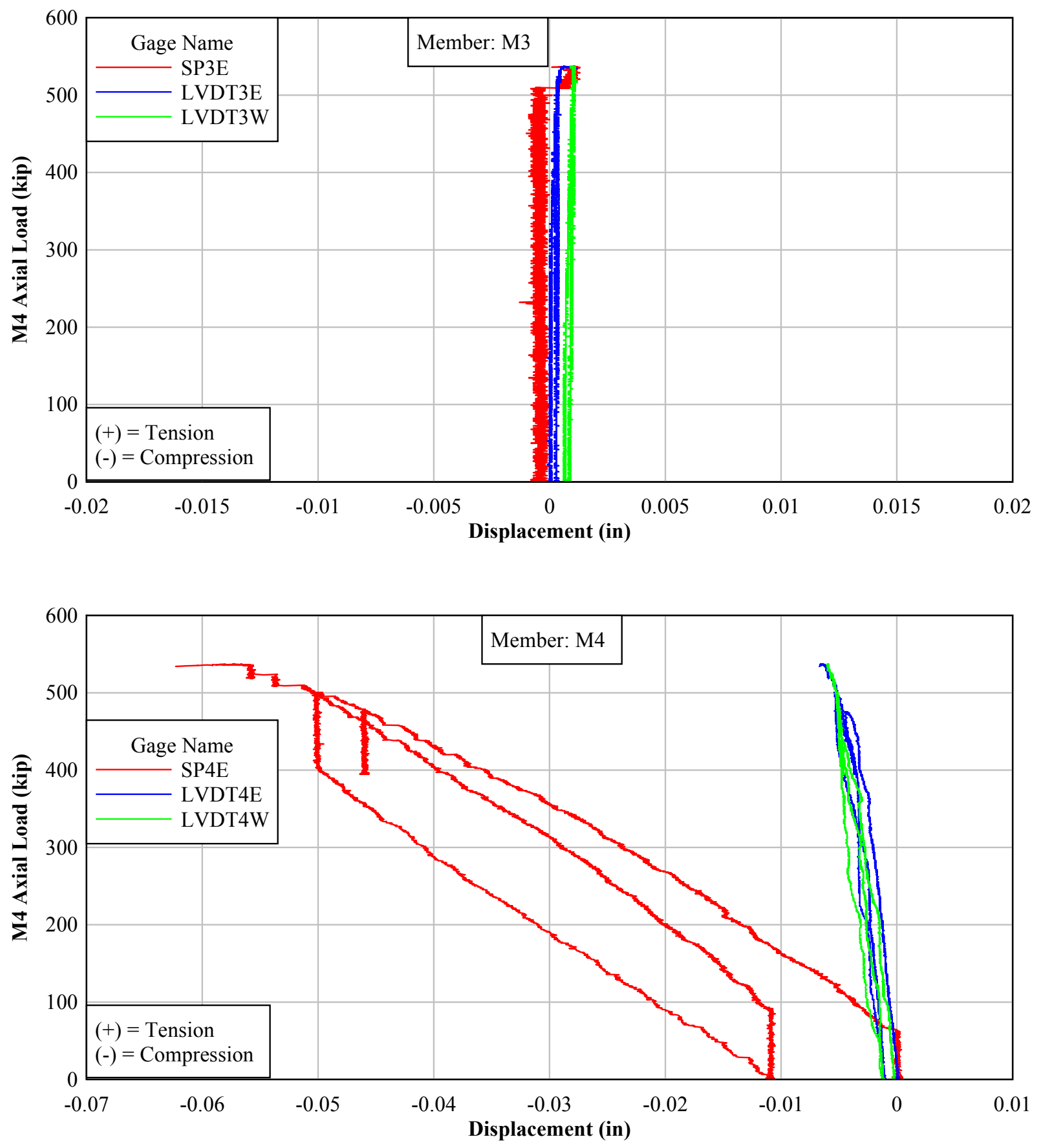


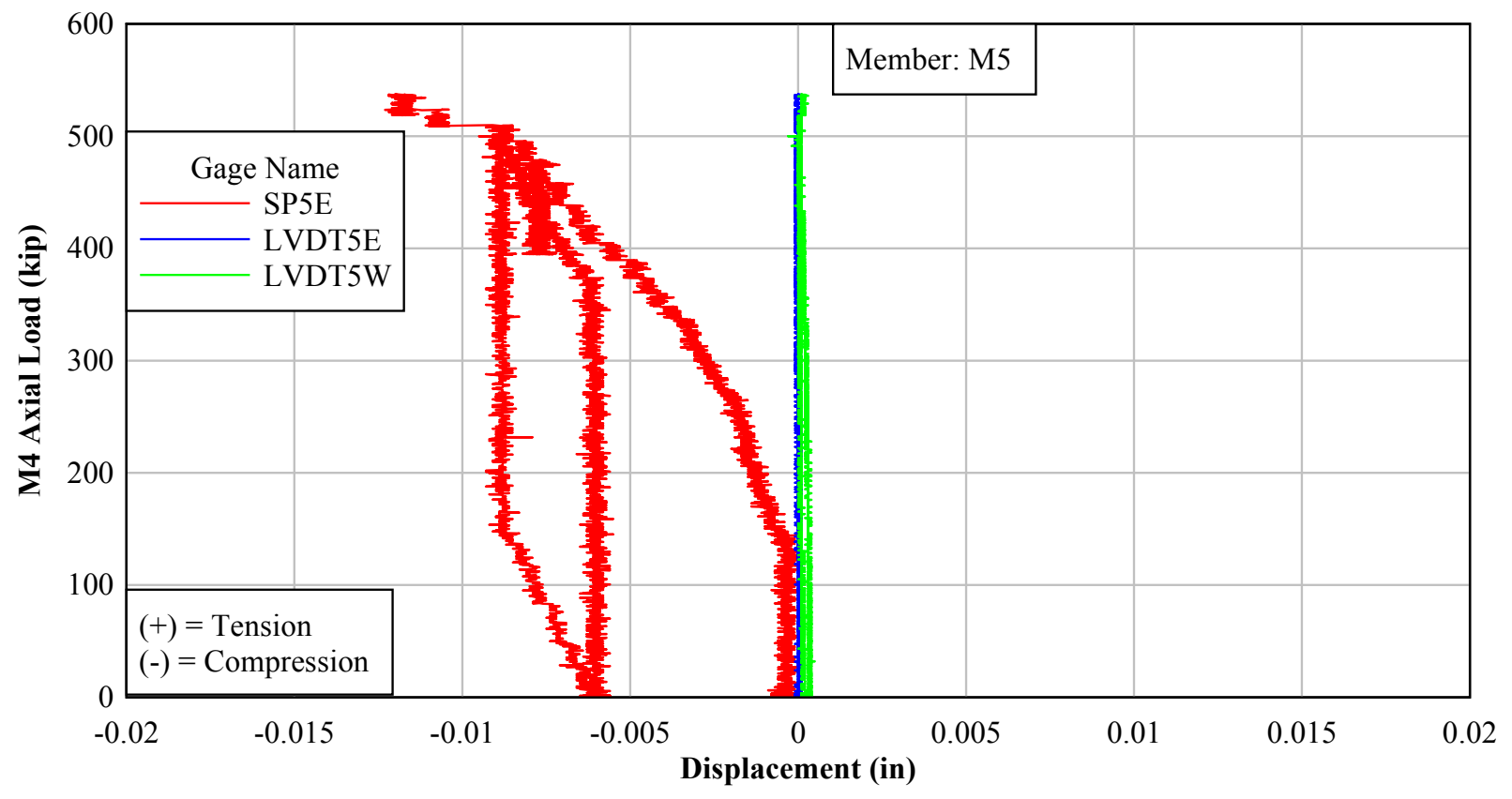

\subsubsection{Gusset Free Edge Strain Versus Load and Displacement}

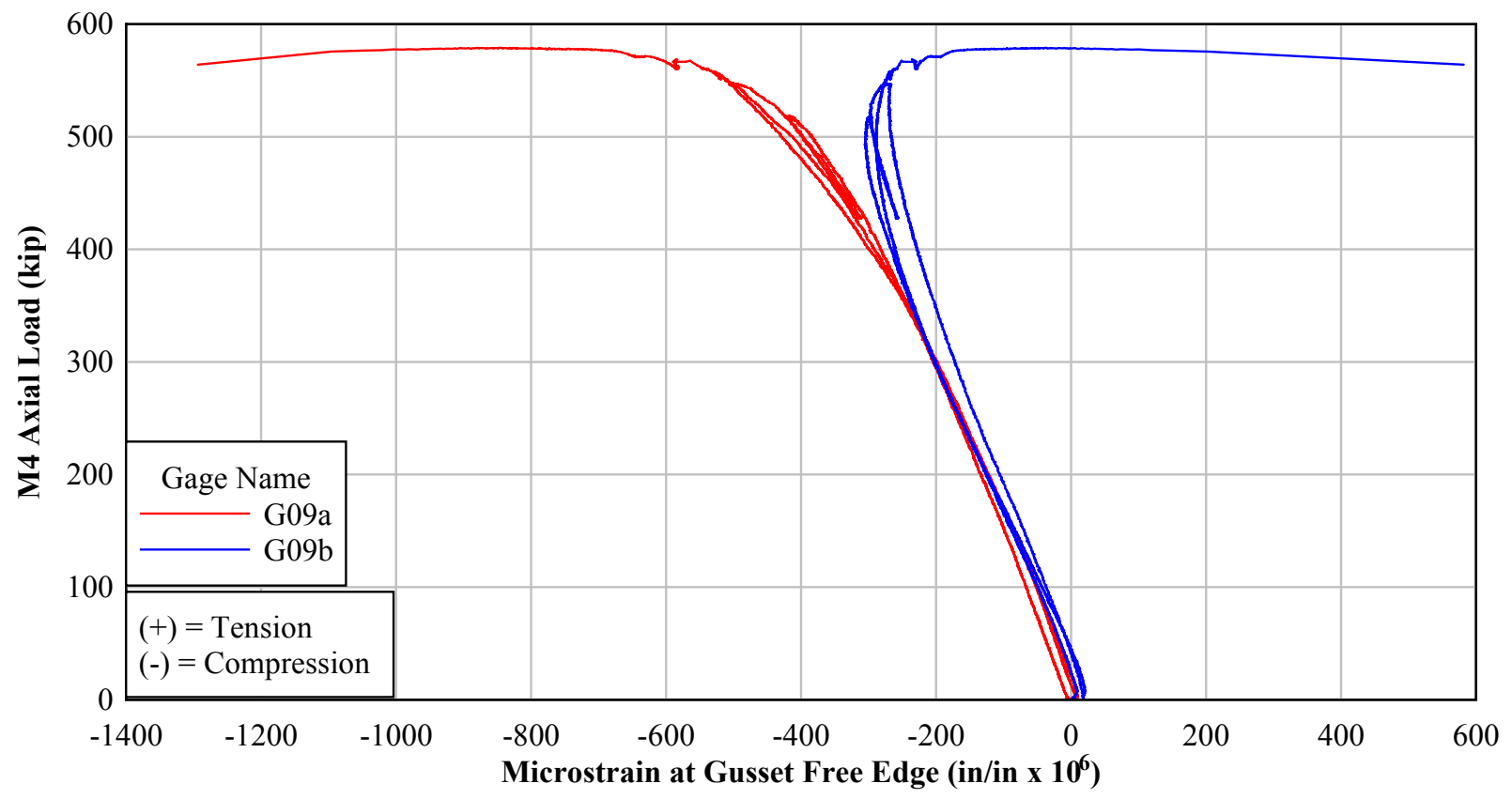




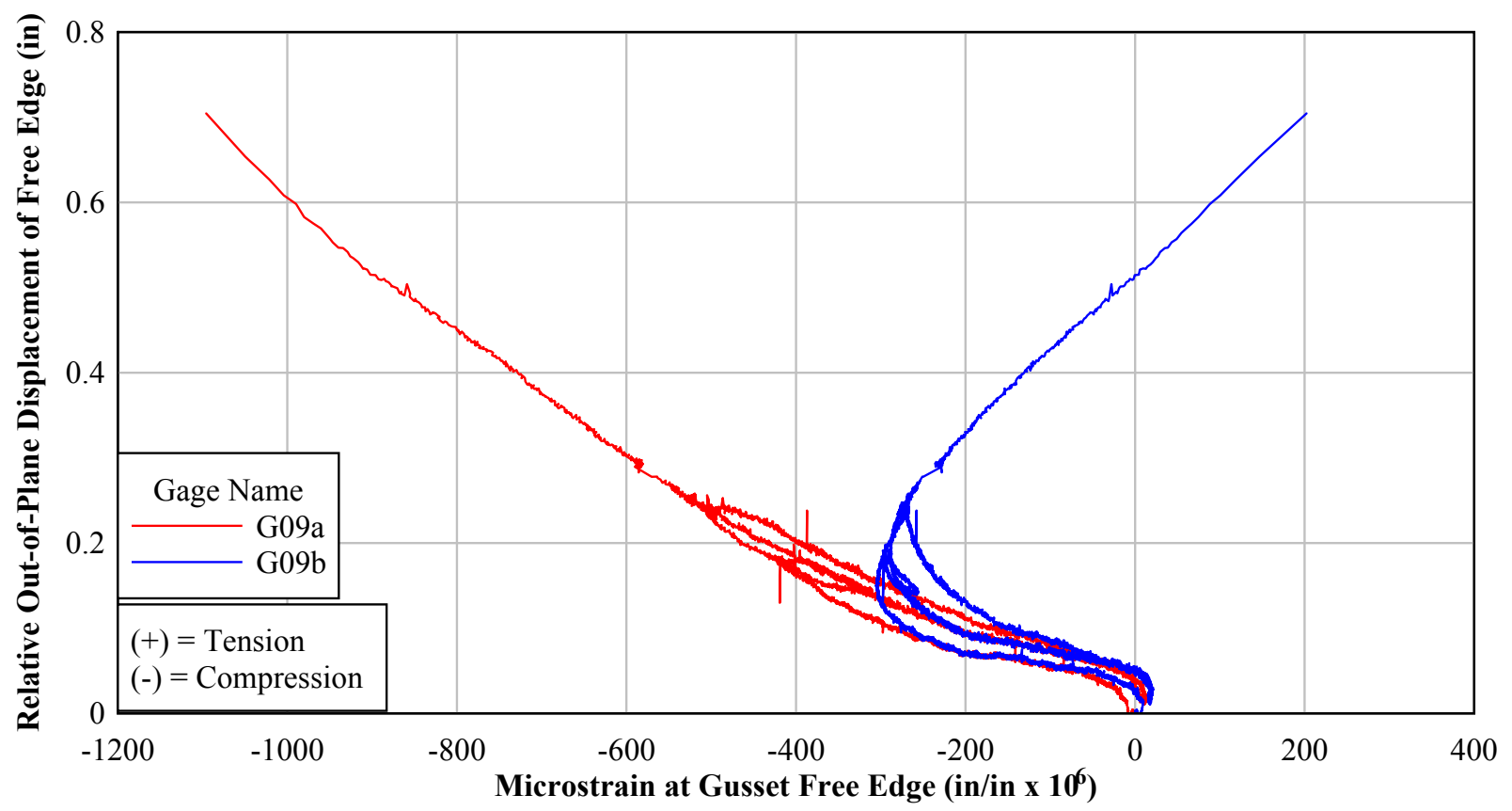

\subsubsection{Strain in M4 Connection Versus Load}

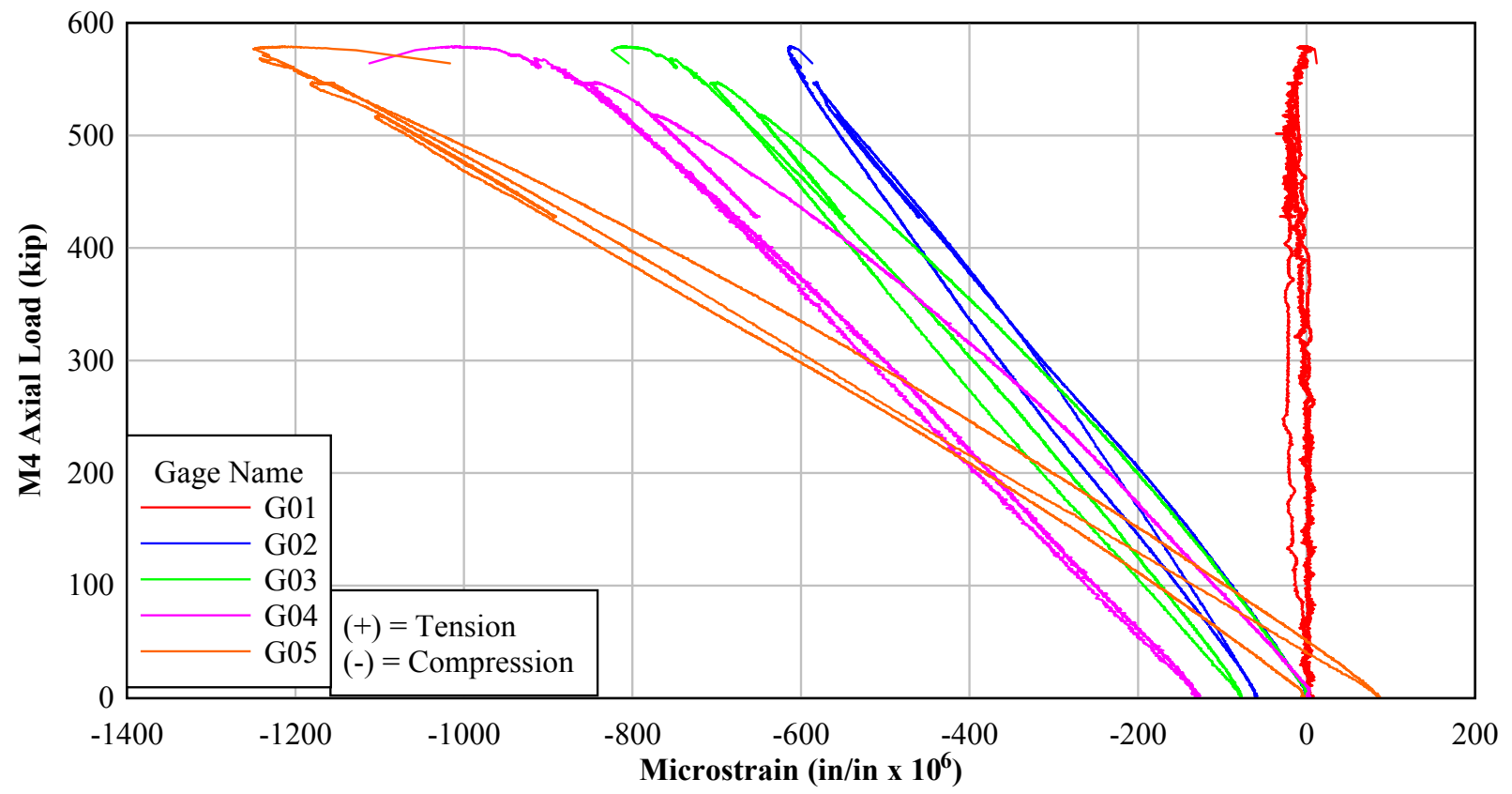




\subsection{TEST 6 DATA}

\subsubsection{Relative Member-to-Gusset Displacement (bolt slip \& work point)}
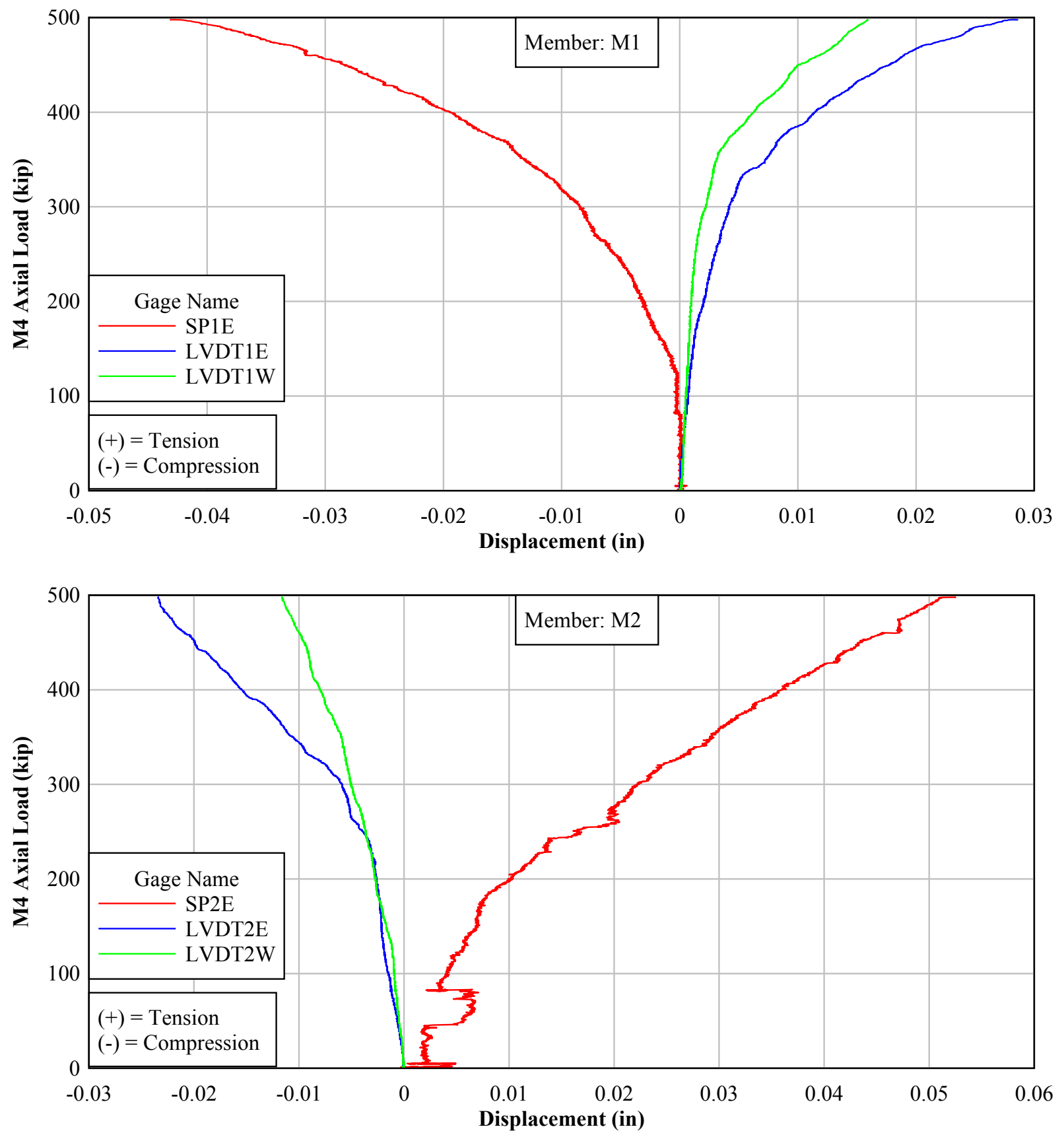

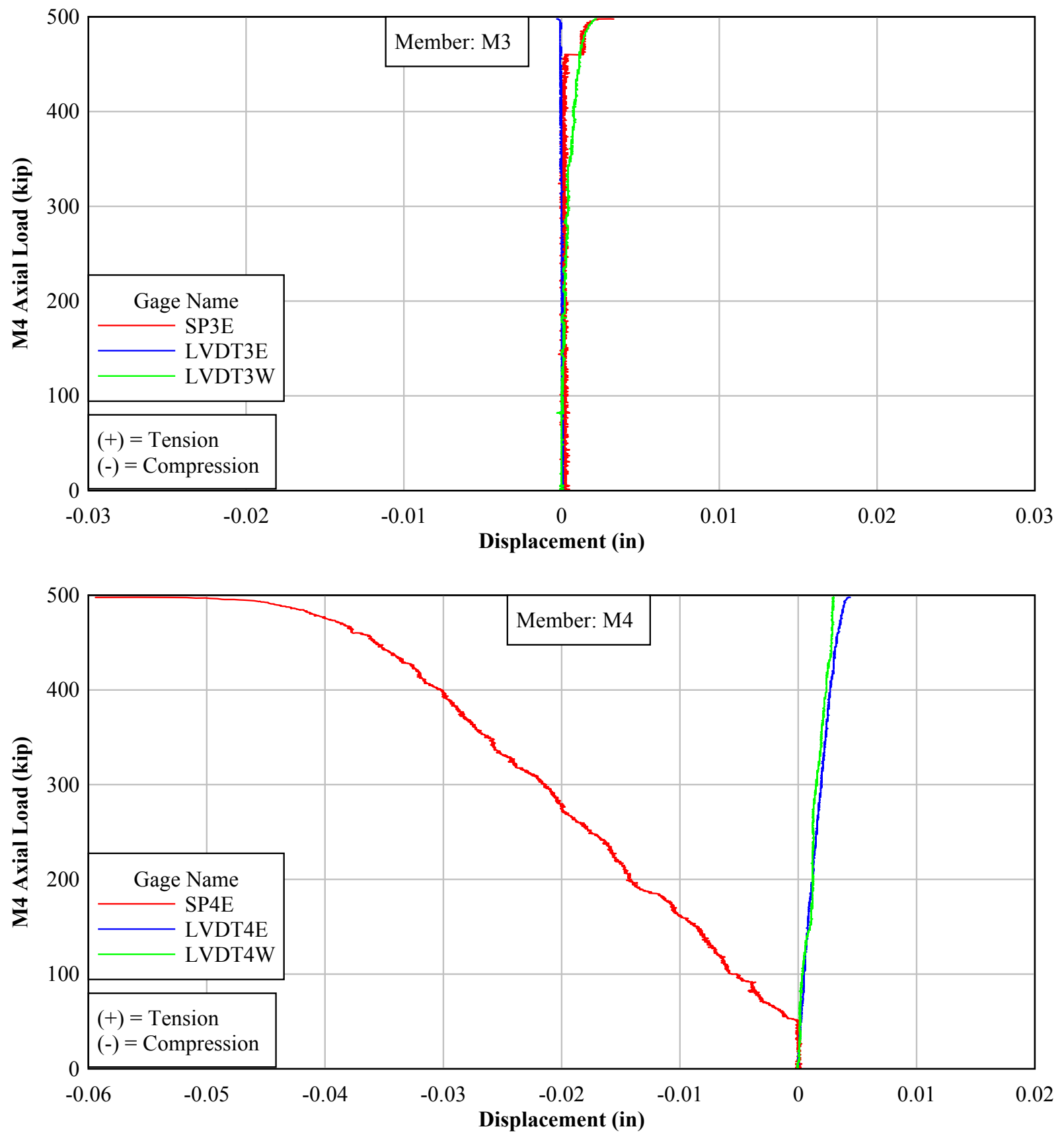


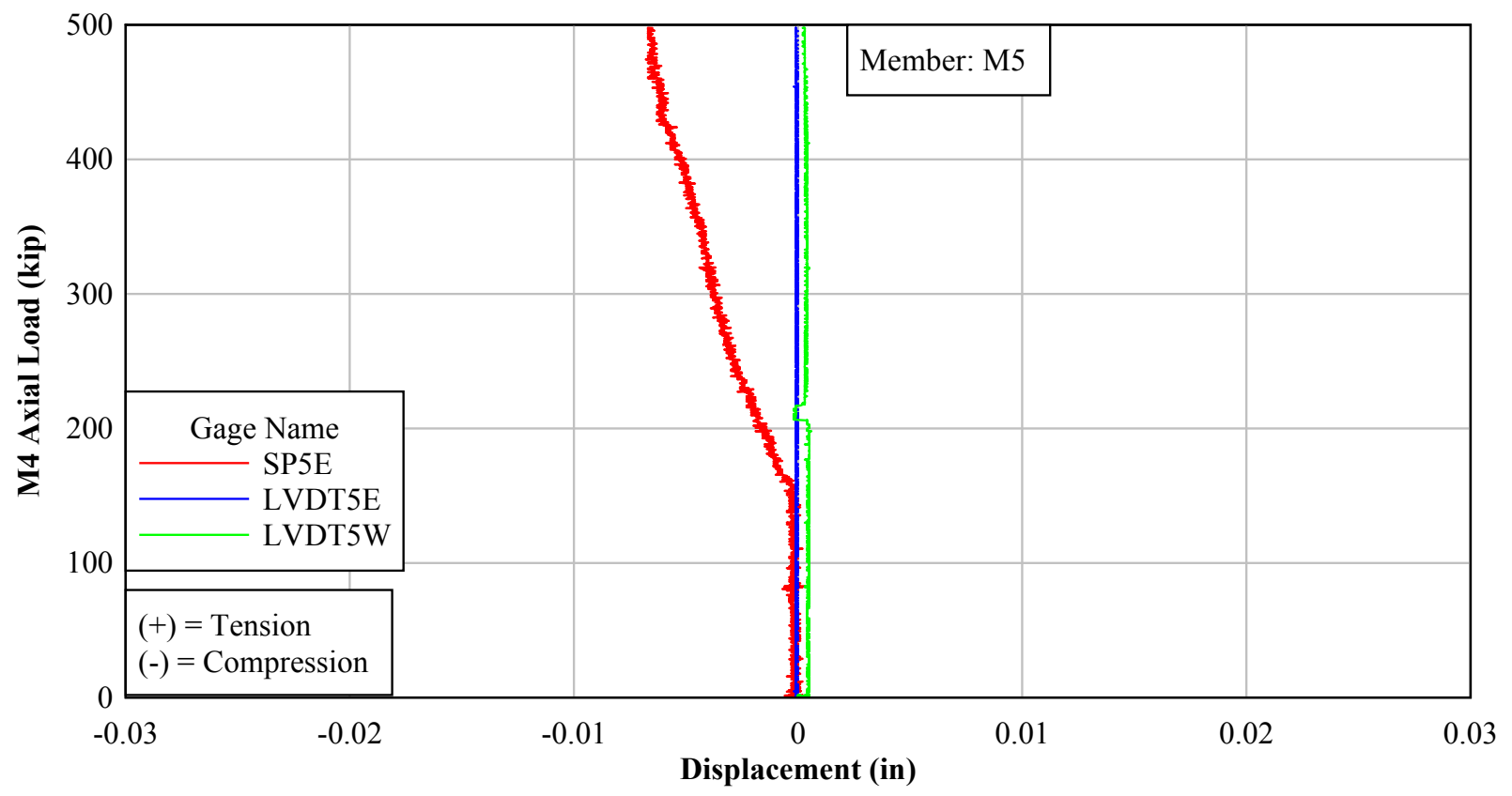

9.7.2 Gusset Free Edge Strain Versus Load and Displacement

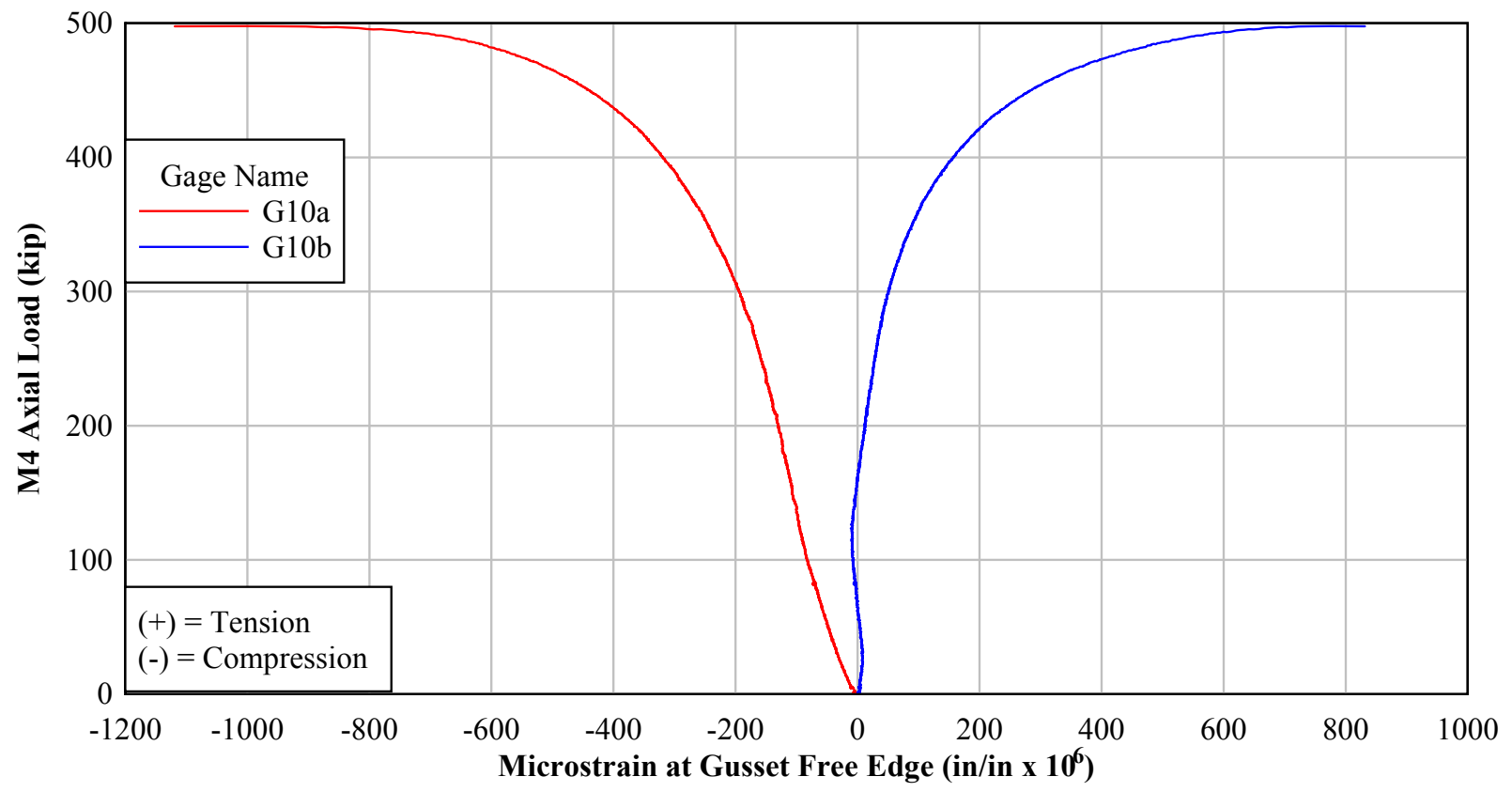




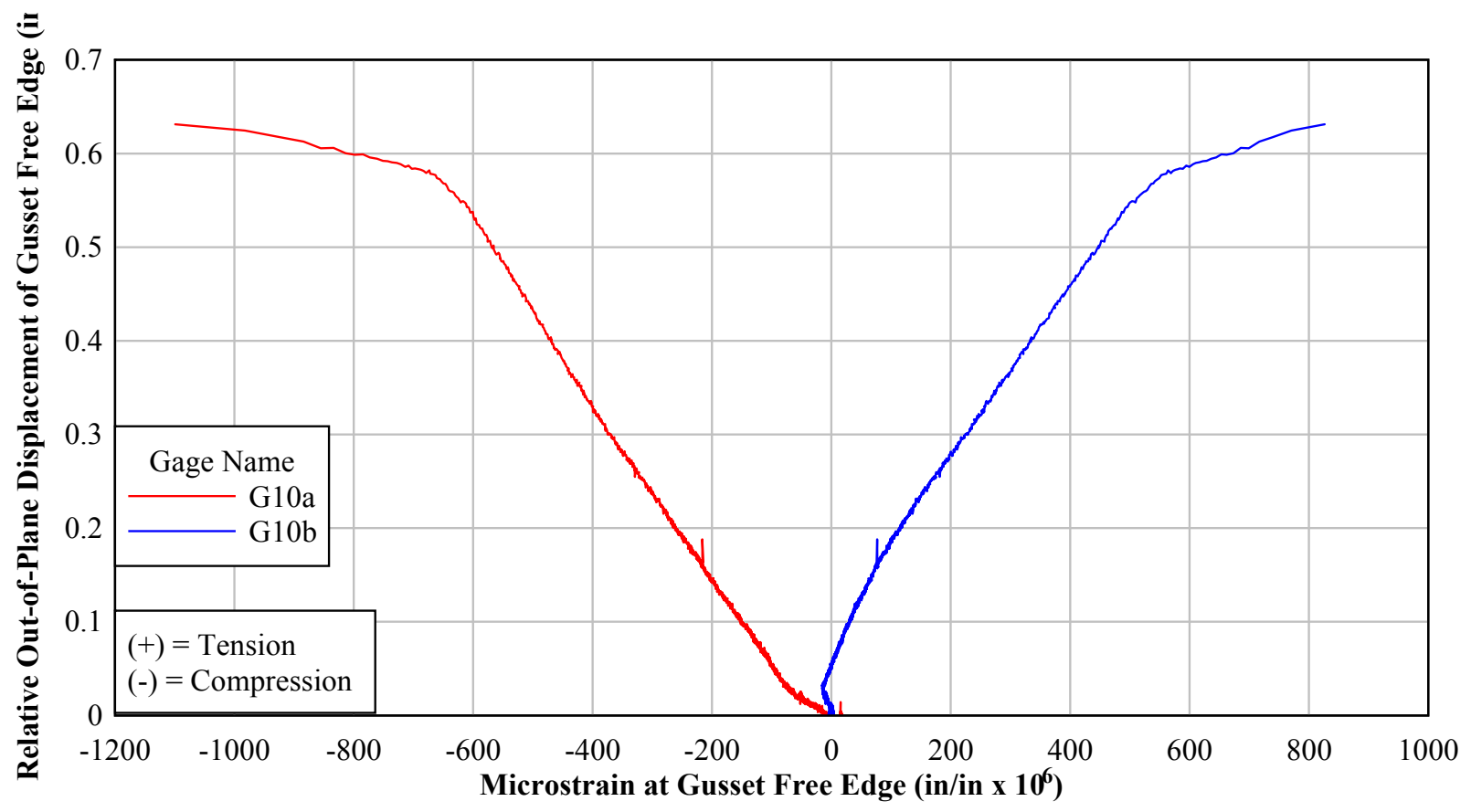

\subsubsection{Strain in M4 Connection Versus Load}

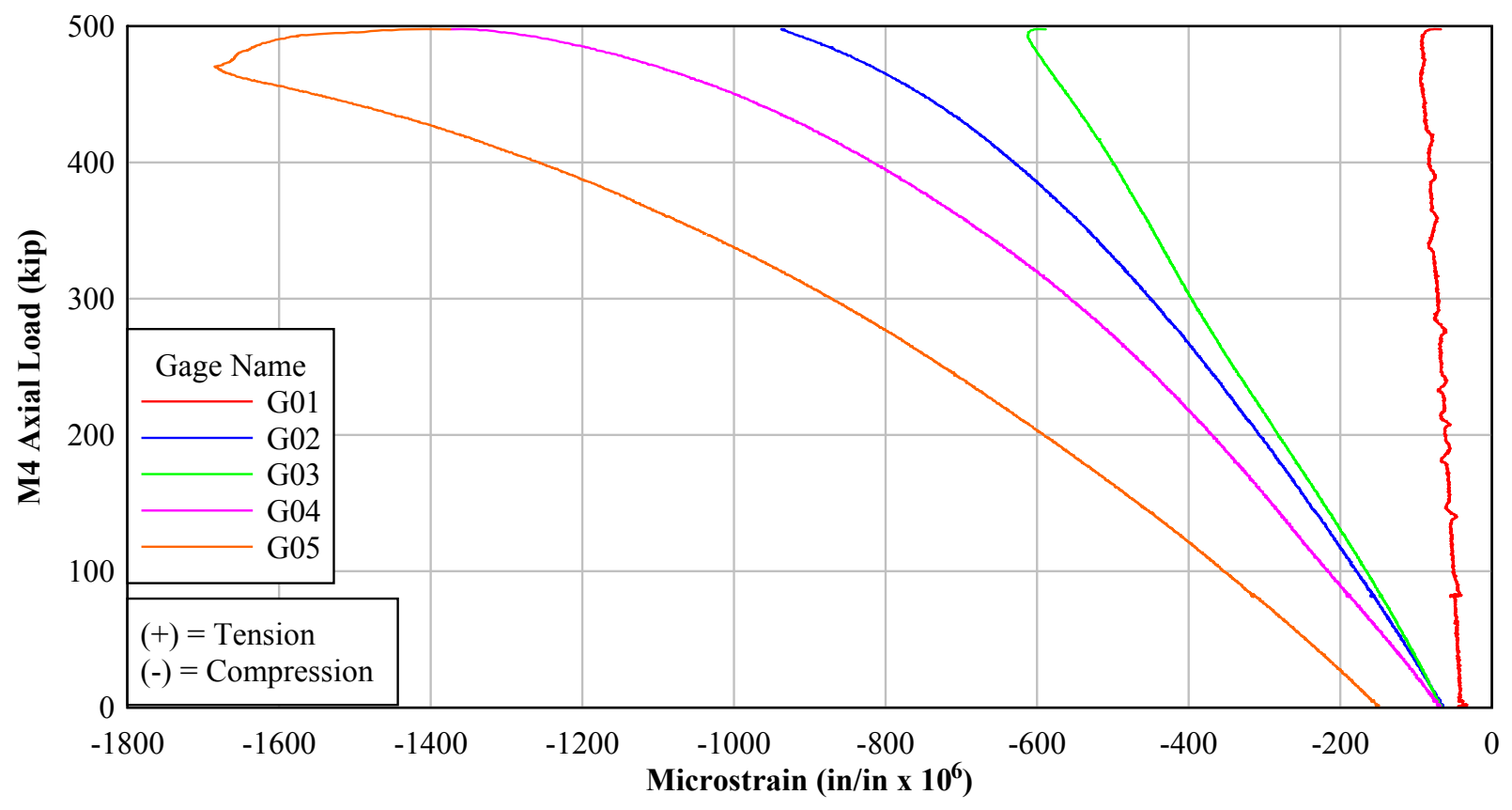


132 



\section{GOTREC \\ AND EDUCATION CONSORTIUM}

P.O. Box 751

Portland, OR 97207

OTREC is dedicated to stimulating and conducting collaborative multi-disciplinary research on multi-modal surface transportation issues, educating a diverse array of current practitioners and future leaders in the transportation field, and encouraging implementation of relevant research results. 